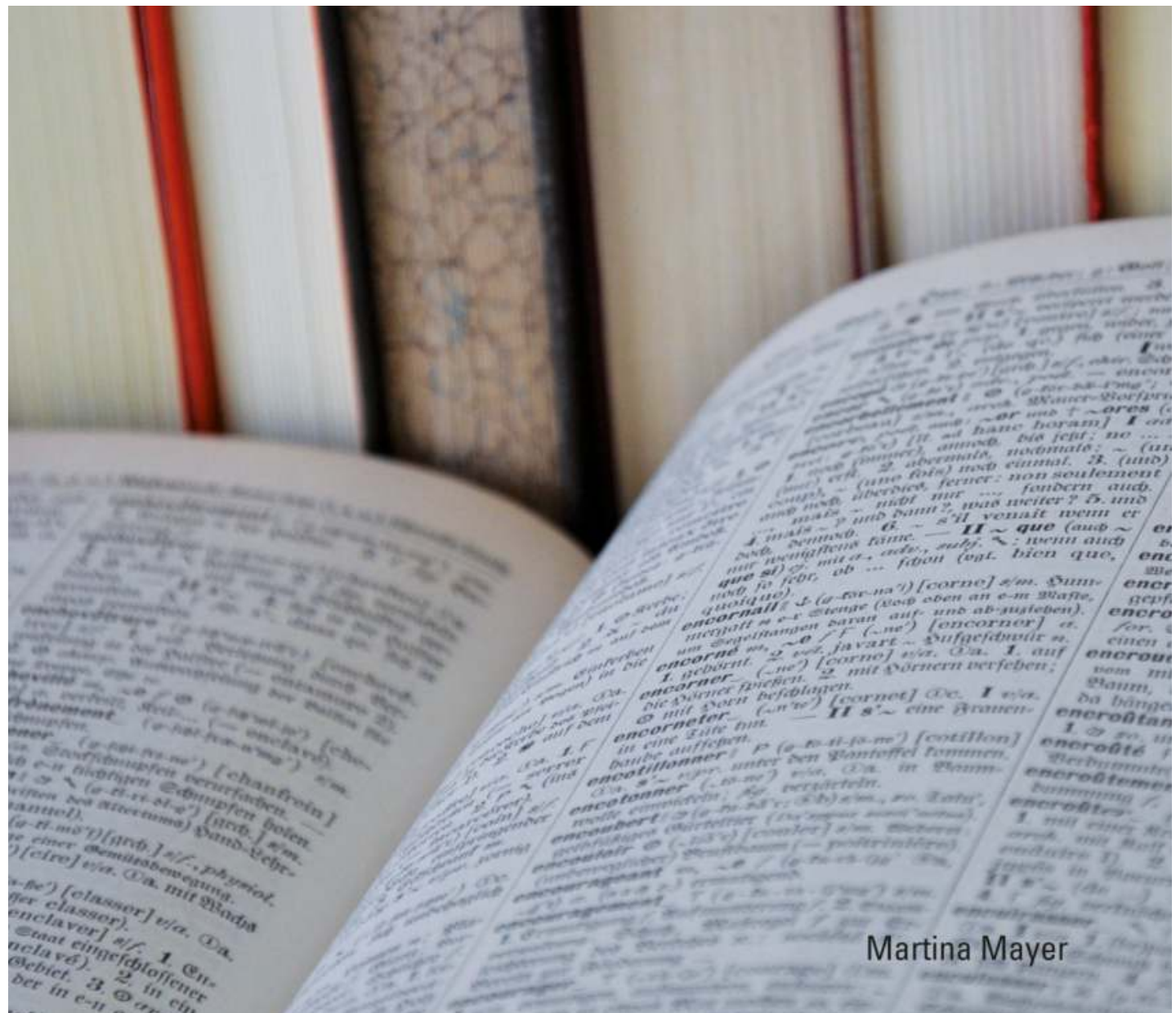

\title{
Sprachpflege und Sprachnormierung in Frankreich am Beispiel der Fachsprachen vom 16. Jahrhundert bis in die Gegenwart
}




\section{SERIES}

Studien des Interdisziplinären Frankreich-Schwerpunkts der Universität Innsbruck 5

Series-Editors: Eva Lavric, Romana Kaier, Ludovic Milot

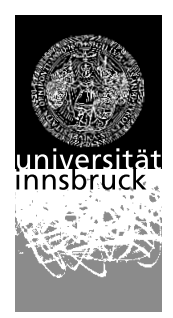



Martina Mayer

Sprachpflege und Sprachnormierung in Frankreich am Beispiel der Fachsprachen vom 16. Jahrhundert bis in die Gegenwart 
Martina Mayer

Institut für Translationswissenschaft, Universität Innsbruck

Diese Publikation wurde mit finanzieller Unterstützung des Vizerektorats für Forschung und des Frankreich-Schwerpunkts der Universität Innsbruck gedruckt.

(C) innsbruck university press, 2013

Universität Innsbruck

1. Auflage

Alle Rechte vorbehalten.

Umschlagbild: @ Martina Mayer

Produktion: Prime Rate Kft.

www.uibk.ac.at/iup

ISBN 978-3-902936-00-4 


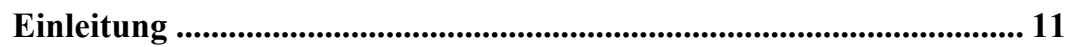

1 Fachsprachen in Europa vor dem 16. Jahrhundert: ein historischer Überblick ...................................................................................................... 15

1.1 FACHSPRACHEN IN VORSCHRIFTLICHER ZEIT: ARBEITSTEILUNG UND DIE FACHSPRACHE

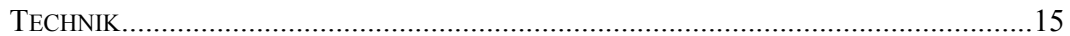

1.2 FACHSPRACHEN UND DIE HERAUSBILDUNG EINES FäCHERKANONS IM MITTELALTER 16

2 Das 16. Jahrhundert: erste Meilensteine der französischen

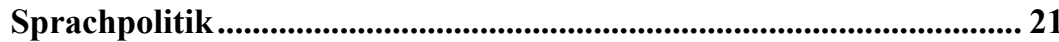

2.1 KULtURGESCHICHTLICHE HiNTERGRÜNDE DER RENAISSANCE IM EUROPÄISCHEN

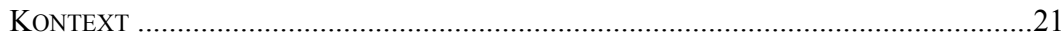

2.1.1 Fachliches Handeln und Fachkommunikation in der Renaissance..........22

2.1.2 Neue Fachtermini und Fachpublikationen im Frankreich der Renaissance 24

2.2 DiE ORDONNANCE DE VILLERS-COTTERÊTS VON 1539_..............................................26

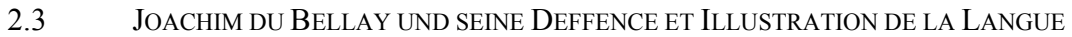

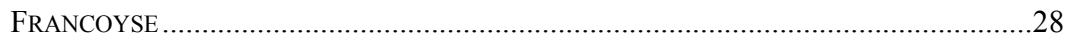

$3 \quad$ Das 17. Jahrhundert: der Sprachpurismus des Grand Siècle ............... 31

3.1 DIE HÖFISCHEN IDEALE DES 17. JAHRHUNDERTS ……………..................................

3.2 „ENFIN MALHERBE VINT“: DIE BeSCHNEIDUNG DER SPRACHE .....................................36

3.3 VAUgeLAS UND SEINE Remarques SUR La LANGUE FranÇOISE .................................38

3.3.1 Fachsprachen in den Remarques sur la Langue Françoise.......................39

3.4 DominiQue BouHours: eIN NACHFolger VAUgelas' ............................................43 
3.5 DiE ACADÉMIE FRANÇAISE UND IHRE KONZEPTION DER SPRACHPFLEGE 45

3.5.1 Fachsprachen in den Augen der Académie française damals und heute.47

3.6 LA BATAILlE DES DICTIONNAIRES: DiE ACADÉMIE FRANÇAISE UND IHRE

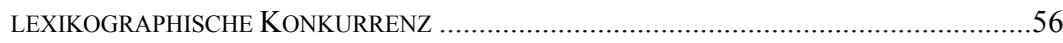

3.6.1 César-Pierre Richelets Dictionnaire françois, contenant les Mots et les Choses .56

3.6.2 Antoine Furetières Dictionnaire universel, contenant généralement tous

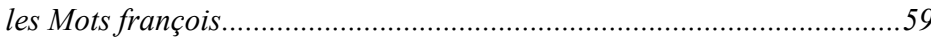

3.6.3 Thomas Corneilles Dictionnaire des Arts et des Sciences ........................60

4 Das 18. und 19. Jahrhundert: das enzyklopädische Zeitalter und die ,langue de la liberté' .......................................................................................... 65

4.1 Die KUlturgeschichtLiChEN HinTERGRÜNDE DES 18. UND 19. JAHRHUNDERTS .....65

4.2 ZUR FACHSPRACHENREFLEXION UND ZU DEN ZIELSETZUNGEN DER

FACHKOMMUNIKATION DES 18. JAHRHUNDERTS .66

4.3 Diderots ENCYClopédie, OU DictionNAire RAisonné DES SCIENCES, DES ARTS ET DES METIERS, PAR UNE SOCIÉTÉ DE GENS DE LETTRES............................................70

4.3.1 Die Entstehungsgeschichte der Encyclopédie im Überblick .....................71

4.3.2 Die Redaktion und der Verkauf der Encyclopédie ..................................73

4.3.2.1 Die Enzyklopädisten: „une société de gens de lettres“...........................74

4.3.2.2 Die Methode: Arbeitsteilung, Textnachbearbeitung, Recherche............75

4.3.2.3 Das Zielpublikum der Encyclopédie ......................................................76

4.3.2.4 Finanzielle und kommerzielle Hintergründe .........................................77

4.3.3 Diderots Sprachauffassung und Fachsprachenkonzept .........................79

4.4 SPRACHPOLITIK WÄHREND UND NACH DER FRANZÖSISCHEN REVOLUTION VON 1789

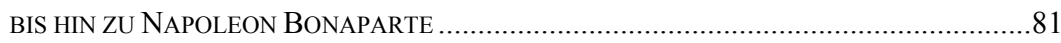

4.4.1 Die sprachlichen Gegebenheiten im revolutionären Frankreich .............82 
4.4.2 Die Umstellung von Systemen und die Einführung revolutionärer Neologismen .....

4.4.3 Von der Machtergreifung Napoleon Bonapartes bis zum Beginn des 20.

Jahrhunderts.

Das 20. und 21. Jahrhundert: eine Rückbesinnung auf die Verteidigung der Sprache

5.1 ZUR FACHSPRACHENREFLEXION DES 20. UND 21. JAHRHUNDERTS .............................89

5.1.1 Fachsprachen und Fächer - eine Definition des 20. Jahrhunderts .........90

5.1.2 Die grundlegenden Charakteristika moderner Fachsprachen................92

5.1.3 Das Fachwort als Wesensmerkmal der Fachsprache .............................94

5.1.4 Der Einfluss der Fachsprachen auf die Gemeinsprache.........................96

5.2 FrANZÖSISCH VS. ENGLISCH, FRANKREICH VS. ENGLAND ........................................99

5.3 DiE GESETZLICHE GRUNDLAGE MODERNER SPRACHPFLEGERISCHER MABNAHMEN...101

5.3.1 Die Loi $n^{\circ} 75-1349$ du 31 décembre 1975 relative à l'emploi de la langue française (Die Loi Bas-Lauriol)......................................................101

5.3.2 Die Loi $n^{\circ}$ 94-665 du 4 août 1994 relative à l'emploi de la langue française (Die Loi Toubon)...................................................................103

5.4 Private SPRACHPFlEGEGESELLSCHAFTEN IN FrANKREICH UND IHRE AKTIVITÄTEN

5.4.1 Actions pour promouvoir le français des affaires (APFA).....................106

5.4.2 Association française de normalisation en matière de langage technique (AFNOR) .106

5.4.3 Association française des Presses d'Université (AFPU) und die ihr zugehörige Association française des Presses d'Université Diffusion (AFPU - D)

5.4.4 Association francophone des Professionnels de l'Aéronautique (Courrier sud) 107 
Inhaltsverzeichnis

5.4.5 Association des Informaticiens de Langue française (AILF)

5.4.6 Association internationale des Amis du Français, Langue olympique et sportive (AIAFLOS)

5.4.7 Association internationale des Démographes de Langue française (AIDELF). 108

5.4.8 Association internationale des Écoles en Sciences de l'Information (AIESI) 108

5.4.9 Association internationale des Sociologues de Langue française (AISLF)

5.4.10 Association des jeunes Scientifiques francophones

5.4.11 Association nationale des Scientifiques pour l'Usage de la Langue française (ANSULF) 109

5.4.12 Centre Audiovisuel de Langues modernes (CAVILAM). 110

5.4.13 Comité d'étude des termes techniques français (CETTF). 110

5.4.14 Comité Universitaire francophone pour le Développement des Échanges scientifiques (CUFDES) .................................................................110

5.4.15 Conseil international de la langue française $(C I L F)$...........................110

5.4.16 Défense de la Langue française .......................................................111

5.4.17 Groupe d'Études et de Recherches pour le Développement des Sciences Sociales (GERDES) 111

5.4.18 Groupement des Associations dentaires francophones (GADEF) .........112

5.4.19 Institut français de l'Emballage et du Conditionnement (IFECPromotion)..... 112

5.4.20 Institut francophone de Paris (IFP) ................................................ 112

5.4.21 Ligue internationale des Scientifiques pour l'Usage de la Langue française (LISULF). 112

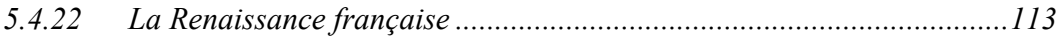

5.4.23 Société d'Ethnographie de Paris ...........................................................113 
Inhaltsverzeichnis

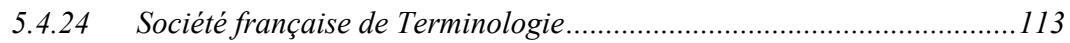

5.4.25 Union internationale des Ingénieurs et des Techniciens utilisant la

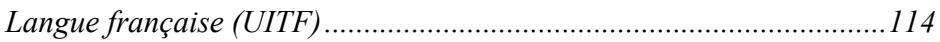

5.5 StaAtliche SPRACHPFLEGEORGANISATIONEN IN FrANKREICH UND IHRE

AKTIVITÄTEN

5.5.1 Haut Comité pour la Défense et l'Expansion de la Langue française, 1966. 115

5.5.2 Association française de terminologie (AFTERM), 1975 .....................116

5.5.3 FRANTERM, 1980 .......................................................................116

5.5.4 Die neuen Sprachpflegeorganisationen von 1984 ..............................117

5.5.4.1 Commissariat général de la langue française .......................................117

5.5.4.2 Comité consultatif de la langue française..............................................117

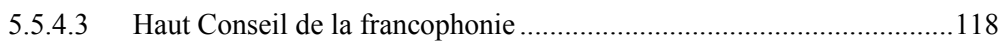

5.5.5 Die neuen Sprachpflegeorganisationen von 1989 .............................118

5.5.5.1 Délégation générale à la langue française (DGLF) ...............................119

5.5.5.2 Conseil supérieur de la langue française (CSLF) .................................119

5.5.6 Die ministeriellen Terminologiekommissionen ...................................120

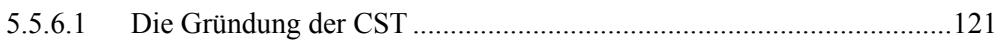

5.5.6.2 Die interne Struktur und Organisationsform: Mitglieder und Arbeitsgruppen.

5.5.6.3 Die Commission générale de terminologie et de néologie (CGTN, 1986-

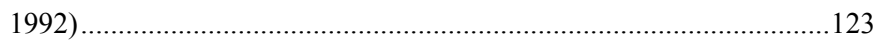

5.5.6.4 Die Typen der von den CST vorgeschlagenen Fachtermini .................123

5.5.6.5 Zur Entstehung eines Neologismus: vom feindlichen Anglizismus über den Term-Vorschlag bis hin zur Publikation

5.6 ERFOLGE UND NIEDERLAGEN: VON DER AKZEPTANZ SPRACHPFLEGERISCHER

MAßNAHMEN IN FRANKREICH 
7.1 ZITIERTE LITERATUR .............................................................................133

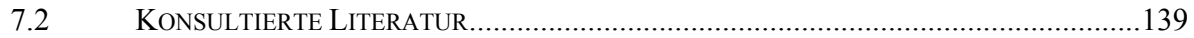

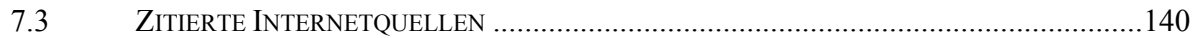

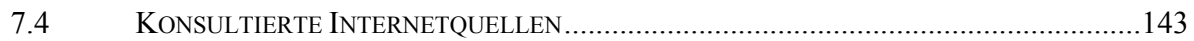

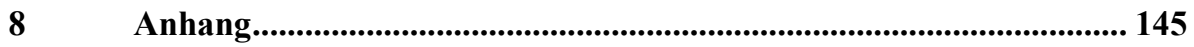

8.1 AusZug Aus Diderots ENCYClopédie: DER ARTIKel ENCYClopédiE......................145

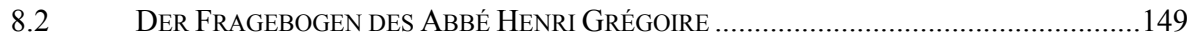

8.3 Die Étitre a Boileau SUR LeS Mots nouveauX von Jean Pons Guillaume

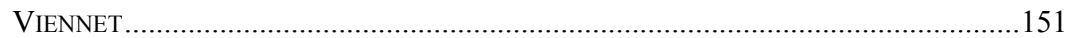

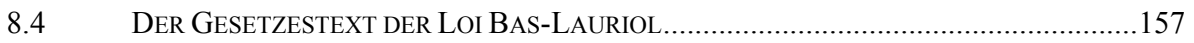

8.5 DER GESETZESTEXT DER LoI TOUBON ..............................................................161

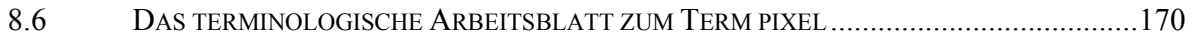

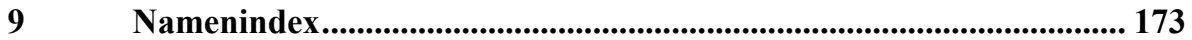




\section{Einleitung}

Unter humanistischem Einfluss trat Europa während der Renaissance erstmals in eine intensive Phase der Sprachpflege und Sprachnormierung ein, zweier Aktivitäten, die aus den sich gerade von der gesamteuropäischen Lingua franca Latein emanzipierenden und häufig weder ausreichend ausgebauten noch zufriedenstellend vereinheitlichten Sprachen bestimmter Sprachgemeinschaften eigenständige Nationalsprachen mit ausreichendem Kommunikationspotenzial und klaren Regeln machen sollten. Letztere sollten mittels einer präskriptiven Definition des guten Sprachgebrauchs aufgestellt werden, um so die noch jungen Nationalsprachen in sich zu festigen und damit gleichzeitig die Stabilität der Nationalstaaten auszubauen. Begriffe wie Sprachpflege, Sprachausbau, Sprachnorm, Sprachpurismus usw. sind daher nicht ausschließlich von linguistischer Bedeutung, sondern ebenso von politischer.

Kaum ein Land kann bezüglich der Sprachpflege bzw. seiner Sprachpolitik auf eine so lange und konsequent betriebene Tradition zurückblicken wie Frankreich. Im 16. Jahrhundert setzte dort ein zunächst intensiv sprachpflegerischer, d.h. auf Elaborierung ausgerichteter, in Folge dann vermehrt sprachpuristischer Diskurs ein. Dessen Inhalte veränderten sich zwar im Laufe der Zeit unter Anpassung an den jeweils vorliegenden kulturhistorischen und sprachpolitischen Kontext, doch trotz der thematischen Verschiebungen innerhalb der Sprachdiskussion lässt sich feststellen, dass dieser in Frankreich selbst über Jahrhunderte hinweg kontinuierlich höchste Bedeutung beigemessen wurde. Bis in die Gegenwart kommt der französischen Sprache sowohl in Fachkreisen als auch bei der Allgemeinheit ihrer Sprachnutzer ein Stellenwert zu, der im europäischen Vergleich einzigartig ist. Durch die intensive innerfranzösische Auseinandersetzung mit der Nationalsprache hat nun Frankreich aus Sicht der meisten anderen Staaten - im Großen und Ganzen sprachpflegerisch weitaus weniger aktiv - in puncto Sprachpolitik eine Art modellhaften Sonderstatus erlangt und steht damit häufig im Mittelpunkt des Interesses der nichtfranzösischen Sprachwissenschaft. Hierzu trägt auch die Tatsache bei, dass Französisch nicht nur in Frankreich selber, sondern auch im Ausland spätestens seit Antoine de Rivarol und seinem Discours sur l'Universalité de la Langue française von 1784 als universell einsetzbare Sprache der Vernunft betrachtet wurde und tatsächlich lange Zeit auf internationaler Ebene als Sprache der Diplomatie, der Politik und der Wissenschaft galt. Zwar haben inzwischen das Englische bzw. Angloamerikanische in verschiedenen Domänen, so z.B. in der Industrie oder in diversen Teilbereichen der Technik, den Platz des Französischen eingenommen, doch genießt die Sprache trotz ihrer schon seit etwa 1930 seitens der Medien, der Politik und zahl- 
reicher „Sprachfreunde“ verlautbarten crise $d u$ français nach wie vor ein gewisses internationales Prestige. In Frankreich selber hingegen verspürt man ob der Gefahr durch das in Form zahlreicher Anglizismen ins Französische hineindrängende Englisch die Notwendigkeit, sich mit Nachdruck auf die bereits im 16. Jahrhundert geforderte Verteidigung der Nationalsprache rückzubesinnen. In der Existenz zahlreicher Sprachpflegeorganisationen, gesetzlicher Grundlagen einer staatlich gelenkten Sprachnormierung und staatenübergreifender sprachpolitischer Aktivitäten im Rahmen der Frankophonie manifestiert sich diese Rückbesinnung überaus deutlich.

Folglich wird der breit gefächerte Themenbereich Sprachpflege und Sprachnormierung in Frankreich nun häufig zum Inhalt wissenschaftlicher Arbeiten, und viele seiner Aspekte, insbesondere solche historischer Art, wurden inzwischen umfassend analysiert, so z.B. der Sprachpurismus des 17. Jahrhunderts, die Schlüsselrolle der Académie française in diesem Zusammenhang, das höfische Sprachideal des honnête homme, staatlich veranlasste Maßnahmen zum Schutz und zur Propagierung des Französischen in verschiedenen Epochen usw. Die Stellung der Fachsprachen hingegen wurde in der bisherigen Auseinandersetzung mit der französischen Sprachpolitik weniger ausgiebig erläutert. Die Zielsetzung der vorliegenden wissenschaftlichen Arbeit ist nun eine erneute Betrachtung der Sprachpflege und Sprachnormierung in Frankreich, dies jedoch mit einem Fokus auf die Fachsprachen. Hierzu soll chronologisch vom 16. Jahrhundert bis in die Gegenwart vorgegangen werden, um Schlüsselmomente für die Pflege, die Normierung, die Verwendung von Fachsprachen zu diskutieren. Da der zu bearbeitende Zeitrahmen relativ umfangreich ist, bieten sich natürlich höchst unterschiedliche Phänomene als solche „Schlüsselmomente“ an: einerseits punktuell auftretende Phänomene, die direkt oder indirekt Einfluss auf die Fachsprachen hatten oder haben, z.B. Erlässe, Gesetze oder die sprachtheoretischen Werke bestimmter Personen; andererseits aber auch prozesshafte Phänomene, beispielsweise kulturhistorische Entwicklungen, die im Zuge sozialer oder wirtschaftlicher Umbrüche neue Ideale, Haltungen und Perspektiven hervorbrachten und damit ausschlaggebend für Veränderungen bezüglich der Fachsprachen waren. Allerdings ist es angesichts der Vielzahl sprachnormativer und lexikographischer Werke, sprachpolitischer Maßnahmen, sprachpflegerisch tätiger Einrichtungen, Vereinigungen und Personen etc. nicht intendiert, mit der vorliegenden Arbeit eine vollständige Analyse der Sprachpflege und Sprachnormierung in Frankreich am Beispiel der Fachsprachen zu erstellen; so wird hier auch weitgehend darauf verzichtet, einleitend allgemeine Informationen $\mathrm{zu}$ grundlegenden 
Begriffen wie Sprachpflege, Sprachnorm, Sprachpolitik, Sprachchauvinismus etc. anzuführen ${ }^{1}$. Ziel ist es vielmehr, einen historischen Abriss zu präsentieren, der durch die bewusste Auswahl und Diskussion besonders wichtiger Ereignisse und Entwicklungen einen möglichst umfassenden Allgemeinüberblick über die Rolle der Fachsprachen innerhalb der französischen Sprachpolitik vermitteln soll. Hierbei steht diese Arbeit im Zeichen eines weit gefassten Fachsprachenbegriffs, was die unterschiedlichen Ausprägungen der Fachsprache betrifft: Ausgangspunkt aller folgender Überlegungen ist das Kollektiv der Fachsprachen ${ }^{2}$. Dieses umfasst gleichberechtigt die unterschiedlichsten Technolekte, ob es sich nun um Werkstattsprachen - wie z.B. die der Handwerke, des Ackerbaus, der Viehzucht, der Schifffahrt etc. - oder die Wissenschaftssprache handelt, ob ein Technolekt der Vergangenheit oder der Gegenwart entstammt, ob er laut der klassischen Aufteilung der Fachsprachen einer praktisch-handwerklich orientierten oder einer theoretischwissenschaftlichen Varietät zugehörig ist. Kommt im Folgenden einem bestimmten Technolekt eine besondere Bedeutung zu, so wird dies explizit angeführt. Ansonsten ist vom erläuterten breiten Fachsprachenbegriff auszugehen.

1 Ausführliche Definitionen und Erläuterungen zu diesen und weiteren Aspekten des Themenbereichs finden sich anderen Ortes, vgl. z.B. Barlow/Nadeau 2008, Bartsch 1987, Blanke/Scharnhorst 2007, Bochmann 1993, Hassler 2001, Mattheier 1997, Scharnhorst 1999, Settekorn 1988 und 1990 etc., um nur einige weiterführende Literaturempfehlungen zu nennen.

2 Siehe hierzu auch Kapitel 5.1.1. 



\section{Fachsprachen in Europa vor dem 16. Jahrhun- dert: ein historischer Überblick}

Die Grundlage der Entstehung der Fachsprachen ist die Spezialisierung menschlicher Aktivitäten im Rahmen einer im Lauf der Geschichte stetig zunehmenden Arbeitsteilung. Diese kann man nun pragmatischen Überlegungen oder aber wie beispielsweise Fluck (1996:27) der unterschiedlichen Verteilung von Begabungen zuschreiben - sicher ist in jedem Fall, dass bereits für weitaus frühere, weniger komplexe Gesellschaften als die heutige von der Existenz erster Fachsprachen auszugehen ist. Zugleich steht allerdings auch fest, dass in diesen Gesellschaften noch keine Fachsprachenreflexion im modernen Sinne erfolgte, ebenso wenig eine Dokumentation der Herausbildung von Fachsprachen.

\subsection{Fachsprachen in vorschriftlicher Zeit: Arbeitsteilung und die Fachsprache Technik}

Roelcke (2005:162, im Original teilweise Fettdruck) ist zu entnehmen, dass ,[...] [d]ie Entstehung von Fachsprachen überhaupt [...] nicht überliefert [ist] [...]", dass aber bereits für die vorgeschichtliche Zeit von Arbeitsteilung als Grundlage spezialisierter menschlicher Kommunikation auszugehen ist, , ,[...] wobei vor allem an die Entstehung von spezifischen Wortschatzeinheiten unter Beibehaltung der jeweils allgemeinsprachlichen Syntax zu denken ist. Die Ausbildung fachspezifischer Eigenheiten auf den Ebenen Grammatik und Text ist vermutlich erst der fachlichen Kommunikation innerhalb sozial und kulturell recht komplexer menschlicher Gemeinschaften vorbehalten.“ Auch Fluck (1996:27) sieht den Ursprung der Fachsprachen in einer frühen Arbeitsteilung ,[...] in den einfach strukturierten Gesellschaften [...]“. Fluck (1996:28) betont im Weiteren, dass für die moderne Fachsprachenforschung die Fachsprachen der vorschriftlichen Zeit nicht wirklich zu erschließen sind und regt zur Überlegung an, ob sie aufgrund der mangelnden Abgrenzung und Definition der Fächer vielleicht noch gar nicht als Fachsprachen, sondern als Gruppensprachen zu gelten hätten.

Währenddessen vertritt Jakob (1998:143f) bezüglich der Reihenfolge in der Entstehung von Arbeitsteilung und der Entstehung von Fachsprachen einen anderen Ansatz: Er geht zunächst davon aus, dass die Techniksprache die älteste Fachsprache überhaupt ist und datiert deren Entstehung auf den Zeitpunkt der ersten 
Technisierung der Menschheit vor ca. zweihunderttausend Jahren. Diese Technisierung mag zwar noch wenig komplex gewesen sein, betraf jedoch verschiedene, den grundlegenden Bedürfnissen des Lebens dienende Tätigkeitsbereiche, was durch die Existenz technischer Artefakte $^{3}$ aus jener Epoche bezeugt wird. Nun setzt allerdings Jakob (1998:144, Fußnote eingefügt von M.M.) die Entstehung der Fachsprache Technik chronologisch noch vor der ersten arbeitsteilig organisierten Gesellschaft an und betont, dass der ,[...] Technikfachsprache gegenüber den anderen Fachsprachen insofern eine Sonderstellung zukommen $\mathrm{mu} \AA^{[4]}$, als sie die historisch älteste Fachsprache ist. Sie ist dies, weil ihre Herausbildung der Entstehung der Arbeitsteilung, der Schaffung von Institutionen und der Entstehung der Wissenschaften vorausging." In vorliegender Arbeit wird nun allerdings wie oben bei Roelcke (2005:162) der Ansatz vertreten, dass auch dem Überleben dienende menschliche Aktivitäten wie beispielsweise die Jagd, das Anfertigen von Waffen und Werkzeugen, die Nahrungszubereitung oder das Ausüben einer Heiltätigkeit spezialisierte Tätigkeiten sind und durchaus von einer ersten Arbeitsteilung zeugen, im Rahmen derer der Kommunikationsbedarf zur Herausbildung von Fachsprachen entstand.

\subsection{Fachsprachen und die Herausbildung eines Fächerkanons im Mittelalter}

Laut Baumann (1998:109) besteht ,[...] [e]in Spezifikum der menschlichen Tätigkeit [...] darin, daß sie an kommunikative Tätigkeit gebunden ist." Nun ist diese natürlich nicht notwendigerweise schriftlich, sondern kann auch mündlich erfolgen, was in Europa in vielen Bereichen, so z.B. im Bezug auf die Fachkommunikation der Handwerker, der Bauern, der Schifffahrt etc., noch die Spätantike hindurch im Großen und Ganzen der Fall war. Erste schriftliche Zeugnisse der Fachkommunikation in Europa stammen aus dem Mittelalter, wobei die damalige „Fachliteratur“ nicht mit heutigen Standards zu vergleichen ist: Schriftlich festgehalten wurden Bauernpraktiken, Lehrgedichte, Rechtsvorschriften, Regelwerke wie z.B. Zunftverordnungen, Rezepte, etc., aber durch das mittelalterliche Weltbild bedingt auch

3 Jakob (1998:143) nennt als Beispiele hierfür diverse Gegenstände wie Jagdwaffen, speziell für die Nahrungszubereitung oder -lagerung verwendete Gefäße und auch Werkzeuge zur Bearbeitung von Fellen für die Anfertigung von Bekleidung.

4 Hier und im Folgenden werden in wörtlichen Zitaten, die nicht mehr gültigen Rechtschreibnormen gemäß abgefasst sind, die Schreibvarianten der Originale beibehalten, ohne dies eigens zu kennzeichnen. Dies gilt für deutschsprachige wie auch für anderssprachige Zitate. 
Textsorten, die in der Gegenwart nicht der Fachliteratur zuzuordnen wären, so z.B. Zaubersprüche, Gebete oder Rätsel. Es liegt heute keinerlei aus dem Mittelalter überlieferte wissenschaftliche Dokumentation bezüglich der Entstehung der Fachsprachen vor, wodurch die moderne Fachsprachenforschung nach wie vor nur Rückschlüsse auf einzelne Merkmale der mittelalterlichen Fachsprachen ziehen kann. Man weiß jedoch dank diverser Textbelege, dass im Mittelalter bestimmten theoretisch-wissenschaftlich orientierten Fachsprachen, so z.B. der Fachsprache der Chemie, der Medizin, der Philosophie, des Rechts und der Kriegskunst, aber auch verschiedenen Handwerkersprachen nicht nur in der mündlichen, sondern auch bereits in der schriftlichen Kommunikation Bedeutung zukam. Deshalb ist beispielsweise bekannt, dass besonders die Werkstattsprachen des Handwerks durch Mundartausdrücke und eine gewisse Bildhaftigkeit geprägt waren. Es ist davon auszugehen, dass ihr Kommunikationsradius eher eng bemessen war, was durchaus auf ein intentionales Verhalten zurückzuführen ist: Sie sollten ausschließlich der Kommunikation innerhalb eines klar von Außenstehenden abgegrenzten Kollektivs, nämlich der Zunft, dienen (vgl. Fluck 1996:27ff). Indem bewusst eine Kommunikationsbarriere nach außen errichtet wurde und das Fachwissen nur jenen zugänglich war, die dazu durch ihre Mitgliedschaft in der Gruppe berechtigt waren, sollten diese spezifischen Kenntnisse geschützt werden. Ein Schlüsselmoment im Bezug auf die Entwicklung der Fachsprachen war allerdings zweifelsohne die Herausbildung eines Fächerkanons ab der Spätantike bzw. im Lauf des Mittelalters, der zunächst eine Dreiteilung zu Grunde lag.

Die Wissenschaftskultur der Spätantike war von den sogenannten Sieben Freien Künsten, lateinisch septem artes liberales, geprägt, die intern wiederum in zwei Blöcke aufgespaltet waren: Das Trivium, auch als Dreiweg oder die redenden Künste bezeichnet, umfasste Grammatik, Rhetorik und Dialektik; das Quadrivium, auch Vierweg bzw. die rechnenden Künste genannt, beinhaltete Arithmetik, Geometrie, Astronomie und Musik. Diese spätantike Aufteilung wurde im Mittelalter an den in Europa inzwischen gegründeten Universitäten aufgegriffen. An den philosophischen Fakultäten, auch Artistenfakultäten genannt, hatten die Studierenden zunächst eine Art Grundausbildung in den Sieben Freien Künsten zu durchlaufen, bevor sie im Rahmen einer Spezialisierung zu einem Doktoratsstudium der Medizin, des Rechts oder der Theologie an einer der oberen Fakultäten zugelassen wurden. Der Universitätsbetrieb erfolgte damals übrigens in ganz Europa auf Basis der gemeinsamen Wissenschaftssprache Latein, was die überregionale Verständigung der Gelehrten begünstigte. Für die Wissenschaft ist im Mittelalter also noch von einer lateinischen Fachkommunikation auszugehen. Erst später, mit der Herausbildung der europäischen Nationalsprachen und dem Buchdruck, entstand vermehrt national- 
sprachige Wissenschaftsliteratur. Das System der Sieben Freien Künste prägte den wissenschaftlich-universitären und edukativen Bereich in ganz Europa bis ins 18. Jahrhundert. Erst mit dem 19. Jahrhundert setzte eine neue Tendenz zu einer staatlich individuellen Fächereinteilung ein.

Als handwerkliches Pendant der Sieben Freien Künste existierten im Mittelalter die Handwerklichen Künste, auch als mechanische Künste oder Artes mechanicae bezeichnet. $\mathrm{Zu}$ diesen zählte man Waffenherstellung und technisches Handwerk (Armatura), Reisen und Handel (Navigatio), Landwirtschaft und Gartenbau (Agricultura), Jagd und Lebensmittelerzeugung (Venatio), die Wollverarbeitung (Lanificium), die Heilkunde (Medicina) sowie die Hofkünste und das Schauspiel (Theatrica). Mit der frühen Neuzeit jedoch fand diese Siebenteilung der Handwerklichen Künste durch eine verstärkte Ausdifferenzierung ein Ende. Die Fachkommunikation war zu Beginn dieser Phase der zunehmenden Spezialisierung noch vorrangig mündlich geprägt: Fachkenntnisse wurden durch Vorzeigen und Nachahmung übermittelt; Buchwissen war für den Erwerb handwerklicher Fähigkeiten nicht maßgeblich bzw. stand einem Großteil der Bevölkerung aufgrund der mangelhaften Alphabetisierung gar nicht offen. Der Wandel hin zu einer zunehmend schriftlichen Fachkommunikation des Handwerks vollzog sich erst später, mit dem Einsetzen des humanistischen Strebens nach einer Wissensvermehrung und mit einer zunehmenden Alphabetisierungsrate. Im Gegensatz zur Fachkommunikation der Sieben Freien Künste erfolgte die des Handwerks von Anfang an hauptsächlich in den Volkssprachen (vgl. Roelcke 2005:162ff).

Parallel zu den bereits genannten Künsten gab es schließlich noch die Magischen Künste, auch unter dem Begriff Artes magicae zusammengefasst. Zunächst gehörten lediglich vier Weissagungskünste (Geomantia, Hydromantia, Aeromantia und Pyromantia) zu den Artes magicae. Im 12. Jahrhundert kamen die Totenbeschwörung (Nigramantia) und die Handlesekunst (Chiromantia) hinzu, und erst im 15. Jahrhundert wurde mit der Integration der Wahrsagung aus dem Schulterblatt (Spatulamantia) ein Siebenschema, vergleichbar dem der anderen beiden Künste, geschaffen (vgl. Haage 1998:270f).

Dieser mittelalterliche Fächerkanon behielt seine Gültigkeit noch bis in die Renaissance hinein. Die ihm eigenen Fachsprachen, die sich damals noch kaum auf die sich gerade herausbildenden europäischen Nationalsprachen erstreckten, sondern großteils nach wie vor lateinisch geprägt waren, wurden damals allerdings nicht wirklich als solche reflektiert: Als das 16. Jahrhundert anbrach und sich die Volkssprachen zunehmend etablierten, stellte sich bestenfalls die Frage, inwiefern das Lateinische in der Fachkommunikation seine Vorrangstellung behalten sollte, bzw. ob und in welchen Bereichen es sinnvoll war, in fachlichen Kontexten nun vermehrt 
auf die aufstrebenden Volkssprachen zurückzugreifen. Die folgenden Kapitel geben mit einem Fokus auf die Fachsprachen Aufschluss über die ersten Schlüsselmomente der Geschichte der französischen Sprachpolitik im 16. Jahrhundert. 



\section{Das 16. Jahrhundert: erste Meilensteine der französischen Sprachpolitik}

Frankreich war im 16. Jahrhundert stark von der Renaissance und deren geistesgeschichtlichem Aspekt, dem Humanismus, geprägt. Diese Prägung brachte für die allgemeine französische Sprachpolitik erste wichtige Weichenstellungen mit sich und wirkte sich zudem intensiv auf die Wissenschaft wie auch andere Bereiche spezialisierter menschlicher Tätigkeit aus. Daraus resultierten auch unmittelbare Auswirkungen auf die Fachsprachen.

\subsection{Kulturgeschichtliche Hintergründe der Renaissance im euro- päischen Kontext}

Das Kernland der Renaissance war Italien, wo diese bereits um 1300 einsetzte. Andere Staaten folgten dem italienischen Modell etwas später, und verallgemeinernd kann gesagt werden, dass die Renaissance im 15. Jahrhundert überall in Europa Bedeutung erlangt hatte. Einen starken Impuls erhielt sie mit dem Ende des oströmischen Reiches 1453, das für viele byzantinische Gelehrte den Anstoß gab, nach Italien auszuwandern. Mit dieser Immigrationswelle gelangten nicht nur zahlreiche antike Manuskripte in den Westen, sondern auch Übersetzungen griechischer Texte, die nun in lateinischer Sprache weiter propagiert wurden. Mit dieser Wiederbelebung umfangreichen griechisch-antiken Wissens verfügte man nach dem Ende des „finsteren Mittelalters“ - das übrigens erst in der Renaissance mit dem Epochenbegriff des medium aevum versehen wurde - plötzlich über eine ganz neue geistige Grundlage, die eine Rückbesinnung auf die Antike, eine Aufwertung des antiken Erbes sowie ein neues Menschenbild mit sich brachte. War im Mittelalter der Mensch noch als prädestiniert und von Gott abhängig betrachtet worden, galt ihm nun ein neues Interesse: Man sah ihn als autonomes Wesen mit spezifischen Fähigkeiten, das durch Wissenserwerb seinen Horizont erweitern und damit bewusst sein eigenes Leben bestimmen konnte. ${ }^{5}$ Da man dem Humanitasgedanken gemäß vom Ideal eines glücklichen, guten, durch Bildung veredelten Menschen ausging, der sich

5 Dies wird zum Beispiel in Pico della Mirandolas 1496 veröffentlichtem Oratio de hominis dignitate, der Rede über die Würde des Menschen, deutlich, die den Menschen zu seinem eigenen Gestalter stilisierte, bis hin zur Einswerdung mit Gott. 
vor allem durch die Sprachbeherrschung vom Tier unterschied, widmeten sich die Gelehrten wieder vermehrt dem Studium der antiken Sprachen. In Folge wurden nicht mehr nur - wie zuvor notwendigerweise üblich - Übersetzungen antiker Texte, sondern vor allem die Originale rezipiert. Dies entsprach ganz der humanistischen Devise ad fontes. Zugleich erlangte der Ciceronianismus, also die Orientierung am als vorbildlich erachteten Latein Ciceros, eine enorme Bedeutung. In der gesamten Romania, so auch in Frankreich, hatte sich das Spätlatein des Mittelalters derart weit vom antiken Latein entfernt, dass sich tatsächlich ein Bruch zwischen den beiden Varietäten vollzog: Die europäischen Volkssprachen begannen sich nun vermehrt auch als Schriftsprachen herauszubilden, galten zunächst allerdings als bar jeder logischen grammatischen Struktur und damit als für die wissenschaftliche Literaturproduktion ungeeignet. ${ }^{6}$ So wurde das klassisch-ciceronianische Latein zur Sprache der Wissenschaft und der Literatur erhoben. Die Renaissance wirkte sich jedoch nicht nur auf die Textrezeption und Textproduktion aus, sondern auch auf andere Bereiche der Kultur: Die Kunst und die Literatur beispielsweise begannen nun, in Form von Nachahmung und Weiterentwicklung antike Vorbilder zu bearbeiten. Die Wissenschaft versuchte, das Mittelalter mit all seinen Unzulänglichkeiten möglichst schnell zu überwinden und strebte in diesem Sinne danach, den Wissensgewinn zu beschleunigen, was auch gelang.

\subsubsection{Fachliches Handeln und Fachkommunikation in der Renaissance}

Der oben angesprochene Erkenntniszuwachs bezog sich im Grunde auf alle Fachgebiete und war zu einem Gutteil einem neuen Wissenschaftsverständnis im Sinne der curiositas, einem ganzheitlichen Bildungsinteresse, zu verdanken. Dies brachte Universalgelehrte ${ }^{7}$ hervor, denen Kalverkämper (1998b:306) eine wichtige Rolle im Bezug auf die Fachkommunikation der Renaissance zuspricht:

6 Später wurden die Volkssprachen allerdings neu bewertet: Leon Battista Alberti verfasste zwischen 1437 und 1441 seine Grammatica della lingua toscana, wodurch ein Bewusstsein für den strukturierten, erfassbaren Aufbau der Volkssprachen entstand. Dank dieser Erkenntnis wurden die Volkssprachen dann doch als literaturfähig eingestuft, was wiederum die Entstehung unterschiedlicher Gattungen umfassender europäischer Nationalliteraturen ermöglichte. In Frankreich setzte diese Entwicklung etwa ab dem 16. Jahrhundert ein. Bis dahin waren auf dem Gebiet des heutigen Frankreichs vor allem Troubadourdichtung und höfische Romane aus dem Mittelalter überliefert worden.

7 Einige dieser Universalgelehrten sind bis in die Gegenwart bekannt, man denke beispielsweise an den bereits genannten Leon Battista Alberti (1404-1472) oder aber an Leonardo da Vinci (1452-1519), die in Personalunion Wissenschaftler, Techniker, Künstler etc. waren. 
Dieser Menschentyp, sei er auch im einzelnen idealisiert, lenkt mit einer dem Zeitgeist entsprechenden Selbstverständlichkeit den Blick auf das fachliche Handeln, auf die Arbeit und ihre Einschätzung, insbesondere ihr gesellschaftliches Ansehen, dann natürlich auf den Ausführenden selbst sowie auf seine Möglichkeiten, sich über seine wissenserfordernden, ausbildungsgebundenen, modern gesagt: qualifizierten Leistungen auch entsprechend ausdrücken und unterhalten zu können.

Die damals dringlich entstehende Notwendigkeit, effizient über Fachwissen kommunizieren zu können, es schriftlich festzuhalten, zu tradieren und bei Bedarf zu aktualisieren, war der Erschließung umfangreichen neuen Wissens innerhalb von kurzer Zeit zuzuschreiben, was aus Gründen der Pragmatik eine stärkere Arbeitsteilung zugunsten enger gefasster Einzelfächer nahe legte. Die im Mittelalter in den Wissenschaften und dem Handwerk mit dem Fächerkanon ${ }^{8}$ bereits etablierte Spezialisierung und Arbeitsteilung differenzierte sich dadurch weiter aus. Dies wiederum erlaubte eine erneute Vertiefung des Fachwissens, dessen Weitergabe nun auch im Sinne der Ausbildung besser koordiniert werden musste (vgl. Kalverkämper 1998b:307). In so gut wie allen Bereichen ergaben sich zahlreiche Neuerungen, die einen noch nie dagewesenen Kommunikationsbedarf generierten: Das Bauwesen beispielsweise hatte sich bereits im Mittelalter als Reaktion auf die zahlreichen Pläne zur Errichtung großer gotischer Sakralbauten mit der Erfindung des Bauhüttenwesens neu organisiert. Im Bereich der Technik wurden wegweisende neue Maschinen, Geräte und Verfahren erfunden, so z.B. das Fernrohr, die Druckerpresse oder aber auch der Buchdruck mit beweglichen Lettern. Besonders letzterer erwies sich sehr schnell als großer gesamteuropäischer Erfolg, wurden doch Bücher durch Johannes Gutenbergs vereinfachtes Druckverfahren wesentlich billiger und Buchwissen damit breiteren Bevölkerungsschichten zugänglich. Damit wurde der Weg zu einer neuen Art des wissenschaftlichen Informationsaustauschs geöffnet: Noch junge Erkenntnisse der Wissenschaft, z.B. in Fächern wie der Medizin oder der Astronomie, konnten schneller und weiter verbreitet werden als je zuvor. Die Malerei verfügte erst seit der Renaissance über die perspektivische Darstellung und die Proportionenlehre. Als Abschluss dieser exemplarischen Auswahl seien an dieser Stelle noch die Entdeckung und Erschließung der Neuen Welt genannt, die ebenfalls einen enormen Kommunikationsbedarf hervorbrachten - dies vor allem in Form eines Benennungsbedarfs zahlreicher bis dato unbekannter Sachen, Erscheinungen und Konzepte. So entstanden überall in Europa neue volkssprachliche und 
lateinische Termini. Die Herausbildung unterschiedlicher Fachtextsorten ${ }^{9}$ wiederum erlaubte deren textuelle Verarbeitung (vgl. Kalverkämper 1998a:69f).

\subsubsection{Neue Fachtermini und Fachpublikationen im Frankreich der Renaissance}

Der gesamteuropäische Benennungsbedarf sowie die Notwendigkeit einer Verbesserung der Fachkommunikation machten natürlich auch vor Frankreich nicht halt. Nun war Frankreich im 16. Jahrhundert sozusagen sprachlich zweigeteilt: Einerseits hatten sich aus dem mittelalterlichen Vulgärlatein bereits verschiedene Regiolekte herausentwickelt, als deren Prestigevariante sich das francien, zu Deutsch Franzisch, der Ile-de-France entpuppt hatte: Das Franzische begann bald, sich anderen Regionalsprachen, z.B. dem Altokzitanischen, dem Gaskognischen, dem Normannischen, dem Pikardischen, dem Provenzalischen usw., gegenüber durchzusetzen, wurde in Folge zur überregional gültigen Volkssprache und letztlich in Form der Langue françoyse zur jungen Nationalsprache Frankreichs. Andererseits herrschte in der wissenschaftlichen Fachkommunikation wie auch in der Literatur immer noch die lateinische Sprache vor. Mit Latein konnte allerdings besonders in fachlichen Kontexten außerhalb der Wissenschaft keine effiziente Kommunikation sichergestellt werden, sprach doch bei Weitem nicht die gesamte französische Bevölkerung Latein. Um Zugang zu fachlichen Informationen zu erhalten, waren besonders die unteren Bildungsschichten auf eine Vulgarisierung angewiesen. Diese Popularisierung fachlicher Inhalte erfolgte durch die Publikation der Fachliteratur in der Volkssprache Französisch. Berschin/Felixberger/Goebl (2008:198) halten hierzu fest:

Die Popularisierung der Wissenschaften durch Veröffentlichungen auf Französisch begann zunächst auf den Gebieten, in denen eine unmittelbare praktische Anwendung möglich war, Lateinkenntnisse jedoch nicht vorausgesetzt werden konnten. Im Falle der Mathematik und Geometrie waren das z.B. Traktate über die Umrechnung von Münzen und Maßen, Anleitungen zum Festungsbau, für die Astronomie Schriften zur Navigation.

9 Hierzu zählten beispielsweise Analysen, Lehrgedichte, literarisch-wissenschaftliche Dialoge und sogenannte Remarques (vgl. Kalverkämper 1998a:70f) - letztere sind besonders nennenswert im Hinblick auf die normative Befassung mit Sprache in Frankreich. Siehe hierzu auch Kapitel 3.3. 
Das noch junge Französisch übernahm also zunächst in jenen fachlichen Kontexten eine Schlüsselrolle, die entweder eher praktisch-handwerklich orientiert waren, oder aber , ,...] wo die Wissenschaft dem Handwerk am nächsten stand $[\ldots]$ “ (Berschin/Felixberger/Goebl 2008:198). In der Medizin beispielsweise war dies in der Chirurgie der Fall. Die „Bader“ des 16. Jahrhunderts übten eine praktisch ausgerichtete Heilkunst aus, die in etwa einem Handwerk gleichzusetzen war, und verfügten häufig nicht über Lateinkenntnisse. Daraus erklärt sich, dass an der Universität von Montpellier ${ }^{10}$ zukünftige Chirurgen bereits seit etwa 1500 auf Französisch unterrichtet werden. Etwa ab 1530 war außerdem eine wachsende Anzahl medizinischer Fachbücher in französischer Sprache erhältlich. Deren Inhalte betrafen großteils die Teilbereiche Chirurgie, Hygiene, Ernährung und das therapeutische Vorgehen im Falle von Epidemien (vgl. Berschin/Felixberger/Goebl 2008:198). Besonders in den letzten drei Bereichen war eine möglichst weite Verbreitung der Inhalte im Interesse aller höchst wünschenswert. Dieses Beispiel illustriert wohl aufs Beste die Hauptmotivation für den im 16. Jahrhundert langsam einsetzenden Übergang von lateinischen fachsprachlichen Publikationen zu französischsprachigen. Im Hinblick auf den bereits genannten ständig zunehmenden Benennungsbedarf im fachlichen Bereich stellt sich nun aber notwendigerweise die Frage nach der Herkunft all der neuen Fachtermini. Klare (1999:15) legt hierzu dar, dass in Frankreich bis zum Anfang des 16. Jahrhunderts vor allem das bas latin, also das bereits weit vom klassischen Latein entfernte Spätlatein, als Wortschatzlieferant diente - dies zunächst bereits zum Ausbau des Altfranzösischen bis etwa 1300, anschließend auch zur weiteren Elaborierung des Mittelfranzösischen. So gelangten zahlreiche mots savants, also Wissenschaftsbegriffe, aus dem Lateinischen ins Französische, was laut Klare (1999:15) ,[...] zu einer Relatinisierung des französischen Wortschatzes führte. Das wird deutlich, wenn man die ersten in französischer Sprache abgefaßten Fachtexte der Medizin, der Finanzwirtschaft, der Astronomie [...] betrachtet.“ Selbstverständlich blieben die aus dem Lateinischen entlehnten Wörter auch über den Beginn des 16. Jahrhunderts hinaus in der französischen Sprache verankert, wodurch Latein selbst zu einem Zeitpunkt, an dem sich bereits das Französische als Sprache der Wissenschaft und anderer Fachbereiche etabliert hatte, zumindest in Gestalt von Lehnwörtern nach wie vor in den Fachsprachen präsent blieb. Dies galt auch für die französische Gerichtssprache des 16. Jahrhunderts.

10 Die medizinische Fakultät der Universität von Montpellier ist die älteste Europas, an der noch aktiv gelehrt wird. Die Universität selber wurde im Jahr 1289 im Zuge eines Zusammenschlusses bereits vorhandener Fakultäten gegründet; darunter befand sich auch die medizinische Fakultät von 1150 (vgl. Wikipédia L'encyclopédie libre s.a. b:Université de Montpellier). 


\subsection{Die Ordonnance de Villers-Cotterêts von 1539}

Die französische Gerichts- bzw. Rechtssprache wurde am 25. August 1539, durch die der Website der Assemblée nationale zu entnehmende Ordonnan du Roy sur le faid de justice [sic], besser bekannt unter der inoffiziellen Bezeichnung Ordonnance de Villers-Cotterêts, vom Lateinischen abgekoppelt - ein Schlüsselmoment für die weitere Pflege und Normierung der französischen Fachsprachen. ${ }^{11}$ Die Ordonnance de Villers-Cotterêts wurde von François $\mathrm{I}^{\mathrm{er}}$ erlassen. ${ }^{12}$ Dessen Thronbesteigung war eine lange Entwicklung hin zu einer immer stärker absolutistisch ausgerichteten Monarchie vorausgegangen, die während der Regentschaft von François $I^{\mathrm{er}}$ einen vorläufigen Höhepunkt erreichte. Der König wollte Impulse einbringen, um sein Reich noch intensiver zu stabilisieren und wahrhaft zentralistisch zu organisieren. So entschloss er sich zur gesetzlichen Festlegung der Staatssprache Französisch. Diese war neben Latein bereits seit dem 12. Jahrhundert ein Instrument der königlichen Verwaltung gewesen (vgl. Müller 1975:23) und wurde 1539 dank der Ordonnance de Villers-Cotterêts offiziell zur verbindlichen Gerichts- bzw. Urkunden- und damit zur Amtssprache. Durch das Edikt verlor Latein seinen Status als wichtigste Schriftsprache nicht nur im rechtlichen Bereich, sondern sukzessive auch in anderen Domänen, und das Französische nahm in allen Bereichen seinen Platz ein (vgl. Müller 1975:36). Indem François $\mathrm{I}^{\mathrm{er}}$ nun mittels seiner Ordonnance de VillersCotterêts Französisch zur einzigen in rechtlichen Belangen zulässigen Sprache erklärte, schloss er allerdings nicht nur Latein in seinem gesamten Herrschaftsbereich aus dem Rechts- und dem staatlichen Verwaltungswesen aus, sondern auch die Regionalsprachen, z.B. Baskisch, Bretonisch, Elsässisch, Flämisch, Katalanisch, Korsisch usw. (vgl. Klare 1999:18). Einerseits konnten die Untertanen ihre Interessen nun grundsätzlich in der französischen Muttersprache vertreten; andererseits wurden sprachliche Minderheiten damit der Allgemeinheit gegenüber benachteiligt und neuerlich vor eine Sprachbarriere gestellt. Es ist nicht davon auszugehen, dass dieser

11 Eine Lektüre des vollständigen Texts der Ordonnance de Villers-Cotterêts unter http://www.assembleenationale.fr/histoire/villers-cotterets.asp gewährt Einblick in die Rechtssprache des 16. Jahrhunderts.

12 François $\mathrm{I}^{\mathrm{er}}$ setzte sich während seiner Regentschaft von 1515 bis 1547 auch für universitären Unterricht in französischer Sprache ein - ein weiterer Beitrag zur Entwicklung der französischen Fachsprachen. So veranlasste er französischsprachigen Unterricht in sog. Lektoraten; das waren Einrichtungen, die Unterricht in Latein, Griechisch, Hebräisch, Mathematik sowie den Naturwissenschaften anboten und aus denen später das Collège Royal sowie das Collège de France hervorgingen. Die Lektorate standen in Konkurrenz zur traditionell katholischen, am Ideal des klassischen Lateins ausgerichteten Sorbonne (vgl. Klare 1999:17f). 
Effekt der Ordonnance de Villers-Cotterêts rein zufälliger Natur war; vielmehr ist anzunehmen, dass sprachliche Minderheiten dadurch motiviert werden sollten, sich dem französischsprachigen Kollektiv anzuschließen.

Im Grunde sind nur zwei der 192 Artikel der Ordonnance de Villers-Cotterêts für die Entwicklung des Französischen maßgeblich: die im Folgenden mit der Einleitung des Edikts zitierten Artikel 110 und 111.

Ordonnan du Roy sur le faid de justice

François, par La [sic] grâce de dieu, Roy de France,

Sçavoir faisons, à tous présens et advenir, que pour aucunement pourvoir au bien de notre justice, abréviation des procès, et soulagement de nos sujets, avons, par édit perpétuel et irrévocable, statué et ordonné, statuons et ordonnons les choses qui s'ensuivent. [...]

Art. 110. - Et afin qu'il n'y ait casue [sic] de douter sur l'intelligence desdits arrêts, nous voulons et ordonnons qu'ils soient faits et écrits si clairement, qu'il n'y ait ni puisse avoir aucune ambiguité ou incertitude ne lieu à demander interprétation.

Art. 111. - Et pour ce que telles choses sont souvent advenues sur l'intelligence des mots latins contenus esdits arrests, nous voulons d'oresnavant que tous arrests, ensemble toutes autres procédures, soient de nos cours souveraines et autres subalternes et inférieures, soient de registres, enquestes, contrats, commissions, sentences, testaments, et autres quelconques, actes et exploicts de justice, ou qui en dépendent, soient prononcés, enregistrés et délivrés aux parties en langage maternel françois et non autrement. [...] (Assemblée nationale s.a.: Ordonnance d'août 1539)

Bereits aus der Einleitung der dem königlichen Willen gemäß unwiderruflichen Ordonnance de Villers-Cotterêts ging klar hervor, dass sie eine Verbesserung der Verfahrensweise in rechtlichen Belangen zum Ziel hatte - dies im Interesse aller Untertanen sowie des königlichen Rechtswesens selber. Der Artikel 110 besagte, dass alle gerichtlichen Beschlüsse so abzufassen seien, dass ihnen keinerlei Mehrdeutigkeit anhafte und dass keinerlei Unsicherheit bei der Auslegung der Texte aufkommen könne. Dadurch solle vor allem von vornherein gewährleistet sein, dass die Richtigkeit der Inhalte der betreffenden Dokumente nicht hinterfragt werde. Der Artikel 111 präzisierte seinerseits, dass derlei Probleme im Bezug auf lateinische 
Ausdrücke bereits häufig vorgekommen seien ${ }^{13}$, weswegen künftig an allen Gerichten sämtliche Rechtsverfahren auf Französisch abzuwickeln seien und alle Erlässe ebenfalls auf Französisch zu ergehen hätten. Weiters seien an den Gerichten aller Instanzen sämtliche Dokumente, so z.B. Urkundenregister, Befragungsprotokolle, Verträge, Gesuche, Urteilssprüche, Testamente usw., aber auch Gerichtsakten und Bescheide sowie die zugehörigen Unterlagen mündlich und schriftlich ausschließlich ,[...] en langage maternel françois [...]", also in der Muttersprache Französisch, abzufassen, zu Protokoll zu nehmen und den beteiligten Parteien zu übermitteln.

Im Grunde hatte die Ordonnance de Villers-Cotterêts eine Justizreform zum Inhalt, die es nicht nur dem Volk ermöglichen sollte, seine eigenen Interessen besser zu vertreten, sondern die auch juridische Abläufe vereinfachen und gerichtlichen Entscheidungen von vornherein mehr Autorität verleihen sollte. Um dies zu erreichen, wurde also der französischen Sprache in der Ordonnance de Villers-Cotterêts eine Schlüsselrolle verliehen; umgekehrt sollte die Ordonnance de Villers-Cotterêts damit im weiteren Verlauf der Geschichte eine Schlüsselrolle für die Sprachpolitik Frankreichs spielen. Pécheur (2001:51) stellt hierzu fest:

Que dans un souci d'efficacité, l'Etat ait souhaité améliorer son gouvernement par le biais d'une meilleure communication, donc par le biais de la langue, rien de plus naturel. D'autant plus qu'on prend conscience à cette époque qu'on peut améliorer la langue et l'écriture et que d'une langue vulgaire peuvent naître des chefs-d'œuvre capables de rivaliser avec les œuvres latines. Donc, $[\ldots]$ on s'est attaché, sur cet embryon de politique linguistique [à savoir sur l'Ordonnance de Villers-Cotterêts], à codifier la langue pour mieux en fixer l'emploi.

\subsection{Joachim du Bellay und seine Deffence et Illustration de la Langue Francoyse}

Einer der ersten, der nach dem Erlass der Ordonnance de Villers-Cotterêts seiner Konzeption der Sprachpflege Ausdruck verlieh, war Joachim du Bellay ${ }^{14}$ (1522-

13 Bereits bevor die Ordonnance de Villers-Cotterêts erlassen wurde, waren Gerichtsbeschlüsse teils auf Französisch verkündet worden, dies obgleich sie in schriftlicher Form auf Lateinisch abgefasst waren. Das hierzu verwendete Latein war zwar weitgehend französisiert worden - Berschin/Felixberger/Goebl (2008:192f) sprechen gar von einem „latinisierte[n] Französisch“ -, Unklarheiten im Verständnis gehörten aber dennoch zur Tagesordnung (vgl. Berschin/Felixberger/Goebl 2008:192f).

14 Eine ausführliche Biografie Joachim du Bellays findet sich in Chamard 1969. 
Das 16. Jahrhundert: erste Meilensteine der französischen Sprachpolitik

1560). Seine Anfang 1549 erschienene und in zwei Bücher aufgeteilte Deffence et Illustration de la Langue Francoyse ${ }^{15}$ verstand sich sowohl als Poetik als auch als programmatische Schrift im Zeichen der Verteidigung und der Bereicherung der französischen Sprache - dies sowohl im Bezug auf die Dichtung als auch auf die Wissenschaft. Verteidigt werden musste die französische Sprache damals vor allem gegen die Vormachtstellung, die dem Lateinischen seitens der humanistischen intellektuellen und literarischen Elite jener Zeit eingeräumt wurde. So hieß es, Latein verfüge über ein umfassenderes Kommunikationspotenzial als Französisch, weswegen Letzteres nicht geeignet sei, neue Literatur entstehen zu lassen. Der Vulgärhumanist du Bellay trat nun dieser Haltung vehement entgegen und vertrat den Standpunkt, alle Sprachen seien einander grundsätzlich gleichwertig, so auch die französische der lateinischen. Es hänge nur von der Zuwendung der Sprachnutzer $\mathrm{ab}$, wie sich eine Sprache letztlich entwickle:

Donques les langues ne sont nées d'elles mesmes en façon d'herbes, racines et arbres : les unes infirmes et debiles en leurs espéces : les autres saines et robustes, et plus aptes à porter le faiz des conceptions humaines : mais toute leur vertu est née au monde du vouloir et arbitre des mortelz ${ }^{[2]}$. Cela (ce me semble) est une grande rayson pourquoy on ne doit ainsi ${ }^{[3]}$ louer une langue et blamer l'autre : veu qu'elles viennent toutes d'une mesme source et origine : $[\ldots]$. Il est vray que par succession de tens ${ }^{[3]}$ les unes, pour avoir eté plus curieusement ${ }^{[4]}$ reiglées, sont devenues plus riches que les autres : mais cela ne se doit attribuer à la felicité ${ }^{[5]}$ desdites langues, ains ${ }^{[6]}$ au seul artifice et industrie des hommes $^{[7]}$ (du Bellay 1969:47f, Fußnoten weggelassen, M.M.).

Was nun die französische Sprache betrifft, sei sie bisher nicht ausreichend gepflegt worden, was einzig und allein in der Verantwortung der Sprachnutzer liege und weswegen man die französische Sprache selber nicht verdammen dürfe:

15 Die Deffence et Illustration de la Langue Francoyse erschien anonym, lediglich mit den Verfasserinitialen I.D.B.A. gezeichnet. Da diese allerdings unschwer als eine Abkürzung von ,Joachim du Bellay d'Anjou“ zu identifizieren sind und das Werk darüber hinaus dem Kardinal Jean du Bellay, einem Cousin zweiten Grades Joachim du Bellays, gewidmet ist, lässt sich daraus leicht auf die Identität des Verfassers schließen (vgl. Chamard 1969:95 sowie Werner 2001:19). Es besteht also Einigkeit über die Autorschaft du Bellays an der Deffence et Illustration de la Langue Francoyse, wobei diese nach Chamard (1969:94f) vor allem auch im Kontext seiner Mitgliedschaft in der Dichtergruppe der Pléiade zu betrachten ist. Die in der Deffence et Illustration de la Langue Francoyse vertretenen Standpunkte waren der gesamten Gruppe rund um Pierre de Ronsard eigen. 
Et si nostre langue n'est si copieuse ${ }^{[1]}$ et riche que la grecque ou latine, cela ne doit estre imputé au default d'icelle, comme si d'elle mesme elle ne pouvoit jamais estre si non pauvre et sterile: mais bien on le doit attribuer à l'ignorance de notz majeurs ${ }^{[2]}$, qui ayans (comme dict quelqu'un ${ }^{[1]}$, parlant des anciens Romains) en plus grande recommendation le bien faire que le bien dire, et mieux aymans laisser à leur posterité les exemples de vertu que les preceptes $^{[2]}$, se sont privez de la gloyre de leurs bien faitz ${ }^{[3]}$, et nous du fruict de l'immitation d'iceux, et par mesme moyen nous ont laissé nostre langue si pauvre et nue, qu'elle a besoing des ornementz et (s'il faut ainsi parler) des plumes d'autruy $^{[4]}$ (du Bellay 1969:66f, Fußnoten weggelassen, M.M.).

Es müsse nun für die bisher versäumte ,illustration“, also die Bereicherung des Französischen, Sorge getragen werden, damit die Sprache zuerst dasselbe Niveau an Ausdruckskraft erlange wie die antiken Vorbilder und diesen in Folge dann sogar langfristig überlegen werden könne. Die Utilität dieses Unterfangens begründete du Bellay übrigens mit einem ökonomischen Argument, nämlich dem immensen Zeitverlust, den das Studium der antiken Sprachen für Gelehrte mit sich brachte. Er sprach in diesem Zusammenhang von Jahrzehnten, die dem Spracherwerb gewidmet werden müssten, um erst anschließend über das Griechische, Lateinische oder Hebräische Zugang zu wissenschaftlichen Inhalten zu erlangen. Für die Zukunft sei es daher von vorrangiger Bedeutung, anstatt der antiken Sprachen Schritt für Schritt das Französische in den Wissenschaften und im Handwerk zu etablieren, um so allen Sprachnutzern die Kommunikation über sämtliche Inhalte - auch solche fachlicher Art - zu ermöglichen. Die antiken Sprachen unverzüglich aus dem fachsprachlichen Bereich zu verbannen sei hingegen keine Option für das 16 . Jahrhundert, da noch zu viel maßgebliches Wissen allein über das Griechische und das Lateinische zu erschließen sei (vgl. du Bellay 1969:133ff).

Um nun die Veredelung der französischen Sprache umzusetzen, wandte sich du Bellay appellativ direkt an die Autoren seiner Zeit und empfahl ihnen mehrfach, antike Werke nicht nur zu übersetzen, sondern sie vor allem auch frei nachzudichten (vgl. du Bellay 1969:82; ib.:103f; ib.:160f;). ${ }^{16}$ Die Bereicherung im Rahmen dieser Imitationen konstituierte sich laut du Bellay (1969:105, Fußnoten weggelassen, M.M.) darin, dass Bestandteile der antiken Sprachen so gezielt ins Französische übernommen werden konnten, denn , $[\ldots]$ ce n'est point chose vicieuse, mais grandement louable, emprunter d'une langue etrangere les sentences ${ }^{[2]}$ et les motz, et les

16 Freies Übersetzen oder Nachdichten betrieb auch du Bellay selbst in seiner Deffence et Illustration de la Langue Francoyse; so inspirierte er sich intensiv am Dialogo delle lingue Sperone Speronis von 1542 (vgl. Klare 1999:17 sowie Werner 2001). 
approprier à la sienne : [...].“ Weiters sprach sich du Bellay (1969:248f, Fußnoten weggelassen, M.M.) dafür aus, neue Wörter zu erfinden - ,[...] celuy qui entreprendra un grand œuvre ${ }^{[2]}$, qu'il ne craigne point d'inventer, adopter et compo$\operatorname{ser}^{[3]}[\ldots]$ quelques motz francoys $[\ldots]^{\text {“ }}$ - und bezog sich dabei nachdrücklich auf einen neu entstandenen Kommunikations- und Benennungsbedarf, insbesondere auch im Bereich der Fachsprachen:

Nul, s'il n'est vrayment du tout ${ }^{[3]}$ ignare, voir privé de sens commun, ne doute point que les choses ${ }^{[4]}$ n'ayent premierement eté : puis apres, les motz avoir eté inventez pour les signifier ${ }^{[5]}$ : et par consequent aux nouvelles choses estre necessaire imposer nouveaux $\operatorname{motz}^{[6]}$, principalement és ars, dont l'usaige n'est point encores commun et vulgaire, ce qui ${ }^{[7]}$ peut arriver souvent à nostre poëte, au quel sera necessaire emprunter beaucoup de choses non encor' traitées en nostre langue. Les ouvriers ${ }^{[8]}$ (afin que je ne parle des sciences liberales) jusques aux laboureurs mesmes, et toutes sortes de gens mecaniques ${ }^{[1]}$, ne pouroint conserver leurs metiers, s'ilz n'usoint de motz à eux usitez et à nous incongneuz $^{[2]}$ (du Bellay 1969:250f, Fußnoten weggelassen, M.M.).

Um nun schließlich die Veredelung des Französischen systematisch voranzutreiben, solle sich der Dichter an verschiedene Empfehlungen halten: Eigennamen aus allen Sprachen sollten ins Französische eingebürgert werden (vgl. du Bellay 1969:255). Weiters sollten ausschließlich französische Wörter - darunter getrost auch Archaismen - verwendet werden (vgl. du Bellay 1969:256ff). Um Syntax wie Stil zu bereichern, seien Infinitive und Adjektive zu substantivieren, Adverbien auf -ment nach Möglichkeit durch Substantive zu ersetzen und neue Kollokationen im Rahmen von Infinitivgruppen zu schaffen (vgl. du Bellay 1969:284f). Außerdem solle sich jeder Dichter nicht nur an der Wissenschaft orientieren, sondern auch am Handwerk, und fachspezifisches Vokabular in seine Werke aufnehmen, um so der französischen Sprache mehr Authentizität zu verleihen:

Encores te veux-je advertir ${ }^{[6]}$ de hanter quelquesfois, non seulement les scavans, mais aussi toutes sortes d'ouvriers et gens mecaniques ${ }^{[7]}$, comme mariniers, fondeurs, peintres, engraveurs ${ }^{[8]}$ et autres, scavoir leurs inventions, les noms des matieres, des outilz, et les termes usitez en leurs ars et metiers, pour tyrer de la ces belles comparaisons et vives descriptions de toutes choses[1] (du Bellay 1969:303f, Fußnoten weggelassen, M.M.).

Im Großen und Ganzen lässt sich resümieren, dass du Bellay in der Wahl seiner Methoden zur Veredelung des Französischen nicht besonders selektiv vorging und den Autoren zahlreiche Freiheiten einräumte, dies stets im Bemühen, das Kommu- 
nikationspotenzial des Französischen mit jedem neuen Wort weiter auszubauen: je größer der Wortschatz, desto reicher die Sprache, desto größer ihre Strahlkraft - so die Auffassung du Bellays. Auf Basis seiner Deffence et Illustration de la Langue Francoyse wurde die französische Sprache also im 16. Jahrhundert dahingehend ausgebaut, dass sie nicht nur in der literarischen Praxis, sondern zugleich auch in der wissenschaftlichen Fachkommunikation ausreichende Ausdrucksformen bot und im Vergleich mit den antiken sowie modernen europäischen Sprachen - zunächst vor allem dem Italienischen, weiters dem Spanischen - in allen Domänen bestehen konnte (vgl. Grimm 2005:109f). Dies war aus französischer Perspektive einerseits natürlich höchst wünschenswert, aber andererseits fehlten der Sprachpolitik des 16. Jahrhunderts ausreichende Kontrollmechanismen. Dadurch, so stellt Kramer (2001:36) fest, ,[drohte] die Bereicherung der französischen Sprache [...] im Chaos und nicht etwa in der Veredelung zu enden." Berschin/Felixberger/Goebl (2008:226) sprechen im selben Zusammenhang von einem „buntscheckigen Bild“, das sich dadurch im französischen Wortschatz ergab. Die stark normativ und puristisch geprägte, im 17. Jahrhundert einsetzende Sprachpolitik mag sich vor diesem Hintergrund als Gegenbewegung zum von du Bellay propagierten Sprachausbau erklären lassen. 


\section{Das 17. Jahrhundert: der Sprachpurismus des Grand Siècle}

Das 17. Jahrhundert stand in Frankreich ganz im Zeichen der Klassik sowie eines absolutistisch regierten und zentralistisch koordinierten Staates: Da das Land im 16. Jahrhundert Krisen wie die Italien- und die Religionskriege durchgestanden hatte, war es zu Beginn des 17. Jahrhunderts besonders wichtig, in allen Domänen des Staates Einheit und damit Stärke zu schaffen. Dies betraf auch die Sprache, die im 16. Jahrhundert zwar zur Amtssprache erklärt und angesichts eines neu entstandenen Kommunikationsbedarfs intensiv gepflegt worden war, jedoch aufgrund des ausufernden Sprachausbaus in sich nicht mehr einheitlich war. Dieser Sprachzustand entsprach nicht den Normen der nach Reinheit strebenden Klassik, was Bemühungen, der französischen Sprache feste Regeln zu verleihen, nach sich zog. So ging das Grand Siècle mit seinen sprachpuristischen und sprachnormativen Ansätzen als das prägendste Jahrhundert der französischen Sprachpolitik in die Geschichte ein. Es wirkt im modernen Französisch immer noch nach. Kramer (2001:38) hält dazu fest:

Es ist offenkundig, daß die sprachregulierenden Maßnahmen, die im 17. Jahrhundert getroffen wurden, ungemein wirksam waren: Im wesentlichen [sic] tritt das Französische heute noch in der Form auf, in die es damals gegossen wurde.

In der Tat wurde im 17. Jahrhundert gezielt versucht, die französische Gesamtsprache dem bon usage des honnête homme gemäß einzufrieren. Dieses sprachpuristische Unternehmen, das die Fachsprachen fortan weitestgehend aus der staatlich-offiziellen Sprachpflege ausschloss, gelang mit relativ durchschlagendem Erfolg. ${ }^{17}$

Auf welchem Ideal aber beruhte der bon usage, und mit welcher Begründung konnte er den Fachsprachen bis ins 18. Jahrhundert hinein jegliche Wichtigkeit innerhalb der französischen Sprache absprechen?

17 Hierbei stellt sich die Frage, ob die Verwendung des Begriffs „Erfolg“ gerechtfertigt ist, müssen sich lebende Sprachen doch verändern und entfalten können. Pécheur (2001:51) spricht im Zusammenhang mit dem Sprachpurismus des 17. Jahrhunderts von einer „folie meurtrière“. Laut Schwarze besteht das Risiko, dass eine Festlegung des ,guten Sprachgebrauches“ im Rahmen einer „,bornierten, autoritären und diskriminatorischen Normierungspraxis“ Sprachen in ihrer natürlichen Entwicklung lähmen würde (vgl. Schwarze 1982:299; ib.:302). 


\title{
3.1 Die höfischen Ideale des 17. Jahrhunderts
}

Im 17. Jahrhundert erreichte der Absolutismus in Frankreich unter Louis XIV seinen Höhepunkt, was für den Adel den Verlust seines feudalen Status sowie viele neue Verpflichtungen mit sich brachte. Der niedrige Landadel einerseits durfte zwar außerhalb des unmittelbaren Umfelds des Königs verbleiben, lebte allerdings häufig unter finanziell prekären Umständen. Der Hochadel andererseits, die haute noblesse, wurde durch den Willen des Königs an den Pariser Hof gebunden und hatte sich dort einem komplexen Regelsystem zu unterwerfen. Der Einzelne konnte Prestige gewinnen und seine Stellung bei Hofe verbessern, sofern er die zahlreichen Regeln der Etikette in allen Bereichen - z.B. in der Wahl der Kleidung, beim Einhalten des Zeremoniells, in der Konversation, im Umgang mit hierarchisch höher oder gleich gestellten Personen etc. - par excellence befolgte. Kam ein Mitglied des Hofadels diesen Anforderungen jedoch nicht nach, so konnte dies laut Elias (1983:353f) schwerwiegende Folgen für die betreffende Person haben:

\begin{abstract}
Als Inhaber von Hofämtern, von Pensionen aus der königlichen Schatulle, von militärischen Ämtern - was immer sie [die Hofadeligen] waren, des Königs Ungnade, falsche Schritte im Konkurrenzkampf der höfischen Fraktionen, Feindschaft eines Günstlings, einer Mätresse, eines Ministers, alles das konnte die Einkommenschancen eines Höflings, die Lebenshaltung seiner Familie ebenso wie sein Prestige, seinen Marktwert innerhalb der höfischen Gesellschaft, seine Aussichten und Hoffnungen in der Zukunft bedrohen. Selbst für Höflinge, die ein beträchtliches Familieneinkommen besaßen, bedeutete Einschränkung oder Verminderung der königlichen Gunst eine schwer zu ertragende Gefahr. Und die Ungnade des Königs, Verbannung vom Hofe, bedeutete für einen Höfling, wie gesagt, mehr oder weniger das Ende seiner sozialen Existenz.
\end{abstract}

Die Anforderungen waren also enorm, und alledem lag das Idealbild des höfischen Menschen, des honnête homme, zu Grunde. ${ }^{18}$ Diesem war es als Mitglied des Adels verboten, eine auf Erwerb ausgerichtete Arbeit auszuüben, um sein Vermögen zu vermehren; hielt er sich nicht an diese Vorgabe, so musste er mit einem Entzug seines Adelstitels durch den König rechnen, einer sogenannten dérogeance (vgl.

18 Über eine exakte Konzeption des Idealbilds des honnête homme gibt Nicolas Farets erstmals 1630 veröffentlichtes Werk L'honnête homme, ou: L'art de plaire à la Cour Aufschluss. 
Grimm 2005:18). Idealiter erweckte ein Mitglied des Adels also gar nicht erst den Eindruck, über spezialisierte Kenntnisse zu verfügen oder in einem Bereich ein Fachmann zu sein, was in der Konversation einen weitgehenden Verzicht auf die Verwendung fachsprachlichen Vokabulars voraussetzte (vgl. Hassler 1998:323f). Dieser war typisch für das Sprachideal des bon usage, des bei Hofe bzw. in den Pariser Salons üblichen, rein mündlich orientierten „guten Sprachgebrauchs“, der zum allgemeingültigen Bewertungsmaßstab in Sprachfragen wurde. ${ }^{19} \mathrm{Er}$ zeugte nicht nur von der Sprachkultiviertheit des Einzelnen, sondern auch von verfeinerten Lebensgewohnheiten. Diese kamen in der Konversation sowohl durch die Ausgrenzung unschicklicher Wörter, der sogenannten mots bas, als auch entsprechender unangemessener Inhalte zum Ausdruck - so waren z.B. Konversationsthemen mit fachlichem Hintergrund der honnêtes gens ebenso wenig würdig wie Gespräche über Körperfunktionen oder Sexualität. Grimm (2005:145, im Original teilweise Fettdruck) beschreibt die Ausgrenzung jeglicher Fachlichkeit aus dem Universum des honnête homme unter einem Rückgriff auf Blaise Pascal wie folgt:

Ihr Repräsentant [jener der honnêteté] lässt sich einfacher durch das definieren, was er nicht ist und auf keinen Fall sein darf, als durch seine positiven Eigenschaften. Als Antipode eines Pedanten rühmt der ,honnête homme' sich zuallererst, über keinerlei spezielle Kenntnisse zu verfügen; er ist vielmehr ein universal interessierter Dilettant, dessen Bildungsideal man mit Pascal [Pascal 1998 - zit. n. Grimm 2005:145] wie folgt beschreiben kann: „Il est bien plus beau de savoir quelque chose de tout que de savoir tout d'une chose; cette universalité est la plus belle.“ Jede Form von Spezialistentum lehnt der ,honnête homme' ab [...].

Diese kategorische Ablehnung bedingte, dass die Fachsprachen aus der offiziellen Sprachpolitik und Sprachpflege des 17. Jahrhunderts - einer ausschließlich am Königshof orientierten Sprachnormierung und -beschneidung - weitgehend ausgegrenzt wurden.

19 Dem bon usage stand der negative mauvais usage gegenüber, der dem arbeitenden Volk zugeschrieben wurde. Vaugelas bezeichnete dies pejorativ als la lie du peuple (vgl. Klare 1999:23) und machte damit eindeutig klar, dass seiner Meinung nach das soziale Niveau ausschlaggebend für das Sprachniveau war. Siehe hierzu auch Kapitel 3.3. 


\section{2 „Enfin Malherbe vint“20: die Beschneidung der Sprache}

François de Malherbe (1555-1628) wurde zwar in der Renaissance geboren, gilt jedoch als Wegbereiter der französischen Klassik und war in seinem Wirken wegweisend für den französischen Sprachpurismus des 17. Jahrhunderts. 1605 wurde er bei Hofe vorgestellt, in Folge geadelt und zum Hofdichter ernannt. Damit erlangte er eine Position, die es ihm erlaubte, normativ in die seit du Bellay und seinem Aufruf zum Sprachausbau ausufernde französische Lexik einzugreifen. Er wollte ganz im Sinne klassischer Ideale - und zugleich konträr zu denen der Pléiade - für Klarheit, Reinheit, Ordnung und Präzision im Ausdruck sorgen, so dass die französische Sprache von allen Sprachnutzern, unabhängig von ihrer sozialen oder geographischen Herkunft innerhalb Frankreichs, gleichermaßen verstanden werden konnte. Malherbe hatte eine strikte Vorstellung von der Sprache und ihrem ständeübergreifenden, richtigen Gebrauch, die niemandem Raum für Freiheiten ließ gänzlich unabhängig von der gesellschaftlichen Stellung der Sprachnutzer:

Pour Malherbe, le principal mérite d'un écrivain, mérite auquel non seulement on doit subordonner mais même sacrifier tous les autres, consiste à écrire avec pureté. Il existe une règle du langage, elle s'applique à tous sans exception; personne, pas même le roi, n'a le droit d'y rien changer ; aucun écrivain, pas même le poète, ne peut s'en licencier; loin que les prétendues licences soient quelquefois une grâce, aucune nécessite ne saurait les excuser. Règle infaillible, faute sans réplique, ces formules reviennent constamment sous la plume de Malherbe ; elles disent assez combien les temps avaient changé (Brunot 1930a:3).

Die Maßnahmen, die bis zum Beginn von Malherbes Wirken bei Hofe zur Sprachpflege getroffen wurden, waren absolut inkompatibel mit seiner Doktrin, die Stabilität vorsah. So erklärte er die Regeln, die vor ihm zum Ausbau des Französischen aufgestellt wurden, eine nach der anderen für ungültig: Zunächst betraf dies die lexikalischen und syntaktischen Entlehnungen aus dem Lateinischen. Dann begann

20 Diese Zeile stammt aus Nicolas Boileaus Chant I in seinem Werk L'Art poétique aus dem Jahr 1674 und würdigt Malherbes Wirken: „,...] Enfin Malherbe vint, et le premier en France / Fit sentir dans les vers une juste cadence: / D'un mot mis en sa place enseigna le pouvoir, / Et reduisit la Muse aux regles du devoir. / Par ce sage Ecrivain la Langue reparée / N'offrit plus rien de rude à l'oreille épurée. / Les Stances avec grace apprirent à tomber, / Et le vers sur le vers n'osa plus enjamber. / Tout reconnut ses loix, et ce guide fidele / Aux Auteurs de ce temps sert encor de modele. / Marchez donc sur ses pas, aimez sa pureté, / Et de son tour heureux imitez la clarté. / [...]“ (Boileau 1970:42f). 
Malherbe, dialektale Ausdrücke - vor allem zahlreiche Gaskognismen, die sich selbst bei Hofe eingebürgert hatten - aus dem Standardfranzösischen zu verbannen. Weiters kritisierte er die Verwendung von Diminutiven, von substantivierten Adjektiven und von Archaismen. Schließlich trat er auch gegen die Verwendung fachsprachlicher Begriffe in der Literatursprache ein: So betrachtete Malherbe zum Beispiel caler ausschließlich als der Fachsprache der Marine zugehörig und daher für die Literatur ungeeignet. Auch Wörter wie entamer, ulcère, poitrine oder idéal schloss er als den Fachsprachen zugehörig vom Gebrauch in der Literatur und in sonstigen nicht-fachsprachlichen Kontexten aus. ${ }^{21}$ Dasselbe Schicksal ereilte Begriffe und Wendungen, die typischerweise vom einfachen Volk gebraucht wurden, beispielsweise un coup de fouet oder faire conte. Mit seinen normativen Urteilen über den Gebrauch der französischen Sprache - die er übrigens anhand von Fallbeispielen, die er als negativ beurteilte, in Form von Randglossen zu Werken von Ronsard und Desportes kund tat (vgl. Berschin/Felixberger/Goebl 2008:229) schuf Malherbe eine Klassifizierung ${ }^{22}$ der Wörter in mots nobles, die schicklich waren und deren Gebrauch er uneingeschränkt gut hieß, in mots bas bzw. expressions plébées, deren Verwendung er radikal entgegentrat, und in mots sales bzw. malpropres, die mit Körperfunktionen in Zusammenhang standen und deren Anwendung daher Tabu war (vgl. Brunot 1930a:4ff). Dieser Dreiteilung entsprechend wären nun so gut wie alle fachsprachlichen Begriffe den mots bas zuzuordnen. Brunot (1930a:9) spricht im Zusammenhang mit Malherbes kategorischem Ausschluss großer Teile der damaligen Lexik vom salonfähigen Wortschatz von ,exagérations incontestables“, denn ,[...] Malherbe épluche le lexique, mais avec une telle sévérité qu'il laisse tomber bien des mots nécessaires, qu'on regrettera pour la plupart de n'oser ramasser et qui seront perdus." Obgleich Malherbe in der Ausübung seiner Sprachbeschneidung auf sich allein gestellt war, weder einer Gruppe noch einer Institution angehörte, stießen seine Ansichten auf breite Akzeptanz und wurden von den Autoren wie auch vom Hof übernommen. Dies wie auch die Tatsache, dass Malherbes sprachpuristische Haltung Nachfolger fand, mag darauf zurückzuführen sein, dass er, wie Kramer (2001:36) präzisiert, ,[...] das Sprachrohr eines in den tonangebenden Kreisen der Gesellschaft verbreiteten neuen Sprachgefühles [war].“

21 Berschin/Felixberger/Goebl (2008:231) weisen in diesem Zusammenhang ausdrücklich darauf hin, dass bei Malherbe zwar „[...] fachsprachliche Ausdrücke abgelehnt [wurden], allerdings nur für den bon usage. Im fachsprachlichen Bereich blieben sie unangetastet."

22 Diese Klassifizierung ist laut Berschin/Felixberger/Goebl (2008:231) im Gegensatz zu Malherbes ansonsten ständeübergreifenden Konzeption des guten Sprachgebrauchs nun durchaus als eine „den sozialen Schichten entsprechende [...] Klasseneinteilung“" zu verstehen. 
Das 17. Jahrhundert: der Sprachpurismus des Grand Siècle

\subsection{Vaugelas und seine Remarques sur la Langue Françoise}

Claude Favre de Vaugelas (1585-1650) war Mitglied der Académie française, hatte großen Anteil an der Redaktion deren ersten Wörterbuchs und steht als Einzelperson zugleich ob seines sprachnormativen Wirkens unmittelbar in der Nachfolge Malherbes. 1647 erschien sein Hauptwerk, Remarques sur la langue française, utiles à ceux qui veulent bien parler et bien écrire, das aufgrund seines Erfolges mehrmals neu aufgelegt wurde. Mit seinen Remarques sur la langue française definierte Vaugelas erstmals den bon usage, stilisierte ihn als einzig erstrebenswertes Sprachideal, grenzte ihn vom mauvais usage ab und machte bereits im Vorwort seiner Remarques sur la langue française klar, dass der bon usage ein elitäres, an einer sprachlichen Prestigevariante ausgerichtetes Sprachkonzept ist:

2. Il y a sans doute deux sortes d'Vsages, vn bon et $v n$ mauvais. Le mauuais se forme du plus grand nombre de personnes, qui presque en toutes choses n'est pas le meilleur, et le bon au contraire est composé non pas de la pluralité, mais de l'élite des voix, et c'est veritablement celuy que l'on nomme le Maistre des langues, celuy qu'il faut suiure pour bien parler, et pour bien escrire en toutes sortes de stiles, [...]. Voicy donc comme on definit le bon Usage. - 3. C'est la façon de parler de la plus saine partie de la Cour, conformément à la façon d'escrire de la plus saine partie des Autheurs du temps. Quand ie dis la Cour, i’y comprens les femmes comme les hommes, et plusieurs personnes de la ville où le Prince reside, qui par la communication qu'elles ont auec les gens de la Cour participent à sa politesse (Vaugelas 1880:12f).

Mit diesem Sprachideal wurde - wie bereits im Kapitel 3.1 dargelegt - bei Vaugelas automatisch und ganz in der Tradition Malherbes ${ }^{23}$ durch den Ausschluss der Fachsprachen vom Normgebrauch die weitgehende Ausgrenzung der Fachsprachen von sämtlichen sprachpflegerischen Aktivitäten betrieben. Aber laut Chassagne et al. (1994:32) traf Vaugelas' Ablehnung nicht nur die Fachsprachen:

23 Abgesehen von derselben sprachpuristischen Grundhaltung strebten Malherbe und Vaugelas allerdings nicht exakt dieselben Ziele an. Malherbe versuchte, durch Ordnung und Norm ein allen Sprachnutzern universell verständliches Französisch hervorzubringen. Vaugelas hingegen bestätigte auf einer gesellschaftlich-politischen Grundlage eine Minderheit in der Richtigkeit und Vorbildhaftigkeit ihrer Sprachverwendung, während er dadurch das Gros der Sprachnutzer außerhalb des normgerechten Sprachgebrauchs und auf einer tieferen hierarchischen Stufe platzierte (vgl. Grimm 2005:118f). 
Il rejette la pédanterie, les archaïsmes du vocabulaire, de la prononciation ou des constructions syntaxiques, de même que les néologismes. Les mots familiers et les termes techniques ne peuvent pas non plus faire partie du beau langage.

Trotz des grundlegenden Ausschlusses der Fachsprachen vom bon usage haben nun aber doch vereinzelte Einträge der Remarques sur la langue française Fachtermini zum Inhalt, wie das folgende Kapitel zeigen wird.

\subsubsection{Fachsprachen in den Remarques sur la Langue Françoise ${ }^{24}$}

Zum grundsätzlichen Aufbau der Remarques sur la langue française ist zunächst anzumerken, dass sich jede remarque, also jeder Einzeleintrag, einem bestimmten, von Vaugelas in der Praxis beobachteten Problemfall des Sprachgebrauchs widmete. Die einzelnen remarques wurden in unsystematischer Reihenfolge aufgeführt - ein Prinzip, das es erlaubte, die Sammlung jederzeit zu erweitern. ${ }^{25}$ Zugleich bedingte dies, dass die Leserschaft der Remarques sur la langue française jedem einzelnen Artikel von vornherein höchste Konzentration entgegenbringen musste, da sie bei kontinuierlicher Lektüre mehrerer Einträge durch keinerlei thematischen Zusammenhang dabei unterstützt wurde, sich die Inhalte besser $\mathrm{zu}$ verinnerlichen. Die Überschriften der einzelnen remarques gaben Aufschluss über den Gegenstand der Einträge, deren Länge je nach Bedarf variierte und deren inhaltliche Struktur keinem einheitlichen Aufbau entsprach: Informationen zur Etymologie, zur Phonetik, zu Synonymen, zur grammatischen oder syntaktischen Konstruktion, zur Richtigkeit oder Fehlerhaftigkeit in der Verwendung eines Ausdrucks sowie Positiv- und Negativbeispiele aus der sprachlichen Praxis etc. gehörten zwar zum allgemeinen Informationsangebot der remarques; im Einzelnen variierten die Inhalte allerdings von Eintrag zu Eintrag. Einträge zu fachsprachlichen Begriffen kamen in den Remarques sur la langue française übrigens nur selten vor. Im Folgenden soll nun anhand von

24 Zur Analyse der Remarques sur la langue française in der vorliegenden Arbeit wurde die überarbeitete Ausgabe von Chassagne aus dem Jahr 1880 herangezogen, die nicht nur die Bemerkungen Vaugelas', sondern auch in späteren Auflagen angebrachte Kommentare von Olivier Patru, Thomas Corneille (1738) sowie der Académie française (1704) enthält, die im Folgenden - soweit vorhanden - auch wiedergegeben werden. Hierbei steht T. C. für Thomas Corneille; A. F. für die Académie française.

25 Dieses Prinzip findet auch heute noch bei modernen Chroniques de Langage nach dem Vorbild Vaugelas' Anwendung und trägt nicht unwesentlich zu deren Erfolg bei. Eine ausführliche Befassung mit diesen remarques der Gegenwart würde allerdings den Rahmen der vorliegenden Arbeit sprengen; daher sei an dieser Stelle auf Schwarze 1977 verwiesen, der sich dem Thema umfassend widmet. 
Das 17. Jahrhundert: der Sprachpurismus des Grand Siècle

vier exemplarisch zitierten fachsprachlich orientierten Einträgen gezeigt werden, wie Vaugelas seine remarques aufbaute bzw. fachsprachliche Begriffe behandelte.

SOUMISSION, et SubMission.

Il y a vingt ans qu'on disoit submission, et non pas soumission, quoy que l'on dist soumettre, et soumis, et non pas submettre, ny submis; maintenant on dit et on escrit, soumission, et non pas submission. Ie sçay bien qu'on dit au Palais, il a fait les submissions au Greffe, mais c'est vn terme de Palais, qui ne tire point à consequence pour le langage ordinaire.

T. C. - Il est hors de doute qu'il faut dire soumission.

A. F. - Submission a cessé d'estre un terme de Palais. On dit aujourd'huy, Il a fait ses soumissions au greffe (Vaugelas 1880:83).

Diese remarque zu den Begriffen soumission bzw. submission entstammt der Fachsprache Recht. In der Überschrift gab Vaugelas - wie in all seinen Einträgen - Aufschluss über den Inhalt der remarque: Durch die Nennung zweier Begriffe in der Überschrift ist bereits darauf zu schließen, dass es sich um konkurrierende Varianten handelt, die in der Sprache ein und dasselbe bezeichnen. Die Tatsache, dass Vaugelas den Begriff submission an zweiter Stelle nannte, könnte nahelegen, dass es sich hierbei um die von ihm nicht favorisierte Variante handelt - ein Phänomen, das sich beispielsweise auch im folgenden Artikel Naviger, Naviguer beobachten lässt -, das allerdings nicht systematisch auf alle remarques zutrifft, die zwei oder mehrere Begriffe im Titel tragen. Zu Beginn des Eintrags erläuterte Vaugelas bereits mit einem Verweis auf Ausnahmefälle der Sprache (,[...] quoy que l'on dist soumettre, et soumis, et non pas submettre, ny submis ; [...]"), welche der beiden Varianten veraltet sei bzw. welche Gültigkeit habe. Dies legte Vaugelas fest, ohne eine Begründung oder weiterführende Erklärung zu seiner Entscheidung anzuführen. Das Anwendungsbeispiel im fachsprachlichen Kontext (,il a fait les submissions au Greffe") aufgrund dessen die Sprachnutzer ausgerechnet zu einem nicht mit Vaugelas' Entscheidung konformen Gebrauch tendieren hätten können, wurde als gerichtssprachlich abgetan $\left(,[\ldots]\right.$ mais c'est vn terme de Palais $\left.[\ldots]^{6}\right)$, womit dieser Ausdruck für die Verwendung durch fachfremde Sprachnutzer als nicht verbindlich eingestuft wurde. Corneille sowie die Académie française zeigten sich im Prinzip einer Meinung mit Vaugelas, wobei die Académie française dem Begriff submission allerdings seine Zugehörigkeit zur Gerichtssprache absprach. Heute ist die Verwendung des Ausdrucks faire des soumissions au Greffe - wohl ganz im Sinne Vaugelas' - in der französischen Rechtssprache nach wie vor fest verankert. 
NAVIGER, NAVIGUER.

Tous les gens de mer, disent, nauiguer, mais à la Cour on dit, naviger, et tous les bons Autheurs l'escriuent ainsi.

T. C. - Quand les gens de mer diroient encore Naviguer, un homme qui donneroit au Public la Relation de ses voyages, diroit Naviger pour bien escrire.

A. F. - L'Académie n'a point de jurisdiction sur les gens de mer pour les empescher de dire naviguer, son sentiment est qu'il faut dire naviger. On dit neantmoins navigable et navigation (Vaugelas 1880:144).

Die oben stehende remarque betrifft die Begriffe naviger bzw. naviguer aus der Werkstattsprache der Seeleute. Deren Normgebrauch des Begriffs, nauiger, nannte Vaugelas auch ausdrücklich. Dennoch sprach er sich in Folge für die orthographische und zugleich phonetische Variante naviger aus $(,[\ldots]$ mais à la Cour on dit, naviger $\left.[\ldots]^{6}\right)$, da diese dem Gebrauch des Hofs wie auch der guten Autoren seiner Zeit entsprach. Vaugelas zögerte also nicht, einen einer Fachsprache entnommenen Begriff den Normen des Hofs zu unterwerfen und zu diesem Zweck die bereits existente fachsprachliche Gebrauchsnorm für ungültig zu erklären. Der usage seitens des Hofs diente Vaugelas hier als Rechtfertigung seiner Entscheidung. Corneille stimmte Vaugelas' bon usage im Grunde zu, präzisierte aber, dass dieser vor allem gelte, wenn der Begriff naviguer bzw. naviger in der Öffentlichkeit gebraucht würde, was als Relativierung Vaugelas' strikter Auslegung gewertet werden kann. Die Académie française stellte wiederum fest, dass sie keine Möglichkeit habe, den Gebrauch der Variante naviguer in der Werkstattsprache zu unterbinden - was nun durchaus die Interpretation nahe legt, sie hätte es gerne getan. Dem richtigen Gebrauch entspräche dennoch die Variante naviger - eine Norm, deren Sinnhaftigkeit besonders unter anschließender Nennung der "Ausnahmen“ navigable und navigation $\mathrm{zu}$ hinterfragen ist. Wie allgemein bekannt ist, bedient sich das Gegenwartsfranzösische heute der ursprünglich im Milieu der Seeleute gebräuchlichen Form naviguer.

TEMPLE feminin.

La temple, cette partie de la teste, qui est entre l'oreille et le front, s'appelle temple, et non pas tempe, sans $l$, comme le prononcent et l'escriuent quelquesvns, trompez par le mot Latin, tempus, d'où il est pris, qui signifie la mesme chose.

A .F. - Ce mot temple est feminin quand il signifie la partie de la teste, qui est entre l'oreille et le front. C'est ainsi qu'il faut escrire et prononcer ce mot. Ceux qui disent tempe ne parlent pas bien (Vaugelas 1880:266). 
Die remarque zum Begriff temple entstammt dem Bereich der Fachsprache Anatomie. Vaugelas führte zunächst eine Definition des Begriffs an und sprach sich dann für den Gebrauch der Variante temple aus. Die in der Überschrift diesmal erst gar nicht erwähnte Alternativvariante tempe sei falsch, obgleich sie sich etymologisch aufgrund der lateinischen Herkunft des Wortes erklären ließe. Wie beim ersten Beispiel zu den Begriffen soumission bzw. submission verzichtete Vaugelas auch hier auf eine Begründung seiner Entscheidung. Die Académie française legitimierte diese, indem sie sich derselben Meinung zeigte. Das heutige Gegenwartsfranzösisch hingegen hat zum oben kritisierten Gebrauch ,,[... tempe, sans $l[\ldots] “$ zurückgefunden, um die menschliche Schläfe zu bezeichnen.

\section{CONJONCTURE.}

Ce mot pour dire vne certaine rencontre bonne ou maunaise dans les affaires, est tres-excellent, quoy que tres-nouueau, et pris des Italiens, qui l'appellent congiontura. Il exprime merueilleusement bien ce qu'on luy fait signifier, de sorte qu'on n'a pas eu grand' peine à le naturaliser. Ie me souuiens que du temps du Cardinal du Perron, et de M. Malherbe, on le trouuoit desja beau, mais on n'osoit pas encore s'en seruir librement. Au reste, il se faut bien garder de dire conjointure, comme disent quelques-vns, car encore que l'on die jointure, et non pas joncture, si est-ce qu'en beaucoup de mots, il n'y a point de consequence à tirer du simple au composé, comme on pourra voir en quelques endroits de ces Remarques.

T. C. - On dit fort bien, en cette conjoncture, la conjoncture étoit favorable, mais comme ce mot est un de ceux que l'on remarque aisement, il faut prendre garde à ne les repeter pas sans nécessité.

A. F. - Conjoncture est un très-bon mot, qui s'est parfaitement establi. Si quelques uns disoient conjointure du temps de M. de Vaugelas, personne ne le dit plus aujourd'huy (Vaugelas 1880:345).

Mit seiner remarque zum Begriff conjoncture nahm Vaugelas einen Neologismus aus der Fachsprache Wirtschaft in sein Werk auf, was erstaunlich ist, sprach sich Vaugelas doch im Allgemeinen gemäß Malherbes Doktrin gegen Neologismen aus. Er bewertete das Wort conjoncture nichtsdestotrotz höchst positiv und bezog sich dabei sogar rechtfertigend auf Malherbe, zu dessen Lebzeiten dieser Neologismus bereits geschätzt, aber kaum verwendet worden sei. Im Anschluss gab Vaugelas einige Empfehlungen zum richtigen bzw. falschen Gebrauch des Wortes ab. Corneille beschränkte sich ebenfalls auf Gebrauchsempfehlungen, allerdings auf solche restriktiver Art: Er wollte einen ausufernden Gebrauch des Begriffs vermeiden. Die Académie française schließlich zeigte sich mit Vaugelas wie auch mit 
Corneille einig. Dass bzw. auf welche Art und Weise das Wort conjoncture heute noch gebraucht wird, ist hinreichend bekannt.

Zusammenfassend kann aufgrund obiger Analyse festgestellt werden, dass Vaugelas in seinen Remarques sur la langue française einerseits dazu tendierte, sprachnormative Entscheidungen zu treffen, ohne diese umfassend zu begründen, und andererseits konsequent fachsprachliche Gebrauchsnormen für ungültig zu erklären, sofern er selber der Meinung war, ein anderer Gebrauch stünde dem bon usage des Hofs näher. Die Tatsache, dass der Hof über keinerlei besondere fachsprachliche Kompetenzen verfügte, schien Vaugelas hierbei nicht zu irritieren. Heute mag solch ein sprachnormatives Vorgehen, das empirisch allein auf den Beobachtungen einer Einzelperson in ihrem Umfeld beruht, zweifelhaft erscheinen; zur Zeit Vaugelas' hingegen wurde es gutgeheißen, stieß auf einen nicht unerheblichen Erfolg und wurde immer wieder aufgegriffen.

\subsection{Dominique Bouhours: ein Nachfolger Vaugelas'}

Der Jesuitenpater Dominique Bouhours (1628-1702) ist einer jener Sprachpfleger bzw. Sprachnormierer, die in Vaugelas' Nachfolge tätig waren. Dabei griff er nicht nur die offene Form von Vaugelas' Remarques sur la langue française auf, sondern bediente sich auch der seit der griechischen Antike bekannten Textsorte des Lehrdialogs, um seine sprachnormativen Inhalte möglichst wirkungsvoll der Öffentlichkeit zu vermitteln. ${ }^{26}$

Seine Lehrdialoge Entretiens d'Ariste et Eugène aus dem Jahr 1671 demonstrierten die voneinander abweichenden Standpunkte zweier honnêtes hommes: Eugènes Diskurs hatte die Perfektion und Untadeligkeit des Französischen im Vergleich zum Spanischen und Italienischen bzw. seine Gleichwertigkeit dem Lateinischen gegenüber zum Inhalt. Ariste hingegen erwähnte das Risiko einer Verarmung der französischen Sprache durch einen übertriebenen Sprachpurismus, der den Verlust notwendigen Fachwortschatzes bedingte. Eugène setzte dem wiederum entgegen, dass Sprachpflege in jeder Sprache nötig und Französisch trotz aller puristischer Ansätze durchaus der Terminologiebildung fähig sei, was er anhand der Existenz von Begriffen aus dem Jagdwesen, der Falknerei und den schönen Künsten belegte (vgl. Bouhours 1962:47ff, zit. n. Aschenberg 2001:57ff). Indem Bouhours seinem

26 Die Textsorte der remarques wie auch die des Lehrdialogs wichen beide weitgehend von der Form eines langwierig zu lesenden wissenschaftlichen Traktats ab und fanden aufgrund dieser Leserfreundlichkeit im 17. Jahrhundert großen Anklang, auch bei Hofe. 
fiktiven Eugène diesen Standpunkt verlieh, konnte er etwaiger Kritik am Sprachpurismus mit wohlüberlegten Argumenten entgegentreten und die von Malherbe begründete und durch Vaugelas weitergeführte Tradition der Sprachnormierung im Sinne des guten Sprachgebrauchs verteidigen und fortsetzen. Bouhours' Definition des bon usage beruhte ähnlich wie bei Vaugelas auf dem Sprachgebrauch des Hofs, insbesondere auf dem des Königs (vgl. Grimm 2005:119):

Les Rois doivent apprendre de lui [du roi de France et de Navarre] à régner ; mais les peuples doivent apprendre de lui à parler (Bouhours 2003:180ff, zit. n. Grimm 2005:119).

Einige Jahre nach den Entretiens d'Ariste et Eugène erschienen schließlich Bouhours' Remarques nouvelles sur la Langue françoise aus dem Jahr 1675 sowie die Suite des Remarques nouvelles sur la Langue françoise von 1687. Diese beiden sprachnormativen Werke gleichen aufs Äußerste Vaugelas' Remarques sur la langue française: Sie bestehen aus in Form von remarques dargelegten Einzelbeobachtungen Bouhours' zum richtigen bzw. falschen Sprachgebrauch. Als Sammlungen solcher remarques können beide Werke als thematische wie methodische Fortsetzung Vaugelas' Wirkens betrachtet werden (vgl. Aschenberg 2001:55), wobei allerdings festzuhalten ist, dass sich laut Aschenberg (2001:54) bei Bouhours ,,[...] eine Umgewichtung in der Festschreibung des guten Sprachgebrauchs ab[zeichnet]: Während Vaugelas in Fragen der Sprachnormierung eindeutig dem mündlichen Sprachgebrauch des Hofs Priorität vor den guten Autoren einräumt [...], richtet Bouhours die sprachpflegerische Arbeit zunehmend an der Literatursprache aus. Dies wiederum artikuliert sich nicht allein in entsprechenden Stellungnahmen, sondern auch in der Abfassung seiner Texte selbst, in ihrer literarischen Gestaltung." So verwendete Bouhours in seinen remarques im Unterschied zu Vaugelas beispielsweise Autorenzitate, um den bon usage besser zu illustrieren und zu belegen. Im Avertissement seiner Remarques nouvelles sur la Langue françoise betonte Bouhours allerdings, dass er nicht zwangsläufig alles aus der Feder berühmter Autoren gutheißen könne:

Mais si je suis contraint quelquefois de ne pas approuver ce que disent des Auteurs celebres, ce n'est pas précisement pour les reprendre, ni par un esprit de critique que je le fais; ce n'est que pour rendre service au public, [...]. Car les plus excellens ouvrages ne sont pas exépts de fautes : \& comme on peut estre Saint, sans estre confirmé en grace : on peut estre bon Auteur, quoyqu'on peche quelque-fois, ou contre la grammaire, ou contre l'usage (Bouhours 1675:Avertissement, ohne Paginierung). 
Abgesehen von diesen geringfügigen Unterschieden zwischen der Vorgehensweise Bouhours' und der seines Vorbilds Vaugelas' lässt sich aber weitgehende Einigkeit zwischen den beiden Sprachnormierern feststellen: Wie auch Vaugelas schloss Bouhours die Fachsprachen, darunter auch die Gerichtssprache, vom bon usage aus, verurteilte den Gebrauch von Archaismen wie auch von Neologismen - es sei denn, diese waren wirklich zur Deckung eines neu entstandenen Benennungsbedarfs notwendig - und widmete sich der genauen Abgrenzung zwischen fälschlicherweise synonym verwendeten Wörtern (vgl. Chassagne et al. 1994:35). Diese sprachnormative Haltung Bouhours' entspricht par excellence jener der bedeutendsten bis in die Gegenwart sprachpflegerisch tätigen Institution Frankreichs: der Académie française.

\subsection{Die Académie française und ihre Konzeption der Sprachpflege}

Die im Jahr 1635 auf Initiative des Kardinals Richelieu und mit Unterstützung König Louis XIII offiziell gegründete Académie française ging aus einem informellen Zirkel Intellektueller, der Société des amis de Conrart, hervor. Diese Gruppe hatte sich bereits zuvor regelmäßig getroffen, um Fragen des richtigen Ausdrucks sowie des guten Stils zu diskutieren. Als der literaturbegeisterte und sich zugunsten einer stabilen Nation für eine starke Sprache einsetzende Kardinal Richelieu von ihrer Existenz erfuhr, ersuchte er die ursprünglich elf Mitglieder der Gruppe, ihrem Zirkel Statuten zu verleihen und sich fortan offiziell um den Schutz und die Pflege der französischen Sprache zu bemühen. Aus Angst, es könnten im Falle einer Ablehnung repressive Maßnahmen gegen sie ergriffen werden, stimmten die Mitglieder der Offizialisierung ihrer Tätigkeit zu, woraufhin bis 1640 auf Wunsch Richelieus zahlreiche neue Mitglieder in die noch junge Académie française aufgenommen wurden. Sinn dieser Unternehmung war es, der Institution durch die Zahl und den Ruf der einzelnen Mitglieder größere Autorität in sprachlichen Fragen zu verleihen (vgl. Frey 2000:5ff). Am 22. Februar 1635 wurden schließlich die Statuten der Académie française beschlossen, deren Artikel 24 über die Hauptaufgabe der Institution Aufschluss gab:

La principale fonction de l'Académie sera de travailler avec tout le soin et toute la diligence possibles à donner des règles certaines à notre langue et à la rendre pure, éloquente et capable de traiter les arts et les sciences ${ }^{[1]}$ (Académie française s.a. d:Statuts complets, Fußnote weggelassen, M.M.). 
Die Académie française war demnach als sprachpflegerische Institution mit konservativer Grundhaltung und der Bereitschaft, die Sprache aktiv zu normieren und wenn nötig zu beschneiden, konzipiert worden. Zugleich sollte sie laut den Statuten aber auch sicherstellen, dass die französische Sprache über ausreichende fachsprachliche Mittel verfügte, um eine zufriedenstellende Fachkommunikation im Handwerk und den Wissenschaften zu ermöglichen (,,[...] la rendre pure, éloquente et capable de traiter les arts et les sciences [...]"). Da die Académie française die Protektion des Königs genoss und damit untrennbar mit dem Hof verbunden war, ergab sich für sie jedoch die moralische Verpflichtung, Vaugelas' an der herrschenden Klasse orientiertes Sprachideal zur einzig gültigen Norm zu erheben. Daraus entstand ein Konflikt mit der ursprünglich angestrebten Pflege der Fachsprachen, da diese im nunmehr auch von der Académie française notwendigerweise als mustergültig betrachteten bon usage wie bereits dargelegt ${ }^{27}$ keinen Platz hatten. Das ob seiner langen Redaktionszeit bereits ungeduldig erwartete Akademiewörterbuch Dictionnaire de l'Académie françoise erschien 1694 und entpuppte sich als ein Gebrauchswörterbuch, in dem allein die Gemeinsprache ${ }^{28}$ einer gesellschaftlichen Elite Berücksichtigung gefunden hatte. Von der ursprünglich in den Statuten verankerten Pflege der Fachsprachen war also im normativen Wirken und den lexikographischen Aktivitäten der Académie française nichts mehr spürbar.

Die Konzentration auf eine als mustergültig empfundene, elitäre Variante der Gemeinsprache hat die Arbeit der Académie française im Großen und Ganzen bis in die Gegenwart geprägt, wobei diese Arbeitsweise laut Lieber (1990:48) lediglich einen , ,...] begrenzten Ausschnitt aus dem Sprachgeschehen dar[stellt], [...] streng puristisch und ausschließlich synchronisch [ist] [...]" und daher häufig Kritik hervorruft. So stellt z.B. Lieber (1990:49) weiters fest, dass ,[d]ie französische Akademie [...] die Gralshüterin einer sprachlichen Vergangenheit [ist], die in vielerlei Hinsicht eine nicht mehr zeitgemäße Norm verkörpert und somit heute einen eher dekorativen als funktionalen Zweck in der französischen Sprachgemeinschaft erfüllt." Kritisch hinterfragt wird auch die von der Académie française in den letzten Dekaden angesichts zahlreicher Vorwürfe immer wieder vorgebrachte Rechtfertigung, sie berücksichtige durchaus die Entwicklung des modernen Sprachgebrauchs. So analysiert Maier (1984:136, im Original teils in Sperrschrift):

Recht geschickt kaschiert die Akademie ihre wahre Intention, eine homogene Sprachvarietät zu konservieren, indem sie bisweilen vorgibt, der Entwicklung

27 Siehe hierzu auch Kapitel 3.1.

28 Dies schließt eine begrenzte Anzahl in die Gemeinsprache übergegangener fachsprachlicher Elemente ein. 
des tatsächlichen Sprachgebrauchs Rechnung tragen zu wollen. Aufgabe und Ziel sei vielmehr, den aktuellen Zustand des besten Französisch zu präsentieren und einen Augenblick seiner Geschichte zu fixieren. Mit anderen Worten: Die Akademie gedenkt, uns mit ihrem Wörterbuch ein präskriptives, starr synchrones Werk mit dem Postulat dauernder Gültigkeit vorzusetzen, ohne zu beachten, daß ein jeder Einzelsprache inhärenter Sprachwandel letztlich doch durch einen Normwandel bedingt ist.

Wie sich die Haltung der Académie française zu den Fachsprachen als einen jener Teilbereiche der Sprache, die sie im 17. Jahrhundert von ihrem Wirken ausgrenzte, im Lauf der Zeit konkret entwickelt hat, lässt sich anhand einer Analyse der Vorworte der Akademiewörterbücher von der ersten bis zur neunten Auflage erschließen.

\subsubsection{Fachsprachen in den Augen der Académie française damals und heute}

Die erste Ausgabe des Wörterbuchs der Académie française erschien 1694 unter dem Titel Le Dictionnaire de l'Académie françoise, dédié au Roy in zwei Bänden, wobei der erste die Buchstaben $A$ bis $L$ umfasste. In der Préface gab die Académie française unter anderem an, es sei bei der Redaktion des Wörterbuchs ihr Ziel gewesen, die französische Sprache so zu illustrieren, wie sie damals war. Dies sei der Grund für die Auslassung alter Wörter gewesen. Fachtermini hingegen seien deshalb nicht berücksichtigt worden, weil sie in der Konversation der honnêtes gens keine Rolle spielten. Die Académie française habe sich deren Gemeinsprache gewidmet und gemeinsprachliche Begriffe auch hinreichend definiert, was ohnehin viel schwieriger sei, als Fachtermini zu definieren: Deren Definition sei für gewöhnlich klarer und einfacher aufgebaut als die Sache oder das Konzept selbst, das sich hinter einem Fachwort verbirgt (vgl. Académie française 1694:Préface, ohne Paginierung, zit. n. Gallica Ansicht 8). So rechtfertigte die Académie française also indirekt die Auslassung der Fachbegriffe mit der Begründung, die lexikographische Arbeit an gemeinsprachlichen Begriffen sei grundsätzlich komplexer und daher lobenswerter.

C'est dans cet estat où la Langue Françoise se trouve aujourd'huy qu'a esté composé ce Dictionnaire; \& pour la representer dans ce mesme estat, l'Académie a jugé qu'elle ne devoit pas y mettre les vieux mots qui sont entierement hors d'usage, ni les termes des Arts \& des Sciences qui entrent rarement dans le Discours; Elle s'est retranchée à la Langue commune, telle qu'elle est dans le commerce ordinaire des honnestes gens, et telle que les 
Orateurs et les Poëtes l'employent; Ce qui comprend tout ce qui peut servir à la Noblesse \& à l'Elegance du discours. Elle a donné la Definition de tous les mots communs de la Langue dont les Idées sont fort simples; \& cela est beaucoup plus mal-aisé que de definir les mots des Arts \& des Sciences dont les Idées sont fort composées ; Car il est bien plus aisé, par exemple, de definir le mot de Telescope, qui est une Lunette à voir de loin, que de definir le mot de voir ; Et l'on esprouve mesme en definissant ces termes des Arts \& des Sciences, que la Definition est tousjours plus claire que la chose definie ; au lieu qu'en definissant les termes communs, la chose definie est toujours plus claire que la Definition (Académie française 1694:Préface, ohne Paginierung, zit. n. Gallica Ansicht 8).

Im Weiteren bekräftigte die Académie française jedoch, fachsprachliche Elemente verschiedener Bereiche mit starkem Einfluss auf die Gemeinsprache durchaus berücksichtigt zu haben. So seien beispielsweise Termini, die Eingang in gemeinsprachliche Redewendungen gefunden hatten, ins Wörterbuch aufgenommen worden. Außerdem habe die Académie française bestimmte Begriffe der Rechtssprache und Termini aus dem Bereich des Finanzwesens in ihrem Dictionnaire aufgeführt, da diese selbst in der Konversation der honnêtes gens gelegentlich Verwendung fänden (vgl. Académie française 1694:Préface, ohne Paginierung, zit. n. Gallica Ansicht 10):

L'Académie en bannissant de son Dictionnaire les termes des Arts \& des Sciences, n'a pas creu devoir estendre cette exclusion jusques sur ceux qui sont devenus fort communs, ou qui ayant passé dans le discours ordinaire, ont formé des façons de parler figurées; comme celles-cy, Je luy ay porté une botte franche. Ce jeune homme a pris l'Essor, qui sont façons de parler tirées, l'une de l'Art de l'Escrime, l'autre de la Fauconnerie. On en a usé de mesme à l'esgard des autres Arts \& de quelques expressions tant du style Dogmatique, que de la Pratique du Palais ou des Finances, parce qu'elles entrent quelquefois dans la conversation (Académie française 1694:Préface, ohne Paginierung, zit. n. Gallica Ansicht 10).

In der zweiten Auflage des Wörterbuchs, das 1718 in zwei Bänden unter dem Titel Nouveau Dictionnaire de l'Académie Françoise. Dédié au Roy erschien, vertrat die Académie française unverändert die Auffassung, dass fachsprachliche Einträge nicht zum Inventar ihrer lexikographischen Werke gehören sollten, es sei denn, ein fachsprachlicher Begriff sei äußerst bekannt und sein Gebrauch alltäglich, womit keine Weiterentwicklung im Vergleich zur ersten Ausgabe des Akademiewörterbuchs feststellbar ist (vgl. Académie française 1718:Préface, zit. n. Baum 1989:61): 
Pour ce qui est des termes d'Art, l'Académie a cru ne devoir admettre dans son Dictionnaire que ceux qui sont extremement connus et d'un grand usage, à moins qu'ils ne soient amenez par le mesme mot de la langue, qui a dans la langue une signification differente ; par exemple, à la suite du mot travail, qui signifie labeur, peine, etc. on trouve travail, qui signifie, une machine qui sert aux Maréchaux pour contenir les chevaux difficiles à ferrer (Académie française 1718:Préface, zit. n. Baum 1989:61).

$\mathrm{Ab}$ der dritten Auflage des Akademiewörterbuchs, 1740 als Dictionnaire de l'Académie françoise. Troisième édition erschienen, begann sich aber eine leichte Änderung in der Haltung der Académie française zu den Fachsprachen abzuzeichnen. Das Vorwort im ersten Band, der die Buchstaben $A$ bis $K$ umfasste, gab darüber Aufschluss, dass in diese Ausgabe wesentlich mehr fachsprachliche Einträge aufgenommen worden seien als in die vorigen. Diese Entscheidung bedeute allerdings nicht, dass die Académie française grundlegend von der sich selbst auferlegten Regel abweichen wolle, ihr lexikographisches Werk an der Gemeinsprache zu orientieren. Die nun dennoch höhere Zahl von Fachtermini begründete die Institution damit, dass in den letzten sechzig Jahren vor Erscheinen des Wörterbuchs fachsprachliche Inhalte in der Fachkommunikation vermehrt in französischer statt in lateinischer Sprache behandelt worden seien; daher sei es angemessen, die von dieser neuen Tendenz betroffenen und deshalb inzwischen häufig auch einem fachfremden Publikum bekannten Fachwörter ins Akademiewörterbuch aufzunehmen (vgl. Académie française 1740:Préface, ohne Paginierung, zit. n. Gallica Ansicht 10):

Le Public ne manquera pas de remarquer qu'il se trouve dans la nouvelle Edition, un bien plus grand nombre de termes d'art \& de science, que dans les deux précédentes. Nous ne nous sommes pas écartez néanmoins de la règle que nos Prédécesseurs s'etoient prescrite, de n'admettre que ceux de ces termes qui sont d'un usage si général, qu'ils peuvent être regardez comme faisant partie de la Langue commune, ou qui sont amenez par un mot de cette Langue. Mais depuis environ soixante ans qu'il est ordinaire d'écrire en François sur les arts \& sur les sciences, plusieurs termes qui leur sont propres, \& qui n'étoient connus autrefois que d'un petit nombre de personnes, ont passé dans la Langue commune. Auroit-il été raisonnable de refuser place dans notre Dictionnaire, à des mots qui sont aujourd'hui dans la bouche de tout le monde (Académie française 1740:Préface, ohne Paginierung, zit. n. Gallica Ansicht 10)? 
Mit dieser zurückhaltenden Öffnung der strikten Norm des bon usage gegenüber bewies nun die Académie française doch eine gewisse Sensibilität für die Notwendigkeit, den Umständen einer sich ändernden Lebenswelt auch in der Sprache Rechnung zu tragen.

Der erste Band der vierten Auflage des Wörterbuchs der Académie française aus dem Jahr 1762, mit dem Titel Dictionnaire de l'Académie françoise. Quatrième édition, beinhaltete die Buchstaben $A$ bis $K$. Das Vorwort dieser Auflage war weitgehend eine Überarbeitung des Vorworts der dritten; somit lassen sich keine wesentlichen Veränderungen in der Perspektive der Académie française auf die Fachsprachen feststellen. Interessant ist allerdings, dass die Académie française hierin zusätzlich einräumte, dass ein ,homme de lettres“ selbst bei einer nichtfachlichen Lektüre auf fachsprachliche Elemente stoßen könne, da es inzwischen üblich geworden sei, wissenschaftliche und andere fachspezifische Inhalte selbst in der Literatur zu behandeln. Aufgrund der weiten Verbreitung grundlegender Fachbegriffe beim fachfremden Publikum sei es also geboten, diesen Aufnahme ins Akademiewörterbuch zu gewähren (vgl. Académie française 1762:Préface, ohne Paginierung, zit. n. Gallica Ansicht 4):

Les sciences \& les arts ayant été plus cultivés \& plus répandus depuis un siècle qu'ils ne l'étoient auparavant, il est ordinaire d'écrire en François sur ces matières. En conséquence plusieurs termes qui leur sont propres, \& qui n'étoient autrefois connus que d'un petit nombre de personnes, ont passé dans la Langue commune. Auroit-il été raisonnable de refuser place dans notre Dictionnaire à des mots qui sont aujourd'hui d'un usage presque général ? Nous avons donc cru devoir admettre dans cette nouvelle Edition, les termes élémentaires des sciences, des arts, \& même ceux des métiers, qu'un homme de lettres est dans le cas de trouver dans des ouvrages où l'on ne traite pas expressément des matières auxquelles ces termes appartiennent (Académie française 1762:Préface, ohne Paginierung, zit. n. Gallica Ansicht 4).

Während im Vorwort zur fünften Auflage des Wörterbuchs, dem Dictionnaire de l'Académie françoise, revu, corrigé et augmenté par l'Académie elle-même. Cinquième édition von 1789 keine fachsprachenrelevanten Informationen genannt wurden, zeigte die sechste Auflage von 1835 ein gänzlich anderes Bild. Im Vorwort des Dictionnaire de l'Académie française. Sixième édition publiée en 1835 schlug die Institution im Rahmen eines Rückblicks auf die zweihundert Jahre ihres Wirkens erstmals leise selbstkritische Töne bezüglich ihrer puristischen Sprachpolitik in der Pflege der Fachsprachen an: 
Sur ce dernier point [à savoir en ce qui concerne les termes des arts et des sciences physiques], en effet, son vocabulaire usuel [celui de la langue française] est pauvre et restreint. Sans doute, il eût été facile de le grossir beaucoup par les nomenclatures techniques et les classifications de chaque science, telles qu'elles existaient alors : on sait que cette idée même fut l'occasion du schisme et des critiques de Furetière, qui en profitant du travail de l'Académie, l'ensevelit dans un Dictionnaire universel des sciences et des arts. [...] Ces nomenclatures, en effet, qui sont autant de langues particulières, changent de fond en comble, par le progrès même des sciences, et n'offriraient souvent aujourd'hui que la date inutile d'une erreur détruite, ou d'une ignorance qu'on n'a plus. La nomenclature médicale ou chimique du dix-septième siècle serait tout à fait dénuée pour nous de sens et d'usage, tandis que la langue littéraire de la même époque est un type immortel. Mais, à part cette question, l'Académie, moins hardie que nos grands écrivains, ou, si l'on veut, plus timide en masse que dans chacun de ses membres, n'avait-elle pas trop restreint les richesses de notre langue, trop ébranché le vieux chêne gaulois ? [...] On peut trouver aussi que l'Académie, en prodiguant les proverbes, a trop épargné certains termes usités des artisans, et qui sont des images ou peuvent en fournir. [...] Si l'Académie était trop dédaigneuse à cet égard, en revanche elle avait beaucoup multiplié les termes de blason et de chasse. C'était un caractère du temps et des mœurs, qui s'est affaibli peu à peu dans les éditions suivantes du Dictionnaire, mais qui a laissé dans notre langue beaucoup d'expressions durables (Institut de France 1835:XIXff, zit. n. Gallica Ansicht 18ff).

Die Académie française gab nun also zu, dass die französische Sprache und damit natürlich auch das Akademiewörterbuch tatsächlich nur über ein beschränktes fachsprachliches Vokabular verfügten. Die Tatsache, dass ein Ausbau dieses Bereichs der Lexik durch fachliche Nomenklaturen versäumt worden war, rechtfertigte die Institution allerdings damit, dass der rasante Erkenntnisfortschritt sowie der damit einhergehende rasche Sprachwandel derartige Maßnahmen nicht hatte sinnvoll erscheinen lassen: Die stetige Veränderung im fachlichen Bereich hätte doch unweigerlich dazu geführt, dass die Sprachnormung und die Lexikographie innerhalb von kürzester Zeit wieder mit obsoleten fachsprachlichen Elementen konfrontiert gewesen wären. Weiters räumte die Institution ein, dass sie beim Ausschluss metaphorisch verwendeter fachsprachlicher Elemente aus ihrem sprachnormativen Wirken eventuell tatsächlich zu restriktiv vorgegangen sei. Im Gegenzug betonte die Académie française allerdings sogleich, dass sie für einen beträchtlichen Ausbau der Lexik in den Fachbereichen Jagd und Wappenkunde verantwortlich zeichne, was eine positiv zu beurteilende Leistung sei: Auch wenn die in diesen Bereichen durch 
ihre Aufnahme ins Akademiewörterbuch für den allgemeinen Gebrauch legitimierten Fachtermini inzwischen an Aktualität eingebüßt hätten, so seien sie doch in Form stehender Wendungen häufig noch in der französischen Sprache präsent (vgl. Institut de France 1835:XIXff, zit. n. Gallica Ansicht 18ff). Im Grunde kann das Vorwort der sechsten Auflage des Akademiewörterbuchs als ansatzweise kritische Bestandsaufnahme der Leistungen der Akademie in der Dauer ihres Bestehens aufgefasst werden. Besonders bemerkenswert an dieser Eigenbilanz ist zum einen, dass es die Akademie selber war, die andeutete, in der Pflege der Fachsprachen nicht immer optimale Entscheidungen getroffen zu haben; zum anderen fällt auf, dass die Institution 1835 erstmals seit ihrer Gründung dazu bereit war, die vermehrte Umsetzung sprachpflegerischer Aktivitäten im Bereich der Fachsprachen zumindest indirekt in Erwägung zu ziehen.

Diese Tendenz der leichten Hinwendung zu den Fachsprachen setzte sich mit der siebten Auflage des Akademiewörterbuchs von 1878 fort: Aus der Aufnahme von etwa 2200 neuen Einträgen - sowohl aus der Gemeinsprache als auch aus den Fachsprachen - ins Dictionnaire de l'Académie française. Septième édition dans laquelle on a reproduit pour la première fois les préfaces des six éditions précédentes lässt sich auf eine weitere Öffnung im sprachnormativen und sprachpflegerischen Wirken der Académie française schließen. So beinhaltete das neue Wörterbuch laut seiner Préface zahlreiche neue Termini aus vielfältigen Fachbereichen (vgl. Institut de France 1878:X, zit. n. Gallica Ansicht 11):

[...] [D]es termes nouveaux de philosophie, d'archéologie, de philologie, ou des expressions empruntées à l'économie politique, à l'industrie, à l'agriculture [ont été admis]. La liste de ces mots, qu'une étude plus approfondie ou une connaissance plus généralement répandue des choses qu'ils expriment a fait passer dans le langage commun, serait longue. La politique aussi, on le pense bien, en a fourni beaucoup : absolutisme, décentralisation, égalitaire, émeutier, fédéralisme, fédéraliste, humanitaire, socialisme, et tant d'autres auxquels, non sans scrupule quelquefois, il a fallu reconnaitre le droit au dictionnaire. Naturellement la part des sciences et des inventions nouvelles a été grande dans les deux mille ${ }^{[29]}$ mots ajoutés. Les chemins de fer, la navigation à vapeur, le télégraphe électrique ont fait irruption dans notre bon vieux français, avec leurs dénominations d'une forme souvent bizarre ou étrangère ; force a été d'admettre : un télégramme, un steamer, un tunnel, des tramways:

29 Die Académie française gibt auf ein und derselben Seite ihrer Préface zwei voneinander abweichende Angaben zur Zahl der neu aufgenommenen Termini an: 2200 bzw. 2 000. Die genaue Anzahl der neu hinzugekommenen Fachwörter konnte leider nicht ermittelt werden. 
l'ombre de nos prédécesseurs a dû plus d'une fois en frémir. L'Académie a pris un soin tout particulier des mots de science, et s'est attachée à en donner des définitions aussi exactes que claires. Si elle y a réussi, comme elle a lieu de l'espérer, le mérite en reviendra à ceux de ses membres qu'elle a pris à son illustre sœur, l'Académie des sciences, laquelle sans doute voudra bien se reconnaître elle-même dans la rédaction de ces articles et n'y trouvera plus rien à redire (Institut de France 1878:X, zit. n. Gallica Ansicht 11, Fußnote hinzugefügt, M.M.).

Einerseits führte die Académie française in dieser Préface nun zwar alle Fächer an, aus denen neue Termini ins Akademiewörterbuch aufgenommen wurden, wobei deren Berücksichtigung durchaus als eine positive lexikographische Leistung gewertet werden kann. Andererseits besagte dieses Vorwort aber auch ganz deutlich, dass die Aufnahme der besagten Termini ins Wörterbuch nicht ohne Vorbehalte beschlossen wurde. Besonders die Aufnahme jener Termini, die „d'une forme souvent bizarre ou étrangère“ als Entlehnungen ins „bon vieux français“ gelangten, stie $\beta$ bei den Mitgliedern der Académie française auf emotionalen Widerstand (,[...] l'ombre de nos prédécesseurs a dû $[\ldots]$ en frémir [...]"). Dass sie diesen überwanden, zeugt jedoch entgegen der für gewöhnlich an der Institution geübten Kritik davon, dass sich die Académiciens zumindest nicht systematisch jedem neu entstandenen Kommunikationsbedarf verschlossen. Innovativ ist in diesem Vorwort der explizite Hinweis auf die interdisziplinäre Zusammenarbeit der Académiciens mit Fachleuten, um bei der Definition der Fachtermini den hohen Qualitätsansprüchen an die eigene lexikographische Arbeit gerecht werden zu können.

Die achte Auflage des Akademiewörterbuchs erschien 1935 unter dem Titel Dictionnaire de l'Académie française. Huitième édition und berichtete in ihrer Préface erneut über die Aufnahme zahlreicher fachsprachlicher Begriffe. ${ }^{30}$ Jedoch wurde zugleich auch deutlich, dass die Akademie die zunehmende Verbreitung der Fachsprachen über die Grenzen der Fächer hinaus und in die Gemeinsprache hinein nicht als positiv bewertete:

Aux dernières années du XIXe siècle, quand l'Académie s'occupa de préparer une nouvelle édition de son Dictionnaire, elle se trouva en présence d'une brusque pénétration des vocabulaires des Sciences et des Arts dans le parler

30 Dank einer Kooperation der Académie française und des Institut National de la Langue Française, kurz $I N a L F$, steht die achte Auflage des Akademiewörterbuches der Allgemeinheit online unter http://atilf.atilf.fr/Dendien/scripts/generic/showps.exe? $p=$ main.txt; host=interface_academie8.txt zur Verfügung und bietet eine einfache Suchfunktion mit schnellem Zugang zu den einzelnen Lemmata. 
de tous qui, depuis, ne devait plus cesser de s'enfler démesurément d'année en année. Non seulement les sciences déjà constituées se renouvelèrent, mais d'autres prirent naissance, comportant en bien des cas des applications à l'industrie. D'autre part, de notables transformations s'opéraient dans l'ordre économique, social et politique. De là un grand nombre de mots nouveaux aussitôt vulgarisés par la conversation, par la presse et par l'école (Académie française s.a. a:Le dictionnaire - Les neuf préfaces - Préface de la huitième édition, 1932-1935).

Im Weiteren erklärte die Académie française in der Préface, sie ginge davon aus, dass viele der Neologismen nur vorübergehend Bestand haben und nicht aus ihrer fachsprachlichen Domäne in die Gemeinsprache übergehen würden. Diese Überlegung habe schließlich als Grundlage für die Auswahl der in der achten Auflage des Akademiewörterbuchs neu aufgenommenen Termini gedient. Die den Begriffen zugeordneten Definitionen waren - wie auch schon für die vorherige Auflage - in Zusammenarbeit mit Fachleuten erstellt worden (vgl. Académie française s.a. a:Le dictionnaire - Les neuf préfaces - Préface de la huitième édition, 1932-1935). Auch für diese Auflage war die Académie française nicht von dem Grundsatz abgegangen, ein Gebrauchswörterbuch des bon usage zu redigieren und so die französische Gemeinsprache gegen eine unkontrollierte Zunahme von Fachtermini zu verteidigen:

Elle [l'Académie française] constate et enregistre le bon usage, celui des personnes instruites et des écrivains qui ont souci d'écrire purement le français. En consacrant cet usage, elle le défend contre toutes les causes de corruption, telles que l'envahissement des mots étrangers, des termes techniques, de l'argot ou de ces locutions barbares qu'on voit surgir au jour le jour, au gré des besoins plus ou moins réels du commerce, de l'industrie, des sports, de la publicité, etc. Ainsi elle modère l'écoulement de la langue, et lui permet, tout en se modifiant sans cesse à la manière des organismes vivants, de rester elle-même et de garder intacts les traits qui sont sa marque et son âme. L'objet précis du Dictionnaire est de présenter l'état actuel de la meilleure langue française et de fixer un moment de son histoire (Académie française s.a. a:Le dictionnaire - Les neuf préfaces - Préface de la huitième édition, 1932-1935).

Die neunte Auflage des Dictionnaire de l'Académie française. Neuvième édition befindet sich noch in Arbeit und liegt derzeit vom Buchstaben $A$ bis zum Eintrag 
raidisseur vor. ${ }^{31}$ Die Académie française informiert auf ihrer Website, dass im Vergleich zur achten Auflage bis dato 13328 neue Einträge zum Wörterbuch hinzugefügt worden seien, gibt allerdings nicht an, wie viele davon auf Fachtermini entfallen (vgl. Académie française s.a. b:Le dictionnaire - La neuvième édition). Aus der ebenfalls online zugänglichen Préface geht jedoch wie aus dem Vorwort der vorigen Auflage hervor, dass eine der Hauptherausforderungen bei der Redaktion dieses lexikographischen Werks der Umgang mit dem enormen Wissenszuwachs, dem Entstehen neuer Fächer, einschneidenden politischen wie sozialen Veränderungen und der damit einhergehenden massiven Neubildung von Fachtermini bzw. in Folge deren Auswahl für das Akademiewörterbuch sei. Dieser liege ein eindeutiges Kriterium zu Grunde: Allein jene Fachtermini, die in der Gemeinsprache tatsächlich zum Stillen eines Kommunikationsbedarfs notwendig seien, werden ins Wörterbuch aufgenommen (vgl. Académie française s.a. c: Le dictionnaire - La neuvième édition - Préface).

Insgesamt lässt sich feststellen, dass die Akademie im Grunde während der vergangenen knapp 380 Jahre ihre Fachsprachenpolitik nicht wirklich geändert hat: Sie ist fachsprachlichen Elementen gegenüber tendenziell ablehnend. Allerdings haben sich die Gründe für diese Ablehnung im Lauf der Zeit gewandelt. Waren Fachtermini für die Akademie früher einfach nicht mit dem bon usage zu vereinbaren, werden sie heute oft aufgrund ihrer fremdsprachigen Herkunft oder ihrer vermuteten Kurzlebigkeit als negativ bewertet. Dennoch hat sich die Attitüde der Académie française zumindest dahingehend gewandelt, dass die Institution fachsprachliche Elemente nunmehr in ihrem lexikographischen Werk duldet. Dies ist aber nicht durch einen Meinungsumschwung zu erklären, sondern allein aufgrund der Tatsache, dass die Akademie die Existenz moderner kommunikativer Bedürfnisse, denen grundlegende wissenschaftliche, politische und gesellschaftliche Veränderungen vorausgingen, nicht verleugnen kann.

31 Die neunte Auflage des Akademiewörterbuchs wurde ab 1986 in Form von Faszikeln herausgebracht, wobei dieser Publikationsmodus allerdings 1992 offiziell eingestellt wurde. 1994 erschien der erste Band der neunten Auflage (von $A$ bis Enzyme). Der zweite Band umfasst die Einträge von Éocène bis Mappemonde, der dritte die Einträge von Maquereau bis Quotité. Zusätzlich sind alle Lemmata von $A$ bis raidisseur online unter http://atilf.atilf.fr/academie9.htm zugänglich (vgl. Académie française s.a. b:Le dictionnaire - La neuvième édition, Stand: 21.3.2012). 


\subsection{La bataille des dictionnaires: Die Académie française und ihre lexikographische Konkurrenz}

Veränderungen wie die oben angesprochenen sind nun natürlich kein Phänomen des 20. oder 21. Jahrhunderts - es gab sie auch schon früher, was auch für die Existenz eines fachsprachlichen Kommunikationsbedarfs gilt. Dass die Académie française diesen im 17. Jahrhundert zwar durchaus erkannt, aber ganz bewusst aus ihrem eigenen Wirkungsbereich ausgelagert hat, verdeutlicht vor allen Dingen die Tatsache, dass die Akademie unter dem Druck konkurrierender Wörterbuchprojekte - hierzu seien vor allem die im Folgenden ausführlicher behandelten von César-Pierre Richelet sowie von Antoine Furetière genannt - Thomas Corneille damit beauftragte, ebenfalls ein Fachwörterbuch der französischen Sprache zu erstellen. Im Zuge der Verwirklichung dieser drei lexikographischen Vorhaben entspann sich ein Konflikt, der unter der Bezeichnung la bataille des dictionnaires in die französische Sprachgeschichte einging.

\subsubsection{César-Pierre Richelets Dictionnaire françois, contenant les Mots et les Choses}

1680, also vierzehn Jahre vor Erscheinen des Akademiewörterbuchs, veröffentlichte César-Pierre Richelet (1631-1698) seinen zweibändigen Dictionnaire françois, contenant les Mots et les Choses: Plusieurs nouvelles Remarques sur la Langue françoise: Ses Expressions Propres, Figurées \& Burlesques, la Prononciation des Mots les plus difficiles, le Genre des Noms, le Regime des Verbes: Avec les Termes les plus connus des Arts \& des Sciences. Le tout tiré de l'Usage et des bons Auteurs de la Langue françoise. Richelet hielt sich bei dessen Redaktion nicht an den bon usage, sondern bezog gezielt anhand der Analyse von Fachtexten auch die Fachlexik mit ein, obgleich seine Zielgruppe laut dem Vorwort des Wörterbuchs ausdrücklich die honnêtes gens bei Hofe waren:

J'ai fait un Dictionnaire François afin de rendre quelque service aux honnêtes gens qui aiment notre Langue. Pour cela j'ai lu nos plus excellens Auteurs, \& tous ceux qui ont écrit des Arts avec réputation. J'ai composé mon livre de leurs mots les plus-reçus, aussi-bien que de leurs expressions les plus-belles. [...] Pour rendre l'ouvrage encore plus-utile, on y fait entrer les termes ordinaires des Arts, [...]. [...] \& on a marqué si le mot est un terme d'art, s'il est vrai qu'il en soit un (Richelet 1680:Avertissement, ohne Paginierung, zit. $n$. Gallica Ansicht 6f). 
Richelet definierte also die Nützlichkeit eines Wörterbuchs unter anderem anhand des Vorhandenseins fachsprachlicher Einträge, womit er den Fachsprachen gegenüber große Offenheit unter Beweis stellte. Mehr noch: Richelet schloss im Vorwort seines Wörterbuchs generell keine Teilbereiche der Sprache aus seiner lexikographischen und damit sprachpflegerischen Arbeit aus (vgl. Richelet 1680:Avertissement). Neben fachsprachlichen Begriffen nahm er beispielsweise selbst mots bas aus dem Bereich der Komödie und Satire oder aber auch mots sales wie z.B. die Bezeichnungen bestimmter Körperteile in sein Wörterbuch auf. Hierbei ging Richelet allerdings dennoch bis zu einem gewissen Grad normativ vor, indem er den soziokulturellen Index entsprechender Einträge wenn nötig mittels verschiedener Kennzeichnungen zum Ausdruck brachte. Laut seiner Explication des Marqves qv'on a mises aux Mots, \& des accens dont on les a marquez kennzeichnete Richelet (1680: Explication des Marqves, ohne Paginierung, zit. n. Gallica Ansicht 10) z.B. mit einem Kreuz $(\dagger),[\ldots]$ que le mot ou la façon de parler n'ont proprement leur usage que dans le stile simple, dans le comique, le burlesque, ou le satirique." Ein Kreuz mit Stern $\left(* \dagger\right.$ oder $\left.\dagger^{*}\right)$ stand bei im übertragenen Sinne gebrauchten Wörtern eines tieferen Sprachniveaus, die ausschließlich ,[...] dans le stile le plus simple, comme dans les vaudevilles, les rondeaux, les épigrammes, \& les ouvrages comiques" verwendet werden durften (Richelet 1680:Explication des Marqves, ohne Paginierung, zit. n. Gallica Ansicht 10). Fachsprachliche Einträge wurden meist durch eine Anmerkung in der Definition gekennzeichnet, so beim Eintrag Pousser:

Pousser. Terme de Doreur sur cuir. C'est prendre de l'or avec le fer à dorer \& l'appliquer sur la couverture du livre. [Pousser les bouquets, les filets, les nerfs.] (Richelet 1680:202, 2. Teil, zit. n. Gallica Ansicht 786)

Generell finden sich in Richelets Wörterbuch zahlreiche Beispiele für fachsprachliche Einträge; exemplarisch seien hier nur zwei weitere zitiert:

Naviger, naviguer, v. $n$. Ces mots signifient faire route sur l'eau, \& se disent tous deux. Naviguer se dit par tous les gens de mer, \& même il commence à être dans la bouche de ceux qui ne fréquentent pas la mer, \& il pourra avec le tems l'emporter sur naviger qui se dit \& s'écrit par la plus-part des personnes qui n'entendent pas les termes de marine, mais ceux qui parlent dans les termes de l'art disent \& écrivent naviguer au Nord \& jamais naviger au Nord (Richelet 1680:64, zweiter Teil, zit. n. Gallica Ansicht 648). 
Das 17. Jahrhundert: der Sprachpurismus des Grand Siècle

Aus Richelets Eintrag zum Term naviger oder naviguer geht wie schon früher bei Vaugelas $^{32}$ eindeutig hervor, dass damals in einem fachlichen Kontext der Begriff naviguer verwendet wurde. Naviger hingegen fand sich nur im Sprachgebrauch von fachfremden Personen, wobei laut Richelet selbst diese Tendenz rückläufig war. Aus der Gegenüberstellung eines positiven und eines negativen Anwendungsbeispiels (,[...] jamais naviger au Nord [...]") lässt sich schließlich schlussfolgern, dass Richelet selber für die fachsprachliche Verwendung des Terms eintrat. Im Gegensatz zu Vaugelas' Ausführungen zu den Wörtern naviger und naviguer, die absolut den Regeln des bon usage entsprachen, respektierte Richelet den Fachterm und gab ihm dem bon usage gegenüber den Vorzug. Eine ähnliche Vorgangsweise lässt sich bei Richelet in Einträgen beobachten, in denen zur Illustration eines Fachterms mots sales aus dem Bereich der Anatomie notwendig waren: In solchen Fällen nahm Richelet die Missachtung des bon usage zugunsten der Redaktion eines treffenden Eintrags in Kauf, wie aus dem folgenden Beispiel ersichtlich wird.

ABAISSEMENT, s.m. Ce mot se trouve au propre dans quelques traitez qui regardent la Chirurgie. Il signifie état d'une chose qui est plus bas qu'elle n'étoit, état d'une chose qui s'est abaissée. [L'Abaissement de la matrice \& du rectum n'est compris sous le nom de hernie que parce qu'il forme des indispositions qui. De Bligni, traité des hernies, p.83] (Richelet 1680:1, Remarques sur le Dictionnaire, zit. n. Gallica Ansicht 17)

Durch die weitgehende Missachtung der Normen des bon usage konnte Richelets Wörterbuch eine wesentlich umfassendere Darstellung des zeitgenössischen französischen Wortschatzes zeigen als beispielsweise das Akademiewörterbuch (vgl. Klare 1977:144). Der Dictionnaire françois, contenant les Mots et les Choses umfasste etwa 25500 Einträge und wurde von Richelet mit der Unterstützung François Cassandres, des Sekretärs von Olivier Patru, der seinerseits wiederum der Académie française angehörte, erstellt. Weiters konnte Richelet auf die Unterstützung Bouhours' zählen. Richelets Werk erhielt in Frankreich allerdings dennoch keine offizielle Druckerlaubnis und musste in Genf gedruckt werden. Anschließend erfolgte der Verkauf des Wörterbuchs in Frankreich inoffiziell, was seinem Erfolg allerdings keinen Abbruch tat: 1685, 1688, 1689, 1690, 1693, 1694 und 1695 erschienen bereits Neuauflagen. Außerdem heißt es, sogar die Mitglieder der Académie française hätten jeweils ein Exemplar des Wörterbuchs besessen (vgl. Chassagne et al. 1994:61f). 
Das 17. Jahrhundert: der Sprachpurismus des Grand Siècle

\subsubsection{Antoine Furetières Dictionnaire universel, contenant généralement tous les Mots françois}

Antoine Furetière (1619-1688) fand mit seinem 1684 bereits auszugsweise, 1690 dann postum in vollständiger Fassung veröffentlichten dreibändigen Dictionnaire universel, contenant généralement tous les Mots françois, tant vieux que modernes, $\&$ les Termes de toutes les Sciences et des Arts : Divisé en trois Tomes bei der Académie française weitaus weniger Zustimmung als Richelet. Obgleich Furetière selber auch Académicien war, brach zwischen ihm und der Akademie aufgrund seines Wörterbuchs ein nicht mehr beizulegender Streit aus, der schließlich 1685 mit dem Ausschluss Furetières aus der Akademie seinen Höhepunkt erreichte.

Furetière wollte - wie bereits der Titel seines Werkes aussagt - ein Wörterbuch mit Anspruch auf Vollständigkeit schaffen; sprachpuristisches Denken lag ihm fern. Das Deckblatt seines enzyklopädisch konzipierten Wörterbuchs gibt Aufschluss über die mehr als 55 Fachgebiete, die Furetière abdeckte:

La Philosophie, Logique, \& Physique, la Medecine, ou Anatomie, Pathologie, Terapeutique, Chirurgie, Pharmacopée, Chymie, Botanique, ou l'Histoire naturelle des Plantes, \& celle des Animaux, Mineraux, Metaux \& Pierreries, \& les noms des Drogues artificielles: La Jurisprudence Civile \& Canonique, Feodale \& Municipale, \& sur tout celle des Ordonnances: Les Mathematiques, la Geometrie, l'Arithmetique, \& l'Algebre, la Trigonometrie, Geodesie, ou l'Arpentage, \& les Sections coniques, l'Astronomie, l'Astrologie, la Gnomonique, la Geographie, la Musique, tant en theorie qu'en pratique, les Instruments à vent \& à cordes ; l'Optique, Catoptrique, Dioptrique, \& Perspective, 1'Architecture civile \& militaire, la Pyrotechnie, Tactique, \& Statique : Les Arts, la Rhetorique, la Poësie, la Grammaire, la Peinture, Sculpture, \&c. la Marine, le Manege, l'Art de faire des armes, le Blason, la Venerie, Fauconnerie, la Pesche, l'Agriculture, ou Maison Rustique, \& la plus-part des Arts mechaniques : Plusieurs termes de Relations d'Orient \& d'Occident, la qualité des Poids, Mesures \& Monnayes, les Etymologies des mots, l'invention des choses, \& l'Origine de plusieurs Proverbes, \& leur relation à ceux des autres Langues : [...] (Furetière 1690:Deckblatt, ohne Paginierung, zit. n. Gallica Ansicht 3, im Original teils kursiv, M.M.)

Sein Wörterbuch umfasste etwa 40000 Einträge, darunter Fachtermini aus Wissenschaft, Kunst und Handwerk, als solche ausgewiesene Archaismen und zahlreiche Neologismen. Der soziokulturelle Index der Einträge wurde auch bei Furetière gekennzeichnet, obwohl die Sprache nicht unbedingt Furetières zentrales Thema war: Er wollte vor allem enzyklopädisches Wissen vermitteln. Dies gelang ihm mit 
umfassenden Definitionen, in die er in Summe mehr als 6000 Auszüge aus literarischen Werken sowie zahlreiche Sprichwörter als Anwendungsbeispiele einband. Das Wörterbuch war aufgrund dieser Konzeption äußerst erfolgreich und wurde 1701, 1702, 1718 sowie 1727 in überarbeiteter Form neu aufgelegt (vgl. Chassagne et al. 2004:63). Laut Hassler (1998:323) lag im 17. Jahrhundert gerade im ,[...] Universalitätsanspruch [...] ein Moment, das den Erfolg extensiver Wörterbücher sicherte. Zu den Adressaten solcher Wörterbücher gehörten neben einer gebildeten Elite auch zunehmend bürgerliche Kreise, die ohne philologische Vorbildung Antwort auf vielfältige Sachfragen suchten.“

Worin lag nun aber der Streit zwischen Furetière und der Académie française begründet? Furetière, der seit 1662 zu den Quarante Immortels zählte, war an der Redaktion des Akademiewörterbuchs beteiligt. Seit 1674 hatte die Académie française dank der Erteilung eines Druckprivilegs durch den König ein Monopol auf die Herausgabe eines Wörterbuchs der französischen Sprache inne. Furetière entschied sich nun aber, ein eigenes Wörterbuch herauszugeben, begann dieses parallel zur Arbeit am Akademiewörterbuch zu redigieren und suchte ebenfalls um die Erteilung eines Druckprivilegs an. Die königliche Druckerlaubnis wurde ihm 1684 erteilt, woraufhin er Auszüge aus seinem Wörterbuch sozusagen als Vorschau auf das Gesamtwerk veröffentlichte. Dies provozierte die Académie française zur Aufforderung, Furetière möge sein Projekt aufgeben, was dieser aber nicht tat. In Folge kam es zu einem zwei Jahre andauernden Streit, in dem die Akademie Furetière des Plagiats und des Diebstahls beschuldigte und schließlich in einem Prozess auch die Aufhebung seines Druckprivilegs erreichte. Furetières Dictionnaire universel wurde dennoch veröffentlicht, allerdings in Den Haag (vgl. Chassagne et al. 1994:63; vgl. Barlow/Nadeau 2008:75ff). Die Académie française ihrerseits fühlte sich dadurch dazu aufgerufen, ein Gegenprojekt zu verwirklichen und beauftragte ihr Mitglied Thomas Corneille offiziell mit der Redaktion eines umfassenden und durch die Académie française autorisierten Fachwörterbuchs.

\subsubsection{Thomas Corneilles Dictionnaire des Arts et des Sciences}

Thomas Corneille (1625-1709) erstellte also den 1694 veröffentlichten, zweibändigen Dictionnaire des Arts et des Sciences im Auftrag der Académie française und versuchte, darin eine möglichst umfassende deskriptive Bestandsaufnahme der französischen Fachlexik zu erstellen, die das zu restriktiv angelegte Akademiewörterbuch des bon usage ergänzen sollte. Corneilles Wörterbuch war aber nicht enzyklopädisch konzipiert wie das Furetières. Proust (1962:205) fasst diese Orientierung wie folgt in Worte: 
Effectivement le travail de Thomas Corneille a surtout été un travail de définition, visant à distinguer les différents sens d'un même mot selon les techniques qui l'emploient, mais non point à décrire ces techniques elles-mêmes.

Thomas Corneille und die Académie française bemühten sich allerdings ganz besonders, bereits bei der Ankündigung des Dictionnaire des Arts et des Sciences darauf hinzuweisen, dass dieses Wörterbuch weitaus mehr als nur eine Sammlung von Fachtermini und Definitionen sei, da es nämlich auch das wichtigste Basiswissen diverser Fachbereiche in zusammengefasster Form vermitteln würde. So informierte die Monatszeitschrift Mercure galant ${ }^{33}$ im August 1694 nicht nur über die Präsentation des Akademiewörterbuchs vor dem König, sondern beschrieb im selben Artikel auch das zeitgleich erscheinende Fachwörterbuch Corneilles:

Il [le Dictionnaire des Arts et des Sciences] a esté entrepris par un Particulier de la Compagnie [c'est à dire de l'Académie française], qui aidé des lumières de quelques autres Académiciens, \& de celles des plus habiles de ceux qui se sont appliquez à la connoissance des Arts, s'est attaché depuis un fort grand nombre d'années à la composition de ce curieux Dictionnaire. Outre les termes qui sont propres à chaque Art, il contient comme un Abrégé de l'Histoire naturelle des Plantes, des Animaux, des Oiseaux, des Poissons, \& quantité d'autres choses fort utiles pour ceux qui veulent sçavoir l'origine des Ordres Religieux, \& de tous ceux de Chevalerie, avec les opinions des differens Heresiarques, qui ont paru dans l'Église depuis la naissance du Sauveur. Ainsi, les Curieux qui acheteront ces quatre Volumes, pourront s'assurer d'avoir le plus ample Dictionnaire qui ait paru jusqu icy (Mercure galant 1694:301ff).

Erstaunlich ist in diesem Ausschnitt aus dem Mercure galant vor allem die Aussage, die Entstehung des Dictionnaire des Arts et des Sciences habe viele Jahre in Anspruch genommen. Schließlich erfolgte seine Redaktion im Vergleich zu der des Akademiewörterbuchs relativ schnell: Corneille hatte den Auftrag zur Redaktion des Dictionnaire des Arts et des Sciences erst nach der Veröffentlichung von Furetières Wörterbuch im Jahr 1690 erhalten. Chassagne et al. (1994:58) präzisieren im Bezug auf die kurze Redaktionszeit, dass Corneilles Wörterbuch auf bereits existente Werke aufbaute und dass es in Folge zu Plagiatsvorwürfen kam, denn ,,[...] [d]es contemporains l'accus[ai]ent [Corneille] d'avoir copié le dictionnaire de Richelet.“

33 Le Mercure galant veröffentlichte an jedem Monatsersten die wichtigsten gesellschaftlichen, politischen und literarischen Neuigkeiten. Chefredakteur des Mercure galant war ab 1680 übrigens Thomas Corneille (vgl. Chassagne et al. 1994:54). 
Die Préface von Corneilles Dictionnaire des Arts et des Sciences - deren Ton und Inhalt wohl eher auf die Académie française als eine persönliche Haltung Corneilles zurückzuführen sind - bezog hierzu keine Stellung, sondern befasste sich in Form einer heftigen Kritik vor allem mit Furetières Fachwörterbuch: So hieß es zunächst, dieses habe zwar bewiesen, dass die Öffentlichkeit großes Interesse an Fachlexikographie habe, es sei jedoch nicht sorgfältig redigiert worden. So gäbe es beispielsweise einen Eintrag Barrometre, der aufgrund seines griechischen Ursprungs eigentlich Barometre lauten müsse; aufgrund der falschen Schreibweise befände er sich nun im Wörterbuch der alphabetischen Reihung entsprechend an der falschen Stelle und sei für jemanden, der den Eintrag nach der richtigen Schreibweise suche, unauffindbar. Ein ähnlicher Fall liege beim Eintrag Varre vor, der richtigerweise Vare lauten müsste. Weiters seien die etymologischen Angaben in den Einträgen Estiomene und Media noche unrichtig. Abgesehen davon weise Furetières Wörterbuch unverständliche Erklärungen auf, denen es an Logik mangle, so z.B. beim Eintrag Thonnine. Außerdem habe Furetière die Begriffe Tamarin und Tamarisc miteinander verwechselt (vgl. Corneille 1694:Préface, ohne Paginierung, zit. n. Gallica Ansicht 3f). Schließlich beendete die Académie française (Corneille 1694:Préface, ohne Paginierung, zit. n. Gallica Ansicht 4) im Vorwort des Dictionnaire des Arts et des Sciences die kritische Analyse von Furetières Wörterbuch unter dem Hinweis, es dauere ,[...] trop long si on rapportoit les autres fautes qu'on a remarquées dans cet Ouvrage [le Dictionnaire de Furetière], comme de dire que la Zedoaire est une graine, quoy que ce soit une racine, ainsi que tous les Auteurs en conviennent. [...]" Bei der Redaktion des Dictionnaire des Arts et des Sciences hingegen - so die Préface - sei mit wahrhaftiger Sorgfalt vorgegangen worden, sodass niemand Grund zur Unzufriedenheit haben müsse. Alle zitierten Autoren seien im Original konsultiert worden; die Einträge seien nicht nur mit Definitionen, sondern auch mit Anmerkungen zum Gebrauch versehen worden, um so das Nützliche mit dem Angenehmen der Lektüre zu verbinden, usw. Es sei natürlich dennoch möglich, dass auch im Dictionnaire des Arts et des Sciences Fehler vorkämen, entweder in Form unzureichend klarer Definitionen, aufgrund eines falschen Verständnisses gewisser Fachtermini seitens der Autoren, oder aber aufgrund von Fehlinformationen in den zitierten Quellen. Abschließend wurde nun die Leserschaft aufgefordert, den Drucker in Kenntnis zu setzen, sollten ihr derlei Fehler oder Unklarheiten auffallen; nur so könne die zweite Auflage des Dictionnaire des Arts et des Sciences verbessert werden (vgl. Corneille 1694:Préface, ohne Paginierung, zit. n. Gallica Ansicht 4ff).

Die bataille des dictionnaires zwischen der Académie française und ihrer lexikographischen Konkurrenz wurde also auf verschiedenen Terrains ausgetragen: Einer- 
seits wurden Gerichte damit befasst, auf juridischer Grundlage über die Existenzberechtigung von Wörterbüchern zu urteilen, was beispielsweise im Fall der Klage der Académie française gegen Furetière der Untermauerung eines offiziell geltend gemachten Autoritätsanspruchs diente. Andererseits wurden die lexikographischen Werke selber durch ihre Vorworte zu Sprachrohren der Verfasser gemacht; diese versuchten natürlich, ihre Leserschaft jeweils von der Qualität ihrer eigenen lexikographischen Arbeit sowie von ihrer persönlichen Auffassung über „richtig“ und „falsch“ in Fragen der Sprachpflege und des Sprachgebrauchs zu überzeugen. Diese Beeinflussung diente der Durchsetzung in einem Konkurrenzkampf um die Vorherrschaft auf dem immer wichtiger werdenden lexikographischen Markt, kündigte sich doch bereits damals eine Tendenz an, die im 18. Jahrhundert noch stärker zu Tage treten sollte: der Wunsch der interessierten Öffentlichkeit nach einem umfassenden Zugang zu enzyklopädischem Wissen. 



\section{Das 18. und 19. Jahrhundert: das enzyklopädi- sche Zeitalter und die, langue de la liberté'}

\subsection{Die kulturgeschichtlichen Hintergründe des 18. und 19. Jahr- hunderts}

Das 18. Jahrhundert war in Frankreich wie auch sonst in einem Großteil Europas von der Aufklärung bestimmt. Diese geistige Strömung stand ganz im Zeichen von Fortschritt und Rationalismus. Das gesamte Wissen jener Zeit sollte gesammelt und der Allgemeinheit zugänglich gemacht werden, um mit seiner Hilfe seit langem tradierte Irrtümer auszuräumen, Vorurteile abzubauen und damit die Emanzipation des Einzelnen von der Herrschaft voranzutreiben, sodass sich eine Entwicklung hin zu einer kritischen Öffentlichkeit vollziehen konnte. Prägend für jene Zeit waren eine noch im 17. Jahrhundert durch Colbert begründete Neuordnung der Wirtschaft, die Entstehung eines Bildungsbürgertums und dessen Beteiligung an wissenschaftlicher bzw. fachlicher Betätigung in einer Vielzahl von Akademien. Dieser gezielte Erwerb neuen Wissens durch einen Teil der Bevölkerung begünstigte die Entwicklung des 18. Jahrhunderts zu einem âge encyclopédique und führte zu einer intensiven damit einhergehenden Befassung mit den Fachsprachen. Kalverkämper (1998c:31) fasst dies wie folgt zusammen:

Das 18. Jh., die Aufklärung, sichtet und kompiliert das in der Tradition Beobachtete, Erkannte und bislang Erforschte und versucht, Ordnung nach wissenschaftlichen Maßgaben in die aufgetürmte Menge an Wissen zu zwingen (Nomenklaturen, Lexikographie [Enzyklopädien]) und prägt einen positiven Begriff von ,Gelehrtentum' und, Wissenschaft' aus.

Die Aufklärung, so kann man sagen, war die Wegbereiterin der Französischen Revolution von 1789, welche mit ihren machtpolitischen und gesellschaftlichen Veränderungen ihrerseits wiederum am Ende des Siècle des lumières stand. Sie ist bis heute prägend für das Selbstverständnis der modernen République française, brachte aber zugegebenermaßen nicht nur Errungenschaften mit sich, so z.B. die Abschaffung feudaler Strukturen und damit die Einführung der Rechtsgleichheit aller Bürger, die Vereinheitlichung von Maßsystemen, die Festlegung des Meters sowie eine erste umfassende Analyse der sprachlichen Gegebenheiten im revolutionären Frankreich durch den Abbé Henri Grégoire, sondern hatte auch Schattenseiten, z.B. den 
Kampf im Zuge der gegenrevolutionären Bewegung oder die Schrecken der Terrorherrschaft. Währenddessen erlangte Napoleon Bonaparte durch seine erfolgreichen militärischen Einsätze immer mehr politisches Ansehen und wurde zum Hoffnungsträger eines erneuerten Frankreichs. Auf dieser Grundlage gelang letztlich sein Staatsstreich vom 18. Brumaire VII, also vom 9. November 1799, der es Napoleon Bonaparte erlaubte, zunächst zum Ersten Konsul der französischen Republik zu werden und sich schließlich zum Kaiser zu krönen. Manche der durch ihn getroffenen Maßnahmen zur Neuordnung Frankreichs wirken bis in die Gegenwart nach, so z.B. der Ausbau der Verkehrswege, seine Reform der Verwaltung im Sinne einer stärkeren Zentralisierung, die Einführung des Code Civil oder die eines neuen Schulsystems. Dieses erlebte gegen Ende des Jahrhunderts unter dem Einfluss Jules Ferrys eine neuerliche Reform: Mit dem 18. März 1882 wurde in Frankreich die allgemeine Schulpflicht eingeführt, die natürlich unmittelbare Folgen auf den Bildungsgrad und den Sprachgebrauch der französischen Bevölkerung hatte. Mit dem 18. und dem 19. Jahrhundert erlebte Frankreich also ohne Zweifel eine Vielzahl prägender Veränderungen. Die folgenden Kapitel sollen darüber Aufschluss geben, in welchem Maße davon auch die Fachsprachen im Rahmen der Fachlexikographie, der Sprachpflege und der Sprachnormierung betroffen waren. Zunächst stellt sich in diesem Kontext nun aber die Frage, inwieweit die Fachsprachen denn im aufgeklärten Frankreich überhaupt reflektiert wurden bzw. welche Bedeutung man ihnen beimaß, nachdem ja zumindest die institutionalisierte Sprachpflege die Fachsprachen das ganze 17. Jahrhundert hindurch von ihren Aktivitäten ausgeschlossen hatte.

\subsection{Zur Fachsprachenreflexion und zu den Zielsetzungen der Fachkommunikation des 18. Jahrhunderts}

Die Aufklärung führte zu Veränderungen in der Sprache: Die präskriptive Norm des bon usage hatte das Französische im 17. Jahrhundert zwar stark durchdrungen; der in der Klassik noch strikt eingeforderte style noble, der ja mit einer generellen Ausgrenzung der Fachsprachen aus jeglicher „respektablen“ Kommunikation einherging, trat nun im aufgeklärten Frankreich aber hinter andere Prioritäten zurück. Man erkannte, dass die Fachsprachen keinesfalls strikt von der Gemeinsprache separiert werden konnten. Brunot (1932:1169) hält fest, es handle sich hierbei um eine „,...] véritable révolution des moeurs et des idées dont on peut suivre le progrès à travers tout le siècle et dans tous les genres.“ Zugleich wurde laut Brunot (1932:1169f) der idealtypische honnête homme neu definiert (,Le nouvel honnête homme tient surtout à ne pas passer pour un imbécile."), was im Kontext der bereits im vorigen Kapitel 
angesprochenen weiteren Verbreitung wissenschaftlicher Erkenntnisse - ein wichtiges soziales Phänomen des 18 . Jahrhunderts - zu betrachten ist. Vor diesem Hintergrund ließ sich also vor allem ab der Mitte des 18. Jahrhunderts eine verstärkte Hinwendung der Allgemeinheit zu den Fachsprachen beobachten, deren Fachtermini nunmehr selbst von den oberen Bevölkerungsschichten ohne jeglichen Prestigeverlust gebraucht werden konnten. Regelrecht in Mode kamen z.B. die Fachsprache der Malerei oder jene der Chemie, aber auch andere Fachsprachen begannen, in gemeinsprachliche Bereiche überzugehen und die nichtfachliche Konversation zu durchdringen. Zugleich erfolgte eine Aufwertung der Fachwörterbücher: Mussten im 17. Jahrhundert Lexikographen wie Richelet oder Furetière noch um die Daseinsberechtigung ihrer fachlich ausgerichteten Werke kämpfen ${ }^{34}$, so wurden nun Fachwörterbücher wie beispielsweise das Dictionnaire de musique von Jean-Jacques Rousseau oder das Petit lexique des termes de marine im Anhang des von JacquesHenri Bernardin de Saint-Pierre verfassten Buchs Voyage à l'Ile de France als durchaus nützliche Werke betrachtet. Der enzyklopädische Gedanke trug dazu bei, dass die arts mécaniques schließlich als den arts libéraux gleichwertig betrachtet wurden und gegen Ende des Ancien Régime die Werkstattsprachen immer weitere Akzeptanz fanden. Sogar bei Damen von Rang waren nun die termes de métier bzw. der langage des ouvriers nicht mehr verpönt, was sich unter anderem aus dem wachsenden Interesse für bahnbrechende Entdeckungen, wissenschaftliche Experimente und neue Erfindungen erklärt. So eignete sich die gebildete Öffentlichkeit eine immer größere Menge an Fachlexik an (vgl. Brunot 1932:1171-1185).

Die Wissenschaft selber widmete sich im 18. Jahrhundert vor allem innerhalb der einzelnen Fächer einer intensiven Reflexion der jeweiligen Fachsprachen, tendierte allerdings eher zur Vulgarisierung fachlicher Inhalte. Dies entsprach der damaligen Forderung der Wissenschaft an die Fachkommunikation, sie müsse dazu in der Lage sein, zunächst der naheliegendsten und größten potenziellen Zielgruppe, nämlich der interessierten französischen Öffentlichkeit, fachliche Information erfolgreich zu vermitteln. Laut Brunot (1926:16) war für die Eigenreflexion der Wissenschaft jener Zeit charakteristisch, dass sie es sich nicht nur zum Ziel gesetzt hatte ,[...] de plaire, ni même d'éclairer, elle prétendait agir et combattre. [...] En outre, elle entendait pénétrer dans la vie et la régénérer.“ Aus dieser Grundhaltung erklärt sich nun nicht nur die Bereitschaft zur Vulgarisierung, sondern auch die Tatsache, dass die lateinische Sprache, die ja nicht allen am Wissenserwerb interessierten Personen zugänglich war, nun im 18. Jahrhundert endgültig aus der Fach-

34 Siehe hierzu auch Kapitel 3.6. 
kommunikation verschwand. Bis dahin hatte sie in bestimmten Bereichen der Wissenschaft - man denke an die Botanik oder an die Darlegung und Diskussion religiöser Inhalte - immer noch den fachlichen Diskurs dominiert. Nun herrschte aber in der gesamten Fachkommunikation Französisch vor (vgl. Brunot 1926:12ff). Es ist allerdings anzumerken, dass es den französischen Fachsprachen verschiedener Bereiche, um eine entsprechend der oben genannten Zielsetzungen erfolgreiche Fachkommunikation sicherzustellen, an präzisen Definitionen einzelner Fachtermini bzw. einer ausreichenden Vereinheitlichung im Gebrauch, teils aber auch an einem entsprechenden Ausbau der fachsprachlichen Lexik mangelte. Wie aus der umfangreichen Analyse einer großen Zahl französischer Fachsprachen in Brunots Histoire de la langue française des origines à 1900. Tome VI: Le XVIIIe siècle. Première partie. Le mouvement des idées et les vocabulaires techniques (1930b) hervorgeht, traten von Fachsprache zu Fachsprache durchaus unterschiedliche Mängel auf. Im Folgenden seien exemplarisch drei der bei Brunot (1930b) behandelten Fachsprachen im Hinblick auf ihren Zustand im 18. Jahrhundert charakterisiert.

Für die Fachsprache der Philosophie galt z.B. ein Mangel an präzisen Definitionen, was sich schon nach Gottfried Wilhelm Leibniz nachteilig auf die Exaktheit der Fachsprachen auswirkte. Diese Situation führte im Frankreich des 18. Jahrhunderts nun laut Brunot (1930b:9) seitens der Philosophen zu der Forderung, dass ,[p]our échapper au piège, il faudrait, suivant le conseil de Leibniz, composer une langue philosophique dans laquelle on déterminerait la signification précise de chaque mot." In Folge dieser Bestrebungen wurde die Fachsprache der Philosophie einer detaillierten Analyse und Diskussion unterzogen, was wiederum dazu führte, dass sie gegen Ende des 18. Jahrhunderts hin doch ,[...] un peu épurée [...]“ war (vgl. Brunot 1930b:11).

In der Fachkommunikation der Wirtschaft und der Politik hingegen fehlte es an einer ausreichenden Einheitlichkeit im Gebrauch der Fachsprachen seitens der vielen Fachsprachennutzer, ein Problem, dem man ebenfalls nur mit einer konkreten Definition bzw. Neudefinition der einzelnen Fachtermini beikommen konnte (vgl. Brunot 1930b:49; ib.:60). Weiters wurden theoretische Überlegungen angestellt, Fachtermini, die nicht allgemein zugänglich waren, generell aus den Fachsprachen der Bereiche Wirtschaft und Politik zu verbannen, so z.B. Lehnwörter, Regionalismen und Archaismen. Dies erwies sich in der Praxis aber wiederum als schwierig, sobald beispielsweise in der wirtschaftlichen Fachkommunikation regionaltypische Produkte behandelt werden sollten o.ä. (vgl. Brunot 1930b:64ff). Zugleich entstand im 18. Jahrhundert in den Fachsprachen der Politik und der Wirtschaft aber auch ein umfangreicher neuer Benennungsbedarf, dem mit der Einführung vieler Neologis- 
men und Entlehnungen aus anderen Fachsprachen, wie z.B. aus jener der Mathematik, des Rechts oder der Astronomie, begegnet wurde (vgl. Brunot 1930b:74-92).

In der Fachsprache der Industrie bestanden vor allem starke regionalbedingte Unterschiede auf lexikalischer Ebene. So verfügten z.B. die Weberei und die Spinnerei - beide in ganz Frankreich betrieben - über regional voneinander divergierende Nomenklaturen: Man konnte innerhalb dieser Handwerke eine normannische, eine ardennische, eine angevinische Fachlexik usw. unterscheiden, wohingegen die Fachsprachen anderer Industriezweige wiederum überraschend einheitlich waren. Dies traf z.B. auf die Seidenindustrie zu, die bekannterweise hauptsächlich in Lyon angesiedelt war und deren Fachsprache aufgrund dieser räumlichen Konzentration im Grunde keine regional bedingten Abweichungen aufwies. Die in anderen Bereichen durchaus notwendige Vereinheitlichung des Gebrauchs der Fachsprachen vollzog sich durch die zunehmende geographische Mobilität der Arbeiter und den dadurch in der täglichen Arbeitsroutine entstehenden Bedarf zur sprachlichen Uniformisierung im Laufe des 18. Jahrhunderts dann aber teilweise ganz automatisch. Heute ist allerdings nicht genau bekannt, welche Änderungen sich zu welchem Zeitpunkt und auf welche Weise vollzogen haben, da besonders für die Werkstattsprachen kaum schriftlich überlieferte Fachkommunikation vorliegt (vgl. Brunot 1930b:394; ib.:405).

Allgemein kann für die Fachsprachen des 18. Jahrhunderts ergänzend festgestellt werden, dass die Fachsprachennutzer in der Praxis im Großen und Ganzen einfach individuell kommunizierten, wie auch immer es ihren subjektiven Anforderungen an die Effizienz am besten entsprach. Die Wissenschaft hätte allerdings eine systematische Revision der fachsprachlichen Nomenklaturen, die Festlegung von Gebrauchsnormen und deren zielgerichtete Umsetzung bevorzugt. Zugleich erschien ein solches Vorgehen insofern aber nicht sinnvoll, da es kaum möglich gewesen wäre, bei den Fachsprachennutzern im praktischen Sprachgebrauch verpflichtend konkrete Maßnahmen durchzusetzen (vgl. Brunot 1930b:406). So kommt es, dass bei einer Analyse der Fachsprachen des 18. Jahrhunderts der Eindruck einer ,provisorischen Lexik" entsteht - unter anderem dann, wenn neu erfundene Gerätschaften gänzlich unökonomisch mit Eigennamen in Form von Wortgruppen wie „,machine pour battre le bled que l'on peut employer au lieu de batteurs en grange“, „machine pour transplanter des grands arbres“ oder „pompe pour éteindre les incendies“ bezeichnet wurden (vgl. Brunot 1930b:414ff). So ist es nachvollziehbar, dass von einem sprachpflegerischen Standpunkt aus betrachtet vor allem eine Vereinheitlichung, eine Ordnung und Vereinfachung der Fachsprachen wünschenswert erschienen, 
weniger ein Ausbau der Lexik, obgleich für alle Fachsprachen des 18. Jahrhunderts gleichermaßen galt, dass sie einen neuen Benennungsbedarf abzudecken hatten. ${ }^{35}$ Dies war also die paradoxe Situation, mit der sich die Fachlexikographie des 18. Jahrhunderts konfrontiert sah. Das folgende Kapitel widmet sich nun dem wohl bekanntesten fachlexikographischen Werk des 18. Jahrhunderts: der Encyclopédie.

\subsection{Diderots Encyclopédie, ou Dictionnaire raisonné des Sciences, des Arts et des Metiers, par une société de gens de lettres}

Als das fachsprachliche Monument der Aufklärung darf wohl getrost die Encyclopédie, ou Dictionnaire raisonné des Sciences, des Arts et des Metiers, par une société de gens de lettres bezeichnet werden, die zwischen 1751 und 1765 in siebzehn Bänden, ergänzt von elf weiteren Bänden mit Bildtafeln, erschien und unter der Leitung von Denis Diderot (1713-1784) und Jean le Rond d'Alembert (1717-1783) redigiert worden war. Dieses Werk, im Folgenden der Einfachheit halber kurz als Encyclopédie bezeichnet, verlieh dem im vorigen Kapitel geschilderten Streben nach Erkenntniszuwachs Ausdruck, indem es einen auch aus einer kommerziellen Perspektive erfolgreichen Versuch darstellte, das gesamte im 18. Jahrhundert vorhandene Wissen möglichst umfassend kompilatorisch darzustellen. Das Konzept hinter der Encyclopédie war erfolgversprechend: Fachwissen sollte vulgarisiert und so in verständlicher Form einem breiten Publikum zugänglich gemacht werden. Damit ging in gewisser Weise eine Neuordnung des Wissens sowie ein Ausbau der Fachlexik in zahllosen Bereichen, so z.B. der Wissenschaft, der Philosophie, dem Handwerk, der Kunst und dem Staatswesen, einher (vgl. Erfurt 2005:85f). Dem lag eine neue, vom Sprachpurismus des 17. Jahrhunderts losgelöste, nicht mehr elitär geprägte Sprachkonzeption zu Grunde, die Klare (1977:144) wie folgt umreißt:

Lexikalische Vielfalt und mit ihr der Neologismus wurden immer deutlicher als Ausdruck des gesellschaftlichen Fortschritts, des Neuen in allen Bereichen des gesellschaftlichen Lebens einschließlich neuer Ideen und Kenntnisse erkannt.

35 Der Abdeckung dieses Benennungsbedarfs kamen die Fachsprachen auch umfassend nach, wie bei Brunot (1930b) ersichtlich wird: Hier findet sich - geordnet nach unterschiedlichen Fächern - ein detaillierter Überblick über eine Vielzahl von im 18. Jahrhundert in die Fachsprachen eingegangenen Neologismen. 
Dies war eine absolut notwendige Entwicklung, konnte doch dem Kommunikationsbedarf des 18. Jahrhunderts mit dem im Rahmen des bon usage als zulässig definierten und damit begrenzten Wortschatz des 17. Jahrhunderts nicht mehr Genüge getan werden. Die neue Einstellung zur Sprache war nun aber ein fruchtbarer Boden, auf dem ein Projekt wie die Encyclopédie gedeihen konnte. Diese war laut Klare (1977:145), „...] Sammelbecken der bürgerlich orientierten Praxis, der Naturwissenschaften und Techniken der materialistischen Weltanschauung, das Sprachrohr der antifeudalistischen Opposition von verschiedenen Gruppierungen des Bürgertums, ihrer verschiedenen philosophischen und ideologischen Strömungen, die unter dem Begriff der Aufklärung subsumiert werden.“ Wie aber wurde die Idee zur Realisierung eines so umfangreichen Projekts wie der Encyclopédie überhaupt geboren?

\subsubsection{Die Entstehungsgeschichte der Encyclopédie im Überblick}

Wie bereits dargelegt standen die Wissenschaften im Frankreich des 18. Jahrhunderts bei der Allgemeinheit hoch im Kurs, doch bedingte die Befassung fachfremder Personen mit fachlichen Inhalten eine Vulgarisierung derselben. Le Gras (1942:27) beschreibt das Interesse an den verschiedensten Fächern wie folgt:

Bourgeois, financiers, magistrats, parlementaires, voire femmes du monde et gens de qualité, chacun s'entretient d'astronomie, physique, chimie, histoire naturelle. Aussi superficiels que soient les hommes, ils éprouvent parfois le besoin de savoir à peu près de quoi ils parlent. Or se procurer des monographies, et même les lire, n'est pas toujours chose aisée. Il faudrait un ouvrage apportant aux gens désireux de s'instruire les matériaux nécessaires.

Natürlich gab es vor der Encyclopédie bereits andere Fachwörterbücher in Frankreich; diese hatten sich allerdings hauptsächlich auf die Darstellung sprachlicher Merkmale konzentriert und suchten weniger, enzyklopädisches Wissen zu vermitteln. Außerdem umfassten sie bei weitem nicht alles verfügbare Wissen. Nun erschien aber 1728 in Großbritannien Ephraim Chambers Cyclopaedia, or an Universal Dictionnary of Arts and Sciences, das - wie der Titel schon sagt enzyklopädisch konzipiert, aktuell und relativ umfassend war. Damit wurde es zu einem großen Erfolg; Grund genug für den Pariser Verleger André-François Le Breton, ein vergleichbares Werk zu planen. Zwei erste Anläufe scheiterten ${ }^{36}$, Le Breton entschied sich jedoch zu einem dritten Versuch - diesmal mit der Unterstüt-

36 Eine ausführliche Darstellung dieser Komplikationen findet sich bei Le Gras (1942:31-36). 
zung von Partnern. So suchte er gemeinsam mit den Verlegern Claude Briasson, Lauren Durand und Michel-Antoine David um ein Druckprivileg zur Verwirklichung eines großen enzyklopädischen Projekts an, und im Jänner 1746 wurde tatsächlich die Erlaubnis zu dessen Realisation erteilt. Die vier Verleger baten daraufhin Denis Diderot, der seine fachlexikographische Kompetenz bereits bei der Übersetzung von Robert James' A Medicinal Dictionary vom Englischen ins Französische unter Beweis gestellt hatte, die Redaktion der Encyclopédie zu leiten. Diderot sagte zu, war sich allerdings der Tatsache bewusst, dass er hierzu weitere Unterstützung brauchte, die er für den mathematischen Teil der Encyclopédie in der Person d'Alemberts fand. Dieser war kurz zuvor Mitglied der Académie des Sciences geworden und erwarb sich in deren Abteilung für Geometrie gerade ein gewisses Renommee als hervorragender Wissenschaftler. So begann unter der Leitung Diderots und d'Alemberts sowie unter der Mitarbeit zahlreicher anderer Gelehrter, Künstler, Handwerker usw. ${ }^{37}$ die Redaktion der Encyclopédie. Diese geriet jedoch ins Stocken, als Diderot im Sommer 1749 wegen subversiver Ideen verhaftet und während hundertein Tagen im Château de Vincennes eingekerkert wurde. Die Fertigstellung der Encyclopédie sollte sich durch die Unterbrechung um mehr als ein Jahr verzögern. Geplant war ein zehnbändiges Werk, von dem 1500 Exemplare gedruckt und jährlich zwei Bände veröffentlicht werden sollten. Im Oktober 1750 erschien der Prospectus zur Encyclopédie, der bereits heftigste Kritik, aber auch großes Lob für das noch nicht veröffentlichte Werk hervorrief. Am 1. Juli 1751 erschien schließlich der erste Band, der auf 915 Seiten den Buchstaben A behandelte. In Folge kam es erneut zu starker Kritik an der Encyclopédie wie auch zu Plagiatsvorwürfen. Seitens der Kirche und des Jesuitenordens wurde gar ein Verbot der Encyclopédie gefordert: Sie sei fehlerhaft und respektiere die Religion nicht in ausreichendem Maße; Diderot sei außerdem ein subversives Element. Daraufhin wurde kurz nach dem Erscheinen des zweiten Bands im Dezember desselben Jahres tatsächlich ein königliches Verbot bezüglich des Verkaufs sowie des Nachdrucks der ersten beiden Bände ausgesprochen. Obgleich dieses Verbot drei Monate später dank der Intervention Madame de Pompadours bei Louis XV wieder zurückgenommen wurde, hatte die Encyclopédie die nächsten vierzehn Jahre hindurch immer wieder mit Rückschlägen zu kämpfen. Zu den Ursachen zählten diverse Intrigen seitens der Kirche, eine verschärfte Zensur und der Verlust wertvoller Mitarbeiter, wie z.B. von d'Alembert selbst, der sich aufgrund der niedrigen Entlohnung sowie

$37 \mathrm{Zu}$ weiteren Informationen über jene, die durch ihre Mitarbeit zur Entstehung der Encyclopédie beitrugen, siehe auch Kapitel 4.3.2.1. 
der sich häufenden Probleme bei der Veröffentlichung aus dem Projekt zurückzog. ${ }^{38}$ Währenddessen blieb die Leserschaft der Encyclopédie treu. Parallel dazu zeichnete sich jedoch ab, dass mehr Wissen in die Encyclopédie einfließen würde, als ursprünglich geplant: Der im November 1757 erschienene siebte Band umfasste erst den Buchstaben $G$, womit klar wurde, dass die vorgesehene Anzahl an Bänden überschritten werden musste. Am 18. Februar 1759 wurde allerdings das Druckprivileg für die Encyclopédie aufgehoben, da es erneut hieß, das Werk sei zu subversiv. Die Redaktion neuer Bände der Encyclopédie wurde damit untersagt - ein Verbot, das allerdings nicht für die Bildtafeln galt, die Diderot nun Anfang 1762 veröffentlichte. Gleichzeitig wurden die verbliebenen Textbände der Encyclopédie heimlich fertiggestellt und ab 1763 auch gedruckt. Im November 1764 bemerkte Diderot jedoch zufälligerweise, dass der Verleger Le Breton bereits seit 1762 ohne Diderots Wissen in zahlreichen Artikeln, die ihm kompromittierend erschienen waren, unmittelbar vor der Drucklegung eine Eigenzensur in Form von Kürzungen und Anpassungen vorgenommen hatte, um nicht erneut den Unmut der Kirche bzw. der Behörden zu wecken. Nach etwa neunzehn Jahren Arbeit an der Encyclopédie führte Diderot sein so durch Le Breton verstümmeltes Werk im August 1765 enttäuscht zu Ende. Zwischen 1767 und 1772 brachte er noch zusätzlich zu den vier bis dahin erschienenen Bänden mit Bildtafeln sieben weitere heraus. Dann beendete er endgültig sein Mitwirken an der enzyklopädischen Unternehmung, wobei die Encyclopédie selber in Form zahlreicher mit Ergänzungen versehener Neuauflagen weiterhin großen Erfolg hatte (vgl. Le Gras 1942:27-167).

\subsubsection{Die Redaktion und der Verkauf der Encyclopédie}

Aus dem geschichtlichen Überblick des vorigen Kapitels geht eindeutig hervor, dass die Encyclopédie ein stark polarisierendes, dennoch aber sehr erfolgreiches Werk war. Dies ist sicherlich dem enormen Wissensdurst der Leserschaft einerseits, aber auch der sorgfältigen Konzeption und Redaktion der Encyclopédie andererseits zu verdanken. So hatte Diderot laut Proust (1962:189f) ohne Zweifel die lexikographischen Vorgängerwerke des 17. Jahrhunderts konsultiert, sie analysiert und kritisiert, um auf dieser Grundlage Kriterien für die Redaktion seines eigenen Werks zu erstellen; dazu gehörte es z.B., höchstmögliche Aktualität durch zeiteffizientes Arbeiten anzustreben und der Redaktion eine authentische Recherche zu Grunde zu

38 Eine äußerst ausführliche Darstellung der Streitigkeiten und Komplikationen rund um die Veröffentlichung der weiteren Bände der Encyclopédie findet sich bei Le Gras (1942:71-129). 
Das 18. und 19. Jahrhundert: das enzyklopädische Zeitalter und die ,langue de la liberté'

legen. Der Artikel Encyclopédie - dem fünften Band selbiger entnommen und im Anhang, Kapitel 8.1, abschnittweise wiedergegeben - gibt Aufschluss darüber. Wie aber konnte Diderot ein solch monumentales Werk wie die Encyclopédie erstellen? Welche waren seine Vorgangsweisen in der lexikographischen Praxis? Diesen und anderen Fragen widmen sich die folgenden Kapitel.

\subsubsection{Die Enzyklopädisten: „une société de gens de lettres“}

Diderot und d'Alembert konnten ein umfangreiches Werk wie die Encyclopédie natürlich nicht alleine erstellen. Sie bedurften der tatkräftigen Hilfe zahlreicher Koautoren und Informanten, deren Identität in manchen Fällen bekannt ist, aus verschiedenen Gründen teilweise aber auch nicht. Proust (1962:15, Fußnoten weggelassen, M.M.) fasst diese Problematik wie folgt zusammen:

Sauf erreur ou omission, les avertissements des volumes de discours et des volumes de planches nous livrent cent quarante-deux noms. Mais sur ces cent quarante-deux, il y en a dix-sept dont nous ne savons rien ${ }^{[27]}$. Ces dix-sept collaborateurs s'ajoutent en fait au nombre indéterminé de ceux qui restent pour nous anonymes : leur nom est enfoui dans un des volumes du dictionnaire, au bas d'un article ou d'une planche ${ }^{[24]}$, ou ils ont souhaité passer inaperçus, ou les éditeurs n'ont pas jugé utile de les signaler.

Eine vollständige Aufstellung der Mitglieder dieser bereits im Titel der Encyclopédie genannten société de gens de lettres, die für die Redaktion des Gesamtwerks verantwortlich zeichnete, ist also nicht möglich. Ebenso schwierig ist es, eine Aussage über die soziale Herkunft der Koautoren der Encyclopédie zu treffen: Ihre Stellung in der damaligen französischen Gesellschaft - ob adeliger oder bürgerlicher Herkunft, ob Träger eines Kirchenamtes, ob mit einem amtlich-königlichen Titel ausgestattet oder nicht - war für die Redaktion der Encyclopédie im Grunde aber auch nicht wichtig; für Diderot zählte bei der Auswahl seiner Mitarbeiter lediglich die Frage, ob sie entsprechende Kenntnisse aufwiesen, um als Autoren mit ausreichender fachsprachlicher und fachlicher Kompetenz zum Entstehen der Artikel beizutragen (vgl. Proust 1962:17f). Unter den namentlich bekannten Enzyklopädisten gehörten etwa 26 Prozent zeitweise oder ständig dem Staatsapparat an; 64 Prozent übten eine freie Profession aus; sie waren Wissenschaftler, Ärzte, Autoren, Künstler oder im Bereich der Technik tätig. Bekannt ist, dass etwa vierzig Künstler und Schriftsteller an der Encyclopédie mitarbeiteten, weiters sechzehn Mediziner, sieben Mathematiker, sieben Naturhistoriker, vier Geographen, vier Chemiker sowie drei Spezialisten für Physik und Mechanik. Die Enzyklopädisten schrieben aber 
nicht zwangsläufig nur Artikel über ihr berufliches Fachgebiet, sondern verfassten auch Einträge zu Fächern, denen sie sich in ihrer Freizeit widmeten: So verfassten z.B. sechs der neun an der Encyclopédie mitwirkenden Finanzbeamte keine Artikel zum Finanzwesen, sondern zur Physiognomie, zum Gartenbau, zur Gravur, zur Feuerwerkstechnik und zum Zeichnen (vgl. Proust 1962:27ff). Abgesehen von der Gruppe der Autoren trugen zahlreiche Personen mit Informationen aus praktischhandwerklich orientierten Fächern zum Gelingen der Encyclopédie bei: Arbeiter, Handwerker, Zunftmeister und Bauern, deren Identität in den meisten Fällen nicht in der Encyclopédie preisgegeben wurde (vgl. Proust 1962:23). Diese Bereitschaft zur Auslassung der Namen der Enzyklopädisten lag wohl unter anderem darin begründet, dass die Leserschaft eines enzyklopädischen Werks des 18. Jahrhunderts wie es scheint nur wenig Wert auf die Kenntnis der Autorennamen legte, sofern die Artikel gut durchdacht und eloquent verfasst waren (vgl. Proust 1962:117). Außerdem verstand sich die Encyclopédie von vornherein als ein kollektives Werk, in dem der Einzelne in den Hintergrund trat:

Elle [1'Encyclopédie] devait refléter un siècle entier, et non l'esprit de tel ou tel. C'est ce qui explique qu'un bon nombre des collaborateurs du dictionnaire, quelquefois par prudence, mais le plus souvent par indifférence, n'ont pas jugé utile de se faire connaître à la postérité par une marque quelconque. La modestie qui, d'une façon générale, caractérise les encyclopédistes, caractérise aussi les premiers d'entre eux, Diderot et d'Alembert. Ils n'ont nulle vanité d'auteur, et ils donnent maintes fois l'exemple du désintéressement personnel (Proust 1962:117f).

So ist nicht mit Sicherheit bekannt, welche Artikel aus Diderots Feder stammten und welche nicht. Es liegen viele anonyme Artikel vor, die nicht allesamt Diderot zugeschrieben werden können, obgleich diese systematische Zuschreibung in der Vergangenheit häufig vorgenommen wurde (vgl. Proust 1962:118ff). Für die anonymen Artikel métier à bas, métier à velours ciselé und métier à étoffes brochées kann jedoch von Diderots Autorschaft ausgegangen werden (vgl. Proust 1962:194).

\subsubsection{Die Methode: Arbeitsteilung, Textnachbearbeitung, Recherche}

Wie bereits erläutert, trugen im Rahmen einer ausgedehnten Arbeitsteilung also zahlreiche Vertreter unterschiedlicher Fachgebiete zur Redaktion der Encyclopédie bei. Dies lag zum einen natürlich an der für einen Einzelnen oder wenige Einzelpersonen nicht zu bewältigenden Menge an Wissen, das für die Encyclopédie aufbereitet werden musste, zum anderen auch an der Tatsache, dass niemand ein „Spezialist 
auf allen Gebieten“" zu sein vermag. Diderot wusste dies ${ }^{39}$ und war sich auch der Tatsache bewusst, dass trotz seiner breit gefächerten Bildung nicht alle Artikel, die aus seiner eigenen Feder stammten, perfekt waren. Proust (1962:151) erläutert hierzu, dass Diderot, wenn es ihm notwendig erschien und er die Möglichkeit dazu hatte, bereit war „[...] de sacrifier ses propres articles si le texte qu'on lui [proposait] [était] meilleur que le sien; il se [contentait] d'ajouter ici un complément, là une mise au point. [...]" In die Encyclopédie flossen zum einen Texte ein, die entweder anderen Werken - vor allem Publikationen der Académie des Sciences - entnommen wurden und entsprechend adaptiert werden mussten, zum anderen aber auch Artikel, die auf Diderots Bitte hin und seinen Anforderungen gemäß exklusiv für die Encyclopédie verfasst wurden. Im Allgemeinen ist davon auszugehen, dass Diderots Hauptaktivität bei der Erstellung der Encyclopédie die Revision der Artikel der von ihm ausgewählten Koautoren war, obgleich er natürlich auch selber zahlreiche Einträge verfasste (vgl. Proust 1962:192f). Abgesehen davon widmete sich Diderot der fachlichen Recherche, sowohl im Hinblick auf seine eigenen Artikel, als auch um die Beiträge anderer Autoren auf ihre inhaltliche Richtigkeit überprüfen zu können. So besuchte er beispielsweise im Jahr 1748 Werkstätten im Großraum Paris, um sich dort selbst ein Bild von der Produktion zu machen, z.B. in der Seidenverarbeitung, in der Strumpfwirkerei, in Kartonagenfabriken, in der Seilerei. Die Arbeiter und Handwerker erklärten Diderot ihre Aufgaben, zeigten ihm ihre Werkzeuge und Maschinen im Detail, nannten ihm deren Namen und ließen ihn durch Erklärungen und Wiederholungen von Begriffen in ihre Fachjargons eintauchen, sodass er deren Termini schließlich ihrer Verwendung in der Praxis gemäß in der Encyclopédie wiedergeben und erläutern konnte (vgl. Proust 1965:50; ib.:95; ib.:168).

\subsubsection{Das Zielpublikum der Encyclopédie}

Diese Authentizität in der Darlegung des Fachwissens entsprach dem für das 18. Jahrhundert typischen Denken der Aufklärung: Das Idealbild des honnête homme des 17. Jahrhunderts, der von allem etwas wissen, aber dennoch in keinem Fach ein Spezialist sein sollte, war dem eines bezüglich der Wissenschaft wie auch der Wirtschaft und ihrer Techniken erkenntnisorientierten Menschen gewichen. Dieser musste auch nützliche Fähigkeiten und praktisches Wissen unter Beweis stellen können, was den Menschentypus des „commerçant-honnête homme“ hervorbrachte - eine Tendenz, die sich bereits ab etwa 1665 abzuzeichnen begonnen hatte, als

39 Siehe hierzu im Anhang, Kapitel 8.1, die Auszüge aus dem von Diderot verfassten Artikel Encyclopédie. 
Colbert Wirtschafts- und Finanzminister geworden war und eine Neuordnung der Wirtschaft in Angriff genommen hatte (vgl. Klare 1999:25). Parallel zu dieser Entwicklung engagierte sich die adelige wie die bürgerliche Bevölkerung zunehmend in zahlreichen wissenschaftlichen Académies, sowohl in Paris als auch in den Regionen Frankreichs: Abgesehen von der königlichen Akademie in Paris gab es Akademien in Dijon, Lyon, Besançon, La Rochelle, Châlons-sur-Marne, Pau, Caen, Rouen, Auxerre, Montpellier, Metz usw. Diese Akademien waren im Rahmen einer gesamteuropäischen Modeerscheinung im Geiste der Renaissance unter Rückbesinnung auf die griechische Antike gegründet worden. Sie befassten sich mit zahlreichen Fächern, standen Fachleuten wie auch fachfremden Personen offen, diskutierten im Sinne eines wissenschaftlichen Austauschs die unterschiedlichsten Sujets und trugen damit Wesentliches zum Ausbau der Fachkommunikation bei (vgl. Proust 1965:20ff). ${ }^{40}$ Es ging darum, so Proust (1965:20), ,[...] à réflechir sur tous sujets et mieux encore, à se communiquer de façon claire et convaincante l'acquis de leur [=les membres des académies] réflexion et de leur expérience." Vor diesem Hintergrund entstand der allgemeine Wunsch nach einem möglichst direkten Zugang zu breitgefächertem Wissen für alle. Somit war der Boden für den kommerziellen Erfolg eines aufwändigen Werks, wie die Encyclopédie es war, bereitet: Vor allem Vertreter des Adels oder des wohlhabenden Bürgertums stellten ein ausreichend großes und entsprechend kaufkräftiges potenzielles Zielpublikum dar.

\subsubsection{Finanzielle und kommerzielle Hintergründe}

Als im Oktober 1750 der Prospectus der Encyclopédie als eine Art Vorschau auf das Gesamtwerk erschien, wurden darin auch die Verkaufskonditionen für das Werk vorgestellt: Die Encyclopédie konnte bis zum 1. Mai 1751 von der am Kauf interessierten Leserschaft vorbestellt werden, dann sollten jedes Jahr zwei Bände erscheinen und den Käufern zugestellt werden, jeweils einer im Juni und einer im Dezember. Für die potenziellen Käufer gab es zwei verschiedene Kaufoptionen: entweder die einer souscription, d.h. einer verbindlichen Vorbestellung mit anschließender Ratenzahlung, oder den Kauf des Gesamtwerks ohne Vorbestellung zu einem späteren Zeitpunkt. Bei einer souscription mussten im Voraus 60 Livres entrichtet werden, weitere 36 Livres bei der Lieferung des ersten Bandes, 24 Livres für jeden weiteren Band und 40 Livres für die beiden geplanten Bände mit Bildtafeln.

40 Auch die Enzyklopädisten waren großteils Mitglied in einer oder gar mehreren Akademien, weswegen ihnen der Stil deren wissenschaftlicher Fachkommunikation geläufig war (vgl. Proust 1965:20). 
Das 18. und 19. Jahrhundert: das enzyklopädische Zeitalter und die ,langue de la liberté'

Daraus ergab sich ein Gesamtpreis von 280 Livres. Wer die Encyclopédie später als Gesamtes erwerben wollte, musste einen Kaufpreis von 372 Livres veranschlagen (vgl. Le Gras 1942:66f). Die genannten Summen waren zu jener Zeit natürlich für große Teile der Bevölkerung, nämlich für die Bauern, Handwerker und Arbeiter mit ihren meist umfangreichen Familien, absolut unmöglich aufzubringen. Proust (1965:77) illustriert dies wie folgt:

Convertir les prix et les revenus indiqués dans ce chapitre [...] n'aurait aucun sens. Précisons seulement, pour permettre quelques comparaisons, que le pain n'a jamais coûté moins de 3 sous la livre, qu'un travailleur adulte en mangeait 3 livres par jour et qu'en 1766 un ménage d'ouvriers lyonnais avec huit enfants devait vivre avec 639 francs pour l'année. A la même époque un revenu annuel de 6000 livres était considéré à Paris comme « convenable», sans plus.

Anhand dieses Vergleichs dürfte bei dem von Proust angegebenen durchschnittlichen Familieneinkommen von 639 Livres (oder, wie in der zitierten Passage angegeben francs; die beiden Bezeichnungen wurden synonym verwendet; eine Livre war übrigens in zwanzig Sous unterteilt; ${ }^{41}$ ) im Jahr nun klar sein, dass die einfache Bevölkerung schon allein aus finanziellen Gründen keinen Zugang zur Encyclopédie haben konnte. Außerdem waren damals bei weitem nicht alle Bevölkerungsgruppen alphabetisiert - vor allem nicht jene, die sich am unteren Ende der sozialen Hierarchie befanden. Die Zielgruppe für den Verkauf war also eindeutig in den wohlhabenden Gesellschaftsschichten angesiedelt.

Geplant war von den Verlegern der Encyclopédie der Druck von 1500 Exemplaren, aber aufgrund der hohen Anzahl an Vorbestellungen wurde die Frist zur souscription um drei Monate verlängert und die Zahl der Exemplare auf 2050 erhöht. Im Februar 1754 hatten aber bereits 3000 Käufer die Encyclopédie vorbestellt; so beschloss man aufgrund der großen Nachfrage schließlich einen Nachdruck der ersten beiden Bände und eine Erhöhung der Druckzahlen für die Folgebände. Die Serie sollte nun zu 4200 Exemplaren pro Band veröffentlicht werden - eine Zahl, die bereits im November 1757 mit der Veröffentlichung des siebten Bandes und 4000 Abonnenten nahezu erreicht worden war. Was die Bildtafeln betrifft, sollten sie ursprünglich wie bereits angegeben für 40 Livres verkauft werden. Da die Anzahl der Bildtafeln jedoch erhöht wurde, stieg auch der Preis: 360 Livres wurden nun in Summe für die Bände mit den Bildtafeln veranschlagt. Dies machte die Encyclopédie für ihre Verleger zu einem großen kommerziellen Erfolg (vgl. Proust

41 Vgl. hierzu Wikipédia s.a. a:Livre (monnaie). 
1962:52f). Berücksichtigt man nur die Bände der Encyclopédie, nicht aber die Bildtafeln, und kalkuliert man lediglich mit der Anzahl der etwa 4000 nachweislich vorhandenen Abonnenten, so ergeben sich allein daraus bereits Einnahmen in Höhe von 1.120.000 Livres. Für die Verleger gestaltete sich allerdings nicht nur die Einnahmen- sondern auch die Ausgabenseite des enzyklopädischen Projekts als höchst lukrativ: Die Herstellungskosten waren besonders auf der Autorenseite sehr niedrig. Diderot beispielsweise verdiente in den ca. dreißig Jahren seiner Mitarbeit an dem Projekt weniger als 80.000 Livres. Die Mehrzahl der anderen Enzyklopädisten arbeitete entweder gratis oder gegen nur geringe Aufwandsentschädigungen an der Redaktion der Encyclopédie mit, was ihnen zwar keinen finanziellen Gewinn einbrachte, den Verlegern durch den freiwilligen Charakter der Mitarbeit der Autoren aber auch nicht erlaubte, diesen die für die meisten Artikel typische Ausdrucksfreiheit abzusprechen. Die meisten Autoren der Encyclopédie hatten das Werk übrigens auch abonniert; seitens der Verleger, für deren Eigenbedarf lediglich eine Anzahl von 25 Exemplaren vorgesehen war, war nämlich nicht geplant, den Autoren das Gesamtwerk zur Verfügung zu stellen (vgl. Proust 1962:58f).

\subsubsection{Diderots Sprachauffassung und Fachsprachenkonzept}

Bei Diderot wurde - wie aus den bisherigen Ausführungen abgeleitet werden kann das Definieren von Fachtermini als eine Aufgabe betrachtet, der auf der Autorenseite ausreichende Fachkompetenz und höchste Präzision im Umgang mit den fachlichen Inhalten und den Fachsprachen selbst zugrunde liegen musste. Nun stand man aber bei der Redaktion der Encyclopédie dem Problem gegenüber, dass der Beschreibung von Fachsprachen außerhalb der fachlichen Praxis der Kontext authentischer Fachkommunikation fehlte. So legt Hassler (1998:326) dar:

Die Verständigung der Fachleute beruht auf der Gewohnheit, die nicht in jedem Fall sprachlich deutlich werden muß, denn gerade fachsprachliche Kommunikation ist in eine Vielfalt von Tätigkeiten eingebunden, die erst ihr Verständnis gewährleisten. Da die Fachsprachen als Bestandteil anderer Tätigkeitsformen der Menschen verwendet und in ihrem Sinn durch diese ergänzt werden, war es notwendig, nicht nur Wort- und Sacherklärungen zu geben, sondern gleichzeitig möglichst viel über die Sprechsituation zu vermitteln. [...] Ein Ausweg wird [von Diderot] nur darin gesehen, Handwerker selbst bei der Arbeit zu beobachten, ihre sprachlichen Äußerungen zu notieren, Artikel gemeinsam mit ihnen zu korrigieren und gegebenenfalls sogar selbst entsprechende Geräte $\mathrm{zu}$ bedienen, um das Zusammenwirken des Sprachlichen mit dem Gegenständlichen bei der Arbeit zu verstehen. 
Allein mit Hilfe des durch persönliche Erfahrung erworbenen Hintergrundwissens konnten laut Diderot also Fachtermini zufriedenstellend beschrieben und damit in ihrer Verwendung normiert werden. Weiters vertrat Diderot ein Fachsprachenkonzept, laut dem die unterschiedlichen Fachsprachen trotz all ihrer Diversität letztlich allesamt integraler Bestandteil der sich stets weiterentwickelnden Gesamtsprache waren (vgl. Proust 1962:212). In seinem Artikel Encyclopédie ${ }^{42}$ (d'Alembert/Diderot 1751-1765b:635ff, zit. n. Gallica Ansicht 656ff) stellte Diderot fest, dass alle existenten Fachtermini ursprünglich einmal Neologismen waren. Nun läge es in der Natur eines solchen Neologismus, nur langsam, durch seine zunehmende Verbreitung und die schrittweise Gewöhnung der Sprachnutzer an den betreffenden Term, seinen Platz in der Sprache zu finden - in anderen Worten: in die Gemeinsprache überzugehen. Damit wird klar, dass Diderot einen sehr realistischen Blick auf die Sprache hatte und sie als in konstantem Wandel befindlich begriff. Zugleich war Diderot laut Proust (1962:213) der Auffassung, dass die Fachsprachen sich nicht in einem idealen Zustand befänden: Die Fachsprachennutzer seien zwar dazu in der Lage, sie zu ihrem Zwecke einzusetzen, da die Fachkommunikation für sie zur alltäglichen Normalität gehöre, aber die Fachsprachen seien in Wirklichkeit $\mathrm{zu}$ wenig ausgebaut und zugleich doch zu reich an Synonymen. Besonders deutlich geht dieser Standpunkt laut Proust (1962:213) aus dem von Diderot verfassten Artikel Art der Encyclopédie (d'Alembert, Jean-Baptiste le Rond/Diderot, Denis 17511765a:716, zit. n. Gallica Ansicht 775) hervor:

De la langue des Arts. J'ai trouvé la langue des Arts très-imparfaite par deux causes ; la disette des mots propres, \& l'abondance des synonymes. Il y a des outils qui ont plusieurs noms différens ; d'autres n'ont au contraire que le nom générique, engin, machine, sans aucune addition qui les spécifie : quelquefois la moindre petite différence suffit aux Artistes pour abandonner le nom générique \& inventer des noms particuliers ; d'autres fois, un outil singulier par sa forme \& son usage, ou n'a point de nom, ou porte le nom d'un autre outil avec lequel il n'a rien de commun. Il seroit à souhaiter qu'on eût plus d'égard à l'analogie des formes \& des usages. [...] Le premier pas qu'il auroit à faire, ce seroit de fixer la valeur des correlatifs, grand, gros, moyen, [...] \&c. [...] Le second pas, ce seroit de déterminer sur la différence $\&$ sur la ressemblance des formes $\&$ des usages d'un instrument \& d'un autre instrument, d'une manœuvre \& d'une autre manœuvre, quand il faudroit leur laisser un même nom \& leur donner des noms différens. Je ne doute point que celui qui entreprendra cet ouvrage, ne trouve moins de termes nouveaux à introduire, que de syno-

42 Siehe hierzu auch die aus dem Artikel Encyclopédie zitierten Passagen im Anhang, Kapitel 8.1. 
nymes à bannir ; \& plus de difficulté à bien définir des choses communes, [...], qu'à expliquer les machines les plus compliquées.

Damit trat Diderot also zunächst für eine systematische Analyse der einzelnen Objekte ein, die in fachsprachlichen Kontexten eine Rolle spielten. Anhand eines Vergleichs sollten seiner Ansicht nach Parallelen und Divergenzen in der Beschaffenheit und Bestimmung der Objekte festgestellt werden. Basierend auf diesen Erkenntnissen konnten anschließend entsprechende normative Entscheidungen bezüglich der passenden Benennung der Objekte getroffen werden. Dabei ging es Diderot nicht um sprachpuristische Bestrebungen vergleichbar mit jenen der Klassik im Sinne einer Beschneidung der Sprache, was auch daran deutlich wird, dass er ganz direkt die Möglichkeit einräumte, neue Termini einzuführen; er verfolgte schlichtweg das Ziel, innerhalb der Fachsprachen Deutlichkeit, Verständlichkeit und die Möglichkeit einer ökonomischen Kommunikation zu schaffen - also das Vorhandensein von Kriterien sicherzustellen, die bis in die Gegenwart zu den funktionalen Eigenschaften der Fachsprachen gezählt werden. ${ }^{43}$ Zugleich legte er in seiner Encyclopédie aber höchsten Wert darauf, im Falle einer Polysemie alle möglichen Bedeutungen eines Terms zu nennen, laut Proust (1965:41),,[...] par exemple tous les sens connus du mot fer, selon qu'il est employé par les ardoisiers, les forgerons, les cordiers, les doreurs, les éperonniers, les filassiers, les fontainiers, les gaîniers, les perruquiers, les plombiers, les relieurs.“

Zusammenfassend kann gesagt werden, dass Diderots Sprachauffassung sowie sein Fachsprachenkonzept wegweisend für die Zukunft waren, erkennt man doch in seinen Anliegen ganz eindeutig die Anforderungen der modernen Fachsprachenforschung an die Fachsprachen wieder, insbesondere an einzelne Fachtermini - allen voran Eindeutigkeit und Kontextfreiheit.

\subsection{Sprachpolitik während und nach der Französischen Revo- lution von 1789 bis hin zu Napoleon Bonaparte}

Die oben angesprochene Tendenz des 18. Jahrhunderts und allem voran Diderots, in der Fachsprache für Einheitlichkeit und Klarheit zu sorgen, setzte sich im Laufe des Jahrhunderts fort und fand in der Sprachpolitik der Französischen Revolution von 1789 in einem weiter gefassten Sinn Verwirklichung. Der Hintergrund der im revo-

43 Siehe hierzu auch Kapitel 5.1.2 sowie 5.1.3. 
lutionären Frankreich getroffenen sprachpolitischen Maßnahmen war die Idee, dass eine einheitliche, stabile und starke Sprache die Grundlage einer vereinten, stabilen und starken Nation sei. Auf die Gesamtsprache bezogen bedeutete dies während der französischen Revolution zunächst die Abwertung der Patois zugunsten des Standardfranzösischen, der proklamierten langue de la liberté, deren Norm nun auf dem gesamten Staatsgebiet allgemeine Verbreitung finden sollte. Um dieses Ziel durch die Implementierung passender Maßnahmen zur - wie Bochmann (1993:V) sagt „Uniformierung und Universalisierung“ des Französischen erreichen zu können, wurde zunächst eine umfassende Analyse der wahren sprachlichen Gegebenheiten des revolutionären Frankreichs unternommen. Anschließend prägten einschneidende, bewusst herbeigeführte strukturelle Reformen in vielen Bereichen des Lebens die Epoche, wodurch sich auch große Veränderungen im sprachlichen Bereich ergaben: Beispielsweise wurde mit der Metrisierung oder der Umstellung auf den Revolutionskalender der fachsprachliche Wortschatz grundlegend beeinflusst. Nach der Revolution hingegen verlagerte sich der Fokus weg von einer Erneuerung der Sprache, hin zur Perfektionierung ihres Gebrauchs durch die Sprachnutzer: Dies erfolgte im Rahmen einer neuen Bildungspolitik, die bereits während der Revolution ansatzweise umgesetzt wurde, unter Napoleon Bonaparte einen weiteren Aufschwung erlebte und gegen Ende des Jahrhunderts unter der Einflussnahme Jules Ferrys und in der Einführung einer allgemeinen Schulpflicht schließlich ihren Höhepunkt fand. ${ }^{44}$ Ausgangspunkt all dessen war allerdings notwendigerweise eine weitgehende Normdurchsetzung des Standardfranzösischen in ganz Frankreich.

\subsubsection{Die sprachlichen Gegebenheiten im revolutionären Frankreich}

Im August 1790, also ein Jahr nach der Revolution, beauftragte die Nationalversammlung den Abbé Henri Grégoire zur ersten Sprachgebrauchsumfrage, die in Frankreich jemals durchgeführt worden war. Der Abbé Grégoire sandte infolgedessen Mitarbeiter in alle Regionen Frankreichs aus, um anhand eines 43 Fragen umfassenden Fragebogens zu überprüfen, wo im Lande die Standardvarietät ausreichend verbreitet war, in welchen Regionen Dialekte vorherrschten, ob die Patois vor allem im Bereich der Fachsprachen vorherrschend waren, in welcher sprachlichen Varietät Schulbildung vermittelt wurde, ob man auf die Patois verzichten könnte bzw. wie sie am besten durch das Standardfranzösische ersetzt wer-

44 Der direkte Einfluss dieser neuen Bildungspolitik auf die Fachsprachen ist als eher gering zu bewerten und wird daher an dieser Stelle nicht weiter analysiert. Eine ausführliche Darstellung des Themas findet sich allerdings bei Bochmann 1993. 
Das 18. und 19. Jahrhundert: das enzyklopädische Zeitalter und die ,langue de la liberté'

den konnten usw. ${ }^{45}$ Innerhalb von vier Jahren sammelte der Abbé Grégoire ausreichend Ergebnisse, um in Form des Rapport sur la nécessité et les moyens d'anéantir les patois et d'universaliser l'usage de la langue française am 4. Juni 1794 der Nationalversammlung einen umfassenden Bericht vorzulegen. Die Bilanz war für die Standardvarietät des Französischen verheerend: So sprachen bei einer Gesamtbevölkerung von etwa 28 Millionen Menschen nur etwa drei Millionen gutes Französisch; die Alphabetisierungsrate war noch geringer. Weitere sechs Millionen waren zu einer Konversation auf Französisch in der Lage. Etwa dreizehn Millionen Franzosen verstanden zwar annähernd Standardfranzösisch, beherrschten es aber nicht wirklich. Mindestens sechs Millionen hingegen sprachen gar kein Französisch, sondern ausschließlich einen der dreißig auf dem Territorium existenten Regiolekte (vgl. Barlow/Nadeau 2008:136f; vgl. Bochmann 1993:64f; ib.:83;). Insbesondere im Bezug auf die Handwerkersprachen und den Jargon der Bauern wurde laut Bochmann (1993:88) festgestellt, dass das ,[...] Wortgut des patois [...] Lücken in der französischen Lexik [auffüllte]“, weswegen man nun vorschlug, die betroffene fachsprachliche Lexik der Patois solle im Sinne einer Aufwertung ins Französische übersetzt und damit in die Standardvarietät integriert werden, die im Bereich der Fachsprachen offenbar nicht ausreichend ausgebaut war. Parallel dazu sollte man, so schlug der Abbé Grégoire vor, der Bevölkerung nicht allzu lange und eher weniger komplexe fachsprachliche Texte in französischer Sprache aus Bereichen wie der Meteorologie, der Landwirtschaft und der Physik zur Verfügung stellen, sodass die darin enthaltene Sprache in Form von nützlichen Kenntnissen in den Alltag der Menschen und folglich in ihren regulären Sprachgebrauch übergehen konnte (vgl. Bochmann 1993:139). Als erste Reaktion auf den Bericht des Abbé Grégoire wurde dem revolutionären Ideal der Gleichheit aller Bürger gemäß jedoch entschieden, dass zunächst jedes französische Kind in jeder Region die Möglichkeit haben müsse, in einer staatlichen Grundschule die französische Standardvarietät in ausreichendem Maße zu erlernen. Damit wurde die Durchsetzung eines homogenen Kommunikationsraums innerhalb des Staatsgebiets angestrebt, was auch in der offiziellen Erklärung des Standardfranzösischen zur langue de la liberté und zur langue nationale seinen Ausdruck fand (vgl. Bochmann 1993:65ff). Die Patois - so z.B. Baskisch, Bretonisch, Flämisch, Korsisch, Normannisch, Limousin, etc. -, die ja einen beträchtlichen Teil der Bevölkerung repräsentierten, wurden zugleich als „Nicht-Sprachen" bzw. als gegenrevolutionär eingestuft und sollten mit allen notwendigen Mitteln ausgerottet werden (vgl. Bochmann 1993:94f). Durch diese vehemente Aus- 
grenzung der Patois aus dem legitimen Sprachgebrauch mussten im Sinne eines konsequenten Vorgehens nun notwendigerweise auch andere regionale Besonderheiten der Sprache als nicht normgerecht eingestuft werden, so z.B. der Wortschatz der Maßsysteme, die sich geographisch bedingt häufig stark voneinander unterschieden. All das erinnert an die Konsequenzen eines anderen großen Ereignisses der französischen Sprachgeschichte - nämlich an die Durchsetzung des Französischen als offizielle Urkundensprache durch die Ordonnance de Villers-Cotterêts ${ }^{46}$ zum Nachteil der Regionalsprachen. Um den sprachpolitischen Zielen der Revolution zu entsprechen, hatte die Abwertung der Regiolekte aber natürlich den gewünschten Effekt:

Der Symbolwert des Französischen gelangte ins Bewusstsein der regionalsprachigen Volksschichten und begünstigte psychologisch ihre Bereitschaft, auf lange Sicht die Nationalsprache als das zukünftige Verständigungsmittel aller französischen Bürger anzuerkennen (Bochmann 1993:78).

Diese Veränderung der Haltung der Sprachnutzer und die ersten Ansätze zugunsten einer vereinheitlichten Schulausbildung im Bereich des Standardfranzösischen können als das Fundament weiterer Reformen zur Vereinheitlichung betrachtet werden, nämlich der - wie Bochmann (1993:81) es nennt - „Verwissenschaftlichung und Geometrisierung aller gesellschaftlichen Lebensbereiche, Raum, Zeit und Sprache“.

\subsubsection{Die Umstellung von Systemen und die Einführung revolutio- närer Neologismen}

Hauptinhalt der jakobinischen Sprachpolitik war der Ausbau sprachlicher Uniformität zugunsten der Herausbildung einer laut Bochmann (1993:101) ,[...] allen Ansprüchen des modernen staatlichen, wirtschaftlichen und intellektuellen Lebens genügenden Nationalsprache $[\ldots]^{\prime \prime}$. Diese Bestrebungen umfassten im Detail die Forderung nach einer einheitlichen Orthographie, einer einheitlichen Grammatik, einer zunehmenden Alphabetisierung der Bevölkerung sowie einem normativen Wörterbuch des revolutionären Frankreichs. Aufgrund der Tatsache jedoch, dass zu jener Zeit ohnehin bereits seit Langem der bon usage des Hofes, der in die Aufklärung hinübertransportiert worden war, die Schriftsprache regierte, waren in Wirklichkeit auf einigen Ebenen des Sprachsystems gar keine umfangreichen 
sprachnormativen bzw. sprachpflegerischen Eingriffe notwendig. Andere Bereiche hingegen bedurften entsprechend der revolutionären Ideale durchaus einer grundlegenden Reform (vgl. Bochmann 1993:101; ib.:126).

So wurden z.B. die Konventionen bezüglich der Höflichkeits- und Anredeformen grundlegend verändert: Es existierten Bürger- und Menschenrechte, der König hatte seit der Revolution keinen Anspruch mehr auf göttliche Gnade und die Nation verfügte über Souveränität. Angesichts dieser neuen Gegebenheiten sollten nun sinnentleerte Formeln, die vor allem für die briefliche Kommunikation mit dem Hof oder mit Ministerien in Anlehnung an eine veraltete Unterwürfigkeit noch typisch waren, abgeschafft werden. Beispielsweise zeichnete man einen Brief an einen Minister nun nicht mehr mit „votre très humble et très obéissant serviteur“, sondern als gleichberechtigter Mitbürger mit ,je suis votre concitoyen, votre frère, votre ami, votre camarade“, wenn nicht überhaupt nur ein einfaches „bonjour“ als Abschlussformel verwendet wurde (vgl. Bochmann 1993:128ff; vgl. Annales patriotiques vom 13. Juli 1790, aus Walter 1948:376ff, zit. n. Bochmann 1993:141f). Weiters duzte man sich kraft eines neuen Gesetzes vom 31. Oktober 1793 (vgl. Kubarth 1999:182) nun allgemein und ersetzte in der mündlichen wie der schriftlichen Kommunikation Anreden wie Monsieur oder Madame durch citoyen bzw. citoyenne, um der égalité und der fraternité gerecht zu werden.

Diesem Eingriff in die Gemeinsprache standen aber noch andere, auch in fachsprachlicher Hinsicht weitreichende gegenüber. So wurde z.B. das chaotische System der Gewichte und Maßeinheiten, das sich je nach Region anders gestaltete und über andere Benennungen verfügte, vereinheitlicht: 1791 schlug die Académie des Sciences den Meter als grundlegendes Längenmaß vor, und noch weitere neue Standardisierungen, die sich in der Sprache widerspiegelten, wurden in der Lebenswelt getroffen. So entschied man, dass das Gesamtgewicht eines Kubikmeters Wasser der entsprach 1000 Litern, von denen wiederum jeder Liter genau ein Kilogramm wog - als Tonne bezeichnet werden sollte. Das Präfix kilo galt ab der offiziellen Einführung des neuen Systems im Jahre 1795 generell als Ausdruck von tausend. Weiters stützte man sich nun in allen Lebensbereichen, auch in der Zeitmessung, auf ein Dezimalsystem; demnach umfasste der neue Republikanische Kalender zwölf Monate zu je dreißig Tagen plus fünf bis sechs Zusatztage am Ende eines jeden Jahres. Die Wochen hatten nun zehn Tage, von denen wiederum jeder in zehn Stunden zu je hundert Minuten unterteilt war. Obgleich den neu aufgeteilten Tagen und Monaten fantasievolle Benennungen zugewiesen wurden, stieß das revolutionäre System bei der Allgemeinheit nicht auf große Akzeptanz: Das alte System der Zeitrechnung hatte gut funktioniert, im Grunde bestand gar kein Umbenennungsbedarf, und man war daran gewöhnt, wohingegen die neuen Termini erst neu erlernt werden 
hätten müssen und sie noch dazu viele der Regionen Frankreichs ausgrenzten, da bei der Auswahl der neuen Monatsnamen vor allem die meteorologischen Konditionen der Ile-de-France berücksichtigt worden waren. Die einzelnen Tage des Monats sollten ebenfalls umbenannt werden: Ursprünglich war hierzu eine an Gemüsesorten, Tiernamen und Handwerksutensilien angelehnte Terminologie vorgesehen, die aber schließlich zugunsten einer durch die lateinischen Zahlen inspirierten Benennung nicht eingeführt wurde; aber auch die so konzipierten Tagesbezeichnungen wie primedi, duodi, tridi etc. fanden nur wenig positive Resonanz (vgl. Barlow/Nadeau 2008:149ff). Bei Sergijewskij (1979:215) findet sich eine Übersicht der vom Dichter Fabre d'Églantine zur Benennung der Monate erdachten und am 30. Oktober 1793 gesetzlich festgelegten Termini:

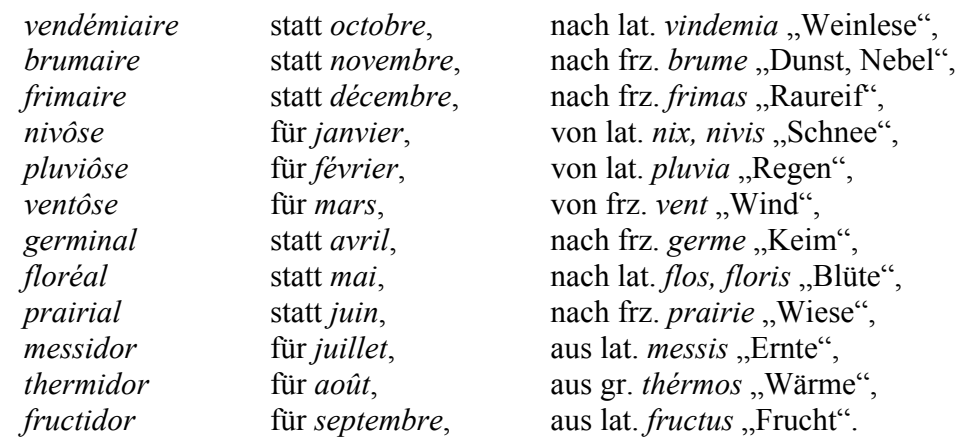

Abgesehen von den bereits genannten strukturellen Reformen und ihren Auswirkungen auf das Französische erfuhr die Sprache während der Revolution viele weitere Veränderungen im Bereich des Fachwortschatzes, dies vor allem in Form der Einführung zahlreicher Revolutionsneologismen. Exemplarisch seien hier nur einige genannt, so die der Fachsprache Technik zugehörige und nach ihrem Erfinder Dr. Guillotin 1790 fixierte Bezeichnung guillotine; der juridische Begriff der expropriation, der seit der Enteignung zahlreicher Landbesitzer ab dem Jahr 1789 in Verwendung ist; das Substantiv métrologie mit seinem Adjektiv métrique, die beide im Zuge der bereits angesprochenen Vereinheitlichung von Maßeinheiten in der Fachsprache des Messwesens neue Bedeutung erlangten; die mitraillade als militärischer Term zur Bezeichnung der Erschießung gegenrevolutionärer Personen; der juridische Fachbegriff des émigrant, der 1793 eingeführt wurde und Personen bezeichnete, die Frankreich verlassen hatten und nicht innerhalb einer gesetzlich festgelegten Frist zurückgekommen waren; die centralisation als Fachwort des Bereichs 
Staatswesen und Verwaltung; etc. (vgl. Sergijewskij 1979:213f; ib.:216;). Auch in dieser Epoche hatte also ein neuer Benennungsbedarf zu einer Erweiterung der fachsprachlichen Lexik geführt.

\subsubsection{Von der Machtergreifung Napoleon Bonapartes bis zum Beginn des 20. Jahrhunderts}

Nach der Machtergreifung Napoleon Bonapartes behielt man einen Teil der während der Revolution vorgenommenen Umstrukturierungen bei, so z.B. das metrische System, die Vereinheitlichung von Gewichten, die zunehmende Zentralisierung in der Verwaltung des Landes etc. Ebenso verblieben natürlich die zahlreichen Revolutionsneologismen in der Sprache. Der niemals sonderlich erfolgreich durchgesetzte Republikanische Kalender hingegen wurde durch Napoleon wieder abgeschafft, womit auch seine Monatsnamen und Tagesbenennungen aus dem Bewusstsein der Menschen schwanden und lediglich noch in der Geschichtsschreibung von einer gewissen Bedeutung blieben. Abgesehen davon war das 19. Jahrhundert ab dem Staatsstreich Napoleons hauptsächlich von weiteren Verwaltungsreformen, vom Ausbau der Verkehrswege und von einer Weiterführung der während der Revolution begonnenen Reform der Bildungspolitik im Sinne der Idee einer staatlichen Schulbildung für alle gekennzeichnet. In linguistischer Hinsicht hatte dies zum einen die Auswirkung, dass aufgrund eines erneuten Benennungsbedarfs wieder zahlreiche Neologismen - auch fachsprachlicher Art - entstanden. Zum anderen wurden die Alphabetisierung der französischen Bevölkerung und damit auch die weitere Verbreitung der Standardvarietät des Französischen bzw. ihr normgerechter Gebrauch zunehmend vorangetrieben. Diese seit der Revolution alle Landesteile betreffende Tendenz setzte sich bis nach Jules Ferrys Einführung der verpflichtenden, kostenlosen und laizistischen Grundschulbildung von 1880 auf diesem Wege fort. Abgesehen von den Neuerungen in der Bildungspolitik und deren Auswirkungen auf die Sprache wirkt allerdings die Herrschaftszeit Napoleons wie auch der Rest des 19. Jahrhunderts in sprachpolitischer Hinsicht aus heutiger Perspektive eher unauffällig. Bochmann (1993:149) fasst dies im Bezug auf Napoleon Bonaparte wie folgt zusammen:

Man findet schwerlich explizite Äußerungen Napoleons hinsichtlich einer aus strategischen Gründen mehr oder minder forcierten Franzisierung eroberter Länder [...] oder Anweisungen für eine zentralistische Sprachpolitik für Frankreich im Inneren der vorrevolutionären Grenzen. An den zitierten Äußerungen des Kaisers wird allenfalls sein Pragmatismus in der Sprachfrage 
sichtbar. Mit anderen Worten fehlen zwischen 1799 und 1814 also nicht nur sprachpolitische Gesetze, sondern auch im Diskurs des Kaisers selbst bleiben die sprachpolitischen Intentionen der hegemonischen Schichten verdeckt.

Sergijewskij (1979:223) erklärt diese Art von Passivität in der Sprachpolitik damit, dass nach Napoleon, mit der Pariser Kommune und der Dritten Republik, ,[d]ie Schaffung einer einheitlichen Nationalsprache, die schon im 16. Jahrhundert einsetzte $[\ldots],[\ldots]$ nunmehr mit dem Übergang der Macht an das Bürgertum ihre Abschlußphase [...]" erlebte.

Nun war also nach vier Jahrhunderten die französische Nationalsprache endlich gefestigt und wahrhaftig allgemein im Land verbreitet, doch kündigte sich bereits im 19. Jahrhundert eine neue Herausforderung für die französische Sprachpolitik an: ein großer Zustrom an neuer Lexik von außen, allem voran aus dem Englischen, der zunächst häufig den Bereich der Fachsprachen betraf und von dort ausgehend begann, auch auf die französische Gemeinsprache spürbar Einfluss zu nehmen. Diese Problematik hat bis in die Gegenwart nichts an Aktualität eingebüßt und im 20. und 21. Jahrhundert eine Rückbesinnung auf die Verteidigung des Französischen bewirkt. Welche Ausprägung hat nun die dem Namen nach ohne Zweifel an Joachim du Bellay angelehnte défense de la langue française heute in Frankreich angenommen? 


\section{Das 20. und 21. Jahrhundert: eine Rückbesin- nung auf die Verteidigung der Sprache}

Schlagwörter wie Sprachnormierung und Sprachpflege hatten über die Jahrhunderte hinweg in keinem europäischen Land so große Bedeutung wie in Frankreich, wo bis heute eine sehr stark institutionalisierte Sprachpflege betrieben wird. Bereits seit etwa 1930 fühlen sich die Franzosen der Bedrohung einer crise du français, eines Sprachverfalls, ausgesetzt. Diese schreiben sie heute in erster Linie der Tatsache zu, dass das Englische und Angloamerikanische weltweit zunächst zahlreiche fachsprachliche Domänen erobert und anschließend in Form von Lehnwörtern damit auch Eingang in die französische Gemeinsprache gefunden haben, was Abwehrreaktionen sowohl seitens der französischen Politik als auch der Öffentlichkeit zur Folge hatte. Die folgenden Kapitel befassen sich nun mit dem Ursprung der französischen Sprachkrise sowie mit den Maßnahmen, die heute zum Schutz des Französischen ergriffen werden. Um eine möglichst stabile theoretische Grundlage für die weiteren Überlegungen zu schaffen, scheint allerdings zunächst eine kurze theoretische Befassung mit dem Wesen der Fachsprachen angebracht, dies natürlich vor dem Hintergrund der modernen Fachsprachenreflexion bzw. -forschung. ${ }^{47}$

\subsection{Zur Fachsprachenreflexion des 20. und 21. Jahrhunderts}

Blicken wir zunächst kurz zusammenfassend auf die Entwicklung der Fachsprachenreflexion in Europa zurück: Im Mittelalter fand keine zielgerichtete Fachsprachenreflexion oder Fachsprachenforschung statt, was sich selbst das 16. und 17. Jahrhundert hindurch nicht wirklich änderte. Ab dem 18. Jahrhundert wurden zwar erste Maßnahmen zur Pflege nationaler Fachsprachen ergriffen, die Fachsprachenreflexion vollzog sich allerdings noch ausschließlich innerhalb der jeweiligen Fächer,

47 Die oben angekündigte „kurze theoretische Befassung“ mit den Fachsprachen hat keinen Anspruch auf Vollständigkeit, sondern soll einen Fokus auf ausgewählte, für das weitere Verständnis der vorliegenden Arbeit besonders maßgebliche Aspekte legen. Es steht jedoch wesentlich umfassendere einführende Literatur zum Thema zur Verfügung, wobei hier exemplarisch Fluck 1996 sowie Roelcke 2005 genannt seien. Besonders detaillierten Zugang zu speziellen Aspekten des Themenbereichs bieten darüber hinaus beispielsweise die Beiträge in den beiden umfangreichen Sammelbänden von Hoffmann/Kalverkämper/Wiegand 1998. Weiters bietet Janich 2004 Einblicke in die Fachkommunikation im Kontext des Sprachbewusstseins. 
und es gab nach wie vor keine eigenständige Fachsprachenforschung. ${ }^{48}$ Innerhalb der Fächer waren die Fachsprachen insofern ein Thema, als es galt, die interne Fachkommunikation zu verbessern, wobei über eine lange Zeitspanne hinweg eine objektive Beschreibung der Fachsprachen gar nicht intendiert war (vgl. Roelcke 2005:7). Ab Beginn des 20. Jahrhunderts hingegen ergaben sich hierin erste Veränderungen: Nun fanden die Fachsprachen im Rahmen unterschiedlicher Forschungsansätze Beachtung, wobei zunächst hauptsächlich die Erforschung der Fachlexik im Vordergrund stand. Erst in den 1950er Jahren vollzog sich die Herausbildung einer eigenständigen Fachsprachenlinguistik. Diese also noch recht junge wissenschaftliche Disziplin widmet sich inzwischen einer breiten Palette von Arbeitsschwerpunkten. Sie hat sich von der ursprünglich ausschließlich auf die Wortebene konzentrierten Befassung mit den Fachsprachen abgewandt und ist zu einer umfassenderen Betrachtungsweise übergegangen, die vermehrt die syntaktische und textlinguistische Ebene der Fachsprachen in den Mittelpunkt des Forschungsinteresses stellt. Zu den Arbeitsschwerpunkten der modernen Fachsprachenlinguistik zählen heute unter anderem folgende Bereiche: die Fachsprachensemantik mit der Definitionslehre sowie Methoden zur Anlage von Fachwortschätzen; die Fachsprachengrammatik einschließlich der Analyse fachsprachlicher Sätze im Bezug auf ihre Länge und Syntax; die Fachtextlinguistik mit den ihr zugehörigen Aspekten der Intertextualität, der Situationalität von Fachtexten sowie der Bestimmung von Fachtextsorten; die Terminologienormung sowie die Fachlexikographie; die Fachsprachendidaktik; die Fachsprachenübersetzung; die Definition und Abgrenzung einzelner Fachsprachen sowie die Abgrenzung zwischen Fach- und Gemeinsprache; usw. (vgl. Roelcke 2005:187f). Die moderne Fachsprachenlinguistik umspannt inzwischen also ein enormes Arbeitsfeld und hat zu neuen Definitionen gefunden. Damit ist zunächst zu erörtern, worum es sich bei Fachsprache(n) im heutigen Sinne denn eigentlich handelt.

\subsubsection{Fachsprachen und Fächer - eine Definition des 20. Jahrhunderts}

Die Fachsprache ist die Gesamtheit aller sprachlichen Mittel, die in einem fachlich begrenzbaren Kommunikationsbereich verwendet werden, um die Verständigung zwischen den in diesem Bereich tätigen Menschen zu gewährleisten. Diese Mittel bilden einen Teil des Gesamtinventars der Sprache im Sinne einer Subsprache. [...] Die Spezifik der Fachsprachen gegenüber der Gemeinsprache und anderen Subsprachen äußert sich besonders deutlich auf

48 Im Bezug auf die Fachsprachenreflexion des 18. Jahrhunderts speziell in Frankreich siehe Kapitel 4.2. 
Das 20. und 21. Jahrhundert: eine Rückbesinnung auf die Verteidigung der Sprache

der Ebene der Lexik, d.h. im Fachwortschatz bzw. in der Terminologie, aber auch in der Verwendung bestimmter grammatischer Kategorien, syntaktischer Konstruktionen und Textstrukturen; gewisse Besonderheiten gibt es bei den Wortformen, ihrer Schreibung und Lautung sowie im Bestand der graphischen Zeichen. Deshalb können frühere Auffassungen, wie die Gleichsetzung von Fachsprache und Terminologie, das Wesen der Fachsprache nicht ausschöpfen (Hoffmann 1987:92).

Spricht Hoffmann in obiger Definition von „einem fachlich begrenzbaren Kommunikationsbereich“, so bezieht er sich auf das, was landläufig unter dem Begriff „Fach“ subsumiert wird: ein spezialisierter Tätigkeitsbereich. Aufgrund einer stetig zunehmenden Arbeitsteilung und Spezialisierung existieren in unserer modernen Gesellschaft heute viele solcher Tätigkeitsbereiche, und jedes einzelne dieser Fächer hat einen speziellen Kommunikationsbedarf, der durch jeweils eine diesen Bedürfnissen entsprechende Fachsprache abgedeckt wird. Somit existieren parallel nebeneinander zahlreiche, den einzelnen Fächern zugeordnete Fachsprachen, deren Anzahl allerdings nicht eindeutig feststellbar ist und bezüglich derer auch verschiedene Schätzungen grobe Abweichungen voneinander aufweisen: Müller (1975:148f) beispielsweise geht zwar grundsätzlich von einer Unfeststellbarkeit der Anzahl der Fächer und der Fachsprachen aus, bezieht sich aber dennoch auf Angaben des Grand Larousse encyclopédique, in denen von 711 Geisteswissenschaften und 529 Naturwissenschaften die Rede ist; alle außerwissenschaftlichen Fachgebiete finden hier jedoch keine Berücksichtigung. Fluck (1996:16) hingegen bezieht sich für denselben Vergleichszeitraum auf eine grobe Schätzung durch Eugen Wüster aus dem Jahre 1973 (Drozd/Seibicke 1973:IX, zit. n. Fluck 1996:16), die sich auf nur etwa 300 Fachbereiche und Fachsprachen beläuft. Wie auch Müller betont Fluck (1996:11) allerdings, dass ,[...] weitgehende Einigkeit in der Verwendung der Pluralform der Begriffsbenennung [Fachsprachen] [besteht], die besagt, daß der Gemein- oder Standardsprache eine größere, bislang nicht fixierbare Zahl von primär sachgebundenen Sprachen als Subsysteme angehören [sic]“. Aufgrund der immensen Dynamik in Forschung und Technik ist in jedem Fall davon auszugehen, dass Schätzungen bezüglich der Anzahl der Fachsprachen sehr schnell veraltet sind. Laut Hoffmann (1987:92) gibt es exakt aus diesem Grund keine Antwort auf die Frage nach der Zahl der existenten Fächer bzw. Fachsprachen:

Aus der horizontalen Gliederung [der Fächer] läßt sich nicht ableiten, wie viele Fachsprachen es gibt. Ihre Zahl entspricht praktisch der der unterschiedlichen Fachgebiete, zu denen im Rahmen des wissenschaftlich-technischen 
Das 20. und 21. Jahrhundert: eine Rückbesinnung auf die Verteidigung der Sprache

Fortschritts immer neue hinzukommen und von denen jedes der Dialektik von Integration und Differenzierung unterworfen ist.

Was differenziert nun aber die einzelnen Fachsprachen voneinander? Und was unterscheidet bzw. verbindet Fachsprachen und Gemeinsprache?

\subsubsection{Die grundlegenden Charakteristika moderner Fachsprachen}

Einerseits unterscheiden sich Fachsprachen von der Gemeinsprache: Am offensichtlichsten zeichnen sie sich durch ihre besondere Lexik aus, aber es gibt noch weitere fachsprachentypische Merkmale, wie z.B. einen hohen Anteil an Symbolen und Sonderzeichen oder einen gewissen Funktionalstil in Fachtexten. Andererseits sind Fach- und Gemeinsprache untrennbar miteinander verknüpft: Während die Gemeinsprache zwar nicht unbedingt auf die Fachsprache angewiesen, jedoch durch die Übernahme fachsprachlicher Wörter in den gemeinsprachlichen Wortschatz häufig durch sie beeinflusst wird $^{49}$, so kann die Fachsprache als Subsystem der Gemeinsprache nicht ohne diese existieren, da die Gemeinsprache die grammatischen und lexikalischen Rahmenbedingungen für die Fachsprache bereitstellt. In jede fachsprachliche Kommunikation, welchem Fach auch immer diese zugehörig ist, fließen also notwendigerweise gemeinsprachliche Elemente ein, wobei diese im Zuge dessen durchaus auch mit fachsprachlichen Elementen terminologische Verbindungen bilden und in dieser Form eine neue fachsprachliche Bedeutung erlangen können. Die einzelnen Fachsprachen hingegen müssen nicht unbedingt auf die kommunikativen Ressourcen anderer Fachsprachen zurückgreifen. Becker und Hundt (1998:126) beschreiben diese Interdependenzen wie folgt:

Besonders wichtig ist die Tatsache, daß jedes Mitglied einer Kommunikationsgemeinschaft über die Alltagssemantik verfügen muß. Die Aneignung und Verwendung der Alltagssemantik mit ihren grundlegenden Begriffen ist unhintergehbar. Im Gegensatz dazu muß man sich die Semantiken anderer kommunikativer Bezugsbereiche nicht vollständig aneignen. Man kann ohne die Kenntnis von Literatur-, Religions-, Wissenschafts- und auch von Technik- und Institutionensemantiken auskommen. Lediglich das, was aus diesen Bereichen, gewöhnlich stark transformiert, in den Alltag hineinreicht, was diesen maßgeblich beeinflusst und verändert, muß in die Alltagssemantik übernommen werden.

49 Siehe hierzu auch Kapitel 5.1.4. 
Demnach unterscheiden sich also die Fachsprachen der einzelnen Fächer voneinander, wobei die Unterschiede vor allem im fachspezifischen Wortschatz begründet liegen. Dieser findet jeweils nur in einem einzigen Fach Anwendung, wohingegen allgemeinwissenschaftlicher Wortschatz sprachliche Mittel umfasst, die bei Bedarf in allen Fachsprachen auftreten können (vgl. Hoffmann 1987:92). Vor allem im Bezug auf ihre sogenannten funktionalen Eigenschaften lassen sich die einzelnen Fachsprachen jedoch durchaus miteinander vergleichen und weisen hierin grundlegende gemeinsame Charakteristika auf. $\mathrm{Zu}$ den funktionalen Eigenschaften der Fachsprachen zählen laut Roelcke (2005:28ff) Deutlichkeit, Verständlichkeit, Ökonomie, Anonymität und Identitätsstiftung.

Der Anspruch an Deutlichkeit betrifft die Darstellungsfunktion der Sprache und wird vor allem durch einen den fachlichen Sachverhalten gegenüber adäquaten Wortschatz erfüllt (vgl. Roelcke 2005:28f). Ein weiteres wesentliches, ebenfalls die Darstellungsfunktion betreffendes Kriterium ist zum Zweck einer fehlerlosen Informationsvermittlung die Forderung nach der Verständlichkeit der Fachsprachen für ihre Rezipienten. Aus einer rein systemlinguistischen Perspektive ist diese bereits durch die Lexik und Syntax der Fachsprachen gegeben. Aus pragmalinguistischer Sicht hingegen müssen fachliche Inhalte mit einem entsprechenden Kotext bzw. Kontext versehen übermittelt werden, um ihre korrekte Rezeption zu gewährleisten, wobei zum Kontext sprachliche wie fachliche Kenntnisse des Informationsempfängers gezählt werden. Dies impliziert, dass fachliche Äußerungen nicht von der Allgemeinheit, sondern nur von einer bestimmten Gruppe dekodiert werden können (vgl. Roelcke 2005:29). Die funktionale Eigenschaft der Ökonomie ist laut Roelcke (2005:30) bei Fachsprachen dann gegeben, wenn ,,...] bei einem bestimmten sprachlichen Einsatz eine maximale fachliche Darstellung erzielt wird, oder [...] [wenn] eine bestimmte fachliche Darstellung durch einen minimalen sprachlichen Einsatz erfolgt." Die Eigenschaft der Anonymität sieht vor, dass der Sender einer fachsprachlichen Äußerung den von ihm geäußerten Inhalten gegenüber in den Hintergrund tritt, beispielsweise, indem er selber in der Äußerung nicht sprachlich gekennzeichnet wird (vgl. Roelcke 2005:30). Was nun zu guter Letzt die Funktion der Identitätsstiftung betrifft, beruht sie auf der Tatsache, dass Fachsprachen bestimmte Kenntnisbereiche betreffende Gruppensprachen sind, die eine Exklusionsund eine Inklusionsidentität schaffen, was unter Umständen durchaus von der Gruppe gewollt sein mag. So grenzen sich beispielsweise wissenschaftliche Schulen durch die Verwendung einer bestimmten Terminologie gezielt von anderen ab, während Firmen von einer firmeneigenen Fachsprache profitieren, um unter anderem ihre Corporate Identity zu festigen (vgl. Roelcke 2005:30f). Hierzu ist weiters festzuhalten, dass Fachsprachen im Rahmen einer soziolinguistischen Identitätsstif- 
tung Experten und Laien voneinander abgrenzen, was im Normalfall mit einem Prestigegewinn für die Experten einhergeht. Schließlich wird im Allgemeinen der Zugang zu einer Fachsprache im Sinne eines erreichten Bildungsideals als äußerst positiv gewertet bzw. als das Vorliegen besonders wertvoller Kompetenzen interpretiert. Damit kann der Zugang zu Fachsprachen unter Umständen sogar Einfluss darauf haben, welcher sozialen Gruppe oder "Schicht" eine fachsprachenkundige Person im Zuge einer Identitätszuschreibung durch Dritte zugeordnet wird.

\subsubsection{Das Fachwort als Wesensmerkmal der Fachsprache}

Ein wesentliches, auch für Fachsprachenunkundige unverzüglich feststellbares Merkmal der Fachsprachen ist der Fachwortschatz. Auch die Fachsprachenforschung hat sich bis in die 1970er Jahre vordergründig mit der lexikalischen Komponente der Fachsprachen befasst, so Roelcke (2005:50, im Original teilweise Fettdruck), der auch feststellt, dass Fachtermini ,[...] sogar als konstitutiv für Fachsprachen überhaupt betrachtet werden. In manchen Fällen werden Fachwortschatz und Fachsprache dann kurzerhand gleichgesetzt. Auch wenn dies angesichts der zahlreichen syntaktischen und textuellen Merkmale von Fachsprachen überzogen erscheint, darf der Wortschatz dennoch als ein wesentlicher Bereich fachsprachlicher Besonderheiten gelten."

Der Fachwortschatz ist nun aber kein homogenes Gebilde, sondern vereint unterschiedliche Komponenten, die je nach dem vorliegenden Kommunikationsbedarf zu unterschiedlichen Verhältnissen in fachlichen Äußerungen vorkommen können. Es handelt sich hierbei um: gemeinsprachlichen Wortschatz, um die notwendigen Rahmenbedingungen zu schaffen; interfachlichen, also sogenannten allgemeinwissenschaftlichen Wortschatz; intrafachlichen, d.h. fachspezifischen Wortschatz; extrafachlichen Wortschatz. ${ }^{50}$ Bei Letzterem handelt es sich laut Roelcke (2005:52) um Wortschatz, der in einer einem bestimmten Fach zuzuordnenden fachsprachlichen Äußerung verwendet wird, obwohl er der Fachsprache dieses Faches nicht eigen ist, sondern der eines anderen. Wird nun nach Roelcke (2005:51f) ein Fachwort aus einer systemlinguistischen, sich also auf eine bestimmte Fachsprache als abgeschlossenes System beziehenden Perspektive unter Kombination mit einem pragmalinguistischen Kontextmodell definiert, so ist ein Fachwort ,[...] die kleinste bedeutungstragende und zugleich frei verwendbare sprachliche Einheit eines fachlichen Sprachsystems, die innerhalb der Kommunikation eines bestimmten menschli-

50 Siehe hierzu auch Kapitel 5.1.2. 
chen Tätigkeitsbereichs im Rahmen geäußerter Texte gebraucht wird. Und ein Fachwortschatz ist die Menge solcher kleinster bedeutungstragender und zugleich frei verwendbarer sprachlicher Einheiten eines fachlichen Sprachsystems, die innerhalb der Kommunikation eines bestimmten menschlichen Tätigkeitsbereiches im Rahmen geäußerter Texte gebraucht werden.“

Um die Präsenz der bereits behandelten funktionalen Eigenschaften von Fachsprachen $^{51}$ zu gewährleisten, so hat zunächst bereits das Fachwort bzw. in Folge der Fachwortschatz verschiedene Kriterien zu erfüllen, worauf idealerweise bereits bei der Aufnahme neuer Termini in eine Fachsprache zu achten ist. Dies ist beispielsweise insbesondere im Hinblick auf systematisch durchgeführte Maßnahmen des Terminologieausbaus - wie z.B. gegenwärtig in Frankreich betrieben ${ }^{52}-$ von absoluter Wichtigkeit, um eine optimale Akzeptanz neugeschaffener fachsprachlicher Termini in der Sprechergemeinschaft zu erreichen. Diese Akzeptanz hängt unter anderem davon ab, ob ein Fachwort den folgenden Kriterien entspricht:

Das Kriterium der Eindeutigkeit zielt darauf ab, Deutlichkeit in der Kommunikation sicherzustellen, weswegen Fachtermini weder Polysemie noch Synonymie, sondern vielmehr Monosemie und Heteronymie aufweisen sollten. Darüber hinaus ist Exaktheit in der Anwendung des Terms vonnöten, wobei die wünschenswerte Eigenschaft der Exaktheit allerdings nicht an das Fachwort selber gebunden ist, sondern von dessen Gebrauch abhängt (vgl. Roelcke 2005:61ff). Liegt eine Homonymie vor, so schadet dies der Präzision eines Fachterms. Zugunsten der Vermeidung kommunikativer Missverständnisse sollten Fachtermini auch frei von morphologischen und graphischen Varianten sein.

Das Kriterium der Kontextfreiheit eines Terms, auch als Autonomie bezeichnet, vermeidet ebenfalls kommunikative Missverständnisse: Durch eine exakte Definition, also eine von vornherein getroffene „Festschreibung“ des Fachwortes, kann sowohl auf Kontext als auch auf Kotext verzichtet werden; dennoch bleibt die Eindeutigkeit erhalten (vgl. Roelcke 2005:67). Polysemie und Homonymie hingegen stehen im Widerspruch zur Kontextfreiheit eines Fachwortes.

Laut dem Kriterium des Metapherntabus sollten Fachtermini nicht unter der Verwendung metaphorisch genutzter Begriffe gebildet werden, da Metaphern nicht mit dem Grundsatz der Kontextfreiheit vereinbar sind. Sie widersprechen weiters der funktionalen Eigenschaft der Anonymität von Fachsprachen, weil sie auf die persönlichen Vorstellungen des Textsenders hinweisen. In der Realität kommen

51 Siehe hierzu auch Kapitel 5.1.2.

52 Siehe hierzu auch Kapitel 5.5.6. 
allerdings sehr wohl fachsprachliche Metaphern vor, die in ihren jeweiligen Fachsprachen durchaus verankert sind, man denke beispielsweise an anatomische Metaphern aus dem Bereich der Technik, wie z.B. Druckkopf, Fräskopf, Bohrkopf etc. (vgl. Roelcke 2005:67f).

Wird bei der Bildung neuer Termini weiters auf das Kriterium einer zumindest für Fachleute ersichtlichen Motiviertheit geachtet, so vereinfacht dies das Verständnis der Fachwörter und erhöht ebenfalls deren Akzeptanz. Modellhaft ist hierzu der Fachwortschatz der Medizin, in dem beispielsweise viele ausschließlich aus motivierten Bausteinen gebildete Komposita wie Laryngoskopie, Gastroskopie, Koloskopie, etc. vorkommen.

Das Kriterium der Kürze von Fachtermini entspricht der fachsprachlichen Forderung nach kommunikativer Ökonomie. Kurze Termini sind einprägsam und zugleich für die Sprachnutzer schnell wieder aus ihrem Gedächtnis abrufbar. Sie können ob ihrer Kürze allerdings in sich selber nicht so viele Einzelinformationen speichern wie längere Termini. Diese wiederum sind allerdings weitaus weniger ökonomisch in der Anwendung, wodurch sie die Sprachnutzer häufig zur Bildung von Abkürzungen motivieren.

Fachwörter weisen im Idealfall außerdem das Kriterium der Konnotationsfreiheit auf, um eine absolut definitionsgemäße Verwendung, frei von persönlichen Wertungen, zu gewährleisten. Schließlich sollten Fachtermini zugunsten ihrer Akzeptanz wie auch der kommunikativen Eindeutigkeit im Hinblick auf ihr Fach, ihre Einzelsprache und ihre Sprachtypologie auch über Systemkonformität verfügen.

Erfüllt ein Fachwort all diese Kriterien, so trägt es angemessen dazu bei, den eigentlichen Zweck der Fachsprachen, nämlich eine funktionelle und effektive Kommunikation, wie bereits an anderer Stelle dargelegt ${ }^{53}$, zu gewährleisten, womit wiederum größere Chancen auf eine Akzeptanz des betreffenden Wortes durch die Fachsprachennutzer besteht. Kommt nun einem solch mustergültigen Fachterm aber auch eine Rolle in der Gemeinsprache zu?

\subsubsection{Der Einfluss der Fachsprachen auf die Gemeinsprache}

Grundsätzlich ist der Frage nach dem Einfluss der Fachsprachen auf die Gemeinsprache vorauszuschicken, dass sich der Erfolg von Fachsprachen nicht über die erreichte Sprecheranzahl definiert, wie es unter anderem bei National- oder Minderheitensprachen der Fall sein kann. Fachsprachliche Erfolgskriterien sind anderer Art;

53 Siehe hierzu auch Kapitel 5.1.2. 
sie beziehen sich beispielsweise auf das Vorhandensein eines ausreichenden Kommunikationspotenzials (vgl. Janich 2004:182ff) oder auf das Vorhandensein der funktionalen Eigenschaften von Fachsprachen. Müller (1975:149f, im Original teilweise durch Sperrschrift hervorgehoben) meint hierzu:

Da eine Fachsprache sich durch das Anwendungsgebiet abgrenzt, ist belanglos, wie groß der Kreis derer ist, die über sie verfügen. Anders als bei der Gemeinsprache, die qua definitione größtmögliche Verbreitung verlangt, anders auch als bei diatopischen, sozialen, qualitativen Registern kann man hier sogar die Regel aufstellen, daß der subsprachliche Charakter in dem Maß zunimmt, wie der Kreis der Beteiligten, die eine bestimmte Fachsprache brauchen, sich verengt.

Soll allerdings der Einflussbereich der Fachsprachen innerhalb der Gemeinsprache festgestellt werden, so ist laut Müller (1975:150) die Sprecheranzahl durchaus maßgeblich:

Beschränkt sich z.B. die Zahl der Fachleute auf wenige hundert, wird es kaum nennenswerte Interferenzen zur Gemeinsprache geben, wesentlich weniger Übergangsmöglichkeiten fachsprachlichen Materials in Gemeinbesitz, geringere Chancen des Ausgleichs, als wenn die Sprache eines Fachgebiets die Sprache von Millionen ist, [...].

Wie aber werden Fachsprachen, die ja Gruppensprachen sind, zur „Sprache von Millionen" bzw. welche ihrer Elemente gelangen in die Gemeinsprache, und wie? Es gibt mehrere wichtige Brücken zwischen fachlichen Inhalten und der Allgemeinheit bzw. zwischen Fach- und Gemeinsprache: Massenmedien sind durch ihre regelmäßige Berichterstattung über wissenschaftliche Erkenntnisse und fachliche Themen die wichtigste Verbindung zwischen der breiten Öffentlichkeit und den Fachsprachen. Sie kommunizieren Fachwissen aus den unterschiedlichsten Bereichen, beispielsweise Politik, Wirtschaft, Forschung, Raumfahrt etc. Auch fachspezifische populärwissenschaftliche Literatur und Fachliteratur erlauben fachfremden Personen Zugang zu breitgefächerten Bereichen spezialisierten Wissens; man denke z.B. an das umfangreiche Angebot an medizinischen Informationen in Patientenratgebern etc. Die den Alltag durchdringende Konsumtionssphäre sorgt schließlich ebenfalls dafür, dass Fachwissen an ein Laienpublikum gelangt, so z.B. durch die Werbung und im Rahmen kommunikativer Situationen hinsichtlich des Verkaufs bzw. Erwerbs von Produkten. Die in diesem Zusammenhang entstehenden Kontakte der Allgemeinheit mit fachlichen Inhalten erstrecken sich vor allen Dingen auf die 
Das 20. und 21. Jahrhundert: eine Rückbesinnung auf die Verteidigung der Sprache

Bereiche Wissenschaft und Technik (vgl. Fluck 1996:160ff). Das Einholen von Informationen über einen zum Kauf in Erwägung gezogenen Rasenmäher, die Lektüre der Gebrauchsanleitung eines neu erworbenen Laptops, ein Beratungsgespräch bei der Auswahl einer Infrarotkabine usw. sind typische Fallbeispiele hierfür. Aufgrund der Propagierung von Fachwissen auf den genannten Wegen sind NichtFachleute nun automatisch vermehrt mit Fachsprachen, im Besonderen vor allem mit dem entsprechenden Fachwortschatz, konfrontiert. Diese Konfrontation ist die Schnittstelle, welche die Einflussnahme von Fachsprachen auf die Gemeinsprache erlaubt - dies unter anderem ${ }^{54}$ in Form einer Aufnahme von Fachtermini in die gemeinsprachliche Lexik. Fluck (1996:161) fasst dies wie folgt zusammen:

Eine Wirkung [der Fachsprachen auf die Gemeinsprache] ergibt sich vor allem dort, wo wissenschaftlich-technischer Fortschritt über die Produktion auf das alltägliche Leben des einzelnen zurückwirkt, wo sich reine und angewandte Wissenschaft berühren. Von hier aus dringen auch wissenschaftliche Fachsprachen in immer neuen Schüben in die gesamtgesellschaftliche Diskussion und damit in die Gemeinsprache ein. [...] Exakte Daten über den Gesamteinfluß oder die Zahl fachsprachlicher Elemente in der Gemeinsprache liegen allerdings nicht vor. [...] In vielen Einzelfällen wird es deshalb umstritten bleiben, ob man nun ein Fachwort noch als spezialsprachlich oder bereits als gemeinsprachlich, das heißt als voll integriertes (aktiv und passiv) Element im gemeinsamen Zeichenvorrat aller Sprachteilhaber, betrachtet.

Obgleich Fach- und Gemeinsprache in mancherlei Hinsicht bis dato nicht eindeutig voneinander abgegrenzt und die quantitativen Auswirkungen des fachsprachlichen Einflusses auf die gemeinsprachliche Lexik nicht exakt definiert werden können, ist eine gewisse „Verwissenschaftlichung“ bzw. „Intellektualisierung“ der Gemeinsprache durch die Fachsprache unumstritten. Dies sind Phänomene, die mit einem Wandel der allgemeinen Lebensumstände und vor allem mit der Entstehung neuer Medien (vgl. Fluck 1996:167) sowie neuer Technologien einhergingen, was nicht von Grund auf als problematisch zu bewerten ist. Allerdings kann der verstärkte Einfluss der Fachsprachen auf die Gemeinsprache eines Landes dann als Bedrohung empfunden werden, wenn die fachsprachlichen Termini, die in die Gemeinsprache

$54 \mathrm{Zu}$ weiteren Arten der Einflussnahme der Fachsprachen auf die Gemeinsprache, wie z.B. Auswirkungen auf die Syntax in Form einer Substantivierungstendenz zur Vermeidung von Paraphrasen, die Nutzung fachspezifischer Wortableitungen auf -er in der Gemeinsprache, „Augenblicksbildungen mit generalisierender Tendenz" oder die Rolle der Fachsprachen in der Bildung gemeinsprachlicher Metaphern sowie ihre Präsenz in Redewendungen gibt Fluck (1996:162-166) ausführlich Aufschluss. 
übernommen werden, aufgrund der fachlichen Dominanz einer anderen Sprachgemeinschaft nicht hauptsächlich der eigenen Nationalsprache entstammen. In einem solchen Falle wird eine Nationalsprache Schritt für Schritt immer stärker von fachsprachlichen Lehnwörtern durchsetzt, was dazu führen kann, dass die betroffene Sprachgemeinschaft einen Sprachverfall feststellt. ${ }^{55}$ Tritt eine solche Lage ein - und dies ist in Frankreich seit Beginn des 20. Jahrhunderts der Fall - bietet es sich im Sinne einer Verteidigung der eigenen Sprache an, diverse Maßnahmen umzusetzen. In Frankreich waren dies beispielsweise die Verabschiedung sprachpflegerischer Gesetze, die Gründung zahlreicher privater und staatlicher Sprachpflegeorganisationen sowie die Einrichtung eines aus Terminologiekommissionen und diversen Kontrollinstanzen bestehenden Systems der staatlich organisierten Sprachnormierung zum weiteren Ausbau der nationalsprachlichen Fachterminologien. ${ }^{56}$ Was war aber eigentlich der Ausgangspunkt der crise du français, die all diesen Maßnahmen zugrunde liegt?

\subsection{Französisch vs. Englisch, Frankreich vs. England}

Die Sprachkrise des Französischen begann mit dem Siegeszug des Englischen. Bereits im 18. Jahrhundert erlebte Großbritannien politische und wirtschaftliche Erfolge, man denke beispielsweise an die Dimensionen des britischen Kolonialreichs oder den rasanten industriellen Fortschritt im Anschluss an die Erfindung der Dampfmaschine. Im Zuge dieser und anderer Entwicklungen, so z.B. dem Einsetzen einer intensiven Rezeption der Werke Shakespeares ab dem 19. Jahrhundert, erlangte die englische Sprache in ganz Europa immer mehr Popularität und wurde auch vermehrt unterrichtet; kurz: Englisch begann bereits im 19. Jahrhundert, dem Französischen Konkurrenz zu machen und von außen auf die französische Sprache einzudrängen (vgl. Schröder 2001:302). Jean Pons Guillaume Viennet (1777-1868) verlieh diesem Phänomen in seiner Épitre à Boileau sur les mots nouveaux Ausdruck, die er 1855 in einer Sitzung des Institut de France vortrug und die bei französischen Sprachpflegevereinen scheinbar bis heute nichts an Aktualität verloren hat; so nahm beispielsweise die private Sprachpflegevereinigung Défense de la Langue française (s.a. b:38) den Text ausschnittweise und ohne Kennzeichnung der Auslassungen - dies vermutlich zugunsten einer stärkeren Wirkung bei der

55 Siehe hierzu auch Kapitel 5.2.

56 Siehe hierzu auch die Kapitel 5.3, 5.4 und 5.5. 
Das 20. und 21. Jahrhundert: eine Rückbesinnung auf die Verteidigung der Sprache

Leserschaft - in die Ausgabe 185, Juli-August-September 1997, ihrer vierteljährlich erscheinenden Revue auf: ${ }^{57}$

On n'entend que des mots à déchirer le fer, Le railway, le tunnel, le ballast, le tender, Express, trucks, wagons; une bouche française Semble broyer du verre ou mâcher de la braise... Certes, de nos voisins l'alliance m'enchante, Mais leur langue, à vrai dire, est trop envahissante ! Faut-il pour cimenter un merveilleux accord Changer l'arène en turf et le plaisir en sport, Demander à des clubs l'aimable causerie, Flétrir du nom de grooms nos valets d'écurie, Traiter nos cavaliers de gentlemen-riders?... Je maudis ces auteurs dont le vocabulaire Nous encombre de mots dont nous n'avons que faire. (Épitre à Boileau, 1853)

So war in Frankreich also spätestens das Fin de siècle bereits von einer Abwehrhaltung englischen Lehnwörtern gegenüber geprägt, wobei Bochmann (1993:57) auf den Punkt bringt, dass ,[...] der Kampf gegen das Fremdwort [meist aber] ein Teil der nationalen Selbstverständigung [ist] oder [...] der Abwehr einer als feindlich deklarierten Kultur [dient]." Es darf also davon ausgegangen werden, dass es sich bei der Ablehnung der Anglizismen in der französischen Sprache nicht nur um einen Machtkampf Französisch vs. Englisch handelte, sondern zugleich um einen Machtkampf Frankreich vs. England. Nach Ende des Zweiten Weltkriegs standen die Sprachnutzer des Französischen plötzlich einer ganz anderen Dimension des Anglizismenproblems gegenüber: Die USA hatten eine neue politische wie wirtschaftliche Vormachtstellung erlangt, wodurch nun nicht mehr nur aus England, sondern auch noch aus dem angloamerikanischen Sprachraum Lehnwörter in die französische Sprache übergingen. Von dieser Durchdringung waren zunächst vor allem die Fachsprachen betroffen. Müller (1975:30) sieht die Ursache hierfür darin, dass die Fachsprachen in der französischen Sprachpflege bereits seit dem 17. Jahrhundert durchgängig nur eine sekundäre Stellung innehatten. Durch diese Vernachlässigung

57 Obgleich die von der Défense de la Langue française ausgewählten Passagen der Épitre bestens Aufschluss über die damals in Frankreich dem Englischen entgegengebrachte Abneigung geben, soll es dennoch dem Original gestattet sein, seine beabsichtigte Gesamtwirkung zu entfalten; der vollständige Originaltext findet sich daher im Anhang, Kapitel 8.3. 
der Fachterminologien bestand nun in Frankreich ausreichend Raum und Bedarf, um englischen Lehnwörtern ihren Vormarsch zu ermöglichen, mussten doch durch zahlreiche Innovationen, so z.B. im Bereich der Technik, der Wirtschaft, der Biologie, der Medizin, der Luftfahrt usw., viele neue Kommunikationsbereiche abgedeckt werden, denen die französische Sprache selber aufgrund ihres mangelnden Ausbaus nicht genügend Kommunikationspotenzial entgegenbringen konnte - dies als Ursprung der crise du français.

\subsection{Die gesetzliche Grundlage moderner sprachpflegerischer Maßnahmen}

Während nun schon etwa ab den 1920er Jahren erste private wie auch vom Staat ins Leben gerufene Sprachpflegeorganisationen diese Defizite in der fachsprachlichen Lexik erkannten und infolgedessen begannen, dem starken Einfluss der englischen Sprache auf die französische mit der Umsetzung entsprechender Maßnahmen entgegenzuwirken $^{58}$, wurde erst in den 1970er Jahren ein erstes und in den 1990er Jahren ein zweites Gesetz zum gezielten Schutz des Französischen erlassen: Die Loi $n^{\circ} 75$ 1349 du 31 décembre 1975 relative à l'emploi de la langue française, besser bekannt unter dem Namen Loi Bas-Lauriol war das erste Sprachgesetz in Frankreich, das mit der Zielsetzung verabschiedet wurde, einen sprachlichen Konsumenten- und Arbeitnehmerschutz zu gewährleisten. Das zweite Sprachgesetz des 20. Jahrhunderts, die Loi $n^{\circ}$ 94-665 du 4 août 1994 relative à l'emploi de la langue française, meist kurz als Loi Toubon bezeichnet, stellt weitgehend eine Modifizierung der Loi Bas-Lauriol im Sinne einer Verschärfung dar.

\subsubsection{Die Loi $n^{\circ}$ 75-1349 du 31 décembre 1975 relative à l'emploi de la langue française (Die Loi Bas-Lauriol) ${ }^{59}$}

Die Loi Bas-Lauriol war ein streng gefasstes Gesetz, das unter Strafandrohung den ausschließlichen Gebrauch der französischen Sprache in allen Domänen der öffentlichen oder kommerziellen Kommunikation vorschrieb, sofern das Kommunikationspotenzial der französischen Sprache dies in irgendeiner Form erlaubte. Dies schloss gemeinsprachliche wie fachsprachliche Kontexte ein. Auf fremdsprachige

58 Siehe hierzu auch die Kapitel 5.4 und 5.5.

59 Der vollständige Gesetzestext der Loi Bas-Lauriol findet sich im Anhang, Kapitel 8.4. 
Begriffe durfte laut der Loi Bas-Lauriol nur in Ausnahmefällen ausgewichen werden: beispielsweise falls die französische Sprache tatsächlich eine Sprachlücke aufweisen sollte, die den Rückgriff auf ein fremdsprachiges Element unumgänglich machte; oder aber falls die betreffende Kommunikation typisch ausländische Produkte betraf, die z.B. eine geschützte Herkunftsbezeichnung trugen oder aus einem anderen Grund der breiten französischen Allgemeinheit hauptsächlich unter der fremdsprachigen Bezeichnung bekannt waren - so der Artikel 2 des Gesetzes. Sämtlichen durch das Gesetz betroffenen französischsprachigen Dokumenten durften allerdings bei Bedarf eine oder mehrere fremdsprachige Übersetzungen beigefügt werden. Im Normalfall einer einsprachigen Kommunikation galt aber jedenfalls der Gebrauch des Französischen als verpflichtend, z.B. wie im Artikel 1 des Gesetzes angegeben im Bezug auf alle für den Handel in irgendeinem Sinne relevanten Dokumente. Dies betraf z.B. Werbematerial sowohl zur Verkaufsförderung von Produkten als auch von Dienstleistungen, Gebrauchsanweisungen, Garantiescheine, Rechnungen, Zahlungsbestätigungen usw. Selbiges galt für alle Nachrichten und Programmankündigungen im Rundfunk sowie im Fernsehen, es sei denn, diese richteten sich ausdrücklich ausschließlich an ein fremdsprachiges Publikum. Die Artikel 4 und 5 des Gesetzes legten fest, dass alle Arbeitsverträge, die innerhalb des französischen Staatsgebietes abgeschlossen wurden und denen dort nachzukommen war, ebenfalls ausschließlich in französischer Sprache abgefasst sein durften, es sei denn, einer der oben genannten Ausnahmefälle traf zu. Der Artikel 6 verpflichtete schließlich alle öffentlichen Einrichtungen, wie Behörden, Schulen, Krankenhäuser usw., aber beispielsweise auch die Betreiber öffentlicher Transportmittel, alle mitgeteilten Informationen, z.B. auf Informationsschildern, Wegweisern, Warnaufklebern usw., zunächst auf Französisch anzubringen; bei Bedarf waren zur Ergänzung auch hier fremdsprachige Übersetzungen gestattet. Laut Artikel 8 waren schließlich alle Behörden dazu verpflichtet, sämtliche Vertragsabschlüsse unabhängig von der Person des Vertragspartners - selbst wenn dessen Mutter- oder Amtssprache nicht Französisch war - ausschließlich auf Französisch abzuwickeln. Übersetzungen der betreffenden Verträge in andere Sprachen waren wieder gestattet. Trotz aller demonstrierter Strenge erwies sich die Loi Bas-Lauriol allerdings als nicht sonderlich wirkungsvoll. Deshalb erfolgte 1994 eine Neuformulierung der Loi Bas-Lauriol in Form der Loi Toubon (vgl. Klare 1999:38). 
Das 20. und 21. Jahrhundert: eine Rückbesinnung auf die Verteidigung der Sprache

\subsubsection{Die Loi $n^{\circ}$ 94-665 du 4 août 1994 relative à l'emploi de la langue française (Die Loi Toubon) ${ }^{60}$}

Die Loi Toubon hat den Zweck, gegen die Abwertung des Französischen im Rahmen der internationalen Fachkommunikation vorzugehen, den Status des Französischen im Bildungs- und Wissenschaftsbetrieb zu erhalten und zugleich dem zunehmenden Gebrauch von Lehnwörtern in allen Domänen entgegenzusteuern. Teilweise entspricht sie in ihrer Aussage exakt der Loi Bas-Lauriol, betrifft wie das Vorgängergesetz gemein- wie fachsprachliche Kontexte, bringt allerdings auch zusätzliche Perspektiven in die Sprachgesetzgebung ein: Sie präzisiert beispielsweise zunächst im Artikel 1, dass in Frankreich im Unterrichtswesen wie auch in allen durch das Arbeitsrecht geregelten Bereichen die französische Sprache das einzig zulässige Kommunikationsmittel sei. Auch in allen Zusammenhängen behördlicher Kommunikation dürfe ausschließlich die französische Sprache verwendet werden. Übersetzungen mündlich oder schriftlich kommunizierter französischer Texte seien bei Bedarf zwar weiterhin in allen Domänen erlaubt, haben nun aber laut Artikel 4 in mindestens zwei Fremdsprachen zu erfolgen, sofern sie im öffentlichen Raum kommuniziert würden. Im Weiteren fixiert das Gesetz in seinem Artikel 6, dass bei in Frankreich abgehaltenen wissenschaftlichen Kongressen sowie ähnlichen Veranstaltungen die französische Sprache nicht als Arbeitssprache ausgeschlossen werden darf. Mit anderen Worten: Jeder einzelne frankophone Teilnehmer einer in Frankreich abgehaltenen Veranstaltung hat das Recht auf französischsprachige Kommunikation. Nur wenn ausschließlich fremdsprachige Teilnehmer verzeichnet werden, darf Französisch als Arbeitssprache ausgeklammert werden. Der Artikel 7 sieht vor, dass allen staatlich subventionierten Veröffentlichungen in Frankreich, sofern sie in einer Fremdsprache abgefasst sind, zumindest eine französische $\mathrm{Zu}$ sammenfassung beigefügt werden muss. Von öffentlicher Hand publizierte Texte müssen, sofern sie fremdsprachige Elemente enthalten, mit einer französischen Übersetzung oder einer Paraphrase des fremdsprachigen Elements versehen werden. Im Bildungswesen sind laut Artikel 11 sowohl der Unterricht, als auch Prüfungen und Aufnahmeverfahren in französischer Sprache abzuwickeln, sofern es sich nicht ausgerechnet um den Fremdsprachenunterricht bzw. um von Grund auf anderssprachige Schulen handelt. Ebenso sind sämtliche Abschlussarbeiten zur Erlangung akademischer Grade auf Französisch einzubringen. Ausnahmen können nur in besonderen Fällen geltend gemacht werden. Der Artikel 12 schreibt vor, dass sämtli-

60 Der vollständige Gesetzestext der Loi Toubon findet sich im Anhang, Kapitel 8.5. 
che Radio- und Fernsehprogramme auf Französisch zu senden seien; ausgenommen sind allerdings Übertragungen kultureller Veranstaltungen aus anderen Ländern, sprachedukative Programme, Kinofilme in Originalversion, Lieder mit anderssprachigen Texten etc.

Die heute vorliegende Loi Toubon ist trotz ihrer zahlreichen Bestimmungen zum Schutz des Französischen allerdings lediglich eine entschärfte Fassung eines anderen Gesetzesentwurfs: In ihrer ursprünglichen Fassung sah die Loi Toubon nämlich vor, nicht nur öffentliche Personen, sondern auch Privatpersonen beim unerlaubten Gebrauch von Fremdwörtern rechtlich zu belangen. Da dies gegen das Recht auf freie Meinungsäußerung verstoßen hätte, wurde der erste Gesetzesentwurf jedoch im Rahmen einer Verfassungsklage vor dem Conseil constitutionnel abgelehnt, woraufhin der derzeit gültige Gesetzestext in Kraft trat (vgl. Braselmann 2001:167). Wie allerdings bereits eingangs in diesem Abschnitt erwähnt, ist das Gesetz nicht die einzige Instanz, die in Frankreich über den Zustand, die Pflege und die gesetzes- sowie sprachnormkonforme Verwendung der französischen Sprache wacht: Zahllose Sprachpflegeorganisationen privater oder staatlicher Natur befassen sich mit dem Wohl der französischen Sprache. Das folgende Kapitel ist den nicht-staatlichen Sprachpflegegesellschaften gewidmet; das Kapitel 5.5 befasst sich mit den staatlichen Sprachpflegeorganisationen und Terminologiekommissionen.

\subsection{Private Sprachpflegegesellschaften in Frankreich und ihre Aktivitäten}

Es gibt wohl in keinem anderen Land eine so vielfältige sprachpflegerische Landschaft wie in Frankreich: Neben den staatlich veranlassten Gründungen von sprachpflegerisch tätigen Einrichtungen ${ }^{61}$ haben sich in Frankreich zahlreiche privat organisierte Sprachpflegegesellschaften in Form von Vereinen, Komitees, Sprachzentren, Kommissionen, Räten, Verbänden, Instituten, Büros, Gesellschaften, Delegationen usw. zur Pflege, zum Schutz und gelegentlich gar zur Rettung oder zur Verteidigung der französischen Sprache herausgebildet. Um einen Überblick über all diese privaten Sprachpflegegesellschaften zu erlangen, ist die Konsultation des Répertoire des Organismes et Associations oeuvrant pour la Promotion de la Langue française hilfreich, im Allgemeinen - so auch in der vorliegenden Arbeit - kurz als Répertoire bezeichnet. Dieses Werk stellt das wohl umfassendste Verzeichnis

61 Siehe hierzu auch Kapitel 5.5. 
Das 20. und 21. Jahrhundert: eine Rückbesinnung auf die Verteidigung der Sprache

staatlicher wie auch privater Einrichtungen zur Pflege der französischen Sprache innerhalb und außerhalb Frankreichs dar und schildert deren Zielsetzungen und Aktivitäten. ${ }^{62}$ Der Répertoire von 2001 verzeichnet insgesamt 348 solcher sprachpflegerisch tätiger Einrichtungen: Davon sind zwanzig der Frankophonie zugehörig und damit supranational organisiert, dreißig sind staatliche Organisationen der Republik Frankreich, und 298 sind privater Natur. Betrachtet man ihre Tätigkeitsfelder im Detail, so ergibt sich eine Zahl von sechs staatlichen Organisationen, die sich insbesondere der Pflege der Fachsprachen widmen. Weiters finden sich 25 private Sprachpflegegesellschaften, die in irgendeiner Form im Bereich der Fachsprachen tätig sind. Im Allgemeinen lässt sich jedoch feststellen, dass die Fachsprachen bei den privaten Sprachpflegegesellschaften häufig lediglich gestreift werden, beispielsweise durch die Herstellung eines beruflichen Netzwerkes für die Angehörigen eines bestimmten Faches o.ä., bzw. dass sich die privaten Sprachpflegegesellschaften generell anderen Arbeitsschwerpunkten widmen. Zu den am häufigsten genannten gehören beispielsweise die Pflege der französischen Gemeinsprache, die Kultivierung und Verbreitung der französischen Lebensart, die Förderung französischsprachiger Literatur, die Förderung einer eigenständigen kulturellen Produktion in Frankreich, der Ausbau französischer Sprachkompetenzen bei Personen französischer und anderer Muttersprache innerhalb wie außerhalb Frankreichs, die Förderung des kulturellen Austausches zwischen verschiedenen Ländern bzw. verschiedenen Religionen, etc. Abschließend ist nun zu betonen, dass der Répertoire nicht als vollständige Bestandsaufnahme aller Einrichtungen zur Sprachpflege betrachtet werden kann, da es zum Zeitpunkt der Redaktion des Répertoire zum einen den Sprachpflegegesellschaften selber oblag, sich bei Wunsch entweder mit oder ohne exakte Beschreibung der Tätigkeitsfelder eintragen zu lassen - oder eben auch nicht; zum anderen wurden nicht alle Einrichtungen in den Répertoire aufgenommen, die dies wünschten (vgl. Délégation générale à la langue française 2001:5ff).

Die folgenden Kapitel geben nun in alphabetischer Reihenfolge einen Überblick über die genannten 25 privaten Sprachpflegegesellschaften, die sich laut dem

62 Für die vorliegende Arbeit wurde die fünfte Auflage des Répertoire aus dem Jahr 2001 zu Rate gezogen. Eine Rückfrage bei der Délégation générale à la langue française et aux langues de France $(D G L F L F)$ als herausgebende Institution hat ergeben, dass derzeit keine neuere Auflage des Répertoire erhältlich ist und selbst der DGLFLF keine tagesaktuelle vollständige Liste der Einrichtungen zur Pflege der französischen Sprache vorliegt. An dieser Stelle ein herzlicher Dank an Madame Renée Zuza von der Mission du développement et de l'enrichissement de la langue française der DGLFLF für sämtliche Auskünfte und die freundliche Zusendung umfangreichen Informationsmaterials. 
Répertoire von 2001 mit der Pflege der Fachsprachen befassen. ${ }^{63}$ Eine zum Zeitpunkt der Entstehung der vorliegenden Arbeit vom Répertoire unabhängig durchgeführte Recherche hat ergeben, dass ein Großteil der genannten Gesellschaften nach wie vor aktiv ist. Eine Gesellschaft - nämlich die im Kapitel 5.4.25 behandelte UITF - wurde 2003 allerdings umbenannt. Außerdem konnte in drei Fällen nicht festgestellt werden, inwiefern bzw. ob die betreffenden Einrichtungen noch ihren Aktivitäten nachgehen; dies wurde in den jeweiligen Kapiteln vermerkt.

\subsubsection{Actions pour promouvoir le français des affaires (APFA)}

Die 1984 gegründete Einrichtung APFA hat es sich zum Ziel gesetzt, die Fachsprache Wirtschaft generell bekannter zu machen und bei Bedarf die Verwendung bestimmter französischer Neologismen dieser Fachsprache gezielt bei den Sprachnutzern zu bewerben. Weiters möchte die Vereinigung unter Beweis stellen, dass es durchaus möglich ist, alle fachlichen Inhalte aus Fremdsprachen unter Beibehaltung einer ausschließlich französischen Terminologie in die französische Sprache zu übersetzen (vgl. DGLF 2001:49).

\subsubsection{Association française de normalisation en matière de langage technique (AFNOR)}

Die AFNOR, 1926 gegründet, verfolgt das Ziel, die Erstellung neuer Terminologienormen in diversen Arbeitsbereichen ebenso wie deren Anwendung in der Praxis zu fördern. Die AFNOR bemüht sich hierin um Einfluss in allen Bereichen der Wirtschaft, vor allem aber in der Grundstoffindustrie, im Bereich industrieller Ausrüstungsgegenstände, des Firmenmanagements, der neuen Informationstechnologien und moderner Dienstleistungsangebote. Indem sich die AFNOR für eine Förderung der französischen Sprache einsetzt, sorgt sie laut eigenen Informationen zugleich für die Aufrechterhaltung bzw. Verbesserung der Lebensqualität in Frankreich; dies erklärt sich daraus, dass für die Sprecher des Französischen die Möglichkeit, sich im eigenen Land in ihrer Sprache universell ausdrücken zu können, unmittelbaren Einfluss auf das Wohlbefinden und die wahrgenommene Lebensqualität hat. Die $A F$ NOR führt diese Aufgaben aus, indem sie französischen Sprachexperten beratend

63 Der Fokus dieses Überblicks liegt auf den Zielen und Aktivitäten der Vereinigungen. Weitere Informationen, so z.B. zu Preisverleihungen, Veranstaltungen oder den Publikationsorganen der privaten Sprachpflegegesellschaften, finden sich im Répertoire bei den Einzelbeschreibungen der jeweiligen Einrichtungen. 
zur Seite steht und so in Frankreich und ganz Europa aktiv an den Prozessen der Terminologienormung teilnimmt. Zugunsten einer Vereinheitlichung der Fachterminologien publiziert sie natürlich auch die Ergebnisse ihrer Arbeit (vgl. DGLF 2001:63). Laut Müller (1975:27f) bearbeitete die staatlich geförderte AFNOR in der Zeit von ihrer Gründung bis 1975 ca. 30000 Termini, indem sie Vorschläge zum Ersatz fremdsprachiger Fachbegriffe durch französische einbrachte. Diese Fachwörter wurden in mit Definitionen versehenen Fachlisten veröffentlicht, um so eine vereinfachte Fachkommunikation innerhalb der Fächer zu fördern.

\subsubsection{Association française des Presses d'Université (AFPU) und die ihr zugehörige Association française des Presses d'Université Diffusion (AFPU - D)}

Die beiden zusammengehörigen Organisationen setzen sich in Arbeitsteilung für eine vermehrte Veröffentlichung wissenschaftlicher Werke in französischer Sprache ein (so vor allem die 1977 gegründete $A F P U$ ) und bemühen sich außerdem um den effizienteren Vertrieb universitärer Literatur (vor allem die 1993 gegründete $A F P U$ $D$ ), womit sie einen Beitrag zur wissenschaftlichen Fachkommunikation leisten (vgl. DGLF 2001:64).

\subsubsection{Association francophone des Professionnels de l'Aéronautique (Courrier sud)}

Diese seit 2000 aktive Vereinigung setzt sich für mehr Sicherheit im Flugbetrieb durch die Verteidigung des Gebrauchs der französischen Sprache in der Luftfahrt ein. $\mathrm{Zu}$ diesem Zweck stellt sie ein Netzwerk zwischen französischsprachigen Personen, die in der Luftfahrt beschäftigt sind, her und fördert jegliche technische Forschung, die einer Steigerung der Flugsicherheit dienlich sein könnte. Parallel dazu setzt sie sich für einen Dialog mit der nicht-französischsprachigen Luftfahrt zum Abbau kommunikativer Hindernisse in der sprachübergreifenden Fachkommunikation ein und bemüht sich um eine Imagesteigerung der französischen Luftfahrt (vgl. DGLF 2001:69).

\subsubsection{Association des Informaticiens de Langue française (AILF)}

Die AILF bemüht sich seit 1981 um einen Austausch zwischen Informatikern und all jenen, die Produkte oder Dienstleistungen aus dem Bereich der modernen Datenver- 
arbeitung nutzen. So sollen Informationen gesammelt werden, die darüber Aufschluss geben, inwiefern die zunehmende Präsenz der Informatik im Alltag Konsequenzen für die kulturelle, aber auch für die linguistische Entwicklung Frankreichs hat (vgl. DGLF 2001:71).

\subsubsection{Association internationale des Amis du Français, Langue olympique et sportive (AIAFLOS)}

Die AIAFLOS wurde gegründet, um den Stellenwert und die Präsenz des Französischen bei den Olympischen Spielen bzw. insgesamt im Bereich des Sports zu verteidigen und ist laut dem Répertoire Mitglied der AFAL, der Association Francophone d'Amitié et de Liaison (vgl. DGLF 2001:72). Diese wiederum ist ein Zusammenschluss diverser frankophoner Organisationen mit unterschiedlichen Arbeitsschwerpunkten und Interessen. Sie nennt allerdings die AIAFLOS nicht in der Liste ihrer aktuellen Mitglieder (vgl. AFAL s.a.:Le répertoire de nos membres). Weiters war bei einer Recherche im April 2012 keine der AIAFLOS zugehörige Website auffindbar, und die im Répertoire von 2001 angegebenen Kontaktdaten der Vereinigung scheinen ebenfalls nicht mehr aktuell zu sein, womit zum Entstehungszeitpunkt der vorliegenden Arbeit unklar ist, ob die AIAFLOS noch existiert.

\subsubsection{Association internationale des Démographes de Langue française $(A I D E L F)$}

Die 1978 gegründete $A I D E L F$ widmet sich der Ausarbeitung demographischer Studien und setzt sich für eine Imagesteigerung der Demographie ein. Weiters verteidigt sie aber auch die französische Sprache innerhalb des Fachs, indem sie sich für die Verwendung des Französischen in Fachpublikationen und bei internationalen Kongressen einsetzt. Darüber hinaus publiziert sie eigene französischsprachige Fachzeitschriften (vgl. DGLF 2001:73).

\subsubsection{Association internationale des Écoles en Sciences de l'Information (AIESI)}

Die AIESI ist ein 1977 gegründeter Verband von Ausbildungseinrichtungen mit dem Schwerpunkt Informatik, tritt als solcher aber nicht nur für eine verbesserte Ausbildung in ihrem Fachbereich ein, sondern auch für eine gezielte Stimulation der französischen Fachsprachenforschung in diesem Bereich (vgl. DGLF 2001:73). 
Das 20. und 21. Jahrhundert: eine Rückbesinnung auf die Verteidigung der Sprache

\subsubsection{Association internationale des Sociologues de Langue française (AISLF)}

Die AISLF, 1958 gegründet und 1963 offizialisiert, setzt sich in linguistischer Hinsicht vor allem für die Fachkommunikation und die Vulgarisierung von Fachwissen ein. So widmet sie sich zum einen der Erforschung soziologischer Sachverhalte, bemüht sich zum anderen im Rahmen eines zweiten Arbeitsschwerpunkts aber auch gezielt um eine einfachere französischsprachige Fachkommunikation zwischen Soziologen. Parallel dazu versucht sie, fachsprachliche Inhalte in vereinfachter Form einer breiten Öffentlichkeit zu vermitteln. Ihr übergeordnetes, alle Fächer betreffendes Ziel ist eine Verbesserung des Status der französischen Sprache als Wissenschaftssprache (vgl. DGLF 2001:75).

\subsubsection{Association des jeunes Scientifiques francophones}

Diese Vereinigung wurde 1995 gegründet, um junge frankophone Wissenschaftler zur Diskussion von Fragestellungen rund um die Frankophonie zu motivieren und hierin eine Schnittstelle zwischen französischsprachigen Institutionen und der Wissenschaft darzustellen. $\mathrm{Zu}$ den Zielen gehörte unter anderem die Bereitstellung eines beruflichen Netzwerks, um Nachwuchswissenschaftler über zusätzliche Ausbildungsmöglichkeiten und die Entwicklung der Wissenschaft an sich zu informieren. Wissenschaftliche Innovationen und der wissenschaftliche Austausch sollten ebenso gefördert werden wie das Französische als Wissenschaftssprache. In diesem Sinne wurden junge Wissenschaftler dazu ermutigt, ihre Fachpublikationen in französischer Sprache abzufassen (vgl. DGLF 2001:77). Zum Entstehungszeitpunkt der vorliegenden Arbeit konnte im Rahmen einer Recherche allerdings keine der Vereinigung zugehörige Website aufgefunden werden, und auch die im Répertoire von 2001 angegebenen Kontaktdaten scheinen nicht mehr aktuell zu sein. Es ist daher nicht auszuschließen, dass die Vereinigung inzwischen aufgelöst wurde.

\subsubsection{Association nationale des Scientifiques pour l'Usage de la Langue française (ANSULF)}

Die 1981 gegründete $A N S U L F$ sieht sich als Vereinigung jener Wissenschaftler, die es als Teil ihrer Verantwortung betrachten, die französische Sprache und deren Ausdruckskraft durch den nationalen und internationalen wissenschaftlichen Austausch auszubauen. Dabei sollen zugleich Beziehungen zu unterschiedlichsten Organisatio- 
nen in Frankreich und außerhalb gepflegt werden, die eine weitere Verbreitung des Französischen in der schriftlichen und mündlichen Fachkommunikation begünstigen könnten (vgl. DGLF 2001:79).

\subsubsection{Centre Audiovisuel de Langues modernes (CAVILAM)}

Dieses seit 1964 betriebene Sprachbildungszentrum hat es sich zum Ziel gesetzt, mittels gemeinsprachlich und fachsprachlich orientierter Sprachkurse die Qualität des Sprachgebrauchs bei frankophonen Sprachnutzern anzuheben. So werden Einzelkurse, Gruppenkurse, Firmenkurse und spezielle studienvorbereitende Kurse angeboten, die unter anderem einen Fokus auf die Fachsprachen der Diplomatie, der internationalen Politik, der Medizin, der Agronomie und der Nuklearenergie legen (vgl. DGLF 2001:87).

\subsubsection{Comité d'étude des termes techniques français (CETTF)}

Das Komitee setzt sich seit 1954 für eine Schließung sprachlicher Lücken im französischen Fachwortschatz ein, indem es neugebildete französische Wörter als Ersatz für in die Fachsprachen eingeflossene Lehnwörter vorschlägt bzw. auf die Möglichkeit des Gebrauchs bereits bestehender französischer Fachtermini hinweist. Dies geschieht in Zusammenarbeit mit Gewerkschaften, Wissenschaftlern, der Industrie und dem Handel. Zugleich will das Komitee zu einer Neustrukturierung, Vereinfachung und Perfektionierung der Fachsprachen anregen (vgl. DGLF 2001:93).

\subsubsection{Comité Universitaire francophone pour le Développement des Échanges scientifiques (CUFDES)}

Dieses Komitee, gegründet 1967, setzt sich dafür ein, dass vermehrt englische Fachtexte aus den Bereichen der Pädagogik, der Wissenschaft und der Technik ins Französische übersetzt und so französischen Sprachnutzern in ihrer Muttersprache zur Verfügung gestellt werden (vgl. DGLF 2001:95).

\subsubsection{Conseil international de la langue française (CILF)}

Der 1968 ins Leben gerufene $C I L F$ setzt sich für einen verstärkten Dialog zwischen dem Französischen und anderen Sprachen ein und steht damit im Zeichen der Sprachenvielfalt. Außerdem widmet er sich der Pflege des Kommunikationspotenzials 
der französischen Sprache (vgl. DGLF 2001:99). Müller (1975:28) erläutert weiters, dass sich der CILF der Sprachpflege unter dem Gesichtspunkt widmet, dass die französische Sprache an das moderne Leben anzupassen sei. Zu diesem Zweck arbeitet der CILF Fachterminologien aus, die sowohl in Frankreich als auch im französischsprachigen Ausland veröffentlicht werden. Das Ziel ist eine supranationale Vereinheitlichung fachlicher Terminologien.

\subsubsection{Défense de la Langue française}

Das Hauptziel der 1958 gegründeten Défense de la Langue française ist es sicherzustellen, dass alle Sprachnutzer des Französischen ausreichend Zugang zu Informationen aller Art in ihrer Muttersprache haben und sich jederzeit auf Französisch ausdrücken können. Dabei überwacht die Défense de la Langue française auch die Einhaltung des richtigen Sprachgebrauchs und der französischen Sprachgesetzgebung $^{64}$. Hierzu gehört laut der Selbstbeschreibung der Vereinigung im Répertoire (DGLF 2001:100) auch die Eindämmung der, ,invasion anarchique des mots étrangers", von der die französische Sprache betroffen sei. Zugleich sieht es die Vereinigung als ihre Aufgabe, die französische Sprache gezielt um Neologismen des modernen Lebens zu bereichern, um sie dem gegenwärtigen Kommunikationsbedarf anzupassen. $\mathrm{Zu}$ guter Letzt bemüht sich die Défense de la Langue française um einen Imagegewinn für das Französische in nicht-frankophonen Ländern. Was die Verteidigung des Französischen gegen die „Invasion von Fremdwörtern“ betrifft, so bezieht sich diese laut Müller (1975:27) vor allem auf jene Terminologien, die bekanntlich besonders stark vom Englischen durchsetzt werden. Der Website der Vereinigung (vgl. Défense de la Langue française s.a. a:Activités de l'Association), die unter dem Patronat der Académie française gegründet wurde, ist zu entnehmen, dass sie sich vor allem der Sprachpflege des Französischen in den Fachsprachen Medizin, Technik, Sport und Freizeit sowie der Wissenschaftssprache widmet.

\subsubsection{Groupe d'Études et de Recherches pour le Développement des Sciences Sociales (GERDES)}

Diese Vereinigung befasst sich seit ihrer Gründung 1966 mit Studien zum Verlagsund Gesundheitswesen, zum Konsumverhalten sowie anderen Bereichen der Wissenschaft. Außerdem arbeitet sie an einer speziell auf die französischen Fachspra-

64 Siehe hierzu auch Kapitel 5.3. 
chen abgestimmten Software zur Erstellung fachsprachlicher Glossare. Generell setzt sich die Vereinigung für den Status des Französischen als Wissenschaftssprache ein (vgl. DGLF 2001:112).

\subsubsection{Groupement des Associations dentaires francophones (GADEF)}

Der GADEF vereint seit 1971 mehrere frankophone Mitgliedsstaaten, hat seinen Sitz in Paris und widmet sich in erster Linie dem wissenschaftlichen Fortschritt innerhalb der Zahnmedizin. Als zweite Zielsetzung gibt die Vereinigung allerdings die Verteidigung der französischen Sprache innerhalb des Fachbereichs sowie dessen Weiterentwicklung im fachsprachlichen Kontext an. Die Motivation hierfür ist der Wunsch nach einer verbesserten Fachkommunikation (vgl. DGLF 2001:113).

\subsubsection{Institut français de l'Emballage et du Conditionnement (IFEC- Promotion)}

Dieses 1951 gegründete Institut widmet sich der fachlichen Entwicklungsarbeit im Bereich der Verpackungstechnik sowie dem Ausbau der Terminologie des Fachbereichs. Zugleich setzt es sich für einen vermehrten Einsatz der französischen Sprache in der Kommunikation rund um Fragen der Verpackungstechnik ein (vgl. DGLF 2001:114).

\subsubsection{Institut francophone de Paris (IFP)}

Die Hauptaktivität des 1974 gegründeten IFP ist die Bereitstellung eines Netzwerks für französischsprachige Wissenschaftler verschiedener Disziplinen, um zwischen ihnen einen fachlichen Austausch sowie die Entstehung von Freundschaften zu fördern. Weiters setzt sich das IFP auf internationalem Niveau für einen vermehrten Gebrauch des Französischen in der Literatur, der Wissenschaft und der Technik ein (vgl. DGLF 2001:115).

\subsubsection{Ligue internationale des Scientifiques pour l'Usage de la Langue française $(L I S U L F)$}

Die 1988 gegründete LISULF arbeitet grenzüberschreitend in Frankreich, Belgien und Kanada. Sie ist ein Forum für Wissenschaftler und Laien, die sich mit dem Einsatz des Französischen in der wissenschaftlichen Kommunikation auseinanderset- 
zen. Weiters versucht die $L I S U L F$, Vertreter der Wissenschaft dazu anzuregen, in der Fachkommunikation verstärkt auf die französische Sprache zurückzugreifen (vgl. DGLF 2001:117).

\subsubsection{La Renaissance française}

Diese bereits 1916 gegründete Vereinigung sieht sich als Interessensvertretung der französischen Sprache sowie der französischen Kultur sowohl in Frankreich als auch in den anderen Staaten der Frankophonie. Darüber hinaus widmet sie sich der Bereicherung der Sprache in verschiedenen Handwerken, technischen Fächern und der Wissenschaft im Allgemeinen. Die Vereinigung, die jegliches politische Engagement von sich weist, ist in Form von Regionalgruppen nicht nur in ganz Frankreich, sondern auch in anderen frankophonen Ländern vertreten (vgl. DGLF 2001:122).

\subsubsection{Société d'Ethnographie de Paris}

Diese schon im Jahr 1859 ins Leben gerufene Gesellschaft setzte sich laut dem Répertoire von 2001 gezielt für die weitere Verbreitung des Französischen in den Disziplinen der Anthropologie, der Ethnologie und der Soziologie ein, wozu ihr als Publikationsorgan die französischsprachige Fachzeitschrift L'Ethnographie diente (vgl. DGLF 2001:125). Die AFAL, der die Société d'Ethnographie de Paris 2001 noch angehörte, nennt die Gesellschaft allerdings nicht in der Liste ihrer aktuellen Mitglieder (vgl. AFAL s.a.:Le répertoire de nos membres). Zugleich beziehen sich allerdings die im Répertoire angegebenen Kontaktdaten der Gesellschaft ausschließlich auf den Sitz der AFAL. Weiters war im Zuge einer Recherche keine der Société d'Ethnographie de Paris zugehörige Website auffindbar, womit zum Entstehungszeitpunkt der vorliegenden Arbeit nicht bekannt ist, ob die Société d'Ethnographie de Paris noch existiert.

\subsubsection{Société française de Terminologie}

Die Arbeit der Société française de Terminologie steht seit ihrer Gründung 1999 ganz im Zeichen der Förderung jeglicher Terminologiearbeit, aber auch verwandter Disziplinen der Sprachwissenschaft, wie z.B. der Lexikographie (vgl. DGLF 2001:125). 
Das 20. und 21. Jahrhundert: eine Rückbesinnung auf die Verteidigung der Sprache

\subsubsection{Union internationale des Ingénieurs et des Techniciens utilisant la Langue française (UITF)}

Im Prinzip sah sich die 1987 gegründete UITF laut ihrer Beschreibung im Répertoire von 2001 hauptsächlich als Berufsgruppenvereinigung für französischsprachige Ingenieure und Techniker, gab aber an, dass es auch zu ihren speziellen Aufgaben gehörte, die Mitglieder in einer zielführenden Verwendung der französischen Sprache in einem beruflichen Kontext zu unterstützen. Die UITF informierte jedoch leider im Weiteren nicht darüber, wie diese fachsprachliche Unterstützung konkret geleistet wurde (vgl. DGLF 2001:130). Inzwischen wurde die UITF mit August 2003 durch die sogenannte Union Internationale des Ingénieurs et des Scientifiques utilisant la Langue française, kurz UISF, ersetzt. Auf ihrer Website gibt die UISF an, ihre Hauptziele seien es, den fachlichen Austausch, die Zusammenarbeit und die Umsetzung diverser Projekte auf nationaler und internationaler Ebene zu fördern (vgl. UISF s.a.:Qu'est-ce que l’UISF?).

Insgesamt lässt sich feststellen, dass die Initiativen der beschriebenen Vereinigungen zur Pflege der Fachsprachen im Großen und Ganzen durchaus gut reflektiert und koordiniert zu sein scheinen: Schlagwörter wie Vernetzung, Austausch und Zusammenarbeit spielen - wie den obigen Kurzbeschreibungen entnommen werden kann für die meisten der Sprachpflegegesellschaften eine große Rolle. Dies lässt darauf schließen, dass ihre Mitglieder sprachpflegerisches Handeln als kollektive Aufgabe betrachten - und wie zu vermuten ist auch als eine moralische Verpflichtung, die angesichts der oft proklamierten und als bedrohlich empfundenen crise du français wohl besonderes Gewicht hat.

\subsection{Staatliche Sprachpflegeorganisationen in Frankreich und ihre Aktivitäten}

Der französische Staat steht der Notwendigkeit der Sprachpflege ähnlich gegenüber wie seine Bürger bzw. die privaten Sprachpflegegesellschaften und verleiht dieser Haltung bereits seit mehr als vierzig Jahren ebenfalls durch die Gründung von Sprachpflegeorganisationen Ausdruck. Diese erzielen mit den Ergebnissen ihrer Arbeit zwar bei weitem nicht immer eine umfassende Akzeptanz seitens der 
Das 20. und 21. Jahrhundert: eine Rückbesinnung auf die Verteidigung der Sprache

Sprachnutzer ${ }^{65}$, genießen aber doch eine gewisse Autorität. Settekorn (1988:107) bringt auf den Punkt, weswegen:

Allgemein wächst das Gewicht einer öffentlichen politischen Handlung, wenn sie zur Behebung einer Krisensituation vollzogen wird. Besondere Situationen erfordern besondere Maßnahmen, oder zumindest solche, die nicht alle Tage getroffen würden. Dem behandelten Sachverhalt wird so eine nach außen getragene offizielle und gewichtige Deutung verliehen.

Die Krisensituation, die der Umsetzung sprachpolitischer Handlungen seitens des französischen Staates zugrunde liegt, ist der seit Beginn des 20. Jahrhunderts diagnostizierte Sprachverfall des Französischen. Als dessen Hauptursache werden die vor allem über die internationale Fachkommunikation in großer Zahl in die französischen Fachsprachen eindringenden und von dort aus weiter in die Gemeinsprache übergehenden Anglizismen betrachtet. ${ }^{66}$ Um diesen Automatismus zu unterbinden, rief der französische Staat im Lauf der Zeit verschiedene Sprachpflegeorganisationen ins Leben, die sich vor allem mit den sprachlichen Lücken im Fachvokabular zu befassen hatten und denen in chronologischer Reihenfolge ihrer Gründung die folgenden Kapitel gewidmet sind.

\subsubsection{Haut Comité pour la Défense et l'Expansion de la Langue française, 1966}

Der Haut Comité pour la Défense et l'Expansion de la Langue française wurde mittels eines Dekrets vom 31. März 1966 durch Georges Pompidou (1911-1974), der damals Premierminister war, und Charles de Gaulle (1890-1970), den damaligen Präsidenten, gegründet. Die Organisation wurde direkt dem Regierungschef unterstellt, was davon zeugte, dass die Sprachkrise vom Staat ernst genommen wurde, und sollte von Amts wegen den Status des Französischen als wichtigste offizielle Verkehrssprache in Europa verteidigen. Da man weltweit um den Status des Französischen fürchtete, sollte der Haut Comité pour la Défense et l'Expansion de la Langue française auch die Präsenz der französischen Sprache innerhalb der internationalen Organisationen sicherstellen. Noch dazu wurde - wohl in Anlehnung

65 Man denke in diesem Zusammenhang beispielsweise an die offiziell beschlossenen Fachtermini der ministeriellen Terminologiekommissionen, die sich häufig im Alltag der Sprecher nicht durchsetzen können. Siehe hierzu auch Kapitel 5.6.

66 Siehe hierzu auch Kapitel 5.2. 
an den Sprachpurismus des 17. Jahrhunderts - die Erhaltung von Einheit und Reinheit der Sprache als Ziel fixiert. Dem lag allerdings keine rein sprachkonservative Haltung zu Grunde: Die französische Sprache sollte durchaus dem modernen Leben angepasst und zu einer kommunikationsfähigen Sprache ausgebaut werden - nur eben ohne Rückgriffe auf englisches oder angloamerikanisches Wortmaterial. Vor allem in den Domänen der Technik, der Wissenschaft, der Industrie und des Handels war die französische Sprache damals nicht ausreichend konkurrenzfähig (vgl. Müller 1975:28). Der Haut Comité pour la Défense et l'Expansion de la Langue française übte seine Aufgaben bis 1973 unter diesem Namen aus, wurde dann unter Beibehaltung seiner Funktionen mittels Dekret vom 28. Februar 1973 in Haut Comité pour la Langue française umbenannt und blieb in Folge bis 1984 aktiv; dann wurde er aufgelöst und durch neue Sprachpflegeorganisationen ersetzt (vgl. Settekorn $1988: 102){ }^{67}$

\subsubsection{Association française de terminologie (AFTERM), 1975}

Die AFTERM wurde 1975 mit dem Ziel gegründet, alle durch private wie staatliche Sprachpflegeorganisationen bis dahin in fachterminologischer Hinsicht unternommenen Bemühungen besser zu koordinieren. Im Weiteren übernahm sie ab dem 3 . April 1978 auch die Supervision über die ministeriellen Terminologiekommissio-

nen. ${ }^{68}$ Zugleich sollte damit eine Trennlinie zwischen den innerfranzösischen terminologischen Bestrebungen und der supranational angelegten Frankophonie gezogen werden. Parallel zu alledem wurde die Idee einer großen französischsprachigen Terminologiedatenbank geboren, zu deren Planung die AFTERM 1979 zwar noch einen Projektentwurf anfertigte, aber zu deren Verwirklichung sie später nichts mehr beitragen konnte, wurde sie doch 1980 durch die neu gegründete FRANTERM ersetzt (vgl. Depecker 2001:28f).

\subsubsection{FRANTERM, 1980}

Der FRANTERM kamen im Grunde dieselben Aufgaben zu wie ihrer Vorgängerorganisation AFTERM: Sie sollte die ministeriellen Terminologiekommissionen in ihrer Arbeit koordinieren und sich zugleich mit der weiteren Planung der zukünftigen Terminologiedatenbank Banque française de terminologie befassen. Im Endef-

67 Siehe hierzu auch Kapitel 5.5.4.

68 Siehe hierzu auch Kapitel 5.5.6. 
fekt existierte die FRANTERM aber nicht lange genug, um große terminologische Erfolge im Ausbau der französischen Fachsprachen herbeizuführen: Bereits 1985 wurde die Organisation aufgelöst (vgl. Depecker 2001:29). Diesem Schritt war 1984 die Gründung neuer Sprachpflegeorganisationen unter der Präsidentschaft François Mitterrands vorausgegangen.

\subsubsection{Die neuen Sprachpflegeorganisationen von 1984}

Am 10. Mai 1981 war François Mitterrand zum neuen Staatspräsidenten gewählt worden. Unter ihm begann eine politische Ära intensivierter sprachpflegerischer Bemühungen, im Zuge derer am 24. August 1983 in einer Ministerratssitzung beschlossen wurde, dass der bereits erwähnte Haut Comité pour la Langue française ${ }^{69}$ aufzulösen und durch drei neue Sprachpflegeorganisationen zu ersetzen sei: den Commissariat général de la langue française, den Comité consultatif de la langue française und den Haut Conseil de la francophonie (vgl. Frey 2000:216f).

\subsubsection{Commissariat général de la langue française}

Dem Artikel 6 des Dekrets Nr. 84-91, veröffentlicht im Journal Officiel (Legifrance.gouv.fr - Le Service Public de la Diffusion du Droit s.a. c: Image JO du 10/02/1984, page: 00555) vom 10. Februar 1984, ist zu entnehmen, dass es zu den Aufgaben des Commissariat général de la langue française gehörte, ,[...] d'animer et de coordonner l'action des administrations et des organismes publics et privés qui concourent à la diffusion et à la défense de la langue française. [...]“; das bedeutete eine Übernahme der Aufgaben des Haut Comité pour la Langue française, schloss aber automatisch auch die Aufsicht über die ministeriellen Terminologiekommissionen ein, die bis dahin die bereits genannte Organisation FRANTERM ${ }^{70}$ ausgeübt hatte. Im Grunde war es somit die Gründung des Commissariat général de la langue française, welche die FRANTERM überflüssig machte.

\subsubsection{Comité consultatif de la langue française}

Der Artikel 2 des Dekrets Nr. 84-91, veröffentlicht im Journal Officiel (Legifrance.gouv.fr - Le Service Public de la Diffusion du Droit s.a. c: Image JO du

69 Siehe hierzu auch Kapitel 5.5.1.

70 Siehe hierzu auch Kapitel 5.5.3. 
Das 20. und 21. Jahrhundert: eine Rückbesinnung auf die Verteidigung der Sprache

10/02/1984, page: 00555) vom 10. Februar 1984, legte die Aufgaben des Comité consultatif de la langue française fest:

Art. 2. - Le comité consultatif de la langue française a pour mission d'étudier, dans le cadre des grandes orientations définies par le Président de la République et le Gouvernement, les questions relatives à l'usage et à la diffusion de la langue française, à la francophonie, aux langues de France et à la politique de la France vis-à-vis des langues étrangères. Il fait des propositions et des recommandations et donne son avis sur les questions dont il est saisi par le Premier ministre. Il entend le rapport d'activité du commissaire général de la langue française.

Der Comité consultatif de la langue française war also - wie auch der Commissariat général de la langue française - dem Amt des Premierministers unterstellt und sollte sich für den Schutz und die Verbreitung des Französischen einsetzen. Besonders erwähnenswert ist im Artikel 2 der Hinweis auf Fragen die ,langues de France“" betreffend. Damit widmete sich die französische Regierung erstmals in der Geschichte den Dialekten und Minderheitensprachen Frankreichs im Sinne einer Wertschätzung des Plurilingualismus im Lande; bis dahin - wie bereits in den Kapiteln zur Ordonnance de Villers-Cotterêts und zur Französischen Revolution angesprochen ${ }^{71}-$ sollten die Minderheitensprachen ja unterdrückt werden.

\subsubsection{Haut Conseil de la francophonie}

Der Haut Conseil de la francophonie war mit der Rolle der Frankophonie und der Bedeutung des Französischen als universell einsetzbare Sprache auf globaler Ebene befasst (vgl. Frey 2000:262). Im Jahr 2004 wurde diese zuvor noch direkt dem Präsidenten untergeordnete Organisation allerdings in Form des Conseil consultatif de la francophonie in die Organisation internationale de la francophonie (OIF) eingegliedert.

\subsubsection{Die neuen Sprachpflegeorganisationen von 1989}

Die Gründung der neuen Sprachpflegeorganisationen im Jahr 1989 ging im Grunde nicht auf eine Änderung der Sprachpolitik Frankreichs zurück, sondern schlichtweg auf einen Wechsel an der Regierungsspitze: Jacques Chirac, der bis zum 10. Mai

71 Siehe hierzu auch die Kapitel 2.2. bzw. 4.4.1. 
1988 unter François Mitterrand Premierminister war, hatte dessen 1984 gegründete Sprachpflegeorganisationen ${ }^{72}$ beibehalten. Nun wurde aber Michel Rocard zum neuen Regierungschef, was mit dem Dekret 89-403 vom 2. Juni 1989 zu einer erneuten Umstrukturierung der staatlichen Sprachpflegeorganisationen führte.

\subsubsection{Délégation générale à la langue française (DGLF)}

Die DGLF ersetzte den Commissariat général de la langue française und unterstand dem Kulturministerium. Ihre Aufgaben entsprachen weitgehend denen des Commissariat général de la langue française, umfassten also wieder unter anderem die Koordinierung anderer Institutionen in der Umsetzung der französischen Sprachpolitik. Die DGLF hatte also in koordinatorischer Funktion Anteil an der Terminologie- und Neologismenplanung Frankreichs. Außerdem widmete sie ihre Arbeit direkt der Verbreitung und dem Schutz des Französischen; damit war sie auch berechtigt, Verstöße gegen die Loi Bas-Lauriol ${ }^{73}$ zu ahnden. Zu ihren Aufgaben gehörte auch die Erforschung französischer Sprachvarietäten (vgl. Lebsanft 2002:69f). Darin entsprach sie der noch jungen, erst seit dem Comité consultatif de la langue française per Dekret verfügten Tendenz der französischen Sprachpolitik, den Minderheitensprachen ein Augenmerk zu schenken. Aus diesem Grund nennt sich die Organisation, die nach wie vor existiert und im Grunde immer noch dieselben Aufgaben erfüllt, seit 2001 auch Délégation générale à la langue française et aux langues de France $(D G L F L F)^{74}$. Mit dieser Umbenennung wurde der sprachlichen Vielfalt Frankreichs Tribut gezollt.

\subsubsection{Conseil supérieur de la langue française (CSLF)}

Der dem Premierminister unterstellte CSLF löste den Comité consultatif de la langue française in seinen Aufgaben ab. Die Aufgaben des CSLF wurden laut Artikel 2 des Dekrets Nr. 89-403, veröffentlicht im Journal Officiel (Legifrance.gouv.fr - Le Service Public de la Diffusion du Droit s.a. d: Image JO du 22/06/1989, page: 07729) vom 2. Juni 1989 festgelegt und stellten mit der Forderung nach einer Anpassung und Bereicherung der französischen Sprache erneut ganz eindeutig die Terminologieplanung in den Vordergrund:

72 Siehe hierzu Kapitel 5.5.4.

73 Siehe hierzu auch Kapitel 5.3.1.

74 Der Einfachheit halber wird die Organisation in den folgenden Kapiteln dementsprechend auch als $D G L F L F$ bezeichnet. 
Das 20. und 21. Jahrhundert: eine Rückbesinnung auf die Verteidigung der Sprache

Art. 2. - Le Conseil supérieur de la langue française a pour mission d'étudier, dans le cadre des grandes orientations définies par le Président de la République et le Gouvernement, les questions relatives à l'usage, à l'aménagement, à l'enrichissement, à la promotion et à la diffusion de la langue française en France et hors de France et à la politique à l'égard des langues étrangères. [...]

$\mathrm{Zu}$ den Mitgliedern des CSLF zählten vor allem Sprachwissenschaftler und Personen des öffentlichen Lebens, die Fragen zur Sprachkultur und zum Sprachgebrauch behandelten. Eine 1989 bzw. 1990 von der Organisation angeregte Rechtschreibreform scheiterte (vgl. Lebsanft 2002:69). Bereits mit der ersten Sitzung des CSLF am 24. Oktober 1989 wurde beschlossen, der Pflege des Französischen besonders vor dem Hintergrund des europäischen Plurilingualismus nachzukommen und die Stellung der französischen Sprache neben der anderer lebender Sprachen prioritär in den Bereichen des Unterrichts, der Wissenschaft, der Technik, der Wirtschaft und der audiovisuellen Medien auszubauen (vgl. Frey 2000:250).

Die bisher genannten staatlichen Sprachpflegeorganisationen hatten nun zusammenfassend betrachtet in erster Linie Aufgaben wie zunächst den Schutz und die Verbreitung des Französischen inne, waren koordinatorisch tätig und zeigten schließlich im Zuge mehrerer interner Umstrukturierungen verstärkt eine offenere Haltung den französischen Minderheitensprachen wie auch der europäischen Vielsprachigkeit gegenüber. Dies kann nun durchaus als tiefgreifender sprachpolitischer Wandel - weg vom Sprachchauvinismus, hin zur reinen Sprachpflege - gewertet werden. Die französische Attitüde gegenüber Lehnwörtern aus Fremdsprachen, allen voran dem Englischen, in den Fachsprachen hingegen hat sich bis in die Gegenwart nicht im Geringsten geändert: Nach wie vor setzt der französische Staat auf eine systematisch betriebene Terminologieplanung, um Anglizismen so weit wie möglich aus dem Französischen zu verbannen. Als Instrument hierzu dient ihm eine Reihe von ministeriellen Terminologiekommissionen.

\subsubsection{Die ministeriellen Terminologiekommissionen}

Die ministeriellen Terminologiekommissionen werden im Französischen häufig als commissions ministérielles de terminologie (CMT) bezeichnet, nennen sich in den Publikationen der DGLFLF allerdings offiziell commissions spécialisées de terminologie et de néologie, kurz CST. Laut der DGLFLF (vgl. Délégation générale à la langue française et aux langues de France 2010:Beiblatt A.3 IV) existierten mit dem 31. Dezember 2010 achtzehn verschiedene Terminologiekommissionen: die 
CST des affaires étrangères, die CST de l'agriculture et de la pêche, die CST de la culture et communication, die CST de la défense, die CST de l'environnement, die CST de l'équipement, des transports et du logement, die CST de l'automobile, die CST de la chimie et des matériaux, die CST des communications électroniques et des activités postales, die CST en matière économique et financière, die CST de l'informatique et des composants électroniques, die CST de l'ingénierie nucléaire, die CST des sciences et de l'industrie pétrolières, die CST de l'éducation et de l'enseignement supérieur, die CST des sciences et techniques spatiales, die CST en matière juridique, die CST des sports sowie die CST compétente pour le domaine de la santé et le domaine social.

\subsubsection{Die Gründung der CST}

Die CST wurden mit einem Beschluss des Premierministers Pierre Mesmer vom 14. Januar 1970 ins Leben gerufen (vgl. Depecker 2001:24f). Ihre Aufgabe sollte die systematische Erarbeitung von Fachterminologie sein, um die französische Sprache im fachsprachlichen Bereich auszubauen und durch die Beseitigung von Sprachlücken das Eindringen von englischen und angloamerikanischen Lehnwörtern in die französische Fach- und von dort ausgehend in die Gemeinsprache so weit wie möglich zu verhindern.

Während der nächsten drei Jahre wurden nun mehr als zehn CST gegründet, von denen jede einem Ministerium zugeordnet war. Im Anschluss daran wurde wiederum für jede einzelne dieser Kommissionen in einem Erlass, einem arrêté de terminologie, festgelegt, wie sie bei der terminologischen Arbeit vorzugehen habe. Im Jänner 1973 wurden im Journal Officiel Erlässe für die CST der Bereiche Audiovisuelle Medien, Bauwesen, Nuklearenergie, Erdölindustrie, Raumfahrt und Transport veröffentlicht. Im November desselben Jahres folgten Erlässe für die Terminologie von Wirtschaft und Finanzen sowie für den Bereich der Informatik. 1975 folgte ein Erlass für den Bereich Gesundheit und Medizin, der 1978 erneuert wurde. Der Erlass für den Bereich Verteidigung erschien noch im August 1976. Bereits zuvor hatte die Arbeit der Kommissionen aber angefangen, zu stagnieren; einzelne CST hatten gar schon ab 1973 damit begonnen, sich wieder aufzulösen. $\mathrm{Ab}$ 1978 wurde diesem Trend jedoch gegengesteuert: Dieselben bzw. thematisch anders ausgerichtete Kommissionen wurden nach Bedarf neu gegründet. So kam z.B. 1980 eine Kommission für den Bereich Werbung hinzu, 1982 folgte eine CST für den Bereich Meer. 1984 wurde die Kommission für den Bereich Außenpolitik ins Leben gerufen, weiters jene für weibliche Berufsbezeichnungen, für die Terminologie der 
Das 20. und 21. Jahrhundert: eine Rückbesinnung auf die Verteidigung der Sprache

Umwelt, der Landwirtschaft sowie des Sports, etc. (vgl. Depecker 2001:24ff). Braselmann (2001:167) resümiert die weitere Entwicklung wie folgt:

Bis 1990 stieg die Anzahl der Kommissionen auf 20 an; sie waren elf Ministerien zugeordnet und splitteten sich in 40 Unterkommissionen auf. Die Kooperation untereinander funktionierte kaum.

5.5.6.2 Die interne Struktur und Organisationsform: Mitglieder und Arbeitsgruppen

Die CST hatten zwar alle im Grunde dieselbe Makrostruktur, unterschieden sich jedoch entsprechend der Bedürfnisse der jeweiligen Kommissionen in der Zahl ihrer Mitglieder und im Detailaufbau. Grundsätzlich galt allerdings, dass jede CST über einen Vorsitzenden mit dem Titel président sowie über einen Sekretär, den secrétaire, verfügte. Ihnen wurden wiederum jeweils Personen zugeordnet, die innerhalb der Ministerien mit terminologischen Fragen betraut waren; Depecker (2001:355) nennt diese hauts fonctionnaires de terminologie. Außerdem gehörten Vertreter externer, nicht-staatlicher Vereinigungen und Firmen zu den Mitgliedern der CST; so war z.B. die Firma $I B M$ in der CST für Informatik vertreten, die Air France in der CST für das Transportwesen, gelegentlich auch in der für Auslandsbeziehungen, und Texas Instruments beteiligte sich in der CST für Elektronikbauteile. Auch Berufsverbände entsandten Mitglieder in die CST, so war die Chambre syndicale des constructeurs d'automobiles beispielsweise in den 1990er Jahren in der Unterkommission für Fahrzeugterminologie innerhalb der CST für das Transportwesen vertreten (vgl. Depecker 2001:351ff). Seit 1996 besteht jedenfalls eine Regelung, die vorsieht, dass in jeder einzelnen CST je ein Vertreter des privaten französischen Normungsinstituts AFNOR sowie der Académie française Mitglied ist (vgl. Kubarth 1999:187).

Die letztgenannte Arbeitsgruppe, die Unterkommission für Fahrzeugterminologie, ist ein perfektes Beispiel für die Notwendigkeit, die einzelnen Terminologiekommissionen wiederum in kleinere Gruppen aufzusplitten, um ihnen eine flexiblere Handhabung der Kommunikationsbedürfnisse ihrer Fachbereiche zu erlauben. So gab es beispielsweise in der CST für Nuklearenergie eine Arbeitsgruppe für Reaktortechnologien, eine weitere für den Reaktorbetrieb usw. Die CST für das Transportwesen war ebenfalls in mehrere spezialisierte Einheiten aufgesplittet, so gab es eine Arbeitsgruppe für die Luftfahrt, eine andere für den Schienenverkehr etc. Die einzelnen Arbeitsgruppen waren in ihrer Organisation sehr autonom, konnten tagen wann sie wollten, waren manchmal offizialisiert worden, existierten in man- 
chen Fällen aber auch nur auf einer informellen Basis, hatten entweder permanent Bestand oder wurden nur gelegentlich ad hoc zur Erledigung einer bestimmten Mission gebildet und dann wieder aufgelöst (vgl. Depecker 2001:361ff).

5.5.6.3 Die Commission générale de terminologie et de néologie (CGTN, 19861992)

Wie oben bereits bei Braselmann (2001:167) zitiert, funktionierte die Kommunikation zwischen den einzelnen Terminologiekommissionen bzw. ihren Untergruppen zumindest bis in die zweite Hälfte der 1980er Jahre nicht sonderlich gut. Um nun eine bessere Kooperation zu gewährleisten, wurde mit dem Dekret Nr. 86-439 vom 11. März 1986 die Commission générale de terminologie et de néologie gegründet, die am 18. Juni 1986 zum ersten Mal in einer Sitzung zusammenkam. Sie sollte sich terminologisch mit jenen fachsprachlichen Bereichen befassen, die noch nicht durch andere CST abgedeckt waren bzw. musste zeiteffektiv über die Einführung von Termini entscheiden, die besonders dringend benötigt wurden. Außerdem gehörte die Harmonisierung der von verschiedenen CST zu ein und demselben terminologischen Problemfall eingebrachten Termvorschläge zu den Aufgaben der Commission générale de terminologie et de néologie. In ihren Verantwortungsbereich fiel zusätzlich zu den genannten Spezialaufgaben - wie es ja für die anderen CST auch der Fall war - die Suche nach französischen Ersatzwörtern für bereits in die Gemeinsprache übergegangene Anglizismen (vgl. Depecker 2001:289f).

\subsubsection{Die Typen der von den CST vorgeschlagenen Fachtermini}

Um nun also Anglizismen in den französischen Fachsprachen durch französische Termini zu ersetzen, müssen letztere erst einmal vorgeschlagen werden. Die CST greifen hierzu nach Braselmann (2001:175f) im Großen und Ganzen auf drei verschiedene Typen von Termvorschlägen zurück:

Künstlich geschaffene Äquivalente sind Kunstprodukte, die gezielt als Ersatz für Lehnwörter vorgeschlagen werden und häufig nur eine geringe Kommunikationsleistung aufweisen. Oft werden der englischen Sprache eigene Wortbildungsmuster bzw. typisch englische Abkürzungen und ähnliche Elemente mehr oder weniger direkt ins Französische eingebürgert, um einen Anglizismus durch ein französisches Wort zu ersetzen; dabei wird aber nicht unbedingt immer auf die Einhaltung französischer Wortbildungsmuster geachtet, was in Folge durchaus zu Schwierigkeiten bei der Akzeptanz von auf diese Weise eingeführten Termini seitens der Sprachnutzer führen kann. So kommt es beispielsweise vor, dass fremdsprachiges Lehngut ledig- 
lich unter einer geringfügigen Anpassung an die französische Orthographie in die französische Sprache aufgenommen wird, wie z.B. bei französisch chalenge für englisch challenge, oder bei französisch drible statt englisch dribble, etc. In den Bereich der künstlich geschaffenen Äquivalente fallen aber auch dem französischen Wortbildungsmaterial entsprechende neu erfundene Wörter, so wie z.B. das französische voyagiste, das der offizielle Ersatz des englischen tour-operator ist.

Spontan entstandene Äquivalente entstehen, wie der Name schon sagt, spontan, sozusagen auf natürlichem Wege, allein durch den unmittelbaren Sprachkontakt zwischen einem Lehnwort und dem Französischen. Die Terminologiekommissionen greifen gelegentlich derartige Äquivalente als Termvorschläge auf, was zur Einführung von Begriffen wie französisch libre-service für englisch self-service führt. Im Sprachkontakt mit dem oben bereits genannten englischen Begriff tour-operator brachte das Französische übrigens ursprünglich als spontan entstandenes Äquivalent tour-opérateur hervor, was von der verantwortlichen CST allerdings verworfen und anschließend durch den frei gebildeten voyagiste ersetzt wurde.

Kooperative, experimentelle Neologismen werden auf gänzlich anderem Wege vorgeschlagen: Sie werden sozusagen präventiv geschaffen, noch bevor ein Lehnwort überhaupt in die französische Fachsprache eindringen kann. Hierbei handelt es sich um Termvorschläge, die von den CST üblicherweise in Form von Wortlisten zu bestimmten Themenbereichen vorgelegt werden; so wurde bereits ein Olympisches Glossar erstellt, oder eine Wortliste zum Thema Fußball. Diese Vorgangsweise bietet den Vorteil, dass unmittelbar in dem Moment, in dem ein Anglizismus beginnt, langsam in die französische Fachsprache einzusickern, den Sprachnutzern sofort eine französische Alternative angeboten werden kann. Eine derart schnelle Reaktion verbessert die Chancen, die Integration eines noch nicht sonderlich bekannten Anglizismus zu verhindern und alternativ sofort den entsprechenden französischen Term durchzusetzen.

Nun stellt sich aber natürlich die Frage, welches Prozedere ein als Termvorschlag eingebrachtes Fachwort durchlaufen muss, bis es zum öffentlich publizierten und staatlich anerkannten Neologismus wird...

\subsubsection{Zur Entstehung eines Neologismus: vom feindlichen Anglizismus über} den Term-Vorschlag bis hin zur Publikation

Wird festgestellt, dass ein unerwünschter Anglizismus Eingang in die französische Fachsprache gefunden hat, so ist es an der für den entsprechenden Fachbereich verantwortlichen CST bzw. an der Commission générale de terminologie et de néologie, darauf zu reagieren und ihre Mitglieder in einer Sitzung dazu anzuhalten, sich mit 
möglichen Lösungsvorschlägen zu befassen. Im Normalfall wird in solchen Sitzungen nicht ein einzelner Term zur Diskussion gestellt, sondern eine ganze Liste von Lehnwörtern behandelt, für die französische Äquivalente gefunden werden müssen. Jedes der Mitglieder hat im Anschluss an eine Sitzung ausreichend Zeit, die einzelnen Problemstellungen zu reflektieren; üblicherweise erfolgt dies in Form von schriftlichen Überlegungen, die von den Mitgliedern der CST individuell auf terminologischen Arbeitsblättern, sogenannten fiches terminologiques de travail oder dossiers terminologiques, festgehalten werden. ${ }^{75} \mathrm{Im}$ Weiteren liegt aber in den verschiedenen CST keine einheitliche Methode zur Bearbeitung oder Diskussion der terminologischen Arbeitsblätter vor. Normalerweise ist von einer Diskussion möglicher Lösungsvorschläge im Plenum auszugehen, so dass zunächst innerhalb der verantwortlichen CST bezüglich jedes einzelnen zur Diskussion gestellten Terms eine Einigung herbeigeführt werden kann. In der Bearbeitung kann in dringlichen Fällen natürlich einem bestimmten Term Priorität eingeräumt werden: Drängt z.B. ein bestimmter Anglizismus in eine französische Fachsprache und hat das Französische wirklich kein Äquivalent zu bieten, so muss aufgrund dieser sprachlichen Lücke schnell reagiert werden, um den betreffenden Anglizismus noch rechtzeitig abzuwehren. In so einem Fall kann ein ursprünglich nicht prioritär gereihter Term durchaus auf der Diskussionsliste vorgezogen werden. Das Ziel jeder Diskussion von Termvorschlägen ist es, einen französischen Term auszuwählen, ihn in Form einer Definition mit einem eindeutigen Sinn zu belegen und damit zum einen die Fachsprachen zu bereichern, zum anderen den Vormarsch der Anglizismen in der französischen Sprache zu unterbinden (vgl. Depecker 2001:366ff). Um für einen besseren Überblick über die Aktivitäten der verschiedenen CST zu sorgen, wurden zwei koordinatorische Maßnahmen gesetzt: Zum einen findet eine jährliche Sitzung der Vorsitzenden aller CST statt, die einem Austausch bezüglich der Arbeitsmethoden dient. Außerdem wurde 1990 eine Datenbank in Betrieb genommen, die alle in Bearbeitung befindlichen Termini verzeichnet und auf die jede CST individuellen Zugriff hat bzw. in die laufend Daten eingespeist werden können. Auf diese Weise kann durch die $D G L F L F$ überprüft werden, wer an welchen Fachtermini arbeitet und welche Ergebnisse wann zu erwarten sind. Fällt schließlich in einer CST eine definitive Entscheidung über die offizielle Anerkennung eines neuen französischen Fachwortes, so muss der betreffende Term verschiedene Konsultations- und

75 Ein Beispiel für den möglichen Aufbau eines solchen terminologischen Arbeitsblattes findet sich in Form einer Abschrift des Dossier terminologique sur le terme PIXEL im Anhang, Kapitel 8.6. Diese Abschrift wurde Depecker (2001:379f) entnommen. Es ist allerdings zu beachten, dass auch die terminologischen Arbeitsblätter nicht in allen CST identisch sind. 
Kontrollniveaus durchlaufen: So sind die Termini seit 1986 zunächst der Académie française vorzulegen, um deren Zustimmung zur Publikation des betreffenden Wortes einzuholen. Erst wenn diese erteilt worden ist, dürfen die in der zentralen Datenbank gespeicherten Termini in digitaler Form zur Publikation weitergereicht werden. Im Durchschnitt ist mit einer Bearbeitungsdauer von drei bis vier Monaten zu rechnen, bis ein in einer Kommission erarbeiteter Fachterm schließlich wirklich der Öffentlichkeit zugänglich ist (vgl. Depecker 2001:388ff). Die Publikation der so beschlossenen offiziellen Termini erfolgt im Journal Officiel sowie in Form der Rapports annuels de la Commission générale de terminologie et de néologie, zugleich aber auch über die Datenbank FranceTerme. ${ }^{76}$ Diese erlaubt es der Allgemeinheit, entweder anhand von ausländischen Fachtermini nach französischen Äquivalenten zu suchen, oder direkt einen französischen Term aufzurufen und so mehr über dessen Hintergründe zu erfahren. So sind zu jedem verzeichneten Begriff terminologische Dossiers abrufbar, die beispielsweise Aufschluss geben, welcher Fachsprache ein Begriff zugehörig ist, welche Synonyme es gibt, welches fremdsprachige Äquivalent durch den französischen Begriff ersetzt wurde etc. Dazu kommen natürlich noch eine Definition wie auch grammatische Informationen. Eine „leere" Suche in allen Fachbereichen ohne Angabe eines bestimmten Terms ergab am 28. März 2012 eine Zahl von 5289 abrufbaren Termini. Für all jene, die Termlisten in Papierform bevorzugen, bietet schließlich das von der Direction des Journaux Officiels herausgegebene und bei der DGLFLF erhältliche Répertoire terminologique (Révision des listes antérieurement publiées). Édition 2000 ein Verzeichnis aller zwischen 1973 und 2000 veröffentlichten Termini. Außerdem bedienen sich die CST auch einer Zusammenarbeit mit diversen Presseagenturen, z.B. der Agence France-Presse und bis zu deren Auflösung 1990 auch der Agence centrale de presse - $A C P$, sowie mit Journalisten und Printmedien, beispielsweise dem Magazin Aéroports de Paris oder dem Nouvel Observateur, um ihre Fachtermini zügig zu verbreiten. Auch die Verteilung fachsprachenspezifischer Broschüren auf entsprechenden Messen dient diesem Zweck (vgl. Depecker 2001:390ff). Grundsätzlich ist also festzustellen, dass die interessierte Allgemeinheit im Prinzip ausreichend $\mathrm{Zu}-$ gang zu den Arbeitsergebnissen der CST hat.

Wie ist nun aber in Summe der Erfolg der gegenwärtig in Frankreich getroffenen Maßnahmen zur Pflege der Fachsprachen zu beurteilen?

76 Die Datenbank FranceTerme ist online direkt unter http://franceterme.culture.fr/FranceTerme/index.html aufrufbar; ebenso ist sie über die Website der DGLFLF unter der Adresse http://www.dglflf.culture.gouv.fr/ und im Weiteren über den Menüpunkt Vocabulaire et Terminologie sowie den Eintrag FranceTerme aufzufinden (Stand: 28.3.2012). 
Das 20. und 21. Jahrhundert: eine Rückbesinnung auf die Verteidigung der Sprache

\subsection{Erfolge und Niederlagen: von der Akzeptanz sprachpflegeri- scher Maßnahmen in Frankreich}

Grundsätzlich ist das Französische natürlich wesentlich von den sprachpflegerischen Bemühungen gekennzeichnet, die seit fünf Jahrhunderten unternommen werden, um die Sprache zu stärken: Die Sprachnutzer sind sich mehr oder weniger einig, dass ihre Sprache des Schutzes und der Pflege bedarf und setzen sich in individuell unterschiedlichem Maße auch dafür ein, wovon allein schon die immense Zahl der in Frankreich existenten Sprachpflegevereinigungen sowie der Fortbestand der Autorität der Académie française als älteste französische Vertreterin der institutionalisierten Sprachpflege zeugen. Die Tatsache, dass aber weiterhin Lehnwörter - vor allem aus dem Englischen und dem Angloamerikanischen - in das Französische eindringen, ist dadurch nicht zu beseitigen. Auch das Engagement der CST zugunsten eines von äußeren Einflüssen reinen Fachfranzösisch ist nur bedingt von Erfolg gekrönt. So stellt beispielsweise Seewald (1992:10f) fest, dass insbesondere der französische Datenverarbeitungswortschatz trotz aller Bemühungen zahlreiche englische Termini aufweist, von denen übrigens manche auch durchaus offiziell von den CST anerkannt wurden, so z.B. der bereits erwähnte Term pixel sowie das bit. Im Bezug auf die weiteren in der Fachsprache der Datenverarbeitung vorhandenen, nicht offiziell anerkannten Lehnwörter betont Seewald (1992:10f), dass bei deren Einsickern ins Französische auch die, ,[...] ebenfalls englisch verfaßten Dokumentationen und Systembeschreibungen, die z.B. von Japan auf den europäischen Markt dringen, [eine Rolle spielen]. Auch deutsche oder französische Produkte werden, selbst wenn sie für den Absatz im eigenen Land mit deutschen bzw. französischen Beschreibungen ausgestattet sind, für den Export mit englischem Dokumentationsmaterial versehen." Diese unvermeidliche Präsenz rein englischsprachiger Fachliteratur im französischen Sprachraum führt natürlich zu weiteren Sprachkontakten, was eine Übernahme von Anglizismen auch in Zukunft begünstigen wird. Die Tatsache, dass abgesehen davon besonders im Bereich der Fachzeitschriften zur Datenverarbeitung viele ins Französische eingebundene Anglizismen vorkommen, wertet Seewald (1992:11) weiters als Zeichen dafür, dass innerhalb des Fachs eine ausgeprägte Grundbereitschaft zur Akzeptanz englischer Fachwörter bei den Fachsprachennutzern vorhanden ist. Dennoch sei im Bezug auf das Französische festzustellen, dass es zumindest in der Fachsprache der Datenverarbeitung prozentuell betrachtet weniger Anglizismen aufweise als das Deutsche.

Um diesen Trend fortzusetzen, müsste allerdings von vornherein vermehrt verhindert werden, dass englische Entlehnungen überhaupt ins Französische gelangen, denn hat sich erst einmal ein Lehnwort in einer Fachsprache etabliert, so ist es äu- 
ßerst schwierig, es wieder aus dem Sprachgebrauch zu entfernen. Braselmann (2001:177) ist hierzu der Ansicht, dass in der französischen Sprachgemeinschaft bestimmte Anglizismen bereits derartig gebräuchlich seien, dass sie trotz aller Bemühungen gar nicht mehr eliminiert werden können, und führt exemplarisch aus der Sprache des Sports die englischen Begriffe corner sowie penalty an, denen das Französische lediglich den coup de pied de coin sowie den tir de réparation entgegenzusetzen hat. Dass im Fall dieser Beispiele die offiziell anerkannten französischen Termini weniger benutzerfreundlich sind als die Englischen, die laut Braselmann (2001:177) inzwischen übrigens selbst seitens der CST offiziell als gebrauchsfähig anerkannt wurden, wird bereits anhand der Länge der französischen Äquivalente deutlich. Kubarth (1999:193) hingegen betont, dass ,[...] viele [...] Übersetzungsvorschläge der ministeriellen Terminologiekommissionen [...] durchaus brauchbar [sind]", und erwähnt z.B. retour für comeback, baladeur für walkman, scanneur für scanner oder manageur für manager. Aus dieser Aufzählung wird allerdings erneut eindeutig klar, dass vor allem kurze und eingängige Termini, die den Sprachnutzern eine ökonomische Kommunikation erlauben, „brauchbar“ sind.

Viele der offiziellen französischen Termini finden nicht unmittelbar Eingang in den Sprachgebrauch bzw. sind oft auch nicht dazu in der Lage, die Anglizismen, die sie eigentlich ersetzen sollten, aus dem realen Sprachgebrauch zu verdrängen. Dies kann sicherlich zum Teil auf die Methoden der CST zurückgeführt werden. So hält Depecker (2001:394f) fest, dass die Arbeit der CST seit jeher mit vielen Problemen konfrontiert war: So fehlte es beispielsweise in den Reihen der Kommissionsmitglieder, die noch dazu recht häufig wechselten, an Linguisten. Eine zu sehr auf einer starren Bürokratie und schwerfälligen Abläufen beharrende Vorgangsweise bremste die Verbreitung neugeschaffener Termini, deren Bearbeitungsphasen ohnehin bereits häufig von längeren Unterbrechungen geprägt waren. Die einzelnen $C S T$ stimmten sich in ihrer Arbeitsweise nicht ab, schafften es nicht, die internen Abläufe zu vereinheitlichen und waren im Hinblick auf die verfügbare Bearbeitungszeit der Menge der zur Diskussion gestellten Termini nicht gewachsen. Schließlich kam zu alledem auch noch die Tatsache, dass sich - wie auch schon bei Seewald (1992:11) angesprochen - die französische Sprachgemeinschaft den Anglizismen immer mehr öffnete, was den Erfolg der Arbeit der CST natürlich automatisch schmälerte.

Eine endgültige Bewertung des Erfolges oder des Scheiterns der staatlichen Maßnahmen zur Pflege der Fachsprachen sei allerdings schwierig, so Depecker (2001:471ff), denn allein schon die Menge der bisher in den CST behandelten und offiziell anerkannten Termini stünde einer exakten Analyse der Akzeptanz einzelner Fachwörter innerhalb der Sprachgemeinschaft im Wege. Weiters mangle es an Be- 
wertungskriterien: So sei beispielsweise bis dato nicht geklärt, nach welcher Zeitspanne man einen künstlich geschaffenen Term als von der Sprechergemeinschaft akzeptiert oder aber abgelehnt betrachten müsse. Wolle man bewerten, inwiefern der Ersatz von Anglizismen durch französische fachsprachliche Elemente geglückt sei, müsse zunächst eine Analyse der Intensität des französisch-englischen Sprachkontakts unternommen und festgestellt werden, zu welchem Grad die französische Sprache tatsächlich von der englischen durchsetzt sei. Weiters sei es maßgeblich, zur Bewertung des Erfolgs festzustellen, wie lange ein Anglizismus in Gebrauch war, bevor der Versuch unternommen wurde, ihn durch ein französisches Äquivalent zu ersetzen; ansonsten sei kein Urteil möglich. Ist ein französisches Fachwort sozusagen präventiv in den „leeren Raum“ einer sprachlichen Lücke gesetzt worden, bevor ein Anglizismus diesen Platz einnehmen konnte, seien wiederum andere Bewertungsmaßstäbe für den Erfolg eines Terms anzuwenden. Und letztlich sei nicht zu unterschätzen, welchen Einfluss die Autorität sprachnormierender Instanzen, seien dies nun ministerielle Terminologiekommissionen, normative Wörterbücher, die FranceTerme oder gar die Académie française, auf das Verhalten der Sprachnutzer haben könne. Somit müssten auch deren Aktivitäten und Versäumnisse in entsprechende Analysen einbezogen werden. Erst unter Berücksichtigung all dieser Kriterien und Überlegungen könne dazu übergegangen werden, den Erfolg der in Frankreich gesetzten sprachpolitischen Maßnahmen im Gesamten, vor allem aber den der ministeriellen Terminologiekommissionen im Einzelnen, zu evaluieren.

Zusammenfassend lässt sich also feststellen, dass keinerlei präzise aktuelle Aussagen zu den Erfolgen und Niederlagen der französischen Sprachpolitik im Bereich der Fachsprachen möglich sind und dass derzeit auch der Erfolg einzelner Termini nicht wirklich bemessen werden kann, da innerhalb der staatlichen Institutionen zur Sprachnormung keine komplexen, unter anderem die obigen Überlegungen einbeziehenden Modelle zur Überprüfung der Akzeptanz offiziell anerkannter Neologismen vorliegen. Für die Zukunft besteht hier mit Sicherheit Handlungsbedarf, ist es doch im Sinne einer Qualitätskontrolle bzw. im Bedarfsfall der Realisierung zielgerichteter Verbesserungsmaßnahmen immer wünschenswert, sich auf aussagekräftige empirische Daten stützen zu können. 



\section{Resümee}

Die vorliegende wissenschaftliche Arbeit sollte einer Betrachtung der im Zeichen intensiver Sprachpflege und Sprachnormierung stehenden Sprachpolitik Frankreichs am Beispiel der Fachsprachen dienen und chronologisch von der Renaissance bis in die Gegenwart in diesem Kontext stehende Schlüsselereignisse, wegweisende Personen, Werke, Gesetze usw. sowie deren Einfluss auf die Entwicklung der Fachsprachen und damit der französischen Sprachlandschaft behandeln. Ein Blick auf die französische Sprachpolitik der Renaissance hat nun gezeigt, dass das 16. Jahrhundert in Frankreich in sprachpflegerischer Hinsicht zunächst vor allem im Zeichen eines Sprachausbaus stand: Die französische Sprache war noch weit von der Erfüllung eines Universalitätsanspruchs entfernt, konkurrierte mit dem Lateinischen und musste dringend ausgebaut werden, um zur wahren Nationalsprache heranreifen zu können, die sie rein nominell seit der Erklärung der französischen Gerichtssprache zur einzig gültigen Urkundensprache durch die Ordonnance de Villers-Cotterêts von 1539 bereits war. Dieser Notwendigkeit der Sprachbereicherung verlieh Joachim du Bellay mit seiner Forderung nach einer deffence und illustration der französischen Sprache Ausdruck. Dem daraus resultierenden, nahezu überbordenden und auch gezielt fachliche Bereiche einbeziehenden Sprachausbau wurde in der Klassik mit sprachpuristischen Bestrebungen begegnet: Auswüchse der Sprache sollten eingedämmt, Eleganz erzeugt, der richtige Sprachgebrauch definiert werden. Mit diesen Bestrebungen des 17. Jahrhunderts wurde die Sprache von innen heraus gefestigt, einem präskriptiven Normideal gemäß vereinheitlicht und zum Instrument eines absolutistischen Staats gemacht, was allerdings die Fachsprachen weitestgehend aus der aktiven Sprachpflege ausschloss. Vielleicht war es aber ausgerechnet dieser Umstand, der die Entstehung einer Art „Protestbewegung“ in Form der Redaktion fachlexikographischer Werke begünstigte. Diese im 17. Jahrhundert aufkeimende Tendenz erreichte im 18. Jahrhundert, dem „enzyklopädischen Zeitalter“, mit der Encyclopédie Diderots und d'Alemberts ihren Höhepunkt: Fortan standen das Streben nach einer Vertiefung individuellen Wissens sowie der Wunsch nach kollektivem Wissensaustausch im Vordergrund, was den Fächern und den ihnen zugehörigen Fachsprachen und Terminologien eine noch nie dagewesene Wichtigkeit verlieh. Allerdings stand bis zur Französischen Revolution von 1789 noch hauptsächlich eine kompilatorische Aufbereitung des Fachwissens und damit der Fachsprachen im Vordergrund. Mit der Revolution verschob sich dieser Fokus aber auf eine Erneuerung, Vereinfachung und Rationalisierung bestehender Systeme. Versuche hierzu brachten teils Kuriositäten der Sprachgeschichte hervor man denke an die neue Terminologie der Zeitrechnung, die mit dem Revolu- 
tionskalender geschaffen wurde -, aber manche davon hatten auch bahnbrechende Resultate zur Folge, z.B. die Einführung des metrischen Systems oder die Vereinheitlichung von Gewichten und Maßeinheiten. Im Anschluss daran, noch während der Revolution, aber auch später unter Napoleon Bonaparte und das gesamte 19. Jahrhundert hindurch, wurde Sprachpolitik in erster Linie in Form einer neuen Bildungspolitik betrieben: Die Bevölkerung sollte grundlegende Sprachkompetenzen erwerben, womit die Fachsprachenpflege in den Hintergrund trat. Neu belebt wurde sie aber mit dem Eintritt ins 20. Jahrhundert, in dem die französische Sprache bereits von Beginn an einer „Invasion der Anglizismen“, vor allem im fachsprachlichen Bereich, ausgesetzt war. Die damit einhergehende crise du français rief den Lehnwörtern gegenüber zahlreiche Abwehrreaktionen hervor, so z.B. in Gestalt einer neuen Sprachgesetzgebung, der Gründung zahlreicher privater wie staatlicher sprachpflegerisch tätiger Einrichtungen und einer systematischen, staatlich koordinierten Terminologieplanung, die der Elaborierung der Fachsprachen und damit deren Schutz dienen soll.

Blickt man von hier aus zurück auf das 16. Jahrhundert, so schließt sich der Kreis der Sprachpflege und Sprachnormierung in Frankreich: Bereits zu Beginn aller sprachpolitischen Bestrebungen stand der Sprachausbau, der für die Gegenwart nach wie vor charakteristisch ist. Eine qualitative und quantitative Bewertung der aktuellen sprachpflegerischen Tätigkeiten in Frankreich ist - wie im vorigen Kapitel dargelegt - aufgrund eines Mangels objektiver Bewertungskriterien allerdings nicht möglich, womit sich der französischen Sprachpolitik für die Zukunft ein weiteres Arbeitsfeld eröffnet: Im Sinne einer strukturierten Fortführung der sprachnormativen Aktivitäten wäre es wünschenswert, fundierte Rückschlüsse auf die Akzeptanz sprachpflegerischer Maßnahmen bei der französischen Sprechergemeinschaft sowie auf die Wirkung der staatlichen Sprachpolitik auf das kollektive Sprachbewusstsein ziehen zu können. Da nun die Grundvoraussetzungen zur Durchführung komplexerer Analysen noch nicht bestehen, empfiehlt es sich wohl, wie in Frankreich bereits seit Jahrhunderten üblich, vorerst einfach weiterhin dem usage als Ausdruck der kommunikativen Bedürfnisse der Sprachgemeinschaft ein Maximum an Aufmerksamkeit zu schenken - und zwar solange, bis die Umsetzung zielgerichteter Maßnahmen im Sinne einer Erhöhung der Akzeptanz staatlich beschlossener Fachterminologie möglich ist. Möge aufgrund der Wichtigkeit des usage daher das letzte Wort dieser wissenschaftlichen Arbeit André Goosse (1975:72) überlassen bleiben:

Il me reste à réaffirmer la force prépondérante de l'usage : là où il a choisi définitivement, même s'il a mal choisi, le théoricien n'a plus qu'à se taire. L'usage a toujours raison, même quand il a tort. 


\section{Literatur}

\subsection{Zitierte Literatur}

Académie française (1718) Nouveau Dictionnaire de l'Académie Françoise. Dédié au Roy. Paris: Chez Jean-Baptiste Coignard, Imprimeur du Roy, et de l'Académie Françoise. MDCCXL. Avec privilège de Sa Majesté.

Aschenberg, Heidi (2001) „Von der Mündlichkeit zur Schriftlichkeit. Sprachapologie und Stilideal in den Sprachdialogen von Dominique Bouhours.“, in: Hassler, Gerda (ed.) Texte und Institutionen in der Geschichte der Französischen Sprache. Bonn: Romanistischer Verlag (Abhandlungen zur Sprache und Literatur 137), 51-67.

Barlow, Julie/Nadeau, Jean-Benoît (2008) The Story of French. The Language that Travelled the World. London: Portico Books.

Baum, Richard (1989) Sprachkultur in Frankreich. Texte aus dem Wirkungsbereich der Académie française. Bonn: Romanistischer Verlag (Abhandlungen zur Sprache und Literatur 21).

Baumann, Klaus-Dieter (1998) „Formen fachlicher Kommunikationsbeziehungen“, in: Hoffmann, Lothar/Kalverkämper, Hartwig/Wiegand, Herbert Ernst (eds.) Fachsprachen. Languages for Special Purposes. 1. Halbband. Berlin/New York: Walter de Gruyter (Handbücher zur Sprach- und Kommunikationswissenschaft 14.1), 109-117.

Becker, Andrea/Hundt, Markus (1998) „Die Fachsprache in der einzelsprachlichen Differenzierung", in: Hoffmann, Lothar/Kalverkämper, Hartwig/Wiegand, Herbert Ernst (eds.) Fachsprachen. Languages for Special Purposes. 1. Halbband. Berlin/New York: Walter de Gruyter (Handbücher zur Sprach- und Kommunikationswissenschaft 14.1), 118-133.

Berschin, Helmut/Felixberger, Josef/Goebl, Hans (2008) Französische Sprachgeschichte. 2., überarbeitete und ergänzte Auflage. Hildesheim: Georg Olms Verlag.

Bochmann, Klaus (1993) Sprachpolitik in der Romania. Zur Geschichte sprachpolitischen Denkens und Handelns von der Französischen Revolution bis zur Gegenwart. Berlin/New York: Walter de Gruyter.

Boileau, Nicolas (1970) L'Art Poétique. Herausgegeben, eingeleitet und kommentiert von August Buck. München: Wilhelm Fink Verlag (Studientexte 6).

Bouhours, Dominique (1962) Les Entretiens d'Ariste et d'Eugène. Présentation de Ferdinand Brunot. Paris: Armand Colin. 
Bouhours, Dominique (1973) Remarques nouvelles sur la Langue françoise (1675). Suite des Remarques nouvelles sur la Langue françoise (1687). Genf: Slatkine Reprints.

Bouhours, Dominique (2003) Les Entretiens d'Ariste et d'Eugène. Édition établie et commentée par Bernard Beugnot et Gilles Declercq. Paris: Honoré Champion.

Braselmann, Petra (2001) „Institutionelle Sprachlenkung in Frankreich: neue Wege. Oder: Neues von der Sprachpflegefront.", in: Hassler, Gerda (ed.) Texte und Institutionen in der Geschichte der Französischen Sprache. Bonn: Romanistischer Verlag (Abhandlungen zur Sprache und Literatur 137), 165-187.

Brunot, Ferdinand (1926) Histoire de la Langue française des Origines à 1900, Tome VII: La Propagation du Français en France jusqu'à la Fin de l'Ancien Régime. Paris: Librairie Armand Colin.

Brunot, Ferdinand ( $\left.{ }^{2} 1930 \mathrm{a}\right)$ Histoire de la Langue française des Origines à 1900, Tome III: La Formation de la Langue classique. Première Partie, Édition revue et corrigée. Paris: Librairie Armand Colin.

Brunot, Ferdinand (1930b) Histoire de la Langue française des Origines à 1900, Tome VI: Le XVIIIe Siècle. Première Partie. Le Mouvement des Idées et les Vocabulaires techniques. Paris: Librairie Armand Colin.

Brunot, Ferdinand (1932) Histoire de la Langue française des Origines à 1900, Tome VI: Le XVIIIe Siècle. Deuxième Partie. La Langue postclassique. Paris: Librairie Armand Colin.

Certeau, Michel de/Dominique, Julia/Revel, Jacques (2002) Une politique de la langue. La Révolution française et les patois : l'enquête de Grégoire. Paris: Éditions Gallimard (Collection Folio/Histoire).

Chamard, Henri (1969) Joachim du Bellay. 1522-1560. Réimpression de l'édition de Lille, 1900. Genf: Slatkine Reprints.

Chassagne, Annie/Gasnault, Pierre/Pastoureau, Mireille/Service du Dictionnaire de l'Académie française (1994) Le Dictionnaire de l'Académie française : 1694-1994 - sa naissance et son actualité. Paris: Institut de France.

Délégation générale à la langue française ( $\left.{ }^{5} 2001\right)$ Langue française et Francophonie. Répertoire des Organismes et Associations œuvrant pour la Promotion de la Langue française. Paris: La Documentation française. 
Délégation générale à la langue française et aux langues de France (2010) Rapport annuel de la Commission générale de terminologie et de néologie. 2010. Paris: Délégation générale à la langue française et aux langues de France.

Depecker, Loïc (2001) L'invention de la langue: le choix des mots nouveaux. Paris: Armand Colin.

Drozd, Lubomir/Seibicke, Wilfried (1973) Deutsche Fach- und Wissenschaftssprache. Bestandsaufnahme, Theorie, Geschichte. Wiesbaden: Brandstetter.

du Bellay, Joachim (1969) La Deffence et Illustration de la Langue francoyse. Edition critique par Henri Chamard. Genf: Slatkine Reprints.

Ehlich, Konrad/Ossner, Jakob/Stammerjohann, Harro (eds.) (2001) Hochsprachen in Europa. Entstehung, Geltung, Zukunft. Freiburg im Breisgau: Fillibach Verlag.

Elias, Norbert (1983) Die höfische Gesellschaft. Untersuchungen zur Soziologie des Königtums und der höfischen Aristokratie. Frankfurt/Main: Suhrkamp (Taschenbuch Wissenschaft 423).

Erfurt, Jürgen (2005) Frankophonie: Sprache - Diskurs - Politik. Basel/Tübingen: A. Franke Verlag (UTB Sprachwissenschaften 2645).

Fluck, Hans-Rüdiger ( $\left.{ }^{5} 1996\right)$ Fachsprachen. Einführung und Bibliographie. Fünfte, überarbeitete und erweiterte Auflage. Basel/Tübingen: A. Francke Verlag (UTB 483).

Frey, Brigitte (2000) Die Académie française und ihre Stellung zu anderen Sprachpflegeinstitutionen. Bonn: Romanistischer Verlag (Abhandlungen zur Sprache und Literatur 130).

Goosse, André (1975) La Néologie française aujourd'hui. Observations et Réflexions. Paris: Conseil international de la langue française.

Greule, Albrecht/Janich, Nina (eds.) (2002) Sprachkulturen in Europa. Ein internationales Handbuch. Tübingen: Gunter Narr Verlag.

Grimm, Jürgen (2005) Französische Klassik. Lehrbuch Romanistik. Stuttgart/Weimar: Verlag J. B. Metzler.

Haage, Bernhard Dietrich (1998) „Anwendungsmöglichkeiten und bisherige Anwendung von philologisch-historischen Methoden bei der Erforschung der Fachsprachen der Artes“, in: Hoffmann, Lothar/Kalverkämper, Hartwig/Wiegand, Herbert Ernst (eds.) Fachsprachen. 
Languages for Special Purposes. 1. Halbband. Berlin/New York: Walter de Gruyter (Handbücher zur Sprach- und Kommunikationswissenschaft 14.1), 269-277.

Hassler, Gerda (1998) „Anfänge der europäischen Fachsprachenforschung im 17. und 18. Jahrhundert", in: Hoffmann, Lothar/Kalverkämper, Hartwig/Wiegand, Herbert Ernst (eds.) Fachsprachen. Languages for Special Purposes. 1. Halbband. Berlin/New York: Walter de Gruyter (Handbücher zur Sprach- und Kommunikationswissenschaft 14.1), 322-326.

Hassler, Gerda (ed.) (2001) Texte und Institutionen in der Geschichte der Französischen Sprache. Bonn: Romanistischer Verlag (Abhandlungen zur Sprache und Literatur 137).

Heinz, Sieglinde/Wandruszka, Ulrich (eds.) (1982) Fakten und Theorien: Beiträge zur romanischen und allgemeinen Sprachwissenschaft; Festschrift für Helmut Stimm zum 65. Geburtstag. Tübingen: Gunter Narr (Tübinger Beiträge zur Linguistik 191).

Hoffmann, Lothar (1987) „Ein textlinguistischer Ansatz in der Fachsprachenforschung“, in: Sprissler, Manfred (ed.) Standpunkte der Fachsprachenforschung. Tübingen: Gunter Narr Verlag (Forum Angewandte Linguistik 11), 91-105.

Hoffmann, Lothar/Kalverkämper, Hartwig/Wiegand, Herbert Ernst (eds.) (1998) Fachsprachen. Languages for Special Purposes. 1. Halbband. Berlin/New York: Walter de Gruyter (Handbücher zur Sprach- und Kommunikationswissenschaft 14.1).

Jakob, Karlheinz (1998) „Techniksprache als Fachsprache“, in: Hoffmann, Lothar/Kalverkämper, Hartwig/Wiegand, Herbert Ernst (eds.) Fachsprachen. Languages for Special Purposes. 1. Halbband. Berlin/New York: Walter de Gruyter (Handbücher zur Sprach- und Kommunikationswissenschaft 14.1), 142-150.

Janich, Nina (2004) Die bewusste Entscheidung - Eine handlungsorientierte Theorie der Sprachkultur. Tübingen: Gunter Narr Verlag (UTB Sprachwissenschaften 2645).

Kalverkämper, Hartwig (1998a) „Darstellungsformen und Leistungen schriftlicher Fachkommunikation: diachrone und synchrone Aspekte“, in: Hoffmann, Lothar/Kalverkämper, Hartwig/Wiegand, Herbert Ernst (eds.) Fachsprachen. Languages for Special Purposes. 1. Halbband. Berlin/New York: Walter de Gruyter (Handbücher zur Sprach- und Kommunikationswissenschaft 14.1), 60-92.

Kalverkämper, Hartwig (1998b) „Fachliches Handeln, Fachkommunikation und fachsprachliche Reflexionen in der Renaissance“, in: Hoffmann, Lothar/Kalverkämper, Hartwig/Wiegand, Herbert Ernst (eds.) Fachsprachen. Languages for Special Purposes. 1. Halbband. Berlin/New York: Walter de Gruyter (Handbücher zur Sprach- und Kommunikationswissenschaft 14.1), 301-322. 
Kalverkämper, Hartwig (1998c) „Rahmenbedingungen für die Fachkommunikation“, in: Hoffmann, Lothar/Kalverkämper, Hartwig/Wiegand, Herbert Ernst (eds.) Fachsprachen. Languages for Special Purposes. 1. Halbband. Berlin/New York: Walter de Gruyter (Handbücher zur Sprach- und Kommunikationswissenschaft 14.1), 24-47.

Kettemann, Bernhard/Muhr, Rudolf (eds.) (2002) Eurospeak - Der Einfluss des Englischen auf europäische Sprachen zur Jahrtausendwende. Frankfurt/Main: Peter Lang Europäischer Verlag der Wissenschaften (Österreichisches Deutsch Sprache der Gegenwart 1).

Klare, Johannes (1977) „Sprache und Gesellschaft im Spiegel der französischen Lexikographie insbesondere des 19. Jahrhunderts“, in: Beiträge zur Romanischen Philologie, 16/1, 143147.

Klare, Johannes (1999) „Sprachpolitik, Sprachkultur und Sprachpflege in Frankreich - gestern und heute", in: Scharnhorst, Jürgen (ed.) Sprachkultur und Sprachgeschichte. Herausbildung und Förderung von Sprachbewusstsein und wissenschaftlicher Sprachpflege in Europa. Frankfurt: Peter Lang (Sprache: System und Tätigkeit 30), 13-45.

Kramer, Johannes (2001) „Das Französische als gemeinschaftsbildende Kraft gestern und heute“, in: Ehlich, Konrad/Ossner, Jakob/Stammerjohann, Harro (eds.) Hochsprachen in Europa. Entstehung, Geltung, Zukunft. Freiburg im Breisgau: Fillibach Verlag, 31-45.

Kubarth, Hugo (1999) „Anglicismes - non merci. Französische Sprachpolitik heute“, in: Kettemann, Bernhard/Muhr, Rudolf (eds.) Eurospeak - Der Einfluss des Englischen auf europäische Sprachen zur Jahrtausendwende. Frankfurt/Main: Peter Lang Europäischer Verlag der Wissenschaften (Österreichisches Deutsch Sprache der Gegenwart 1), 181-208.

Lebsanft, Franz (2002) „Französisch“, in: Greule, Albrecht/Janich, Nina (eds.) Sprachkulturen in Europa. Ein internationales Handbuch. Tübingen: Gunter Narr Verlag, 64-73.

Le Gras, Joseph (1942) Diderot et l'Encyclopédie. Paris: Société Française d'Éditions Littéraires et Techniques (Les Grands Événements Littéraires).

Lieber, Maria (1990) „Zwei normative ,Kontrahenten’: Maurice Grevisse und die Académie française“, in: Settekorn, Wolfgang (ed.) Sprachnorm und Sprachnormierung: Deskription Praxis - Theorie. Wilhelmsfeld: Gottfried Egert Verlag (Pro Lingua 7), 45-57.

Maier, Elisabeth (1984) Studien zur Sprachnormtheorie und zur Konzeption der Sprachnorm in französischen Wörterbüchern. Frankfurt/Main: Verlag Peter Lang (Heidelberger Beiträge zur Romanistik 17). 
Müller, Bodo (1975) Das Französische der Gegenwart. Varietäten, Strukturen, Tendenzen. Heidelberg: Carl Winter Universitätsverlag.

Pascal, Blaise (1998) Euvres complètes. Édition de Michel Le Guern. Nouvelle édition. 2 Tomes. Paris: Gallimard (Collection Bibliothèque de la Pléiade).

Pécheur, Jacques (2001) „Nouveaux espaces pour le français“, in: Ehlich, Konrad/Ossner, Jakob/Stammerjohann, Harro (eds.) Hochsprachen in Europa. Entstehung, Geltung, Zukunft. Freiburg im Breisgau: Fillibach Verlag, 47-72.

Proust, Jacques (1962) Diderot et l'Encyclopédie. Paris: Armand Colin.

Proust, Jacques (1965) L'Encyclopédie. Paris: Armand Colin (Section de Langues et Littératures 387).

Roelcke, Thorsten $\left({ }^{2} 2005\right)$ Fachsprachen. 2., durchgesehene Auflage. Berlin: Erich Schmidt Verlag (Grundlagen der Germanistik).

Scharnhorst, Jürgen (ed.) (1999) Sprachkultur und Sprachgeschichte. Herausbildung und Förderung von Sprachbewusstsein und wissenschaftlicher Sprachpflege in Europa. Frankfurt: Peter Lang (Sprache: System und Tätigkeit 30).

Schröder, Konrad (2001) „Englisch als Nachbarsprache, englisch als internationale Sprache“, in: Ehlich, Konrad/Ossner, Jakob/Stammerjohann, Harro (eds.) Hochsprachen in Europa. Entstehung, Geltung, Zukunft. Freiburg im Breisgau: Fillibach Verlag, 301-308.

Schwarze, Christoph (1982) „Sprachnormierung und Sprachpflege“, in: Heinz, Sieglinde/Wandruszka, Ulrich (eds.) Fakten und Theorien: Beiträge zur romanischen und allgemeinen Sprachwissenschaft; Festschrift für Helmut Stimm zum 65. Geburtstag. Tübingen: Gunter Narr (Tübinger Beiträge zur Linguistik 191), 299-310.

Seewald, Uta (1992) „Besonderheiten der Wortbildung im französischen Wortschatz der Datenverarbeitung“, in: Fachsprache - International Journal of LSP, 14/1, 2-13.

Sergijewskij, Maxim W. (1979) Geschichte der französischen Sprache. München: Beck (Beck'sche Elementarbücher).

Settekorn, Wolfgang (1988) Sprachnorm und Sprachnormierung in Frankreich. Einführung in die begrifflichen, historischen und materiellen Grundlagen. Tübingen: Max Niemeyer Verlag (Romanistische Arbeitshefte 30). 
Settekorn, Wolfgang (ed.) (1990) Sprachnorm und Sprachnormierung: Deskription - Praxis - Theorie. Wilhelmsfeld: Gottfried Egert Verlag (Pro Lingua 7).

Sprissler, Manfred (ed.) (1987) Standpunkte der Fachsprachenforschung. Tübingen: Gunter Narr Verlag (Forum Angewandte Linguistik 11).

Vaugelas, Claude Favre de (1880) Remarques sur la Langue françoise, par Vaugelas. Nouvelle Édition, par A. Chassang. Tome Premier. Paris: Léopold Cerf.

Walter, Gérard (1948) La Révolution française vue par ses journaux. Bourges: Tardy.

Werner, Edeltraud (2001) „Italiens Beitrag zur Geschichte der französischen Sprache: Sperone Speroni bei Joachim du Bellay“, in: Hassler, Gerda (ed.) Texte und Institutionen in der Geschichte der Französischen Sprache. Bonn: Romanistischer Verlag (Abhandlungen zur Sprache und Literatur 137), 19-35.

\subsection{Konsultierte Literatur}

Bartsch, Renate (1987) Sprachnormen: Theorie und Praxis. Tübingen: Max Niemeyer Verlag (Konzepte der Sprach- und Literaturwissenschaft 38).

Direction des Journaux officiels (2000) Répertoire terminologique (Révision des listes antérieurement publiées). Édition 2000. Paris: Direction des Journaux officiels (Textes d'Intérêt Général).

Faret, Nicolas (1970) L'honnête homme, ou: L'art de plaire à la Cour. Publié par M. Magendie. Genf: Slatkine Reprints.

Gaxotte, Pierre (1965) L'Académie Française. Paris: Hachette.

Helfrich, Uta (1993) Neologismen auf dem Prüfstand. Ein Modell zur Ermittlung der Akzeptanz französischer Neologismen. Wilhelmsfeld: Gottfried Egert Verlag (Pro lingua 17).

Hoffmann, Lothar/Kalverkämper, Hartwig/Wiegand, Herbert Ernst (eds.) (1999) Fachsprachen. Languages for Special Purposes. 2. Halbband. Berlin/New York: Walter de Gruyter (Handbücher zur Sprach- und Kommunikationswissenschaft 14.2).

Kalverkämper, Hartwig (1998) „Fach und Fachwissen“, in: Hoffmann, Lothar/Kalverkämper, Hartwig/Wiegand, Herbert Ernst (eds.) Fachsprachen. Languages for Special Purposes. 1. Halbband. Berlin/New York: Walter de Gruyter (Handbücher zur Sprach- und Kommunikationswissenschaft 14.1), 1-24. 
Schmitt, Christian (1998) „Die Rolle von Fachsprachen im Kontakt von Einzelsprachen II: Englisch - Französisch im 20. Jahrhundert", in: Hoffmann, Lothar/Kalverkämper, Hartwig/Wiegand, Herbert Ernst (eds.) Fachsprachen. Languages for Special Purposes. 1. Halbband. Berlin/New York: Walter de Gruyter (Handbücher zur Sprach- und Kommunikationswissenschaft 14.1), 771-784.

Schwarze, Christoph (1977) Sprachschwierigkeiten, Sprachpflege, Sprachbewusstsein. Das Phänomen der „,Chroniques de Langage“. Konstanz: Universitätsverlag Konstanz (Konstanzer Universitätsreden 91).

\subsection{Zitierte Internetquellen}

Académie française (1694) Le Dictionnaire de l'Académie françoise, dédié au Roy. Tome Premier. A-L. Paris: Chez la Veuve de JEAN BAPTISTE COIGNARD, Imprimeur ordinaire du Roy, \& de l'Académie françoise, ruë S. Jacques, à la Bible d'Or : et chez JEAN BAPTISTE COIGNARD, Imprimeur et Libraire ordinaire du Roy, \& de l'Académie françoise, ruë S. Jacques, prés S. Severin, au Livre d'Or. Veröffentlicht von Gallica - la bibliothèque numérique de la Bibliothèque nationale de France, in ihrer Datenbank unter:

http://gallica.bnf.fr/ark:/12148/bpt6k503971/f2.image.r=.langDE (Stand: 21.3.2012).

Académie française (1740) Dictionnaire de l'Académie françoise. Troisième édition. Tome Premier. A-K. Paris: Chez Jean-Baptiste Coignard, Imprimeur du Roy, \& de l'Académie françoise. Veröffentlicht von Gallica - la bibliothèque numérique de la Bibliothèque nationale de France, in ihrer Datenbank unter: http://gallica.bnf.fr/ark:/12148/bpt6k50401f.r=.langDE (Stand: 21.3.2012).

Académie française (1762) Dictionnaire de l'Académie françoise. Quatrième édition. Tome Premier. A-K. Paris: Chez la Veuve de BERNARD BRUNET, Imprimeur de l'Académie Françoise, Grand'Salle du Palais, \& rue basse des Ursins. Veröffentlicht von Gallica - la bibliothèque numérique de la Bibliothèque nationale de France, in ihrer Datenbank unter: http://gallica.bnf.fr/ark:/12148/bpt6k504034/f1.image.r=.langDE (Stand: 21.3.2012).

Académie française (s.a. a) Le dictionnaire - Les neuf préfaces - Préface de la huitième édition (1932-1935), http://www.academie-francaise.fr/le-dictionnaire-les-neufs-prefaces/preface-de-la-huitieme-edition-1932-1935 (Stand: 14.3.2013).

Académie française (s.a. b) Le dictionnaire - La neuvième édition, http://www.academiefrancaise.fr/dictionnaire/index.html (Stand: 21.3.2012).

Académie française (s.a. c) Le dictionnaire - La neuvième édition - Préface, http://www.academie-francaise.fr/dictionnaire/index.html (Stand: 22.3.2012). 
Académie française (s.a. d) Statuts complets, http://www.academie-francaise.fr/role/ (Stand: 21.3.2012).

AFAL (s.a.) Le répertoire de nos membres, http://www.afalassociation.com/repertoire-desmembres/ (Stand: 19.4.2012).

Assemblée nationale (s.a.) Ordonnance d'août 1539 (ou " ordonnance de Villers-Cotterêts ») prise par le Roi François I Ir imposant l'usage du français dans les actes officiels et de justice enregistrée au Parlement de Paris le 6 septembre 1539, http://www.assemblee-nationale.fr/histoire/villers-cotterets.asp (Stand: 15.3.2012).

Corneille, Thomas (1694) Dictionnaire des Arts et des Sciences. Par M. D. C. de l'Académie françoise. Tome Premier. A-L. Paris: Chez la Veuve de JEAN BAPTISTE COIGNARD, Imprimeur ordinaire du Roy, \& de l'Académie Françoise, ruë S. Jacques, devant la ruë des Noyers, à la Bible d'Or. Et chez JEAN BAPTISTE COIGNARD, Imprimeur et Libraire ordinaire du Roy, \& de l'Académie Françoise, ruë S. Jacques, prés S. Severin, au Livre d'Or. Veröffentlicht von Gallica - la bibliothèque numérique de la Bibliothèque nationale de France, in ihrer Datenbank unter: http://gallica.bnf.fr/ark:/12148/bpt6k50507s/f2.image.r=.langDE (Stand: 22.3.2012).

d'Alembert, Jean-Baptiste le Rond/Diderot, Denis (1751-1765a) Encyclopédie, ou Dictionnaire Raisonné des Sciences, des Arts et des Métiers, par une Société de Gens de Lettres. Tome Premier. Paris: Chez Briasson/David/Le Breton/Durand. Veröffentlicht von Gallicala bibliothèque numérique de la Bibliothèque nationale de France, in ihrer Datenbank unter: http://gallica.bnf.fr/ark:/12148/bpt6k50533b/f3.image.r=.langDE (Stand: 26.3.2012).

d'Alembert, Jean-Baptiste le Rond/Diderot, Denis (1751-1765b) Encyclopédie, ou Dictionnaire Raisonné des Sciences, des Arts et des Métiers, par une Société de Gens de Lettres. Tome Cinquième. Paris: Chez Briasson/David/Le Breton/Durand. Veröffentlicht von Gallica - la bibliothèque numérique de la Bibliothèque nationale de France, in ihrer Datenbank unter: http://gallica.bnf.fr/ark:/12148/bpt6k50537q.r=.langDE (Stand: 24.3.2012).

Défense de la langue française (s.a. a) Activités de l'Association, http://www.langue-francaise.org/Activites.php (Stand: 27.3.2012).

Défense de la langue française (s.a. b) Défense de la langue française No. 185. Beitrag Viennet, Seite 38, http://www.langue-francaise.org/dlf185.PDF (Stand: 2.5.2012).

Furetière, Antoine (1690) Dictionnaire universel, contenant généralement tous les Mots françois, tant vieux que modernes, \& les Termes de toutes les Sciences et des Arts : Divisé en trois Tomes. Tome Premier. A-E. Den Haag: Arnout \& Renier Leers. Veröffentlicht von 
Gallica - la bibliothèque numérique de la Bibliothèque nationale de France, in ihrer Datenbank unter: http://gallica.bnf.fr/ark:/12148/bpt6k57951269.r=.langDE (Stand: 22.3.2012).

Institut de France (1835) Dictionnaire de l'Académie française. Sixième édition publiée en 1835. Tome Premier. Paris: Imprimerie et Librairie de Firmin Didot Frères, Imprimeurs de l'Institut de France. Veröffentlicht von Gallica - la bibliothèque numérique de la Bibliothèque nationale de France, in ihrer Datenbank unter:

http://gallica.bnf.fr/ark:/12148/bpt6k50407h/f2.image.r=.langDE (Stand: 21.3.2012).

Institut de France (1878) Dictionnaire de l'Académie française. Septième édition dans laquelle on a reproduit pour la première fois les préfaces des six éditions précédentes. Tome Premier. A-H. Paris: Librairie de Firmin-Didot et Cie, Imprimeurs de l'Institut de France. Veröffentlicht von Gallica - la bibliothèque numérique de la Bibliothèque nationale de France, in ihrer Datenbank unter: http://gallica.bnf.fr/ark:/12148/bpt6k504096.r=.langFR (Stand: 21.3.2012).

Legifrance.gouv.fr - Le Service Public de la Diffusion du Droit (s.a. a) Image JO du 04/01/1976, page : 00189 - Loi $n^{\circ}$ 75-1349 du 31 décembre 1975 relative à l'emploi de la langue française, Teil 1,

http://www.legifrance.gouv.fr/jopdf/common/jo_pdf.jsp?numJO=0\&dateJO=19760104\&page Debut $=00189$ \&pageFin $=\&$ pageCourante $=00189$ (Stand: 26.3 .2012$)$.

Legifrance.gouv.fr - Le Service Public de la Diffusion du Droit (s.a. b) Image JO du 04/01/1976, page : 00190 - Loi $n^{\circ}$ 75-1349 du 31 décembre 1975 relative à l'emploi de la langue française, Teil 2, http://www.legifrance.gouv.fr/jopdf/common/jo_pdf.jsp?numJO=0\&dateJO=19760104\&page Debut $=00189 \&$ pageFin $=\&$ pageCourante $=00190$ (Stand: 26.3.2012).

Legifrance.gouv.fr - Le Service Public de la Diffusion du Droit (s.a. c) Image JO $d u$ 10/02/1984, page : 00555 - Decrét $n^{\circ} 84-91$ du 9 février 1984 instituant un commissariat général et un comité consultatif de la langue française, http://www.legifrance.gouv.fr/jopdf/common/jo_pdf.jsp?numJO=0\&dateJO=19840210\&page Debut $=00554 \&$ pageFin $=\&$ pageCourante $=00555$ (Stand: 27.3 .2012$)$.

Legifrance.gouv.fr - Le Service Public de la Diffusion du Droit (s.a. d) Image JO du 22/06/1989, page : 07729 - Decrét $n^{\circ} 89-403$ du 2 juin 1989 instituant un conseil supérieur de la langue française et une délégation générale à la langue française, http://www.legifrance.gouv.fr/jopdf/common/jo_pdf.jsp?numJO=0\&dateJO=19890622\&num Texte $=\&$ pageDebut $=07729 \&$ pageFin $=($ Stand: 27.3.2012 $)$. 
Legifrance.gouv.fr - Le Service Public de la Diffusion du Droit (s.a. e) JORF $n^{\circ} 180 d u 5$ août 1994, page 11392 - LOI no 94-665 du 4 août 1994 relative à l'emploi de la langue française (1), http://www.legifrance.gouv.fr/affichTexte.do?dateTexte=\&categorieLien=id\&cidTexte= JORFTEXT000000349929\&fastPos $=1 \&$ fastReqId=1895934813\&oldAction=rechExpTexteJo rf (Stand: 26.3.2012).

Mercure galant (1694) Mercure galant, dédié à Monsieur le Dauphin, Aoust 1694. Paris: Chez Michel Brunet, Grand'Salle du Palais, au Mercure galant, http://books.google.fr/books?id=_GRBAAAAcAAJ\&printsec=frontcover\&hl=fr\&source=gbs _ge_summary_r\&cad $=0 \# \mathrm{v}=$ onepage\&q\&f=false (Stand: 22.3.2012).

Richelet, César-Pierre (1680) Dictionnaire françois, contenant les Mots et les Choses, plusieurs nouvelles Remarques sur la Langue françoise : Ses Expressions Propres, Figurées \& Burlesques, la Prononciation des Mots les plus difficiles, le Genre des Noms, le Regime des Verbes: Avec les Termes les plus connus des Arts \& des Sciences. Le tout tiré de l'Usage et des bons Auteurs de la Langue françoise. Genf: Chez Jean Herman Widerhold. Veröffentlicht von Gallica - la bibliothèque numérique de la Bibliothèque nationale de France, in ihrer Datenbank unter: http://gallica.bnf.fr/ark:/12148/bpt6k509323/f1.image.r=.langDE

(Stand: 22.3.2012).

UISF (s.a.) Qu'est-ce que l'UISF ?, http://www.uisf.fr/wakka.php?wiki=FaQ

(Stand: 19.4.2012).

University of Toronto (s.a.) Épitre à Boileau sur les mot nouveaux, http://projects.chass.utoronto.ca/langueXIX/viennet/ (Stand: 26.3.2012).

Wikipédia - L'encyclopédie libre (s.a. a) Livre (monnaie), http://fr.wikipedia.org/wiki/Livre_\%28monnaie\%29 (Stand: 25.3.2012).

Wikipédia - L'encyclopédie libre (s.a. b) Université de Montpellier, http://fr.wikipedia.org/wiki/Universit\%C3\%A9_de_Montpellier (Stand: 15.3.2012).

\subsection{Konsultierte Internetquellen}

Académie française (1798) Dictionnaire de l'Académie françoise, revu, corrigé et augmenté par l'Académie elle-même. Cinquième édition. Tome Premier. A-K. Paris: Chez J.J. Smits et Cie, Imp.-Lib. Veröffentlicht von Gallica - la bibliothèque numérique de la Bibliothèque nationale de France, in ihrer Datenbank unter: http://gallica.bnf.fr/ark:/12148/bpt6k50405t/f1.image.r=.langDE (Stand: 21.3.2012). 



\section{Anhang}

\subsection{Auszug aus Diderots Encyclopédie: der Artikel Encyclopédie}

Der Artikel Encyclopédie aus Denis Diderots gleichnamigem Werk gibt unter anderem Aufschluss über die Erwartungen, die im 18. Jahrhundert an ein enzyklopädisches Werk gerichtet wurden, über die Schwierigkeiten und Notwendigkeiten bei der Redaktion eines solchen sowie über den Stellenwert von Fachtermini in Diderots Augen. Die im Folgenden zitierten Auszüge des Artikels sollen zum einen verdeutlichen, welches gedankliche Konzept sich im 18. Jahrhundert hinter dem Begriff Enzyklopädie verbarg. Zum anderen erlauben sie einen Rückschluss auf den Aufbau der Einträge der Encyclopédie: Diese unterschieden sich in ihrer Ausführlichkeit und ihrem Stil sehr von denen anderer, bis dahin in französischer Sprache erschienener fachlexikographischer Werke. Aufgrund der Länge des Artikels Encyclopédie wurde dieser hier im Sinne einer exemplarischen Darstellung lediglich ausschnittsweise wiedergegeben. Die zitierten Textpassagen wurden dem fünften Band der Encyclopédie (d'Alembert/Diderot 1751-1765b:635ff, zit. n. Gallica Ansicht 656ff) entnommen.

* ENCYCLOPÉDIE, s. f. (Philosoph.) Ce mot signifie enchaînnemens de connoissances $;[\ldots]$.

En effet, le but d'une Encyclopédie est de rassembler les connoissances éparsés [sic] sur la surface de la terre ; d'en exposer le système général aux hommes avec qui nous vivons, \& de le transmettre aux hommes qui viendront après nous ; afin que les travaux des siecles passés n'aient pas été des travaux inutiles pour les siecles qui succéderont ; que nos neveux, devenant plus instruits, deviennent en même tems plus vertueux $\&$ plus heureux, \& que nous ne mourions pas sans avoir bien mérité du genre humain.

Il eût été difficile de se proposer un objet plus étendu que celui de traiter de tout ce qui a rapport à la curiosité de l'homme, à ses devoirs, à ses besoins, \& à ses plaisirs. Aussi quelques personnes accoutumées à juger de la possibilité d'une entreprise, sur le peu de ressources qu'elles apperçoivent en elles-mêmes, ont prononcé que jamais nous n'acheverions la nôtre. Voyez le Dict. de Trévoux, derniere édis. Au mot Encyclopédie. Elles n'entendront de nous pour toute réponse, que cet endroit du chancelier Bacon, qui semble leur être particulièrement adressé. [...]

Quand on vient à considerer la matiere immense d'une Encyclopédie, la seule chose qu'on apperçoive distinctement, c'est que ce ne peut être l'ouvrage d'un 
seul homme. Et comment un seul homme, dans le court espace de sa vie, réussiroit-il à connoitre \& à développer le système universel de la nature \& de l'art? tandis que la société savante \& nombreuse des académiciens de la Crusca a employé quarante années à former son vocabulaire, \& que nos académiciens françois avoient travaillé soixante ans à leur dictionnaire, avant que d'en publier la premiere édition ! Cependant, qu'est-ce qu'un dictionnaire de langue ? qu'est-ce qu'un vocabulaire, lorsqu'il est exécuté aussi parfaitement qu'il peut l'être ? Un recueil très-exact des titres à remplir par un dictionnaire encyclopédique \& raisonné.

Un seul homme, dira-t-on, est maître de tout ce qui existe ; il disposera à son gré de toutes les richesses que les autres hommes ont accumulées. Je ne peux convenir de ce principe ; je ne crois point qu'il soit donné à un seul homme de connoitre tout ce qui peut être connu; de faire usage de tout ce qui est; de voir tout ce qui peut être vû ; de comprendre tout ce qui est intelligible. Quand un dictionnaire raisonné des sciences \& des arts ne seroit qu'une combinaison méthodique de leurs élémens, je demanderois encore à qui il appartient de faire de bons élémens; si l'exposition élémentaire des principes fondamentaux d'une science ou d'un art, est le coup d'essai d'un éleve, ou le chefd'œuvre d'un maître. Voyez l'article ÉLÉMENS DES SCIENCES.

Mais pour démontrer avec la derniere évidence, combien il est difficile qu'un seul homme exécute jamais un dictionnaire raisonné de la science générale, il suffit d'insister sur les seules difficultés d'un simple vocabulaire.

Un vocabulaire universel est un ouvrage dans lequel on se propose de fixer la signification des termes d'une langue, en définissant ceux qui peuvent être définis, par une énumération courte, exacte, claire \& précise, ou des qualités ou des idées qu'on y attache. Il n'y a de bonnes définitions que celles qui rassemblent les attributs essentiels de la chose désignée par le mot. Mais a-t-il été accordé à tout le monde de connoître \& d'exposer ces attributs? L'art de bien définir est-il un art si commun? Ne sommes nous pas tous, plus ou moins, dans le cas même des enfans, qui appliquent avec une extrême précision, une infinité de termes à la place desquels il leur seroit absolument impossible de substituer la vraie collection de qualités ou d'idées qu'ils représentent ? De-là, combien de difficultés imprévues, quand il s'agit de fixer le sens des expressions les plus communes? On éprouve à tout moment que celles qu'on entend le moins, sont aussi celles dont on se sert le plus. Quelle est la raison de cet étrange phénomene? C'est que nous sommes sans cesse dans l'occasion de prononcer qu'une chose est telle; presque jamais dans la nécessité de déterminer ce que c'est qu'être tel. [...]

Concluons donc qu'on n'exécutera jamais un bon vocabulaire sans le concours d'un grand nombre de talens, parce que les définitions de noms ne different point des définitions de choses (Voyez l'art. DÉFINITION), \& que les choses ne peuvent être bien définies ou décrites que par ceux qui en ont 
fait une longue étude. Mais, s'il en est ainsi, que ne faudra-t-il point pour l'exécution d'un ouvrage où, loin de se borner à la définition du mot, on se proposera d'exposer en détail tout ce qui appartient à la chose ?

Un Dictionnaire universel \& raisonné des Sciences \& des Arts ne peut donc être l'ouvrage d'un homme seul. Je dis plus : je ne crois pas que ce puisse être l'ouvrage d'aucune des sociétés littéraires ou savantes qui subsistent, prises séparément ou en corps.

[...] [O]ccupées chacune d'un objet particulier, qui est sans doute du ressort d'un dictionnaire universel, elles en négligent une infinité d'autres qui doivent y entrer ; \& vous n'en trouverez aucune qui vous fournisse la généralité de connoissances dont vous aurez besoin. [...]

Après y avoir sérieusement réfléchi, je trouve que l'objet particulier d'un académicien pourrait être de perfectionner la branche à laquelle il se seroit attaché [...]. [...] [L]'Académie devroit avoir pour but de rassembler tout ce qui s'est publié sur chaque matiere, de le digérer, de l'éclaircir, de le serrer, de l'ordonner et d'en publier des traités où chaque chose n'occupât que l'espace qu'elle mérite d'occuper et n'eût d'importance que celle qu'on ne lui pourroit enlever. Combien de mémoires, qui grossisent nos recueils, ne fourniroient pas une ligne à de pareils traités !

C'est à l'éxecution de ce projet étendu, non seulement aux differents objets de nos académies, mais à toutes les branches de la connoissance humaine, qu'une Encyclopédie doit suppléer; Ouvrage qui ne s'executera que par une société de gens de lettre et d'artistes, épars, occupé chacun de sa partie, \& liés seulement par l'intérêt général du genre humain, et par un sentiment de bienveillance réciproque.

Je dis une société de gens de lettres \& d'artistes, afin de rassembler tous les talens. Je les veux épars, parce qu'il n'y a aucune société subsistante d'où l'on puisse tirer toutes les connoissances dont on a besoin, \& que, si l'on vouloit que l'ouvrage se fit toûjours \& ne s'achevât jamais, il n'y auroit qu'à former une pareille société. Toute société a ses assemblées, ces assemblées laissent entr'elles des intervalles, elles ne durent que quelques heures, une partie de ce tems se perd en discussions, \& les objets les plus simples consument des mois entiers ; [...].

L'Encyclopédie a rassemblé ses matériaux en assez peu de tems. Ce n'est point un vil intérêt qui en a réuni \& haté les auteurs ; ils on vû leurs efforts secondés par la plûpart des gens de lettres dont ils pouvoient attendre quelques secours; \& ils n'ont été importunés dans leurs travaux que par ceux qui n'avoient pas le talent n'cessaire pour y contribuer seulement d'une bonne page. $[\ldots]$

[...] Si le gouvernement se mêle d'un pareil ouvrage, il ne se fera point. Toute son influence doit se borner à en favoriser l'exécution. [...] Une Encyclopédie 
ne s'ordonne point. C'est un travail qui veut plûtôt être suivi avec opiniâtreté, que commence avec chaleur. [...]

Mais ce qui doit donner le plus grand poids aux considérations précédentes, c'est qu'une Encyclopédie, ainsi qu'un vocabulaire, doit être commencée, continuée, \& finie dans un certain intervalle de tems, \& qu'un intérêt sordide s'occupe toûjours à prolonger les ouvrages ordonnés par les rois. Si l'on employait à un dictionnaire universel \& raisonné les longues années que l'étendue de son objet semble exiger, il arriveroit par les révolutions, qui ne sont guere moins rapides dans les Sciences, \& sur-tout dans les Arts, que dans la langue, que ce dictionnaire seroit celui d'un siecle passé, de même qu'un vocabulaire qui s'exécuteroit lentement, ne pourroit être que celui d'un regne qui ne seroit plus. Les opinions vieillissent, $\&$ disparoissent comme les mots ; l'intérêt que l'on prenoit à certaines inventions s'affaiblit de jour en jour, \& s'éteint ; si le travail tire en longueur, on se sera étendu sur des choses momentanées, dont il ne sera déjà plus question ; [...].

Mais ce qui donnera à l'ouvrage l'air suranné, \& le jettera dans le mépris, c'est sur-tout la révolution qui se fera dans l'esprit des hommes, \& dans le caractere national. [...]

Les connoissances les moins communes sous le siecle passé, le deviennent de jour en jour. Il n'y a point de femmes, à qui l'on ait donné quelqu'éducation, qui n'employe avec discernement toutes les expressions consacrées à la Peinture, à la Sculpture, à l'Architecture, \& aux Belles-Lettres. Combien y a-t-il d'enfans qui ont du Dessein, qui savent de la Géométrie, qui sont Musiciens, à qui la langue domestique n'est pas plus familiere que celle de ces arts, \& qui disent, un accord, une belle forme, un contour agréable, une parallele, une hypothenuse, une quinte, un triton, un arpègement, un microscope, [...]. Les esprits sont encore emportés d'un autre mouvement général vers l'Histoire naturelle, l'Anatomie, la Chimie, [...]. Les expressions propres à ces sciences sont déja très-communes, \& le deviendront nécessairement davantage. Qu'arrivera-t-il delà ? c'est que la langue, même populaire, changera de face ; qu'elle s'étendra à mesure que nos oreilles s'accoutumeront aux mots, par les applications heureuses qu'on en fera. Car si l'on y refléchit, la plûpart de ces mots techniques, que nous employons aujourd'hui, ont été originairement du néologisme ; c'est l'usage \& le tems qui leur ont ôté ce vernis équivoque. [...] Cependant les connoissances ne deviennent \& ne peuvent devenir communes, que jusqu'à un certain point. [...] On ignore, à la vérité, quelle est cette limite. On ne sait jusqu'où tel homme peut aller. On sait bien moins encore jusqu'où l'espece humaine iroit, ce dont elle seroit capable, si elle n'étoit point arrêtée dans ses progrès. $[\ldots]$ 


\subsection{Der Fragebogen des Abbé Henri Grégoire}

Die vorliegende Abschrift des Fragebogens des Abbé Henri Grégoire wurde Certeau/Dominique/Revel (2002:13ff) entnommen. Die Fragen 6, 9, 12 und 23 haben Fachsprachenbezug bzw. dienten zum Ausfindigmachen sprachlicher Lücken in der Standardvarietät des Französischen.

1. - L'usage de la langue française est-il universel dans votre contrée ? Y parle-t-on un ou plusieurs patois?

2. - Ce patois a-t-il une origine ancienne et connue ?

3. - A-t-il beaucoup de termes radicaux, beaucoup de termes composés?

4. - Y trouve-t-on des mots dérivés du celtique, du grec, du latin, et en général des langues anciennes et modernes?

5. - A-t-il une affinité marquée avec le français, avec le dialecte des contrées voisines, avec celui de certains lieux éloignés, où des émigrants, des colons de votre contrée, sont allés anciennement s'établir?

6. - En quoi s'éloigne-t-il le plus de l'idiome national ? n'est-ce pas spécialement pour les noms des plantes, des maladies, les termes des arts et métiers, des instruments aratoires, des diverses espèces de grains, du commerce et du droit coutumier? On désirerait avoir cette nomenclature.

7. - Y trouve-t-on fréquemment plusieurs mots pour désigner la même chose ? 8. - Pour quels genres de choses, d'occupations, de passions, ce patois est-il plus abondant?

9. - A-t-il beaucoup de mots pour exprimer les nuances des idées et les objets intellectuels ?

10. - A-t-il beaucoup de termes contraires à la pudeur ? Ce que l'on doit en inférer relativement à la pureté ou à la corruption des mœurs ?

11. - A-t-il beaucoup de jurements et d'expressions particulières aux grands mouvements de colère?

12. - Trouve-t-on dans ce patois des termes, des locutions très-énergiques, et même qui manquent à l'idiome français?

13. - Les finales sont-elles plus communément voyelles que consonnes ?

14. - Quel est le caractère de la prononciation? Est-elle gutturale, sifflante, douce, peu ou fortement accentuée?

15. - L'écriture de ce patois a-t-elle des traits, des caractères autres que le français?

16. - Ce patois varie-t-il beaucoup de village à village ?

17. - Le parle-t-on dans les villes ?

18. - Quelle est l'étendue territoriale où il est usité ?

19. - Les campagnards savent-ils également s'énoncer en français ?

20. - Prêchait-on jadis en patois ? Cet usage a-t-il cessé ? 
21. - A-t-on des grammaires et des dictionnaires de ce dialecte ?

22. - Trouve-t-on des inscriptions patoises dans les églises, les cimetières, les places publiques, etc. ?

23. - Avez-vous des ouvrages en patois, imprimés ou manuscrits, anciens ou modernes, comme droit coutumier, actes publics, chroniques, prières, sermons, livres ascétiques, cantiques, chansons, almanachs, poésie, traductions, etc. ?

24. - Quel est le mérite de ses divers ouvrages ?

25. - Serait-il possible de se les procurer facilement ?

26. - Avez-vous beaucoup de proverbes patois particuliers à votre dialecte et à votre contrée?

27. - Quelle est l'influence respective du patois sur les mœurs, et de celles-ci sur votre dialecte?

28. - Remarque-t-on qu'il se rapproche insensiblement de l'idiome français, que certains mots disparaissent, et depuis quand?

29. - Quelle serait l'importance religieuse et politique de détruire entièrement ce patois?

30. - Quels en seraient les moyens?

31. - Dans les écoles de campagne, l'enseignement se fait-il en français ? les livres sont-ils uniformes?

32. - Chaque village est-il pourvu de maîtres et de maîtresses d'école ?

33. - Outre l'art de lire, d'écrire, de chiffrer et le catéchisme, enseigne-t-on autre chose dans ces écoles?

34. - Sont-elles assidûment surveillées par MM. Les Curés et Vicaires ?

35. - Ont-ils un assortiment de livres pour prêter à leurs paroissiens ?

36. - Les gens de la campagne ont-ils le goût de la lecture ?

37. - Quelles espèces de livres trouve-t-on plus communément chez eux ?

38. - Ont-ils beaucoup de préjugés, et dans quel genre ?

39. - Depuis une vingtaine d'années, sont-ils plus éclairés ? leurs mœurs sontelles plus dépravées ? leurs principes religieux ne sont-ils pas affaiblis?

40. - Quelles sont les causes et quels seraient les remèdes à ces maux ?

41. - Quels effets moraux produit chez eux la révolution actuelle?

42. - Trouve-t-on chez eux du patriotisme, ou seulement les affections qu'inspire l'intérêt personnel ?

43. - Les ecclésiastiques et les ci-devant nobles ne sont-ils pas en butte aux injures grossières, aux outrages des paysans et au despotisme des maires et des municipalités? 


\subsection{Die Épître à Boileau sur les mots nouveaux von Jean Pons Guillaume Viennet}

Die Abschrift der Épitre à Boileau sur les mots nouveaux stammt aus dem Bereich CHASS - Computing in the Humanities and Social Sciences der Website der Faculty of Arts \& Science der University of Toronto (s.a.: Épitre à Boileau sur les mots nouveaux).

C'en est fait, Despréaux, le mauvais goût l'emporte,

La langue de ton siècle est une langue morte ;

Et si, pour le malheur des nouveaux Chapelains

Pluton te renvoyait au séjour des humains,

De vingt jargons divers le mélange bizarre

Te ferait de stupeur regagner le Tartare.

Des ossements blanchis de ces pauvres auteurs,

Qu'ont chassés d'Hélicon tes sarcasmes vengeurs,

S'élève d'heure en heure une race éphémère,

Qui, d'un art inconnu poursuivant la chimère,

Aboie à tes pareils, et, d'un air triomphant,

Du nom de rococo flétrit qui les défend.

La loi de ces pandours est de n'en pas connaître.

Chacun, libre en sa marche, est son juge et son maître ;

Et ta langue, impuissante à les glorifier,

N'a pu même suffire à les qualifier.

Il faut des noms nouveaux pour ces nouveaux artistes.

Ils se nomment entre eux bohèmes, fantaisistes.

Ils ont, pour se louer, des termes inconnus,

Que la tour de Babel n'a pas même entendus,

Supercoquentieux, chicandard, titanesque ;

Et si, leur reprochant ce langage burlesque,

Un honnête lecteur interdit à ses fils

Les livres, les journaux par ces mots envahis,

Des novateurs sur lui s'acharne la furie.

Ils traitent sa raison de pudibarderie ;

Mettent au ban du siècle et de l'humanité

L'ennemi du progrès et de la liberté ;

Et le Néologisme, en conquérant vandale,

Poursuit impunément sa course triomphale.

Ainsi les mots nouveaux nous pleuvent par milliers.

Philosophes, savants, voleurs et boutiquiers,

Artistes, prosateurs, poëtes, tout s'en mêle. 
Chacun fait son argot, sa grammaire nouvelle.

Chacun peut à son gré, sans crainte d'un revers,

Dégingander sa prose et déhancher ses vers,

Barbariser son style, empenner son génie,

Et comme ses lecteurs flouer la prosodie.

Des critiques acharnés viendront le lendemain

Vanter de ses écrits le lyrisme et l'entrain.

Viens lire à ces Ronsards ton code poétique.

Nous sommes trois à peine, en ce siècle anarchique,

Qui, te prenant pour guide au risque de broncher,

Sur tes pas glorieux essayons de marcher.

Eh! quels cris sont les leurs ! Dieu sait comment on nous traite!

Quels brocards sont tombés sur mon dos et sur ma tête !

Mais Dieu d'un triple airain les avait cuirassés,

Et leurs traits à mes pieds retombent émoussés.

Par cinquante ans de lutte, à toute heure, exercée,

Ma muse, Despréaux, n'est point encor lassée ;

Et jeune encor de verve, au déclin de mes ans,

Défendra jusqu'au bout le goût et le bon sens.

Je maudis ces auteurs dont le vocabulaire

Nous encombre de mots dont nous n'avons que faire ;

Qui, sur de vains succès basant un fol orgueil,

D'un œil ambitieux fixent notre fauteuil ;

Qui, pour utiliser leur frivole existence,

Des corrupteurs du goût activent la licence,

Formulent leur pensée en style de Purgon,

Ou qui gardant au cœur la foi de Saint-Simon,

S'indignant que la femme à l'homme soit soumise,

Demandent que l'État la désubalternise.

Je veux qu'un philosophe, en termes nets et clairs,

M'explique, s'il le peut, Dieu, l'âme et l'univers.

Lorsque, se dépouillant de science et de guide,

Du doute et du néant s'élançant dans le vide,

Descartes, pas à pas, refoulant l'horizon,

Est monté jusqu'au Dieu que cherchait sa raison,

Il n'a point, affectant des formules obscures,

A mon intelligence imposé des tortures.

Son style, ferme et noble en sa simplicité,

Fait sans peine à mes yeux luire la vérité ;

Et c'est en m'expliquant ces augustes mystères,

Qu'il découvre ta langue et ses formes sévères.

Pascal, dans cette voie, à son tour entraîné, 
Fixe en l'assouplissant la langue de Réné ;

Et le grand Bossuet, sondant le même abîme, Sans nuire à la clarté, la fait grande et sublime.

Mais la clarté répugne aux modernes penseurs. Le Nord nous a lâché de terribles docteurs, Qui des épais brouillards de leur métaphysique, Des termes nébuleux de leur style algébrique, Nous voilent la lumière et nous rendent la nuit, Le doute désolant par Descartes détruit. Si mon esprit, troublé d'une double doctrine, Veut de l'idée enfin connaître l'origine, Un Welche me répond que l'objectivité A fait passer l'idée à la réalité ;

Et qu'en son propre sein, par la même entremise, Cette idée à son tour enfin se réalise.

J'écoute ; et mon docteur, me croyant convaincu, En cherchant l'idéal, se perd dans l'absolu, Subjective, objective; et tirant de ces verbes Un flot de substantifs, d'adjectifs et d'adverbes, M'accable enfin des mots d'extériorité, De téléiologie [sic] et de passivité, Qu'au siècle d'Abailardon eût traités d'infâmes, Et qu'avec leur auteur on eût livrés aux flammes. Ces Welches, cependant, des adeptes vantés, Sont au sein de Paris traduits et colportés. Qui m'en fera justice ? Irai-je en ma colère Déférer au parquet traducteur et libraire ; Et du tort qu'à ma langue ils auront pu causer, Du temps que j'ai perdu me faire indemniser? Hélas! les novateurs m'ont fermé ces refuges ; Et leur néologisme a perverti les juges.

Ce n'était point assez de ce patois grossier, Que voulait t'imposer ta race de greffier, Qu'au mépris de tes vers et des vers de Racine, A nous jeter au nez la pratique s'obstine. Le juge, au lieu d'arrêts prononce des verdicts ; Les bandits condamnés deviennent des convicts.

La rage de ces mots à faces étrangères

Gagne au Palais-Bourbon nos chambres légifères. Leurs actes sont des bills, et la votation Est le terme obligé de la discussion.

Dans ce métier, qu'alors on soldait en outrages, 
Nous avons revêtu vingt fois de nos suffrages Des lois où figuraient, près du sucre ou du rack, Le tudesque thalweg et le saxon drawback.

Là, pour le mot budget importé d'Angleterre, J'ai vu gronder trente ans une effroyable guerre, Le centre sous le feu prêt à se disloquer, Le côtés gauche et droit s'unir pour l'attaquer, Lancer incessamment sur le banc des ministres Mensonges, démentis et présages sinistres. Impuissantes fureurs ! Ce mot victorieux Seul de tant de combats est sorti glorieux ; Laissant sur le carreau rois et chartes royales, Gorgeant de millions ses colonnes fiscales, Grossi de règne en règne, et toujours affamé, Se riant des tribuns qui l'avaient réformé, Le traître nous revient sans bruit et sans esclandre, Comme un phénix muet qui renaît de sa cendre.

Son palais vainement a changé de patrons :

J'ai vu de Février les apprentis Solons

Frappant du même coup le trône et le lexique, Par le verbe acclamer ouvrir leur république ; Et comme eux en hurlant le peuple l'acclamait; Et dans ce peuple immense aucun ne réclamait Contre un chef qui, prenant sa place dans l'histoire, D'un affreux barbarisme entachait sa mémoire ; Et de tant de bonheur, de gloire, de plaisir, Qu'à la France, à l'Europe, au monde, à l'avenir, Avait de ces Solons promis le manifeste, Ce verbe, Despréaux, est tout ce qui nous reste.

Ta langue trouve ainsi parmi ses corrupteurs, Ceux même que la loi lui donnait pour tuteurs. Que dis-je ! au moment même où ma muse indignée Repousse de ces mots l'adultère lignée, Un de nos immortels, et des plus glorieux, Du verbe fluctuer vient d'affliger mes yeux. Que dire à l'ouvrier qui, pour son industrie, Fait les mots de boulange ou de droguisterie, Qui, rougissant des noms de linger, de tailleur, Se nomme chemisier et confectionneur?

Que dire au jeune auteur qui, pour former son style, Voudra collaborer au quart d'un vaudeville? Quel reproche adresser à l'un de nos schérifs, 
Qui, d'un chemin de fer révisant les tarifs, Oubliant que sous l'eau tout moisit et se rouille, Affranchit le transport des risques de la mouille?

Mais quels termes nouveaux nous portent ces chemins?

C'est là que l'étranger les verse à pleines mains.

La vapeur, renversant douanes et barrières, Les fait entrer sans droit par toutes nos frontières. On n'entend que des mots à déchirer le fer, Le rail-way, le tunnel, le ballast, le tender, Express, trucks et wagons.... Une bouche française Semble broyer du verre et mâcher de la braise. Eh ! qu'avons-nous besoin de ces termes bâtards, Pour peindre ces chemins, merveille de nos arts, Ce fer qui, sur le sable, allongeant ses lanières, En rayons accouplés dessinant leurs ornières, Court sur les monts fendus ou de voûtes percés, Sur les fleuves soumis, les vallons rehaussés, Ces longs convois de chars, d'élégantes voitures, Glissant comme le vent sur leurs doubles nervures, Emportant dans leur course arsenaux et greniers, Escadrons, bataillons et des peuples entiers ; Et ce gaz, qui, doublant, triplant la force humaine, Dans l'espace accourci les pousse ou les entraîne, Et l'effrayant cylindre où l'onde en bouillonnant, Produit cette vapeur qui s'échappe en grondant?

Non, la nature et l'art n'offrent point de merveille Qu'on ne puisse chanter sans m'écorcher l'oreille. Je renie un auteur qui vient par vanité Rejeter sa misère et sa stérilité Sur la langue où Corneille et Pascal et Molière De leur œuvre immortelle ont puisé la matière. Sera-t-elle plus riche, alors que nos marins Auront du nom de docks baptisé leurs bassins ; $\mathrm{Si}$, pour me garantir d'un cheval qui galoppe, Au lieu de l'arrêter il faut que je le stoppe. Pour nommer ces vaisseaux que pousse la vapeur, Le grec nous façonnait un mot plein de douceur ; Mais ce mot, dont ma muse admirait l'euphonie, A, pour venir à nous, passé par la Russie ; La guerre le repousse, et les coureurs des mers Laissent le pyroscaphe et prennent les steamers. 
Certes, de nos voisins l'alliance m'enchante ;

Mais leur langue, à vrai dire, est trop envahissante, Et jusque dans nos jeux, nous jette à tout propos Les substantifs sifflants des Saxons et des Scots.

Passe encore pour le wisth, il vient des trois royaumes ;

Mais le monde avant eux courait aux hippodromes.

Faut-il, pour cimenter un merveilleux accord,

Changer l'arène en turf et le plaisir en sport,

Demander à des clubs l'aimable causerie,

Flétrir du nom de grooms nos valets d'écurie ;

Traiter nos cavaliers de gentlemen-riders;

Et de Racine un jour parodiant les vers,

Montrer, au lieu de Phèdre, une lionne anglaise,

Qui, dans un handicap ou dans un steaple-chease,

Suit de l'œil un wagon de sportsmen escorté,

Et fuyant sur le turf par le truck emporté ?

Voilà, cher Despréaux, de quelle mélodie

L'Anglais et nos lions menacent ta patrie.

Ah ! si le nom de Wurtz a pu t'épouvanter,

A ce déluge affreux pourrais-tu résister?

J'en suffoque moi-même et je reprends haleine.

La voix de Ristori retentit sur la scène ;

Je vais en l'écoutant dissiper mon chagrin.

Et me débarbouiller en lisant ton Lutrin. 


\subsection{Der Gesetzestext der Loi Bas-Lauriol}

Der auf den folgenden Seiten wiedergegebene Gesetzestext der Loi $n^{\circ}$ 75-1349 $d u$ 31 décembre 1975 relative à l'emploi de la langue française, kurz Loi Bas-Lauriol, wurde dem Journal Officiel vom 4. Januar 1976, vom staatlichen Service Legifrance.gouv.fr - Le Service Public de la Diffusion du Droit (s.a. a: Image JO du 04/01/1976, page: 00189 - Loi n ${ }^{\circ} 75-1349$ du 31 décembre 1975 relative à l'emploi de la langue française, Teil 1 sowie s.a. b: Image JO du 04/01/1976, page: 00190 Loi $\mathrm{n}^{\circ}$ 75-1349 du 31 décembre 1975 relative à l'emploi de la langue française, Teil 2) online veröffentlicht, entnommen.

LOI $n^{\circ}$ 75-1349 du 31 décembre 1975

relative à l'emploi de la langue française (1).

L'Assemblée nationale et le Sénat ont adopté,

Le Président de la République promulgue la loi dont la teneur suit :

Art. 1er. - Dans la désignation, l'offre, la présentation, la publicité écrite ou parlée, le mode d'emploi ou d'utilisation, l'étendue et les conditions de garantie d'un bien ou d'un service, ainsi que dans les factures et quittances, l'emploi de la langue française est obligatoire. Le recours à tout terme étranger ou à toute expression étrangère est prohibé lorsqu'il existe une expression ou un terme approuvés dans les conditions prévues par le décret $n^{\circ} 72-19 \mathrm{du} 7$ janvier 1972 relatif à l'enrichissement de la langue française. Le texte français peut se complèter d'une ou plusieurs traductions en langue étrangère.

Les mêmes règles s'appliquent à toutes informations ou présentations de programmes de radiodiffusion et de télévision, sauf lorsqu'elles sont destinées expressément à un public étranger.

L'obligation et la prohibition imposées par les dispositions de l'alinéa 2 s'appliquent également aux certificats de qualité prévus à l'article 7 de la loi de finances $n^{\circ}$ 63-628 du 2 juillet 1963 .

Art. 2. - Les dispositions de l'article 1er ne sont pas applicables à la dénomination des produits typiques et spécialités d'appellation étrangère connus du plus large public.

En outre, des décrets préciseront dans quelles conditions des dérogations pourront être apportées aux dispositions de l'article 1er lorsque leur application serait contraire aux engagements internationaux de la France.

Art. 3. - Les infractions aux dispositions de l'article 1er ci-dessus sont, sans préjudice des dispositions de l'article 8 de la loi susvisée du 2 juillet 1963 , constatées et poursuivies comme en matière d'infractions à la loi du 1er août 
1905 sur la répression des fraudes, et punies des peines prévues à l'article 13 de cette loi.

Art. 4. - L'article L. 121-1 du code du travail est complété par les alinéas suivants :

«Toutefois, le contrat de travail constaté par écrit et à exécuter sur le territoire français est rédigé en français. Il ne peut contenir ni terme étranger ni expression étrangère lorsqu'il existe une expression ou un terme approuvés dans les conditions prévues par le décret $\mathrm{n}^{\circ} 72-19$ du 7 janvier 1972 relatif à l'enrichissement de la langue française.

«Lorsque l'emploi qui fait l'objet du contrat ne peut être désigné que par un terme étranger sans correspondant en français, le contrat de travail doit comporter une explication, en français, du terme étranger.

"Lorsque le salarié est étranger et le contrat constaté par écrit, une traduction du contrat est rédigée, à la demande du salarié, dans la langue de ce dernier ; les deux textes font également foi en justice. En cas de discordance entre les deux textes, seul le texte rédigé dans la langue du salarié étranger peut être invoqué contre ce dernier. »

Art. 5. - L'article L. 311-4 du code du travail est complété par les dispositions suivantes :

«3e Un texte rédigé en langue étrangère ou contenant des termes étrangers ou des expressions étrangères, lorsqu'il existe une expression ou un terme approuvés dans les conditions prévues par le décret $n^{\circ} 72-19$ du 7 janvier 1972 relatif à l'enrichissement de la langue française.

" Lorsque l'emploi ou le travail offert ne peut être désigné que par un terme étranger sans correspondant en français, le texte français doit en comporter une description suffisamment détaillée pour ne pas induire en erreur au sens du paragraphe $2 \mathrm{e}$ ci-dessus.

«Les interdictions portées au 3e ci-dessus ne s'appliquent qu'aux services à exécuter sur le territoire français, quelle que soit la nationalité de l'auteur de l'offre ou de l'employeur, et alors même que la parfaite connaissance d'une langue étrangère serait une des conditions requises pour tenir l'emploi proposé. Toutefois, les directeurs de publications principalement rédigées en langues étrangères peuvent recevoir des offres d'emploi rédigées dans ces langues. En outre, les offres d'emploi expressément faites à l'intention de ressortissants étrangers peuvent être rédigées en langue étrangère. »

Art. 6. - Toute inscription apposée par des personnes utilisant, à quelque titre que ce soit, un bien appartenant à une collectivité publique, à un établissement public, à une entreprise publique ou à une entreprise concessionnaire d'un service public devra être rédigée en langue française. Le texte français peut se 
complèter d'une ou plusieurs traductions en langue étrangère. Il ne peut contenir ni expression ni terme étrangers lorsqu'il existe une expression ou un terme approuvés dans les conditions prévues par le décret $n^{\circ} 72-19$ du 7 janvier 1972 relatif à l'enrichissement de la langue française.

Dans les bâtiments et sur les terrains fréquentés par des étrangers, ainsi qu'à l'intérieur des véhicules de transport en commun qui peuvent être utilisés par des étrangers, toute inscription est rédigée en langue française et peut se complèter d'une ou plusieurs traductions en langue étrangère.

En cas d'inobservation des dispositions du présent article, la collectivité propriétaire du bien peut mettre l'utilisateur en demeure de faire cesser, à ses frais et dans le délai fixé par elle, l'irrégularité constatée.

L'usage du bien peut être retiré au contrevenant, même en l'absence de dispositions expresses dans la rédaction du contrat qu'il a souscrit, ou de l'autorisation qui lui a été accordée, si la mise en demeure n'a pas été suivie d'effet.

Art. 7. - L'octroi, par les collectivités et les établissements publics, des subventions de toute nature est subordonné à l'engagement pris par les bénéficiaires de respecter les dispositions de la présente loi.

Toute violation de cet engagement peut entraîner, après mise en demeure, la restitution de la subvention.

Art. 8. - Quel qu'en soient l'objet et les formes, les contrats conclus entre une collectivité ou un établissement publics et une personne quelconque doivent être rédigés en langue française. Ils ne peuvent contenir ni expression ni terme étrangers lorsqu'il existe une expression ou un terme approuvés dans les conditions prévues par le décret $n^{\circ} 72-19$ du 7 janvier 1972 relatif à l'enrichissement de la langue française.

Toutefois, les contrats conclus par une personne publique française avec un ou plusieurs contractants publics ou privés étrangers peuvent comporter, outre la rédaction en français, une rédaction en langue étrangère faisant foi au même titre que la rédaction en français.

Art. 9. - Les dispositions de la présente loi entreront en vigueur au jour de sa publication au Journal officiel, à l'exception des dispositions des articles 1er, 2 et 6 qui entreront en vigueur à l'expiration du douzième mois suivant cette publication.

La présente loi sera exécutée comme loi de l'Etat.

Fait à Paris, le 31 décembre 1975. 
VALÉRY GISCARD D'ESTAING.

Par le Président de la République :

Le Premier ministre,

JACQUES CHIRAC.

Le ministre des affaires étrangères,

JEAN SAUVAGNARGUES.

Le ministre du travail,

MICHEL DURAFOUR.

Le ministre du commerce et de l'artisanat, VINCENT ANSQUER.

Loi n ${ }^{\circ}$ 75-1349 TRAVAUX PREPARATOIRES (1)

Assemblée nationale :

Proposition de loi $\mathrm{n}^{\circ} 306$;

Rapport et rapport supplémentaire de M. Lauriol, au nom de la commission des lois $\left(\mathrm{n}^{\circ} 517\right.$ et $\left.\mathrm{n}^{\circ} 1694\right)$;

Discussion et adoption le 6 juin 1975.

Sénat :

Proposition de loi, adoptée par l'Assemblée nationale, nº 367 (1974-1975);

Rapport de M. Georges Lamousse, au nom de la commission des affaires culturelles, $\mathrm{n}^{\circ} 21$ (1975-1976);

Discussion et adoption le 23 octobre 1975.

Assemblée nationale :

Proposition de loi, modifiée par le Sénat ( $\left.{ }^{\circ} 1929\right)$;

Rapport de M. Lauriol, au nom de la commission des lois ( $\left.\mathrm{n}^{\circ} 2073\right)$;

Discussion et adoption le 19 décembre 2013. 


\subsection{Der Gesetzestext der Loi Toubon}

Der Gesetzestext der Loi $n^{\circ}$ 94-665 du 4 août 1994 relative à l'emploi de la langue française, kurz Loi Toubon, wurde der Website des staatlichen Services Legifrance.gouv.fr - Le Service Public de la Diffusion du Droit (s.a. e:JORF n 180 du 5 août 1994 page 11392 - LOI no 94-665 du 4 août 1994 relative à l'emploi de la langue française (1) ) entnommen.

JORF nº180 du 5 août 1994 page 11392

LOI

LOI no 94-665 du 4 août 1994 relative à l'emploi de la langue française (1)

NOR: MCCX9400007L

Le Président de la République promulgue la loi dont la teneur suit:

Art. 1er. - Langue de la République en vertu de la Constitution, la langue française est un élément fondamental de la personnalité et du patrimoine de la France.

Elle est la langue de l'enseignement, du travail, des échanges et des services publics.

Elle est le lien privilégié des Etats constituant la communauté de la francophonie.

Art. 2. - Dans la désignation, l'offre, la présentation, le mode d'emploi ou d'utilisation, la description de l'étendue et des conditions de garantie d'un bien, d'un produit ou d'un service, ainsi que dans les factures et quittances, l'emploi de la langue française est obligatoire.

[Dispositions déclarées non conformes à la Constitution par décision du Conseil constitutionnel no 94-345 DC du 29 juillet 1994.] Les mêmes dispositions s'appliquent à toute publicité écrite, parlée ou audiovisuelle.

Les dispositions du présent article ne sont pas applicables à la dénomination des produits typiques et spécialités d'appellation étrangère connus du plus large public.

La législation sur les marques ne fait pas obstacle à l'application des premier et troisième alinéas du présent article aux mentions et messages enregistrés avec la marque.

Art. 3. - Toute inscription ou annonce apposée ou faite sur la voie publique, dans un lieu ouvert au public ou dans un moyen de transport en commun et destinée à l'information du public doit être formulée en langue française. [Dispositions déclarées non conformes à la Constitution par décision du 
Conseil constitutionnel no 94-345 DC du 29 juillet 1994.] Si l'inscription rédigée en violation des dispositions qui précèdent est apposée par un tiers utilisateur sur un bien appartenant à une personne morale de droit public, celle-ci doit mettre l'utilisateur en demeure de faire cesser, à ses frais et dans le délai fixé par elle, l'irrégularité constatée. Si la mise en demeure n'est pas suivie d'effet, l'usage du bien peut, en tenant compte de la gravité du manquement, être retiré au contrevenant, quels que soient les stipulations du contrat ou les termes de l'autorisation qui lui avait été accordée.

Art. 4. - Lorsque des inscriptions ou annonces visées à l'article précédent, apposées ou faites par des personnes morales de droit public ou des personnes privées exerçant une mission de service public font l'objet de traductions, celles-ci sont au moins au nombre de deux.

Dans tous les cas où les mentions, annonces et inscriptions prévues aux articles 2 et 3 de la présente loi sont complétées d'une ou plusieurs traductions, la présentation en français doit être aussi lisible, audible ou intelligible que la présentation en langues étrangères.

Un décret en Conseil d'Etat précise les cas et les conditions dans lesquels il peut être dérogé aux dispositions du présent article dans le domaine des transports internationaux.

Art. 5. - Quels qu'en soient l'objet et les formes, les contrats auxquels une personne morale de droit public ou une personne privée exécutant une mission de service public sont parties sont rédigés en langue française. Ils ne peuvent contenir ni expression ni terme étrangers lorsqu'il existe une expression ou un terme français de même sens approuvés dans les conditions prévues par les dispositions réglementaires relatives à l'enrichissement de la langue française.

Ces dispositions ne sont pas applicables aux contrats conclus par une personne morale de droit public gérant des activités à caractère industriel et commercial et à exécuter intégralement hors du territoire national.

Les contrats visés au présent article conclus avec un ou plusieurs cocontractants étrangers peuvent comporter, outre la rédaction en français, une ou plusieurs versions en langue étrangère pouvant également faire foi. Une partie à un contrat conclu en violation du premier alinéa ne pourra se prévaloir d'une disposition en langue étrangère qui porterait préjudice à la partie à laquelle elle est opposée.

Art. 6. - Tout participant à une manifestation, un colloque ou un congrès organisé en France par des personnes physiques ou morales de nationalité française a le droit de s'exprimer en français. Les documents distribués aux participants avant et pendant la réunion pour en présenter le programme doi- 
vent être rédigés en français et peuvent comporter des traductions en une ou plusieurs langues étrangères.

Lorsqu'une manifestation, un colloque ou un congrès donne lieu à la distribution aux participants de documents préparatoires ou de documents de travail, ou à la publication d'actes ou de comptes rendus de travaux, les textes ou interventions présentés en langue étrangère doivent être accompagnés au moins d'un résumé en français.

Ces dispositions ne sont pas applicables aux manifestations, colloques ou congrès qui ne concernent que des étrangers, ni aux manifestations de promotion du commerce extérieur de la France.

Lorsqu'une personne morale de droit public ou une personne morale de droit privé chargée d'une mission de service public a l'initiative des manifestations visées au présent article, un dispositif de traduction doit être mis en place.

Art. 7. - Les publications, revues et communications diffusées en France et qui émanent d'une personne morale de droit public, d'une personne privée exerçant une mission de service public ou d'une personne privée bénéficiant d'une subvention publique doivent, lorsqu'elles sont rédigées en langue étrangère, comporter au moins un résumé en français.

[Dispositions déclarées non conformes à la Constitution par décision du Conseil constitutionnel no 94-345 DC du 29 juillet 1994.]

Art. 8. - Les trois derniers alinéas de l'article L. 121-1 du code du travail sont remplacés par quatre alinéas ainsi rédigés:

« Le contrat de travail constaté par écrit est rédigé en français.

[Dispositions déclarées non conformes à la Constitution par décision du Conseil constitutionnel no 94-345 DC du 29 juillet 1994.] « Lorsque l'emploi qui fait l'objet du contrat ne peut être désigné que par un terme étranger sans correspondant en français, le contrat de travail doit comporter une explication en français du terme étranger.

«Lorsque le salarié est étranger et le contrat constaté par écrit, une traduction du contrat est rédigée, à la demande du salarié, dans la langue de ce dernier. Les deux textes font également foi en justice. En cas de discordance entre les deux textes, seul le texte rédigé dans la langue du salarié étranger peut être invoqué contre ce dernier.

«L'employeur ne pourra se prévaloir à l'encontre du salarié auquel elles feraient grief des clauses d'un contrat de travail conclu en violation du présent article. »

Art. 9. - I. - L'article L. 122-35 du code du travail est complété par un alinéa ainsi rédigé: 
«Le règlement intérieur est rédigé en français. [Dispositions déclarées non conformes à la Constitution par décision du Conseil constitutionnel no 94-345 DC du 29 juillet 1994.] Il peut être accompagné de traductions en une ou plusieurs langues étrangères. » II. - Il est inséré, après l'article L. 122-39 du code du travail, un article L. 122-39-1 ainsi rédigé:

« Art. L. 122-39-1. - Tout document comportant des obligations pour le salarié ou des dispositions dont la connaissance est nécessaire à celui-ci pour l'exécution de son travail doit être rédigé en français. [Dispositions déclarées non conformes à la Constitution par décision du Conseil constitutionnel no 94-345 DC du 29 juillet 1994.] Il peut être accompagné de traductions en une ou plusieurs langues étrangères.

«Ces dispositions ne sont pas applicables aux documents reçus de l'étranger ou destinés à des étrangers. » III. - Aux premier et troisième alinéas de l'article L. 122-37 du code du travail, les mots: « articles L. 122-34 et L. 122-35 » sont remplacés par les mots: « articles L. 122-34, L. 122-35 et L. 122-39-1 ».

IV. - Il est inséré, après l'article L. 132-2 du code du travail, un article L. 1322-1 ainsi rédigé:

«Art. L. 132-2-1. - Les conventions et accords collectifs de travail et les conventions d'entreprise ou d'établissement doivent être rédigés en français. Toute disposition rédigée en langue étrangère [Dispositions déclarées non conformes à la Constitution par décision du Conseil constitutionnel no 94-345 DC du 29 juillet 1994] est inopposable au salarié à qui elle ferait grief. »

Art. 10. - Le 30 de l'article L. 311-4 du code du travail est ainsi rédigé: « 30 Un texte rédigé en langue étrangère [Dispositions déclarées non conformes à la Constitution par décision du Conseil constitutionnel no 94-345 DC du 29 juillet 1994].

«Lorsque l'emploi ou le travail offert ne peut être désigné que par un terme étranger sans correspondant en français, le texte français doit en comporter une description suffisamment détaillée pour ne pas induire en erreur au sens du 20 ci-dessus.

«Les prescriptions des deux alinéas précédents s'appliquent aux services à exécuter sur le territoire français, quelle que soit la nationalité de l'auteur de l'offre ou de l'employeur, et aux services à exécuter hors du territoire français lorsque l'auteur de l'offre ou l'employeur est français, alors même que la parfaite connaissance d'une langue étrangère serait une des conditions requises pour tenir l'emploi proposé. Toutefois, les directeurs de publications rédigées, en tout ou partie, en langue étrangère peuvent, en France, recevoir des offres d'emploi rédigées dans cette langue. »

Art. 11. - I. - La langue de l'enseignement, des examens et concours, ainsi que des thèses et mémoires dans les établissements publics et privés d'enseigne- 
ment est le français, sauf exceptions justifiées par les nécessités de l'enseignement des langues et cultures régionales ou étrangères ou lorsque les enseignants sont des professeurs associés ou invités étrangers.

Les écoles étrangères ou spécialement ouvertes pour accueillir des élèves de nationalité étrangère, ainsi que les établissements dispensant un enseignement à caractère international, ne sont pas soumis à cette obligation.

II. - Il est inséré, après le deuxième alinéa de l'article 1er de la loi no 89-486 du 10 juillet 1989 d'orientation sur l'éducation, un alinéa ainsi rédigé:

« La maîtrise de la langue française et la connaissance de deux autres langues font partie des objectifs fondamentaux de l'enseignement. »

Art. 12. - Avant le chapitre Ier du titre II de la loi no 86-1067 du 30 septembre 1986 relative à la liberté de communication, il est inséré un article 20-1 ainsi rédigé:

«Art. 20-1. - L'emploi du français est obligatoire dans l'ensemble des émissions et des messages publicitaires des organismes et services de radiodiffusion sonore ou télévisuelle, quel que soit leur mode de diffusion ou de distribution, à l'exception des oeuvres cinématographiques et audiovisuelles en version originale.

«Sous réserve des dispositions du 2o bis de l'article 28 de la présente loi, l'alinéa précédent ne s'applique pas aux oeuvres musicales dont le texte est, en tout ou partie, rédigé en langue étrangère.

« L'obligation prévue au premier alinéa n'est pas applicable aux programmes, parties de programme ou publicités incluses dans ces derniers qui sont conçus pour être intégralement diffusés en langue étrangère ou dont la finalité est l'apprentissage d'une langue, ni aux retransmissions de cérémonies culturelles. [Dispositions déclarées non conformes à la Constitution par décision du Conseil constitutionnel no 94-345 DC du 29 juillet 1994.] « Lorsque les émissions ou les messages publicitaires visés au premier alinéa du présent article sont accompagnés de traductions en langues étrangères, la présentation en français doit être aussi lisible, audible ou intelligible que la présentation en langue étrangère. »

Art. 13. - La loi no 86-1067 du 30 septembre 1986 précitée est ainsi modifiée: I. - Après le sixième alinéa du II de l'article 24 , il est inséré un alinéa ainsi rédigé:

« - le respect de la langue française et le rayonnement de la francophonie. » II.

- A l'article 28, il est inséré, après le 4o, un 4o bis ainsi rédigé:

« $4 \mathrm{o}$ bis Les dispositions propres à assurer le respect de la langue française et le rayonnement de la francophonie; ».

III. - A l'article 33, il est inséré, après le 2o, un 20 bis ainsi rédigé: 
« 20 bis Les dispositions propres à assurer le respect de la langue française et le rayonnement de la francophonie; ».

Art. 14. - I. - L'emploi d'une marque de fabrique, de commerce ou de service constituée d'une expression ou d'un terme étrangers est interdit aux personnes morales de droit public dès lors qu'il existe une expression ou un terme français de même sens approuvés dans les conditions prévues par les dispositions réglementaires relatives à l'enrichissement de la langue française.

Cette interdiction s'applique aux personnes morales de droit privé chargées d'une mission de service public, dans l'exécution de celle-ci.

II. - Les dispositions du présent article ne sont pas applicables aux marques utilisées pour la première fois avant l'entrée en vigueur de la présente loi.

Art. 15. - L'octroi, par les collectivités et les établissements publics, de subventions de toute nature est subordonné au respect par les bénéficiaires des dispositions de la présente loi.

Tout manquement à ce respect peut, après que l'intéressé a été mis à même de présenter ses observations, entraîner la restitution totale ou partielle de la subvention.

Art. 16. - Outre les officiers et agents de police judiciaire agissant conformément aux dispositions du code de procédure pénale, les agents énumérés aux 10,30 et 40 de l'article L. 215-1 du code de la consommation sont habilités à rechercher et constater les infractions aux dispositions des textes pris pour l'application de l'article 2 de la présente loi.

A cet effet, les agents peuvent pénétrer de jour dans les lieux et véhicules énumérés au premier alinéa de l'article L. 213-4 du même code et dans ceux où s'exercent les activités mentionnées à l'article L. 216-1, à l'exception des lieux qui sont également à usage d'habitation. Ils peuvent demander à consulter les documents nécessaires à l'accomplissement de leur mission, en prendre copie et recueillir sur convocation ou sur place les renseignements et justifications propres à l'accomplissement de leur mission.

Ils peuvent également prélever un exemplaire des biens ou produits mis en cause dans les conditions prévues par décret en Conseil d'Etat.

Art. 17. - Quiconque entrave de façon directe ou indirecte l'accomplissement des missions des agents mentionnés au premier alinéa de l'article 16 ou ne met pas à leur disposition tous les moyens nécessaires à cette fin est passible des peines prévues au second alinéa de l'article 433-5 du code pénal. 
Art. 18. - Les infractions aux dispositions des textes pris pour l'application de la présente loi sont constatées par des procès-verbaux qui font foi jusqu'à preuve du contraire.

Les procès-verbaux doivent, sous peine de nullité, être adressés dans les cinq jours qui suivent leur clôture au procureur de la République.

Une copie en est également remise, dans le même délai, à l'intéressé.

Art. 19. - Après l'article 2-13 du code de procédure pénale, il est inséré un article 2-14 ainsi rédigé:

«Art. 2-14. - Toute association régulièrement déclarée se proposant par ses statuts la défense de la langue française et agréée dans les conditions fixées par décret en Conseil d'Etat peut exercer les droits reconnus à la partie civile en ce qui concerne les infractions aux dispositions des textes pris pour l'application des articles 2, 3, 4, 6, 7 et 10 de la loi no 94-665 du 4 août 1994 relative à l'emploi de la langue française. »

Art. 20. - La présente loi est d'ordre public. Elle s'applique aux contrats conclus postérieurement à son entrée en vigueur.

Art. 21. - Les dispositions de la présente loi s'appliquent sans préjudice de la législation et de la réglementation relatives aux langues régionales de France et ne s'opposent pas à leur usage.

Art. 22. - Chaque année, le Gouvernement communique aux assemblées, avant le 15 septembre, un rapport sur l'application de la présente loi et des dispositions des conventions ou traités internationaux relatives au statut de la langue française dans les institutions internationales.

Art. 23. - Les dispositions de l'article 2 entreront en vigueur à la date de publication du décret en Conseil d'Etat définissant les infractions aux dispositions de cet article, et au plus tard douze mois après la publication de la présente loi au Journal officiel.

Les dispositions des articles 3 et 4 de la présente loi entreront en vigueur six mois après l'entrée en vigueur de l'article 2.

Art. 24. - La loi no 75-1349 du 31 décembre 1975 relative à l'emploi de la langue française est abrogée, à l'exception de ses articles 1er à 3 qui seront abrogés à compter de l'entrée en vigueur de l'article 2 de la présente loi et de son article 6 qui sera abrogé à la date d'entrée en vigueur de l'article 3 de la présente loi.

La présente loi sera exécutée comme loi de l'Etat. 
Fait à Paris, le 4 août 1994.

FRANCOIS MITTERRAND

Par le Président de la République:

Le Premier ministre,

EDOUARD BALLADUR

Le ministre d'Etat, ministre de l'intérieur

et de l'aménagement du territoire,

CHARLES PASQUA

Le ministre d'Etat, garde des sceaux,

ministre de la justice,

PIERRE MEHAIGNERIE

Le ministre des affaires étrangères,

ALAIN JUPPE

Le ministre de l'éducation nationale,

FRANCOIS BAYROU

Le ministre de l'économie,

EDMOND ALPHANDERY

Le ministre de l'équipement, des transports et du tourisme, BERNARD BOSSON

Le ministre du travail, de l'emploi

et de la formation professionnelle,

MICHEL GIRAUD

Le ministre de la culture et de la francophonie,

JACQUES TOUBON

Le ministre du budget,

porte-parole du Gouvernement,

NICOLAS SARKOZY

Le ministre de l'enseignement supérieur et de la recherche, FRANCOIS FILLON

(1) Loi no 94-665.

- Travaux préparatoires:

Sénat:

Projet de loi no 291 (1993-1994);

Rapport de M. Jacques Legendre, au nom de la commission des affaires culturelles, no 309 (1993-1994);

Discussion les 12, 13 et 14 avril 1994 et adoption le 14 avril 1994 .

Assemblée nationale:

Projet de loi, adopté par le Sénat, no 1130;

Rapport de M. Francisque Perrut, au nom de la commission des affaires culturelles, no 1158 et annexe, avis de M. Xavier Deniau, rapporteur, au nom de la commission des affaires étrangères, no 1178 ; 
Discussion les 3 et 4 mai et adoption le 4 mai 1994.

Sénat:

Projet de loi, adopté par l'Assemblée nationale, no 401 (1993-1994);

Rapport de M. Jacqes [sic] Legendre, au nom de la commission des affaires culturelles, no 437 (1993-1994);

Discussion et adoption le 26 mai 1994.

Assemblée nationale:

Projet de loi, adopté avec modifications par le Sénat en deuxième lecture, no 1289 ;

Rapport de M. Francisque Perrut, au nom de la commission des affaires culturelles, no 134;

Discussion et adoption le 13 juin 1994.

Rapport de M. Jean-Paul Fuchs, au nom de la commission mixte paritaire, no 1429 ;

Discussion et adoption le 30 juin 1994.

Sénat:

Projet de loi no 502 (1993-1994);

Rapport de M. Jacques Legendre, au nom de la commission mixte paritaire, no 547 (1993-1994);

Discussion et adoption le 1er juillet 1994.

- Conseil constitutionnel:

Décision no 94-345 DC du 29 juillet 1994 publiée au Journal officiel du 2 août 1994. 


\subsection{Das terminologische Arbeitsblatt zum Term pixel}

Die Abschrift des terminologischen Arbeitsblatts zur Entwicklung des Terms pixel wurde Depecker (2001:379f) entnommen.

[...] À preuve [pour la démarche bien réfléchie qui menait au choix d'un nouveau terme], cet exemple de dossier terminologique élaboré sur le terme pixel en 1980, date où se posait la question de son emprunt en français. C'est M. Charles Goillot, détenteur de la chaire de physique à l'Institut national agronomique de Paris-Grignon (INAPG), qui en rédigea le dossier :

\section{«1. Origine}

Pixel provient d'une abréviation aménagée (par le X central) de l'expression américaine : picture element (élément d'image).

2. Nature

Ce terme est donc une abréviation et non un acronyme, créant un néologisme.

\section{Sémantique}

L'objet désigné par ce terme est toujours le résultat d'un échantillonnage en valeurs discrètes (provenant, par exemple, de la numérisation en valeurs discrètes d'un enregistrement analogique).

NB : il se rapporte à l'état des données affichées et non à la source de ces données.

\section{Choix du terme}

Sont proposés :

1) PIXEL

2) ELIM : abréviation française non aménagée de l'expression « élément d'image », par analogie avec l'abréviation américaine.

3) Autre?

Le terme de Pixel nous semble préférable et nous proposons de le conserver tel quel en français, pour les raisons suivantes :

a) argument d'usage : il est déjà très employé par toute la communauté de la télédétection, en tous pays.

Le terme est à ce point banalisé que les lexiques des derniers mensuels de télédétection parus aux Etats-Unis ne le mentionnent plus comme terme nécessitant une définition !

b) argument phonétique : la qualité phonétique du terme Pixel est bonne et meilleure que celle d'élim.

c) Distance homophonique à d'autres termes :

- PIXEL est bien distant de tout autre terme français. Par contre, 
- ELIM est trop proche :

- de l'article défini : le, l' ...

- de termes tels que : « élimer», « éliminer » et de leurs dérivés.

Quelques phrases typiques montreront comparativement la meilleure convenance de PIXEL par rapport à ELIM, particulièrement sur le plan phonétique :

- L'image comprend 512 lignes de 512 pixels/élims

- Les pixels/élims se répartissent en n classes.

- L'élimination du pixel/élim [sic] de la classe n...

- Le pixel/élim [sic] représente une résolution de 60/80 m au sol.

- La zone considérée représente quatre-vingts pixels/élims.

\section{Définition}

Nous proposons la définition suivante : Plus petite surface homogène, constitutive d'une image enregistrée. Avec le commentaire complémentaire: Par exemple : dans le cas de la numérisation d'une bande magnétique analogique, le pixel provient de l'intégration, selon un pas donné, du signal enregistré sur la bande. » 



\section{Namenindex}

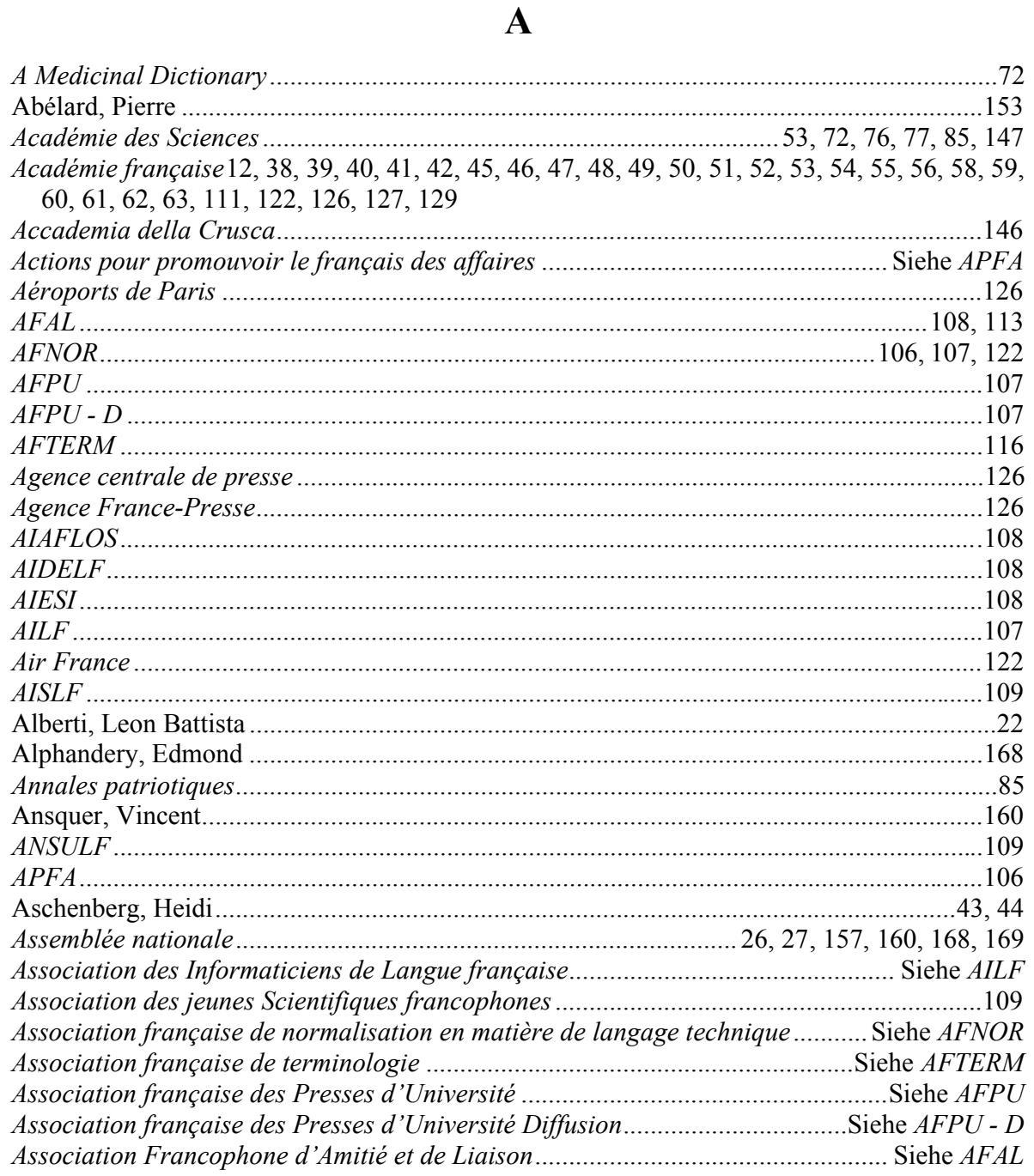


Association francophone des Professionnels de l'Aéronautique.....

Siehe Courrier sud

Association internationale des Amis du Français, Langue olympique et sportive.

Siehe AIAFLOS

Association internationale des Démographes de Langue française Siehe $A I D E L F$

Association internationale des Écoles en Sciences de l'Information Siehe AIESI

Association internationale des Sociologues de Langue française Siehe AISLF Association nationale des Scientifiques pour l'Usage de la Langue française .. Siehe ANSULF

\section{B}

Balladur, Edouard 168

Banque française de terminologie.

Barlow, Julie $13,60,83,86$

Bartsch, Renate .13

Baum, Richard. 48,49

Baumann, Klaus-Dieter .16

Bayrou, François 168

Becker, Andrea .92

Bernardin de Saint-Pierre, Jacques-Henri. .67

Berschin, Helmut. $24,25,28,32,37$

Blanke, Detlev.... .13

Bochmann, Klaus $13,82,83,84,85,87,100$

Boileau, Nicolas

Boileau-Despréaux, Nicolas $36,100,151,152,154,156$

Bosson, Bernard Siehe Boileau, Nicolas

Bossuet, Jacques-Bénigne .168

Bouhours, Dominique 153

Braselmann, Petra $43,44,45,58$

Briasson, Claude $104,122,123,128$

Brunot, Ferdinand $36,37,66,67,68,69,70$

Cassandre, François. .58

CAVILAM. 110

Centre Audiovisuel de Langues modernes Siehe CAVILAM

Certeau, Michel de 149

CETTF

CGTN. 123,124

Chamard, Henri .28, 29

Chambers, Ephraim .71

Chambre syndicale des constructeurs d'automobiles .122 
CHASS

151

Chassagne, Annie $38,39,45,58,60,61$

Château de Vincennes .72

Chirac, Jacques.. 118,160

Cicero, Marcus Tullius 110,111

CILF. 66

Code Civil 65,77

Colbert, Jean-Baptiste .26

Collège de France .26

Collège Royal

Comité consultatif de la langue française $117,118,119$

Comité d'étude des termes techniques français Siehe CETTF

Comité Universitaire francophone pour le Développement des Échanges scientifiques.... Siehe CUFDES

Commissariat général de la langue française $117,118,119$

Commission générale de terminologie et de néologie... Siehe $C G T N$

Computing in the Humanities and Social Sciences Siehe $C H A S S$

Conrart, Valentin. . .45

Conseil constitutionnel. $104,161,162,163,164,165,169$

Conseil consultatif de la francophonie. .118

Conseil d'Etat $162,166,167$

Conseil international de la langue française. Siehe CILF

Conseil supérieur de la langue française. Siehe $C S L F$

Corneille, Pierre 155

Corneille, Thomas $39,40,41,42,43,56,60,61,62$

Courrier sud 107

CSLF 119,120

CUFDES 110

Cyclopaedia, or an Universal Dictionnary of Arts and Sciences .71

\section{D}

d'Alembert, Jean-Baptiste le Rond. $70,72,74,75,80,131,145$ d'Églantine, Fabre .86

da Vinci, Leonardo .22

David, Michel-Antoine. .72

de Gaulle, Charles 115

Défense de la Langue française $99,100,111$

Deffence et Illustration de la Langue Francoyse. $28,29,30,32$

Délégation générale à la langue française et aux langues de France. Siehe DGLFLF Deniau, Xavier 168 Depecker, Loïc $116,117,121,122,123,125,126,128,170$ 
Descartes, René 153

Desportes, Phillipe

Despréaux, Nicolas Siehe Boileau, Nicolas

$D G L F$ $106,107,108,109,110,111,112,113,114,119$

$D G L F L F$ $105,119,120,125,126$

Dialogo delle lingue 30

Dictionnaire de l'Académie française. Huitième édition ...........................................................53

Dictionnaire de l'Académie française. Neuvième édition ....................................................54

Dictionnaire de l'Académie française. Septième édition ......................................................52

Dictionnaire de l'Académie française. Sixième édition publiée en 1835 ...................................50

Dictionnaire de l'Académie françoise ............................................................................46, 47

Dictionnaire de l'Académie françoise, revue, corrigé et augmenté ........................................50

Dictionnaire de l'Académie françoise. Quatrième édition .......................................................50

Dictionnaire de l'Académie françoise. Troisième édition .....................................................49

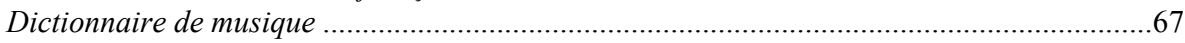

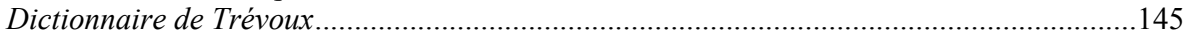

Dictionnaire des Arts et des Sciences..............................................................60, 61, 62

Dictionnaire françois, contenant les Mots et les Choses ..............................................56, 58

Dictionnaire raisonné des Sciences, des Arts et des Metiers...................... Siehe Encyclopédie

Dictionnaire universel, contenant généralement tous les Mots françois ....................51, 59, 60

Diderot, Denis ............................................... 70, 72, 73, 74, 75, 76, 79, 80, 81, 131, 145

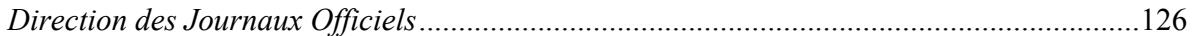

Discours sur l'Universalité de la Langue française ...........................................................11

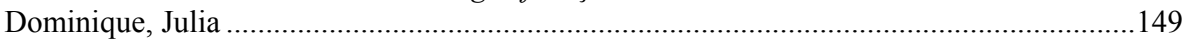

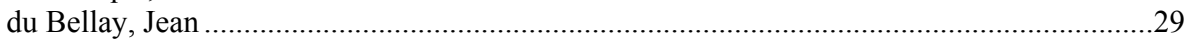

du Bellay, Joachim ....................................................... 28, 29, 30, 31, 32, 36, 88, 131

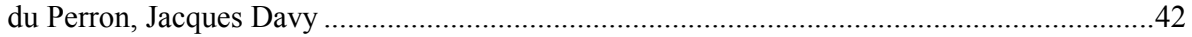

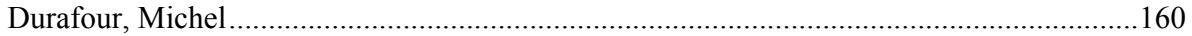

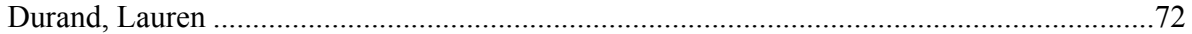

$\mathbf{E}$

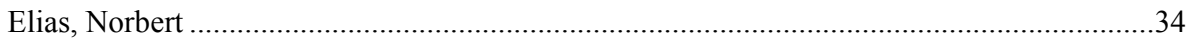

Encyclopédie ............................. 70, 71, 72, 73, 74, 75, 76, 77, 78, 79, 80, 81, 131, 145, 147

Entretiens d'Ariste et Eugène......................................................................................43, 44

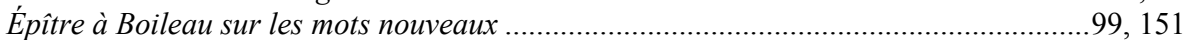

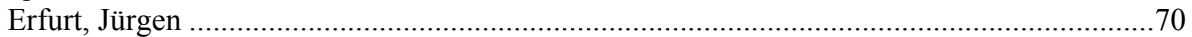

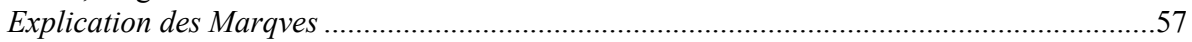

$\mathbf{F}$

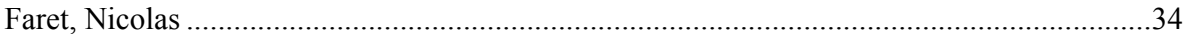


Felixberger, Josef $24,25,28,32,37$

Ferry, Jules $66,82,87$

Fillon, François .168

Fluck, Hans-Rüdiger $15,17,89,91,98$

FranceTerme 126, 129

François $\mathrm{I}^{\mathrm{er}}$ 26,27

FRANTERM 116,117

Frey, Brigitte $45,117,118,120$

Fuchs, Jean-Paul 169

Furetière, Antoine $51,56,59,60,61,62,63,67$

\section{G}

GADEF 112

Gallica..... $47,48,49,50,51,52,53,56,57,58,59,62,80,145$

GERDES 111

Giraud, Michel 168

Giscard d'Estaing, Valéry...... 160

Goebl, Hans. $24,25,28,32,37$

Goillot, Charles 170

Goosse, André 132

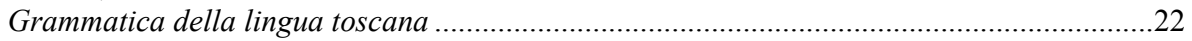

Grand Larousse encyclopédique..... .91

Grégoire, Abbé Henri. $65,82,83,149$

Grimm, Jürgen. $32,35,38,44$

Groupe d'Études et de Recherches pour le Développement des Sciences Sociales Siehe GERDES

Groupement des Associations dentaires francophones Siehe $G A D E F$

Guillotin, Joseph Ignace. .86

Gutenberg, Johannes .23

\section{H}

Haage, Bernhard Dietrich. .18

Hassler, Gerda $13,35,60,79$

Haut Comité pour la Défense et l'Expansion de la Langue française. 115,116

Haut Comité pour la Langue française 116,117

Haut Conseil de la francophonie. 117,118

Histoire de la langue française des origines à 1900. Tome VI: Le XVIIIe siècle. Première partie. Le mouvement des idées et les vocabulaires techniques

Hoffmann, Lothar. $89,91,93$

Hundt, Markus .92 


\section{I}

$I B M$ 122

IFEC-Promotion

IFP .

INaLF. .53

INAPG. 170

Institut de France.

$51,52,53,99$

Institut français de l'Emballage et du Conditionnement

Institut francophone de Paris

Institut national agronomique de Paris-Grignon

Siehe IFP

Institut National de la Langue Française.

Siehe INAPG

Siehe INaLF

\section{J}

Jakob, Karlheinz

15,16

James, Robert

.72

Janich, Nina.... 89,97

Journal Officiel

$117,119,121,157,159,167,169$

Juppé, Alain 168

\section{K}

Kalverkämper, Hartwig $22,23,24,65,89$

Klare, Johannes $25,26,30,35,58,70,71,77,102$

Kramer, Johannes $32,33,37$

Kubarth, Hugo. $85,122,128$

L'Art poétique. .36

L'Ethnographie 113

L'honnête homme, ou: L'art de plaire à la Cour .34

La Renaissance française. 113

Lamousse, Georges .160

Lauriol, Marc .160

Le Breton, André-François 71,73

Le Gras, Joseph $71,73,78$

Lebsanft, Franz. 119,120

Legendre, Jacques 168,169

Leibniz, Gottfried Wilhelm .68

Lieber, Maria. .46 
Ligue internationale des Scientifiques pour l'Usage de la Langue française ...... Siehe LISULF

LISULF 112,113

Loi Bas-Lauriol $101,102,103,119,157,167$

Loi $n^{\circ} 75-1349$ du 31 décembre 1975 relative à l'emploi de la langue française Siehe Loi BasLauriol

Loi $n^{\circ}$ 94-665 du 4 août 1994 relative à l'emploi de la langue française ...... Siehe Loi Toubon Loi Toubon $101,102,103,104,161,167,168$

Louis XIII .45

Louis XIV .34

Louis XV .72

Lutrin 156

\section{M}

Madame de Pompadour .72

Maier, Elisabeth 46

Malherbe, François de $36,37,38,42,44$

Mattheier, Klaus J. .13

Mehaignerie, Pierre .168

Mercure galant .61

Mesmer, Pierre 121

Mirandola, Pico della .21

Mission du développement et de l'enrichissement de la langue française

Mitterrand, François

$117,119,168$

Molière. .155

Müller, Bodo .... $26,91,97,100,107,111,116$

\section{$\mathbf{N}$}

Nadeau, Jean-Benoît. $13,60,83,86$ Napoleon Bonaparte. $66,81,82,87,88,132$

Nouveau Dictionnaire de l'Académie Françoise. . .48

Nouvel Observateur. 126

\section{$\mathbf{O}$}

OIF 118

Oratio de hominis dignitate.

Ordonnan du Roy sur le faid de justice Ordonnance de Villers-Cotterêts. Organisation internationale de la francophonie. Siehe Ordonnance de Villers-Cotterêts $26,27,28,84,118,131$ Siehe $O I F$ 


\section{$\mathbf{P}$}

Pascal, Blaise $35,152,155$

Pasqua, Charles 168

Patru, Olivier. 39,58

Pécheur, Jacques 28,33

Perrut, Francisque 168,169

Petit lexique des termes de marine 67

Pléiade 29,36

Pompidou, Georges .115

Proust, Jacques $60,73,74,75,76,77,78,79,80,81$

\section{$\mathbf{R}$}

Racine, Jean 153,156

Rapport sur la nécessité et les moyens d'anéantir les patois .83

Rapports annuels de la Commission générale de terminologie et de néologie.......................126

Rede über die Würde des Menschen. Siehe Oratio de hominis dignitate

Remarques nouvelles sur la Langue françoise.... .44

Remarques sur la langue française, utiles à ceux qui veulent bien parler et bien écrire .38, 39, 43, 44

Répertoire. $104,105,106,108,109,111,113$

Répertoire des Organismes et Associations oeuvrant pour la Promotion de la Langue française Siehe Répertoire

Répertoire terminologique 126

Revel, Jacques. 149

Richelet, César-Pierre. $56,57,58,59,61,67$

Richelieu, Armand Jean du Plessis de 45

Rivarol, Antoine de 11

Rocard, Michel 119

Roelcke, Thorsten

Ronsard, Pierre de $15,16,18,89,90,93,94,95,96$

Rousseau, Jean-Jacques. 29,37

Sarkozy, Nicolas 168

Sauvagnargues, Jean 160

Scharnhorst, Jürgen .13

Schröder, Konrad .99

Schwarze, Christoph. 33,39

Seewald, Uta 127,128 
Seibicke, Wilfried

.91

Sergijewskij, Maxim W

$86,87,88$

Settekorn, Wolfgang....

$13,115,116$

Shakespeare, William. .99

Société d'Ethnographie de Paris....

Société des amis de Conrart. 45

Société française de Terminologie

Sorbonne

Speroni, Sperone

Suite des Remarques nouvelles sur la Langue françoise 44

\section{$\mathbf{T}$}

Texas Instruments 122

Toubon, Jacques

\section{$\mathbf{U}$}

UISF 114

UITF. 106,114

Union Internationale des Ingénieurs et des Scientifiques utilisant la Langue française .... Siehe UISF

Union internationale des Ingénieurs et des Techniciens utilisant la Langue française...... Siehe UITF

Université de Montpellier...... .25

University of Toronto . 151

\section{V}

Vaugelas, Claude Favre de $35,38,39,40,41,42,43,44,45,46,58$

Viennet, Jean Pons Guillaume. 99,151

Voyage à l'Ile de France.

\section{W}

Walter, Gérard. 85

Werner, Edeltraud 29,30

Wiegand, Herbert Ernst 89

Wurtz, Charles Adolphe.... 156

Wüster, Eugen... 
Namenindex

\section{Z}

Zuza, Renée... 
Die vorliegende Publikation beruht auf der Diplomarbeit ,Sprachpflege und Sprachnormierung in Frankreich am Beispiel der Fachsprachen. Vom 16. Jahrhundert bis in die Gegenwart", die von Frau Martina Mayer am Institut für Translationswissenschaft der Universität Innsbruck zur Erlangung des Titels „Mag. phil.“ eingereicht und mit dem Frankreich-Preis 2012 des interdisziplinären Frankreich-Schwerpunkts der Universität Innsbruck ausgezeichnet wurde. Mit den Frankreich-Preisen werden einmal jährlich herausragende wissenschaftliche Arbeiten mit klarem Frankreich-Bezug in den Kategorien Master-/Diplomarbeit, Dissertation und Post-Doc prämiert. Eine Liste der bisherigen PreisträgerInnen sowie die Kriterien zu Einreichung und Verleihung der Frankreich-Preise finden Sie unter:

http://www.uibk.ac.at/frankreichschwerpunkt/frankreich_preis/

Der interdisziplinäre Frankreich-Schwerpunkt wurde 2001 gegründet und wird von der Universität Innsbruck und der französischen Botschaft in Österreich getragen. Seine Hauptaufgabe ist die Förderung der wissenschaftlichen Kooperation und des akademischen Austauschs zwischen der Universität Innsbruck und den französischen Universitäten und Hochschulen. Neben seiner Funktion als Fördergeber organisiert er selbst und in Zusammenarbeit mit Instituten der Universität Innsbruck und französischen Partnern wissenschaftliche Veranstaltungen wie Tagungen, Symposien, Workshops, Gastvorträge und Ringvorlesungen.

La présente publication repose sur le mémoire de maîtrise « Sprachpflege und Sprachnormierung in Frankreich am Beispiel der Fachsprachen. Vom 16. Jahrhundert bis in die Gegenwart » fait par Martina Mayer au département de Traductologie de l'Université d'Innsbruck pour le grade de « Mag. phil. », et auquel le Pôle interdisciplinaire d'études françaises de l'Université d'Innsbruck a décerné le Prix de la France 2012.

Le Pôle d'études françaises décerne une fois par an le Prix de la France pour des travaux scientifiques faits à l'Université d'Innsbruck et qui sont en rapport direct avec la France, ce dans les catégories post-doc, thèses et mémoires de maîtrise/master. Vous trouverez une liste des lauréats ainsi que les conditions pour recevoir le Prix de la France à l'adresse suivante :

http://www.uibk.ac.at/frankreichschwerpunkt/frankreich_preis/ 
Le Pôle interdisciplinaire d'études françaises a été fondé en 2001 et est financé par l'Université d'Innsbruck et par l'Ambassade de France en Autriche. Sa vocation première est de promouvoir la coopération scientifique et les échanges académiques entre les enseignants-chercheurs des universités et grandes écoles françaises et ceux de l'Université d'Innsbruck. A côté de son activité de subvention, le Pôle interdisciplinaire d'études françaises organise lui-même et co-organise avec les départements de l'Université d'Innsbruck et des partenaires français des colloques scientifiques, des conférences, des lectures, des journées d'études et des cycles de cours. 